\title{
TOWARDS CONSUMER 4.0 INSIGHTS AND OPPORTUNITIES UNDER THE MARKETING 4.0 SCENARIO
}

EDITED BY: Maria Pilar Martinez-Ruiz, Monica Gomez-Suárez,

Ana Jiménez-Zarco and Alicia Izquierdo-Yusta PUBLISHED IN: Frontiers in Psychology

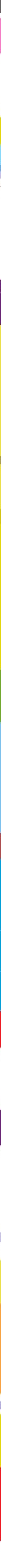

frontiers Research Topics 


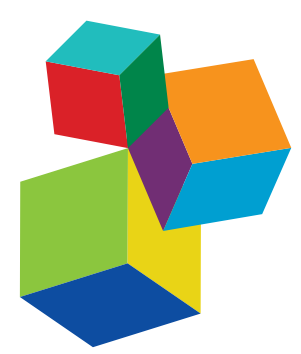

Frontiers eBook Copyright Statement

The copyright in the text of individual articles in this eBook is the property of their respective authors or their respective institutions or funders. The copyright in graphics and images within each article may be subject to copyright of other parties. In both cases this is subject to a license granted to Frontiers.

The compilation of articles constituting this eBook is the property of Frontiers.

Each article within this eBook, and the eBook itself, are published under the most recent version of the Creative Commons CC-BY licence. The version current at the date of publication of this eBook is CC-BY 4.0. If the CC-BY licence is updated, the licence granted by Frontiers is automatically updated to the new version.

When exercising any right under the CC-BY licence, Frontiers must be attributed as the original publisher of the article or eBook, as applicable.

Authors have the responsibility of ensuring that any graphics or other materials which are the property of others may be included in the

CC-BY licence, but this should be checked before relying on the

CC-BY licence to reproduce those materials. Any copyright notices relating to those materials must be complied with.

Copyright and source acknowledgement notices may not be removed and must be displayed in any copy, derivative work or partial copy which includes the elements in question.

All copyright, and all rights therein, are protected by national and international copyright laws. The above represents a summary only.

For further information please read Frontiers' Conditions for Website

Use and Copyright Statement, and the applicable CC-BY licence.

ISSN 1664-8714

ISBN 978-2-88966-485-6

DOI 10.3389/978-2-88966-485-6

\section{About Frontiers}

Frontiers is more than just an open-access publisher of scholarly articles: it is a pioneering approach to the world of academia, radically improving the way scholarly research is managed. The grand vision of Frontiers is a world where all people have an equal opportunity to seek, share and generate knowledge. Frontiers provides immediate and permanent online open access to all its publications, but this alone is not enough to realize our grand goals.

\section{Frontiers Journal Series}

The Frontiers Journal Series is a multi-tier and interdisciplinary set of open-access, online journals, promising a paradigm shift from the current review, selection and dissemination processes in academic publishing. All Frontiers journals are driven by researchers for researchers; therefore, they constitute a service to the scholarly community. At the same time, the Frontiers Journal Series operates on a revolutionary invention, the tiered publishing system, initially addressing specific communities of scholars, and gradually climbing up to broader public understanding, thus serving the interests of the lay society, too.

\section{Dedication to Quality}

Each Frontiers article is a landmark of the highest quality, thanks to genuinely collaborative interactions between authors and review editors, who include some of the world's best academicians. Research must be certified by peers before entering a stream of knowledge that may eventually reach the public - and shape society; therefore, Frontiers only applies the most rigorous and unbiased reviews.

Frontiers revolutionizes research publishing by freely delivering the most outstanding research, evaluated with no bias from both the academic and social point of view. By applying the most advanced information technologies, Frontiers is catapulting scholarly publishing into a new generation.

\section{What are Frontiers Research Topics?}

Frontiers Research Topics are very popular trademarks of the Frontiers Journals Series: they are collections of at least ten articles, all centered on a particular subject. With their unique mix of varied contributions from Original Research to Review Articles, Frontiers Research Topics unify the most influential researchers, the latest key findings and historical advances in a hot research area! Find out more on how to host your own Frontiers Research Topic or contribute to one as an author by contacting the Frontiers Editorial Office: frontiersin.org/about/contact 


\section{TOWARDS CONSUMER 4.0 INSIGHTS AND OPPORTUNITIES UNDER THE MARKETING 4.0 SCENARIO}

\section{Topic Editors:}

Maria Pilar Martinez-Ruiz, University of Castilla-La Mancha, Spain Monica Gomez-Suárez, Autonomous University of Madrid, Spain Ana Jiménez-Zarco, Open University of Catalonia, Spain Alicia Izquierdo-Yusta, University of Burgos, Spain

Citation: Martinez-Ruiz, M. P., Gomez-Suárez, M., Jiménez-Zarco, A., Izquierdo-Yusta, A., eds. (2021). Towards Consumer 4.0 Insights and Opportunities under the Marketing 4.0 Scenario. Lausanne: Frontiers Media SA. doi: 10.3389/978-2-88966-485-6 


\section{Table of Contents}

05 Editorial: Toward Consumer 4.0 Insights and Opportunities Under the Marketing 4.0 Scenario

María Pilar Martínez-Ruiz, Mónica Gómez-Suárez, Ana Isabel Jiménez-Zarco and Alicia Izquierdo-Yusta

08 Assessing Risk Aversion From the Investor's Point of View Antonio Díaz and Carlos Esparcia

14 The Cognitive Dimension and the Affective Dimension in the Patient's Experience

Pedro Reinares-Lara, Alfredo Rodríguez-Fuertes and Blanca Garcia-Henche

24 Archeological Tourist Destination Image Formation: Influence of Information Sources on the Cognitive, Affective and Unique Image

Nuria Huete-Alcocer, Maria Pilar Martinez-Ruiz, Víctor Raúl López-Ruiz and Alicia Izquiedo-Yusta

37 Assessing Consumer Behavior in the Wine Industry and Its Consequences for Wineries: A Case Study of a Spanish Company

Rosa M. Muñoz, M. Valle Fernández and Maria Yolanda Salinero

44 Consumer Motivation in Developed Economies With Secular Stagnation Fernando Evaristo Callejas-Albiñana, Irene Martín de Vidales Carrasco, Isabel Martínez-Rodríguez and Ana Isabel Callejas-Albiñana

57 Studying Consumer Behavior in an Online Context: The Impact of the Evolution of the World Wide Web for New Avenues in Research

Maria Pilar Martinez-Ruiz and Karin S. Moser

61 Dealing With Human Resources in the Age of Consumer 4.0: Aiming to Improve Service Delivery

Juan Jose Blazquez-Resino, Santiago Gutiérrez-Broncano,

Pablo Ruiz-Palomino and Pedro Jimenez-Estevez

64 Impact of Shopping Tourism for the Retail Trade as a Strategy for the Local Development of Cities

Ana Isabel Muro-Rodríguez, Israel Roberto Pérez-Jiménez and

Jesús Antonio Sánchez-Araque

69 Proposal for Lines of Research Into Consumer Behavior: Examples in the Tourism Industry

Juan Jose Blazquez-Resino, Santiago Gutiérrez-Broncano and Mario Arias-Oliva

72 Are Health e-Mavens the New Patient Influencers?

Ana M. Díaz-Martín, Anne Schmitz and María Jesús Yagüe Guillén

76 Revealing Unconscious Consumer Reactions to Advertisements That Include Visual Metaphors. A Neurophysiological Experiment

Jesús García-Madariaga, Ingrit Moya, Nuria Recuero and María-Francisca Blasco

92 Future-Oriented Happiness: Its Nature and Role in Consumer Decision-Making for New Products

Debora Bettiga and Lucio Lamberti 
106 Value Co-creation in Third-Party Managed Virtual Communities and Brand Equity

Natalia Rubio, Nieves Villaseñor and MaJesús Yagüe

110 Differential Effects of Monetary and Social Rewards on Product Online Rating Decisions in E-Commerce in China

Cuicui Wang, Weizhong Fu, Jia Jin, Qian Shang, Xuan Luo and Xin Zhang

125 A PLS-Neural Network Analysis of Motivational Orientations Leading to Facebook Engagement and the Moderating Roles of Flow and Age

Inma Rodríguez-Ardura and Antoni Meseguer-Artola 


\section{Editorial: Toward Consumer 4.0 Insights and Opportunities Under the Marketing 4.0 Scenario}

\begin{abstract}
María Pilar Martínez-Ruiz ${ }^{1 *}$, Mónica Gómez-Suárez², Ana Isabel Jiménez-Zarco ${ }^{3}$ and Alicia Izquierdo-Yusta ${ }^{4}$

'Department of Business Administration, University of Castilla-La Mancha, Albacete, Spain, ${ }^{2}$ Department of Finance and Marketing Research, Autónoma University of Madrid, Madrid, Spain, ${ }^{3}$ Department of Economic and Business, Open University of Catalonia, Barcelona, Spain, ${ }^{4}$ Departament of Economic and Business Administration, University of Burgos, Burgos, Spain
\end{abstract}

Keywords: marketing 4.0, consumer 4.0, technology, virtual, COVID

\section{Editorial on the Research Topic}

\section{Toward Consumer 4.0 Insights and Opportunities under the Marketing 4.0 Scenario}

This Research Topic aims to shed light on the current academic and practical perspectives within the so-called "Consumer 4.0" paradigm. The related perspective on Marketing 4.0 represents new opportunities and concerns for Social Science. Thus, there is a need to find a balance between theoretical frameworks, opinions, and empirical applications, and thereby stimulate dialogues among researchers and professionals. In short, this collection of papers encapsulates the literature on how technological evolution is impacting different actors (companies, consumers, patients, and tourists, etc.) and interacting in various sectors. We also propose research lines based on the combination of two key factors: the advancement of technologies and the impact of the SARS-COV-2 pandemic.

This collection builds upon a previous Research Topic, "From consumer experience to affective loyalty: challenges and prospects in the psychology of consumer behavior 3.0," which influenced subsequent research on the opportunities and challenges inherent to Marketing 4.0. The primary objective of the current Research Topic is to analyze how virtual transformation affects the behavior of very different organizations, industries, and consumers.

This Research Topic collection includes 15 research articles spanning diverse publication formats, including 8 Original Research Articles, 4 Opinion Reviews, and 3 Mini-reviews. Although different, the papers have common threads, examining the impact of Information and Communication Technology (ICT) on market demand and business strategy. They are also connected either through the functional scope within the organization or the focal sector in which they are applied.

Blazquez-Resino et al. highlight how for companies to be competitive, it is important to establish synergy between Industry 4.0 and Marketing 4.0. Muñoz et al. discuss how investments in technology influence the orientation toward entrepreneurship in SMEs, showing how digital transformation has allowed direct and rapid access to information about consumers in an atomized market, in this case, wine. In an examination of the financial field, Callejas-Albiñana et al. conducted a panel data study among a selected sample of countries to determine the influence of different exogenous factors, aiming to explain stagnation in recent years and outline proposals for new government intervention strategies.

In Marketing 4.0, which reflects the impact of the technological revolution on the marketing arena (Jiménez-Zarco et al., 2019), companies face high volumes of information (Big Data) (Lies, 2019) that can be analyzed through data mining techniques (Data Mining) (Sener et al., 2019). 
Studies on "Big Data" illustrate the importance of capturing and analyzing huge amounts of information and Rubio et al. underscore the importance of virtual communities on the co-creation process. Díaz-Martín et al. analyzed the concept of health e-mavens, showing the importance of conducting investigations with data mining and user-generated content. Through an in-depth review of financial literature, Díaz and Esparcia analyzed investors' risk aversion in terms of different environments, financial products, and temporality, etc. The authors utilized Big Data on financial products to uncover new research lines for risk reduction.

Virtual developments also allow scholars to better measure the impact of business strategies on an individual's behavior, namely by monitoring activities in cyberspace, which include search engine queries, social network relationships, and website purchases. In this regard, Wang et al. used behavioral and ERP (event-related potentials) measures to explore the priming effects of monetary and social rewards on e-commerce consumer decisions in China. In their analysis of individual behavior in relation to specific advertising strategies, García-Madariaga et al. reveal the importance of using neurophysiological measures to analyze the appropriate use of visual metaphors, as well as how to maximize impact and ensure that advertising is effective.

The extensive use and adoption of technology has not only impacted organizations, it has given rise to a new type of consumer: Consumer 4.0. In an omni-channel context, combining digital and physical media, this type of customer maintains positive and lasting relationships with multiple firms and other actors. However, the characteristics of digital media are particularly impactful on these individual's brand decisions as they complete their brand journey. In this vein, Martinez-Ruiz and Moser analyzed the evolution of the worldwide web and its impact on consumer behavior.

As the online environment has evolved, scholars have emphasized the importance of the psychological aspects of consumer behaviour-namely, individual preferences, emotions, and sensory experiences. For instance, Bettiga and Lamberti shed light on the still vague concepts of anticipated and anticipatory happiness. Their results demonstrate the importance of designing visual product communication in a way that elicits positive feelings of anticipated and anticipatory emotions in the viewer. Building upon gratifications theory, Rodriguez-Ardura and Messeguer-Artola developed an integrative and context-specific model that links engagement with enjoyment, self-presentation, and community belonging, which were all identified as motivational factors among Facebook users. Meanwhile, Reinares-Lara et al. measured the experience of people through two dimensions of satisfaction: cognitive (the most studied so far in academic research) and affective (the least analyzed), derived from the analysis of neurophysiological data.

According to the previously mentioned category, the tourism industry provides useful case studies for understanding the huge impact of technology. Blazquez-Resino et al. show how ICTs are important for understanding the development of loyalty, making an important distinction between passive attitudinal loyalty, active attitudinal loyalty, and behavioral loyalty. Huete-Alcocer et al. discuss how building an image of a holiday destination is a critical factor in the perceptions and evaluations of that destination by tourists. This study accounts for not only cognitive and affective components but also the unique image component. Moreover, they demonstrate that eWOM is a powerful means of promoting cultural tourism. Focusing on shopping tourism, Muro-Rodríguez et al. highlight its importance for cities, identifying differentiation strategies for cities as shopping destinations and setting out recommendations based on the analysis of key factors for listing a city as a shopping destination.

\section{FUTURE RESEARCH DIRECTIONS}

Since the start of the SARS-COV-2 pandemic in early 2020, consumers and companies have faced a new environmental variable that has accelerated the process of digitization and the incorporation of new technologies. This exogenous phenomenon will produce changes in the global economy, organizational management, and consumer habits. Some will be transitory, while others will be permanent. Future papers (and topics) therefore need to investigate how the pandemic will interact with Marketing 4.0 and influence the competitive strategies that allow organizations to obtain competitive advantages and offer adapted products and services to meet these new demands. Notably, disruptive or emerging technologies that companies were previously using as a test have been incorporated in a masive scale into infrastructures in many countries during the pandemic.

For example, traditionally, neuroscientific techniques have been used to measure consumer reactions to advertising-related stimuli or to assess the effectiveness of discount coupons or gifts. Easy-to-use neuro-marketing tools are now being implemented to measure the emotions and experiences of consumers from neurophysiological data relating to a wide range of companies from different sectors (including retail, health, and tourism, etc.) and/or diverse purchasing contexts (such as online, offline, and omnichannel, etc.).

Scholars with access to longitudinal data (pre- and postCOVID-19), should measure buyer behavior in terms of the variables that influence them before, during, and after the decision-making process.

These variables include the impact of perceived risk, which leads consumers to conduct a more systematic and prolonged process of searching for information, mainly on social networks or web pages (Hansen et al., 2018). The relationship between its different components (physical, functional, economic, social, and psychological) may also change based on the product category (Emilien et al., 2017). However, the economic crisis inflicted by the pandemic may produce the opposite effect. Even though the perceived risk is high, certain middle-class segments that were previously financially healthy might be struggling with their basic food shopping.

The next variable relates to consumer preferences for different attributes/values and whether they have remained stable or changed. In the mass consumer sector, and particularly in food or personal hygiene, it is worth studying whether consumers 
are more likely to use safety as a criterion for choosing a product or not. Following on from this, in the future, scholars should explore technological ways of tracking or tracing health or food products.

\section{AUTHOR CONTRIBUTIONS}

All authors listed have made a substantial, direct and intellectual contribution to the work, and approved it for publication.

\section{REFERENCES}

Emilien, G., Weitkunat, R., and Lüdicke, F. (2017). Consumer Perception of Product Risks and Benefits. New York: Springer International Publishing.

Hansen, J. M., Saridakis, G., and Benson, V. (2018). Risk, trust, and the interaction of perceived ease of use and behavioral control in predicting consumers' use of social media for transactions. Comput. Hum. Beh. 80, 197-206.

Jiménez-Zarco, A. I., Rospigliosi, A., Martínez-Ruiz, M. P., and IzquierdoYusta, A. (2019). "Marketing 4.0: Enhancing consumer-brand engagement through big data analysis," in Web Services: Concepts, Methodologies, Tools, and Applications, ed. Information Resources Management Association (Hershey, PA: IGI Global), 2172-2195.

Lies, J. (2019). Marketing intelligence and big data: digital marketing techniques on their way to becoming social engineering techniques in marketing. Int. J. Interact. Multimed. Artif. Intell. 5, 134-144. doi: 10.9781/ijimai.2019.05.002

\section{FUNDING}

This research was conducted under the framework of different research projects and groups: Observatorio de la Innovación en la Distribución Comercial (University of Castilla-La Mancha); TECHNOCONS Consumer Behavior and Technology. (Autónoma University of Madrid); and the I2TIC Research Group (Open University of Catalonia).

Sener, A., Barut, M., Oztekin, A., Avcilar, M. Y., and Yildirim, M. B. (2019). The role of information usage in a retail supply chain: a causal data mining and analytical modeling approach. J. Bus. Res. 99, 87-104. doi: 10.1016/j.jbusres.2019.01.070

Conflict of Interest: The authors declare that the research was conducted in the absence of any commercial or financial relationships that could be construed as a potential conflict of interest.

Copyright (c) 2021 Martínez-Ruiz, Gómez-Suárez, Jiménez-Zarco and IzquierdoYusta. This is an open-access article distributed under the terms of the Creative Commons Attribution License (CC BY). The use, distribution or reproduction in other forums is permitted, provided the original author(s) and the copyright owner(s) are credited and that the original publication in this journal is cited, in accordance with accepted academic practice. No use, distribution or reproduction is permitted which does not comply with these terms. 


\title{
Assessing Risk Aversion From the Investor's Point of View
}

\author{
Antonio Díaz and Carlos Esparcia* \\ Department of Economics and Finance, Universidad de Castilla-La Mancha, Albacete, Spain
}

Throughout the financial literature, there is a great deal of debate about the nature of investors' risk preferences. In an ever-changing world, the main schools of knowledge discuss the constant or dynamic basis of these preferences. Based on an exhaustive review of the subject of risk aversion, this paper contributes to filling the gap that exists in the literature on the risk aversion parameter that best fits the investors' behavior toward risk. The main determinants of risk attitude are examined and the different and most novel methodologies and perspectives are carefully analyzed.

Keywords: risk aversion, economic cycles, market risk premium, pricing models, big data

OPEN ACCESS

Edited by:

Alicia Izquierdo-Yusta, University of Burgos, Spain

Reviewed by: Inés González,

Escuela de Negocios

de Navarra, Spain

Lars Tegtmeier,

Merseburg University of Applied Sciences, Germany

${ }^{*}$ Correspondence:

Carlos Esparcia

carlos.esparcia@uclm.es

Specialty section:

This article was submitted to Organizational Psychology, a section of the journal Frontiers in Psychology

Received: 30 April 2019 Accepted: 12 June 2019 Published: 02 July 2019

Citation:

Díaz A and Esparcia C (2019) Assessing Risk Aversion From the Investor's Point of View.

Front. Psychol. 10:1490. doi: 10.3389/fpsyg.2019.01490

\section{INTRODUCTION}

Risk aversion is one of the pillars of the theories used by economists. The theory of choice is also extensively analyzed by social sciences such as anthropology, psychology, political science, sociobiology, and sociology. Investor choice theory analyzes the behavior of individuals when confronted with the task of ranking risky alternatives and the assumption of nonsatiation. Markowitz (1952) considers that an investor is risk averse when shelhe receives more utility from the actuarial value of a gamble obtained with certainty than from taking the gamble itself. Markowitz (1952) and later Tobin (1958) consider risk attitude in the portfolio selection process, implementing the theory of games and economic behavior described by Von Neumann and Morgenstern (1944). Beyond the characterization of a risk-averse utility function and how to measure a risk premium, Pratt (1964) and Arrow (1965) provide a specific definition of risk aversion. The Pratt-Arrow definition of risk aversion is useful because it provides much more insight into people's behavior in the face of risk.

Risk preferences depend on a great deal of determinants; but, in order to make their implementation easier, the classical literature summarizes them by a single risk aversion coefficient. However, fixed risk attitude coefficients could yield strategies that do not consider the variability in the agents' expectations. The financial literature considers risk aversion through a constant parameter or, alternatively, through a time-dependent parameter with respect to different macroeconomic and financial variables. As an additional component, recent developments take advantage of growing data processing capacity to reduce uncertainty and estimate ever more accurate changing risk aversion. The use of big data in financial markets enables faster and faster processing of data on many macro and financial variables. This better quality information provides insight into the expectations of modern investors and reduces their uncertainty about investment outcomes. In this context, the aim of this paper is to review the risk aversion literature by comparing the invariant and dynamic nature of risk preferences. 


\section{BACKGROUND}

Individual preferences are complex, depending on a variety of economic, political, human, or even cultural factors. Risk aversion plays a key role to understand the behavior of different economic periods and, above all, economic recessions. This parameter amplifies the response of the most relevant macroeconomic variables to shocks of uncertainty and is, in short, the point of conciliation that makes it possible to relate finance, macroeconomics, and uncertainty. An extensive literature analyzes how fluctuations in economic uncertainty influence the dynamics of the economic cycle (see, e.g., Bernanke, 1983; Bertola and Caballero, 1994; Abel and Eberly, 1994, 1996; Caballero and Pindyck, 1996; Bloom, 2009; Bachmann and Bayer, 2013) and help explain the countercyclical behavior of major economic variables (e.g., Campbell and Taksler, 2003; Storesletten et al., 2004; Eisfeldt and Rampini, 2006; Bloom, 2009). However, the traditional way in which macroeconomists explained economic fluctuations largely ignored the importance of risk aversion in understanding economic cycles. Thereunder, the new macroeconomy recognizes that financial shocks are relevant to the real economy. Jurado et al. (2015) observe a timevarying relationship between uncertainty and real activity based on a new measure of uncertainty linking financial risk aversion coefficients with macroeconomic variables. In this sense, market risk premium and volatility reach their highest values in financial crises rather than in times of economic recession or war (Muir, 2016). Guiso et al. (2018) link changes in investor risk aversion to changes in wealth, expected income, and perceived probabilities and emotional changes in the utility function. Several authors highlight the interaction between political uncertainty and individual risk aversion. In this sense, Pástor and Veronesi (2013) incorporate this relationship into a general equilibrium model, while Brogaard and Detzel (2015) and Baker et al. (2016) examine this interaction by fitting political uncertainty through an index based on press reports.

Numerous studies show that risk aversion increases with age (e.g., Jianakoplos and Bernasek, 2006; Bucciol and Miniaci, 2011; Boyle et al., 2012; Brooks et al., 2018). Hansen et al. (1999) and Ilut and Schneider (2014) consider that consumers have pessimistic beliefs and, faced with a range of possible outcomes, act as if the worst outcomes occurred, displaying a behavior known as "ambiguity aversion." This concept explains why many households do not invest in the stock market since the return on this investment is more ambiguous (i.e., they are not able to assign probabilities to possible outcomes) than the return on a bank deposit or a Treasury Bill (Dow and Werlang, 1992). Zhang et al. (2019) relate risk aversion with pessimism and rare disasters. Goetzmann et al. (2016) propose the availability heuristic theory in which the most recent observations have the greatest impact on an individual's decisionmaking. Investors assign more probability to future stock market falls after a stock market crash. Kamstra et al. (2003) relate risk aversion to seasonal affective disorder, a depressive disorder associated with declining daylight hours. Nofsinger et al. (2018) examine the influence of behavioral biases as testosterone or stress on the individual's risk aversion. Hoffmann and Post $(2016,2017)$ link up investor return experiences, confidence and investment beliefs and show why confident investors trade more than less confident investors. Falk et al. (2018) and Potrafke (2019) find a positive correlation between patience and intelligence. Suen (2018) suggests a possible discrepancy between individual and aggregate risk aversion in the context of background risk. Finally, a branch of literature proofs the influence of social factors, ethical preferences, or religious beliefs on investor's risk attitude (e.g., Eisenhauer, 2008; Nielsen et al., 2017; Berrada et al., 2018).

\section{Constant Risk Aversion}

Although risk preferences depend on several factors, most theoretical literature fits the risk aversion as an invariant parameter that represents the personal level of risk attitude. Simple models are very relevant as they help us set ideas. Assuming constant risk aversion allows models to reach precise and relatively simple formulas for relationships between variables. Table 1 shows some applications of constant risk aversion parameters compared to other applications with time-varying coefficients. Empirical studies show contradictory evidence for this invariable parameter over time. For instance, the risk attitude parameter appears as stable for correlative periods of time in Chou (1988), or much more unstable in French et al. (1987).

Safra and Segal (1998) define constant risk aversion as the invariant preference relation between outcomes of two distributions when adding or multiplying them by the same positive number. Quiggin and Chambers (2004) show that risk attitude is strongly linked with the family of generalized expected utility preferences which exhibit constant risk aversion. These expected utility preferences are constant only if the investor's utility function is quadratic, which is consistent with the capital asset pricing model (CAPM). In addition, these preferences are a generalization of both, invariant risk preferences (e.g., Quiggin and Chambers, 1998; Safra and Segal, 1998) and mean-standard deviation attitude. Other approaches link shapeinvariant pricing kernels to the estimation of a constant risk aversion parameter (e.g., Lawton et al., 1972; Grith et al., 2013).

TABLE 1 | Invariant vs. time-varying risk aversion applications.
Invariant risk aversion

Expected utility and quadratic functions Shape-invariant pricing kernels Ambiguity and unawareness models

Point estimations for a whole data sample period

\section{Time-varying risk aversion}

Dependent on the economic cycle Time-varying pricing kernels Macroeconomic and financial uncertainty measures Implicit dynamic risk aversion in option prices and realized returns Construction of proxies of the market sentiment by PCA Dynamic risk aversion and the CAPM model

Time-varying risk aversion and GARCH-M models
Source: Compiled by the authors. 
Recently, Dominiak and Tsjerengjimid (2018) generalized the preference structure in Gilboa and Schmeidler (1989) to allow for the decision maker's ex post preferences to be ambiguity averse, which implies constant risk appetite. Other studies assume that investor's risk preferences are constant and invariant to changes of unawareness and unforeseen contingencies (e.g., Karni and Vierø, 2013, 2015; Mengel et al., 2016; Ma and Schipper, 2017). Baillon and Placido (2019) demonstrate that most ambiguity models forecast that risk aversion remains constant when individuals improve overall.

\section{Time-Varying Risk Aversion}

Considering the variability in agents' expectations, to model the risk aversion parameter has a cost in terms of complexity. Empirical papers document time-varying risk premia in several financial markets (e.g., Fama, 1984; Hodrick and Srivastava, 1986; Keim and Stambaugh, 1986; Harvey, 1989; Li et al., 2011). There are several studies in financial literature that refer to time-varying risk aversion as a dependent parameter of different macroeconomic and financial variables. In a seminal paper on asset pricing, Campbell and Cochrane (1999) consider that an individual is more or less risk averse according to the economic and political circumstances. Their "habit formation" model incorporates large and frequent variation of the risk aversion parameter. In the same vein, Brandt and Wang (2003) develop a consumption-based asset pricing model in which aggregate risk aversion responses to both consumption growth and inflation news. Eisenbach and Schmalz (2016) consider "anxious" investors, who are more risk averse to an imminent risk than to distant one and propose a theory that leads to a downward-sloping term structure of risk premia. In the same vein, Andries et al. (2018) propose a horizon-dependent risk aversion model involving term structures of risk premium consistent with the evidence that agents are more reluctant to immediate risks than to deferred risks. Behavioral approaches have also incorporated time-varying risk aversion by way of dynamic loss aversion or conditional disappointment aversion (e.g., Barberis et al., 2001; Routledge and Zin, 2010).

As mentioned, risk preferences are closely related to economic cycles. Many studies indicate that risk aversion is countercyclical. This way, Rosenberg and Engle (2002) observe a countercyclical investor risk aversion parameter by fitting a dynamic pricing kernel. Based on the consumption-based model of Campbell and Cochrane (1999), Li (2007) shows the influence of dynamic risk aversion on asset pricing by observing that countercyclical changes in risk attitude lead to a procyclical time-varying risk premium. Furthermore, Cochrane (2017) notes that risk premia are countercyclical over time and are also coordinated across asset classes. Finally, González et al. (2018) observe the key role of time-varying risk aversion as a macroeconomic determinant of stock market betas.

Time-varying risk preferences have been modeled in several ways. A branch of the financial literature focuses on risk aversion implicit in option prices and realized returns. Option contracts offer several advantages when considering risk preferences (e.g., Bliss and Panigirtzoglou, 2004). To price options, it is only necessary to infer a discounted cash flow for a given horizon. In addition, there are options for different maturities. The multiplicity of prices for different payments on the same underlying asset provided by the options makes it possible to construct a density function for the distribution of the possible values of the underlying asset. The risk attitude implicit in option prices contains information of investors' behavior toward risk and, hence, its variability may be captured by the jumps in risk premia implicit in the market. From option prices and realized returns on the S\&P500 index, Jackwerth (2000) derives investor's risk aversion functions and observes how shapes around financial crises change dramatically. As expected from the economic theory, these functions are positive and diminish in wealth during the pre-crisis period. On the other hand, their behavior is not consistent with the hypotheses after this event. Several authors, such as Aït-Sahalia and Lo (2000), Bedoui and Hamdi (2015), Yoon (2017), Kiesel and Rahe (2017), and Liao and Sung (2018), implement an implicit estimation of the individuals' risk attitude from the joint observations of the cross-section of option premiums and time series of underlying assets. They examine the risk preference of market participants in different states of the world and find that risk aversion level strongly increases during stressed market conditions.

Other approaches are related to the construction of indices or proxies that represent the time-varying aggregate investor sentiment in a given financial market. The main aversion indicators can be grouped into different types: indicators that use a principal component analysis (PCA) on several financial variables (e.g., Baker and Wurgler, 2006, 2007; Han and Li, 2017; Cheema et al., 2018; Bekaert et al., 2019); indicators based on the correlation between volatilities and changes in asset prices (e.g., Kumar and Persaud, 2002); volatility indices, such as the "VIX" that uses the implied volatility of option prices on the Chicago Board Options Exchange (CBOE); and many others. For instance, Baker and Wurgler (2006) elaborate a composite index of investor sentiment derived from the first principal component of six basic proxies of investor sentiment based on various stock market indicators. On the basis of a dynamic asset pricing model with stochastic risk aversion, Bekaert et al. (2019) propose a measure of a time-varying risk aversion computed at a daily frequency that distinguishes the time variation in economic uncertainty (the amount of risk) from time variation in risk aversion (the price of risk). Most of these risk aversion indicators are used by other authors to test their ability to forecast financial crises. For example, Coudert and Gex (2008) use logit and multilogit models and observe that risk aversion indicators are good leading indicators of stock market crises.

There is a line of research linking investor risk aversion with the market risk premium derived from conditional heteroscedasticity models. The mean-variance Capital Asset Pricing Model (CAPM) of Sharpe (1964) and Lintner (1965) assumes constant second-order moments to arrive at its valuation expression, which is based on a linear relationship between expected return and risk. However, an extensive empirical evidence shows a conditional heteroscedasticity in the stock 
markets (e.g., Christie, 1982; Poterba and Summers, 1986; French et al., 1987) ${ }^{1}$. In parallel, models of Autoregressive Conditional Heteroscedasticity (ARCH) are developed (Engle, 1982) with a multitude of subsequent extensions (e.g., Bollerslev, 1986; Ding et al., 1993; Engle and Ng, 1993). Authors such as Giovannini and Jorion $(1987,1989)$ analyze the effects of conditional risk aversion and ARCH models for both market risk premium and performance in the static CAPM model. Given the instability of risk aversion coefficients and risk premiums over different time periods, Chou et al. (1992) improve the ARCH-in-mean (ARCH-M) model of Engle et al. (1987) with a rolling estimation procedure in which the timevarying risk aversion is integrated by a Kalman filter method. This methodology is widely applied and expanded by the use of Generalized Autoregressive Conditional Heteroskedasticity in-mean models (GARCH-M) to test the validity of dynamic risk aversion parameters in the estimation of the market risk premium (e.g., Flannery et al., 1997; Elyasiani and Mansur, 1998; Devaney, 2001; Cotter and Hanly, 2010; Dias, 2017).

Recent literature proposes text-processing techniques based on Internet search volume of certain keywords to predict returns, rather than measures based on market trading volumes and returns. There is a debate about whether these high-frequency measures actually measure time-varying risk aversion (e.g., Vlastakis and Markellos, 2012; Kearney and Liu, 2014) or whether, on the contrary, they capture retail investors' attention toward the stock market (e.g., Da et al., 2011; Jacobs and Weber, 2012; Vlastakis and Markellos, 2012; Dimpfl and Jank, 2016) or even the investor sentiment (e.g., Da et al., 2015; Heston and Sinha, 2017). In any case, social networks can provide information on the collective behavior of investors, their state of mind, and thus allow an estimation of risk aversion at each instant of time. Financial analysis improves by increasing the speed of processing and the amount of data available. Big data and faster processors enhance investors' forecasts of future returns. As faster and wider access to information about assets reduces uncertainty, investors tend to perceive them as "safer" (Veldkamp, 2006) and makes portfolio selection results more predictable (Kacperczyk et al., 2016; Begenau et al., 2018). Given that traditional literature states that more risk-averse investors demand more information (e.g., Willinger, 1989; Eeckhoudt and Godfroid, 2000), future research can further explore the extent to which the greater current availability of information accessible to all investors could imply a reduction in risk aversion.

${ }^{1}$ This evidence is one more of the traditional criticisms of CAPM, such as the unobservability of the market portfolio (Roll, 1977) or the need to incorporate additional risk factors (e.g., Banz, 1981).

\section{REFERENCES}

Abel, A. B., and Eberly, J. C. (1994). A unified model of investment under uncertainty. Am. Econ. Rev. 84, 1369-1384.

Abel, A. B., and Eberly, J. C. (1996). Optimal investment with costly reversibility. Rev. Econ. Stud. 63, 581-593. doi: 10.2307/2297794

Aitt-Sahalia, Y., and Lo, A. W. (2000). Nonparametric risk management and implied risk aversion. J. Econ. 94, 9-51. doi: 10.1016/S0304-4076(99)00016-0

\section{CONCLUSIONS}

This literature review summarizes, critically examines, and clarifies alternative viewpoints of the most relevant contributions in each of the facets that affect the study and use of risk aversion in financial models. We review the literature with a view to providing a clear understanding of both constant or invariable risk aversion and variable risk attitude over time in the context of investor behavior and investment decisions in an environment of uncertainty.

Despite the influence of risk aversion in the investment context, most classical financial literature considers fixed values to reflect common levels of risk aversion over a full sample period. The use of a static estimate of the risk aversion coefficient over large timeframes may be desirable in simplifying models but could lead to investment decisions that do not reflect the investor's actual attitude toward risk. On this basis, an extensive literature both in economics and in many other disciplines shows the large number of determinants of risk aversion and proofs its changing nature over time. New macroeconomy and financial theory recognize the key role of risk aversion in economic cycles, finding a countercyclical relation between risk preferences and the economic period. Many asset pricing models exhibit countercyclical risk aversion, including a behavioral dimension by way of risk-averse utility functions. Furthermore, several approaches allow the inclusion of dynamic risk aversion, such as volatility or sentiment indices, implied methods based on financial option pricing, the rolling ARCH-M model and the Kalman filter methodology, or information technology and big data analysis.

\section{AUTHOR CONTRIBUTIONS}

All authors listed have made a substantial, direct and intellectual contribution to the work, and approved it for publication. Corresponding author contributed to the design and implementation of the research. Both authors have collaborated in the review of the literature and in the writing of the manuscript.

\section{FUNDING}

This research was supported by MINECO (ECO2017-89715-P) and UCLM (2019-GRIN-27072, co-financed with FEDER funds).

Andries, M., Eisenbach, T. M., and Schmalz, M. C. (2018). "Asset pricing with horizon-dependent risk aversion" in FRB of New York staff report. Vol. 703.

Arrow, K. (1965). Aspects of the theory of risk-bearing. (Yrjö Jahnssonin Säätiö: Helsinki).

Bachmann, R., and Bayer, C. (2013). 'Wait-and-See' business cycles? J. Monet. Econ. 60, 704-719. doi: 10.1016/j.jmoneco.2013.05.005

Baillon, A., and Placido, L. (2019). Testing constant absolute and relative ambiguity aversion. J. Econ. Theory. 181, 309-332. doi: 10.1016/j.jet.2019.02.006 
Baker, S. R., Bloom, N., and Davis, S. J. (2016). Measuring economic policy uncertainty. Q. J. Econ. 131, 1593-1636. doi: 10.1093/qje/qjw024

Baker, M., and Wurgler, J. (2006). Investor sentiment and the cross-section of stock returns. J. Financ. 61, 1645-1680. doi: 10.1111/j.1540-6261.2006.00885.x

Baker, M., and Wurgler, J. (2007). Investor sentiment in the stock market. J. Econ. Perspect. 21, 129-151. doi: 10.1257/jep.21.2.129

Banz, R. W. (1981). The relationship between return and market value of common stocks. J. Financ. Econ. 9, 3-18. doi: 10.1016/0304-405X(81)90018-0

Barberis, N., Huang, M., and Santos, T. (2001). Prospect theory and asset prices. Q. J. Econ. 116, 1-53. doi: 10.1162/003355301556310

Bedoui, R., and Hamdi, H. (2015). Option-implied risk aversion estimation. J. Econ. Asymmetries 12, 142-152. doi: 10.1016/j.jeca.2015.06.001

Begenau, J., Farboodi, M., and Veldkamp, L. (2018). Big data in finance and the growth of large firms. J. Monet. Econ. 97, 71-87. doi: 10.1016/j. jmoneco.2018.05.013

Bekaert, G., Engstrom, E., and Xu, N. (2019). The time variation in risk appetite and uncertainty (No. 25673).

Bernanke, B. (1983). Non-monetary effects of the financial crisis in the propagation of the great depression. Am. Econ. Rev. 73, 257-276.

Berrada, T., Detemple, J., and Rindisbacher, M. (2018). Asset pricing with beliefs-dependent risk aversion and learning. J. Financ. Econ. 128, 504-534. doi: 10.1016/j.jfineco.2018.03.002

Bertola, G., and Caballero, R. J. (1994). Irreversibility and aggregate investment. Rev. Econ. Stud. 61, 223-246. doi: 10.2307/2297979

Bliss, R. R., and Panigirtzoglou, N. (2004). Option-implied risk aversion estimates. J. Financ. 59, 407-446. doi: 10.1111/j.1540-6261.2004.00637.x

Bloom, N. (2009). The impact of uncertainty shocks. Econometrica 77, 623-685. doi: $10.3386 /$ w13385

Bollerslev, T. (1986). Generalized autoregressive conditional heteroskedasticity. J. Econ. 31, 307-327. doi: 10.1016/0304-4076(86)90063-1

Boyle, P. A., Yu, L., Buchman, A. S., and Bennett, D. A. (2012). Risk aversion is associated with decision making among community-based older persons. Front. Psychol. 3. doi: 10.3389/fpsyg.2012.00205

Brandt, M. W., and Wang, K. Q. (2003). Time-varying risk aversion and unexpected inflation. J. Monet. Econ. 50, 1457-1498. doi: 10.1016/j.jmoneco. 2003.08.001

Brogaard, J., and Detzel, A. (2015). The asset-pricing implications of government economic policy uncertainty. Manag. Sci. 61, 3-18. doi: 10.1287/ mnsc.2014.2044

Brooks, C., Sangiorgi, I., Hillenbrand, C., and Money, K. (2018). Why are older investors less willing to take financial risks? Int. Rev. Financ. Anal. 56, 52-72. doi: 10.1016/j.irfa.2017.12.008

Bucciol, A., and Miniaci, R. (2011). Household portfolios and implicit risk preference. Rev. Econ. Stat. 93, 1235-1250. doi: 10.1162/REST_a_00138

Caballero, R. J., and Pindyck, R. S. (1996). Uncertainty, investment, and industry evolution. Int. Econ. Rev. 37, 641-662. doi: 10.2307/2527445

Campbell, J. Y., and Cochrane, J. H. (1999). By force of habit: a consumptionbased explanation of aggregate stock market behavior. J. Polit. Econ. 107, 205-251. doi: 10.1086/250059

Campbell, J. Y., and Taksler, G. B. (2003). Equity volatility and corporate bond yields. J. Financ. 58, 2321-2349. doi: 10.1046/j.1540-6261.2003.00607.x

Cheema, M. A., Man, Y., and Szulczyk, K. R. (2018). Does investor sentiment predict the near-term returns of the chinese stock market? Int. Rev. Financ. doi: 10.1111/irfi.12202

Chou, R. Y. (1988). Volatility persistence and stock valuations: some empirical evidence using garch. J. Appl. Econ. 3, 279-294. doi: 10.1002/jae.3950030404

Chou, R., Engle, R. F., and Kane, A. (1992). Measuring risk aversion from excess returns on a stock index. J. Econ. 52, 201-224. doi: 10.1016/0304-4076(92)90070-8

Christie, A. A. (1982). The stochastic behavior of common stock variances: value, leverage and interest rate effects. J. Financ. Econ. 10, 407-432. doi: 10.1016/0304-405X(82)90018-6

Cochrane, J. H. (2017). Macro-finance. Rev. Finance 21, 945-985. doi: 10.1093/ $\mathrm{rof} / \mathrm{rfx} 010$

Cotter, J., and Hanly, J. (2010). Time-varying risk aversion: an application to energy hedging. Energy Econ. 32, 432-441. doi: 10.1016/j.eneco.2009.08.009

Coudert, V., and Gex, M. (2008). Does risk aversion drive financial crises? Testing the predictive power of empirical indicators. J. Empir. Financ. 15, 167-184. doi: 10.1016/j.jempfin.2007.06.001
Da, Z., Engelberg, J., and Gao, P. (2011). In search of attention. J. Financ. 66, 1461-1499. doi: 10.1111/j.1540-6261.2011.01679.x

Da, Z., Engelberg, J., and Gao, P. (2015). The sum of all FEARS investor sentiment and asset prices. Rev. Financ. Stud. 28, 1-32. doi: 10.1093/rfs/ hhu072

Devaney, M. (2001). Time varying risk premia for real estate investment trusts: a GARCH-M model. Q. Rev. Econ. Finance 41, 335-346. doi: 10.1016/ S1062-9769(00)00074-0

Dias, G. F. (2017). The time-varying GARCH-in-mean model. Econ. Lett. 157, 129-132. doi: 10.1016/j.econlet.2017.06.005

Dimpfl, T., and Jank, S. (2016). Can Internet search queries help to predict stock market volatility? Eur. Financ. Manag. 22, 171-192. doi: 10.1111/ eufm. 12058

Ding, Z., Granger, C. W. J., and Engle, R. F. (1993). A long memory property of stock market returns and a new model. J. Empir. Financ. 1, 83-106. doi: 10.1016/0927-5398(93)90006-D

Dominiak, A., and Tserenjigmid, G. (2018). Belief consistency and invariant risk preferences. J. Math. Econ. 79, 157-162.

Dow, J., and Werlang, S. R. C. d. (1992). Uncertainty aversion, risk aversion, and the optimal choice of portfolio. Econometrica 60, 197-204. doi: $10.2307 / 2951685$

Eeckhoudt, L., and Godfroid, P. (2000). Risk aversion and the value of information. J. Econ. Educ. 31, 382-388. doi: 10.1080/00220480009596456

Eisenbach, T. M., and Schmalz, M. C. (2016). Anxiety in the face of risk. J. Financ. Econ. 121, 414-426. doi: 10.1016/j.jfineco.2015.10.002

Eisenhauer, J. G. (2008). Ethical preferences, risk aversion, and taxpayer behavior. J. Socio-Econ. 37, 45-63. doi: 10.1016/j.socec.2007.01.030

Eisfeldt, A. L., and Rampini, A. A. (2006). Capital reallocation and liquidity. J. Monet. Econ. 53, 369-399. doi: 10.1016/j.jmoneco.2005.04.006

Elyasiani, E., and Mansur, I. (1998). Sensitivity of the bank stock returns distribution to changes in the level and volatility of interest rate: a GARCH-M model. J. Bank. Financ. 22, 535-563.

Engle, R. F. (1982). Autoregressive conditional heteroscedasticity with estimates of the variance of United Kingdom inflation. Econometrica 50, 987-1007. doi: $10.2307 / 1912773$

Engle, R. F., Lilien, D. M., and Robins, R. P. (1987). Estimating time varying risk premia in the term structure: the Arch-M model. Econometrica 55, 391-407. doi: 10.2307/1913242

Engle, R. F., and Ng, V. K. (1993). Measuring and testing the impact of news on volatility. J. Financ. 48, 1749-1778. doi: 10.1111/j.1540-6261.1993.tb05127.x

Falk, A., Becker, A., Dohmen, T., Enke, B., Huffman, D., and Sunde, U. (2018). Global evidence on economic preferences. Q. J. Econ. 133, 1645-1692. doi: 10.1093/qje/qjy013

Fama, E. F. (1984). Forward and spot exchange rates. J. Monet. Econ. 14, 319-338. doi: 10.1016/0304-3932(84)90046-1

Flannery, M. J., Hameed, A. S., and Harjes, R. H. (1997). Asset pricing, timevarying risk premia and interest rate risk. J. Bank. Financ. 21, 315-335. doi: 10.1016/S0378-4266(96)00044-1

French, K. R., Schwert, G. W., and Stambaugh, R. F. (1987). Expected stock returns and volatility. J. Financ. Econ. 19, 3-29. doi: 10.1016/0304405X(87)90026-2

Gilboa, I., and Schmeidler, D. (1989). Maxmin expected utility with non-unique prior. J. Math. Econ. 18, 141-153. doi: 10.1016/0304-4068(89)90018-9

Giovannini, A., and Jorion, P. (1987). Interest rates and risk premia in the stock market and in the foreign exchange market. J. Int. Money Financ. 6, 107-123. doi: 10.1016/0261-5606(87)90016-7

Giovannini, A., and Jorion, P. (1989). The time variation of risk and return in the foreign exchange and stock markets. J. Financ. 44, 307-325. doi: 10.1111/j.1540-6261.1989.tb05059.x

Goetzmann, W., Kim, D., and Shiller, R. (2016). Crash beliefs from investor surveys (No. 22143).

González, M., Nave, J., and Rubio, G. (2018). Macroeconomic determinants of stock market betas. J. Empir. Financ. 45, 26-44. doi: 10.1016/j. jempfin.2017.10.003

Grith, M., Härdle, W., and Park, J. (2013). Shape invariant modeling of pricing kernels and risk aversion. J. Financ. Economet. 11, 370-399. doi: 10.1093/ jjfinec/nbs019

Guiso, L., Sapienza, P., and Zingales, L. (2018). Time varying risk aversion R. J. Financ. Econ. 128, 403-421. doi: 10.1016/j.jineco.2018.02.007 
Han, X., and Li, Y. (2017). Can investor sentiment be a momentum time-series predictor? Evidence from China. J. Empir. Financ. 42, 212-239. doi: 10.1016/j. jempfin.2017.04.001

Hansen, L. P., Sargent, T. J., and Tallarini, T. D. (1999). Robust permanent income and pricing. Rev. Econ. Stud. 66, 873-907. doi: 10.1111/1467-937X.00112

Harvey, C. R. (1989). Time-varying conditional covariances in tests of asset pricing models. J. Financ. Econ. 24, 289-317. doi: 10.1016/0304-405X(89)90049-4

Heston, S. L., and Sinha, N. R. (2017). News vs. sentiment: predicting stock returns from news stories. Financ. Anal. J. 73, 67-83. doi: 10.2469/faj.v73.n3.3

Hodrick, R. J., and Srivastava, S. (1986). The covariation of risk premiums and expected future spot exchange rates. J. Int. Money Financ. 5, 5-21.

Hoffmann, A. O. I., and Post, T. (2016). How does investor confidence lead to trading? Linking investor return experiences, confidence, and investment beliefs. J. Behav. Exp. Financ. 12, 65-78. doi: 10.1016/j.jbef.2016.09.003

Hoffmann, A. O. I., and Post, T. (2017). How return and risk experiences shape investor beliefs and preferences. Account. Finance 57, 759-788. doi: 10.1111/acfi. 12169

Ilut, C. L., and Schneider, M. (2014). Ambiguous business cycles. Am. Econ. Rev. 104, 2368-2399. doi: 10.1257/aer.104.8.2368

Jackwerth, J. C. (2000). Recovering risk aversion from option prices and realized returns. Rev. Financ. Stud. 13, 433-451. doi: 10.1093/rfs/13.2.433

Jacobs, H., and Weber, M. (2012). The trading volume impact of local bias: evidence from a natural experiment. Rev. Finance 16, 867-901. doi: 10.1093/ $\mathrm{rof} / \mathrm{rfr} 022$

Jianakoplos, N. A., and Bernasek, A. (2006). Financial risk taking by age and birth cohort. South. Econ. J. 72, 981-1001. doi: 10.2307/20111864

Jurado, K., Ludvigson, S. C., and Ng, S. (2015). Measuring uncertainty. Am. Econ. Rev. 105, 1177-1216. doi: 10.1257/aer.20131193

Kacperczyk, M., Van Nieuwerburgh, S., and Veldkamp, L. (2016). A rational theory of mutual funds' attention allocation. Econometrica 84, 571-626. doi: 10.3982/ECTA11412

Kamstra, M. J., Kramer, L. A., and Levi, M. D. (2003). Winter blues: a SAD stock market cycle. Am. Econ. Rev. 93, 324-343. doi: 10.1257/000282 803321455322

Karni, E., and Vierø, M.-L. (2013). "Reverse Bayesianism”: a choice-based theory of growing awareness. Am. Econ. Rev. 103, 2790-2810. doi: 10.1257/ aer.103.7.2790

Karni, E., and Vierø, M.-L. (2015). Probabilistic sophistication and reverse Bayesianism. J. Risk Uncertain. 50, 189-208. doi: 10.1007/s11166-015-9216-5

Kearney, C., and Liu, S. (2014). Textual sentiment in finance: a survey of methods and models. Int. Rev. Financ. Anal. 33, 171-185. doi: 10.1016/j. irfa.2014.02.006

Keim, D. B., and Stambaugh, R. F. (1986). Predicting returns in the stock and bond markets. J. Financ. Econ. 17, 357-390. doi: 10.1016/0304-405X(86)90070-X

Kiesel, R., and Rahe, F. (2017). Option pricing under time-varying risk-aversion with applications to risk forecasting. J. Bank. Financ. 76, 120-138. doi: 10.1016/j.jbankfin.2016.11.006

Kumar, M. S., and Persaud, A. (2002). Pure contagion and investors' shifting risk appetite: analytical issues and empirical evidence. Int. Finance 5, 401-436. doi: $10.1111 / 1468-2362.00102$

Lawton, W. H., Sylvestre, E. A., and Maggio, M. S. (1972). Self modeling nonlinear regression. Technometrics 14, 513-532. doi: 10.1080/00401706. 1972.10488942

Li, G. (2007). Time-varying risk aversion and asset prices. J. Bank. Financ. 31, 243-257. doi: 10.1016/j.jbankfin.2006.02.005

Li, D., Ghoshray, A., and Morley, B. (2011). "Uncovered interest parity and the risk premium" in Department of Economics Working Papers (No. 24072) (University of Bath, Department of Economics).

Liao, W. J., and Sung, H.-C. (2018). Implied risk aversion and pricing kernel in the FTSE 100 index. North Am. J. Econ. Finance. doi: 10.1016/j.najef. 2018.08.009

Lintner, J. (1965). The valuation of risk assets and the selection of risky investments in stock portfolios and capital budgets. Rev. Econ. Stat. 47, 13-37. doi: 10.2307/1924119

Ma, W., and Schipper, B. C. (2017). Does exposure to unawareness affect risk preferences? A preliminary result. Theor. Decis. 83, 245-257. doi: 10.1007/ s11238-017-9594-z
Markowitz, H. (1952). Portfolio selection. J. Financ. 7, 77-91.

Mengel, F., Tsakas, E., and Vostroknutov, A. (2016). Past experience of uncertainty affects risk aversion. Exp. Econ. 19, 151-176. doi: 10.1007/ s10683-015-9431-6

Muir, T. (2016). Financial crises and risk premia. Q. J. Econ. 132, 765-809. doi: 10.1093/qje/qjw045

Nielsen, J. S., Bech, M., Christensen, K., Kiil, A., and Hvidt, N. C. (2017) Risk aversion and religious behaviour: analysis using a sample of Danish twins. Econ. Hum. Biol. 26, 21-29. doi: 10.1016/j.ehb.2017.01.004

Nofsinger, J. R., Patterson, F. M., and Shank, C. A. (2018). Decision-making, financial risk aversion, and behavioral biases: the role of testosterone and stress. Econ. Hum. Biol. 29, 1-16. doi: 10.1016/j.ehb.2018.01.003

Pástor, L., and Veronesi, P. (2013). Political uncertainty and risk premia. J. Financ. Econ. 110, 520-545. doi: 10.1016/j.jfineco.2013.08.007

Poterba, J. M., and Summers, L. H. (1986). The persistence of volatility and stock market fluctuations. Am. Econ. Rev. 76, 1142-1151.

Potrafke, N. (2019). Risk aversion, patience and intelligence: evidence based on macro data. Econ. Lett. 178, 116-120. doi: 10.1016/j.econlet.2019.02.026

Pratt, J. W. (1964). Risk aversion in the small and in the large. Econometrica 32, 122-136. doi: 10.2307/1913738

Quiggin, J., and Chambers, R. G. (1998). Risk premiums and benefit measures for generalized-expected-utility theories. J. Risk Uncertain. 17, 121-137. doi: 10.1023/A:1007767512327

Quiggin, J., and Chambers, R. G. (2004). Invariant risk attitudes. J. Econ. Theory 117, 96-118. doi: 10.1016/j.jet.2003.09.006

Roll, R. (1977). A critique of the asset pricing theory's tests; part i: on past and potential testability of the theory. J. Financ. Econ. 4, 129-176.

Rosenberg, J. V., and Engle, R. F. (2002). Empirical pricing kernels. J. Financ. Econ. 64, 341-372. doi: 10.1016/S0304-405X(02)00128-9

Routledge, B. R., and Zin, S. E. (2010). Generalized disappointment aversion and asset prices. J. Financ. 65, 1303-1332. doi: 10.1111/j.1540-6261.2010.01571.x

Safra, Z., and Segal, U. (1998). Constant risk aversion. J. Econ. Theory 83, 19-42. doi: 10.1006/jeth.1997.2457

Sharpe, W. F. (1964). Capital asset prices: a theory of market equilibrium under conditions of risk. J. Financ. 19, 425-442.

Storesletten, K., Telmer, C. I., and Yaron, A. (2004). Cyclical dynamics in idiosyncratic labor market risk. J. Polit. Econ. 112, 695-717. doi: 10.1086/383105

Suen, R. M. H. (2018). Standard risk aversion and efficient risk sharing. Econ. Lett. 173, 23-26. doi: 10.1016/j.econlet.2018.09.005

Tobin, J. (1958). Liquidity preference as behavior towards risk. Rev. Econ. Stud. 25, 65-86.

Veldkamp, L. L. (2006). Media frenzies in markets for financial information. Am. Econ. Rev. 96, 577-601. doi: 10.1257/aer.96.3.577

Vlastakis, N., and Markellos, R. N. (2012). Information demand and stock market volatility. J. Bank. Financ. 36, 1808-1821. doi: 10.1016/j. jbankfin.2012.02.007

Von Neumann, J., and Morgenstern, O. (1944). Theory of games and economic behavior. (Princeton, New Jersey: Princeton University Press).

Willinger, M. (1989). Risk aversion and the value of information. J. Risk Insur. 56, 104-112. doi: 10.2307/253017

Yoon, S.-J. (2017). Time-varying risk aversion and return predictability. Int. Rev. Econ. Finance 49, 327-339. doi: 10.1016/j.iref.2017.02.006

Zhang, J., Kong, D., Liu, H., and Wu, J. (2019). Asset pricing with time varying pessimism and rare disasters. Int. Rev. Econ. Finance 60, 165-175. doi: 10.1016/j.iref.2018.11.005

Conflict of Interest Statement: The authors declare that the research was conducted in the absence of any commercial or financial relationships that could be construed as a potential conflict of interest.

Copyright (c) 2019 Díaz and Esparcia. This is an open-access article distributed under the terms of the Creative Commons Attribution License (CC BY). The use, distribution or reproduction in other forums is permitted, provided the original author(s) and the copyright owner(s) are credited and that the original publication in this journal is cited, in accordance with accepted academic practice. No use, distribution or reproduction is permitted which does not comply with these terms. 


\title{
The Cognitive Dimension and the Affective Dimension in the Patient's Experience
}

\author{
Pedro Reinares-Lara ${ }^{1 *}$, Alfredo Rodríguez-Fuertes ${ }^{1}$ and Blanca Garcia-Henche ${ }^{2}$ \\ ${ }^{1}$ Department of Business Economics, Universidad Rey Juan Carlos, Madrid, Spain, ${ }^{2}$ Department of Economy and Business \\ Management, Universidad de Alcalá, Madrid, Spain
}

OPEN ACCESS

Edited by:

Alicia Izquierdo-Yusta, University of Burgos, Spain

Reviewed by: Jorge Pelegrín-Borondo, University of La Rioja, Spain

Maria Dolores Reina, National University of Distance

Education (UNED), Spain

*Correspondence:

Pedro Reinares-Lara pedro.reinares@urjc.es

Specialty section:

This article was submitted to

Organizational Psychology, a section of the journal Frontiers in Psychology

Received: 04 July 2019 Accepted: 10 September 2019 Published: 25 September 2019

Citation:

Reinares-Lara P, Rodríguez-Fuertes A and Garcia-Henche B (2019)

The Cognitive Dimension and the Affective Dimension in the Patient's

Experience.

Front. Psychol. 10:2177. doi: 10.3389/fpsyg.2019.02177
This article deals with the experience of the specific client of health services, that is, the patient. Satisfaction questionnaires are usually applied to assess patient experience. However, this tool provides only a cognitive evaluation; it does not afford an affective dimension of the experience. The objective of the present study is to verify the relationship between the cognitive dimension of patient experience, collected through questionnaires, and the affective dimension, derived from the analysis of neurophysiological data. We propose a novel methodology that integrates physiological data collected by facial expression analysis to identify patients' emotions. A first, qualitative procedure was carried out to define the patient journey. This was recorded on video and later used in the experiment. The experiment collected information from the participants using two techniques. First, as they viewed the videos, facial expression analysis (FEA) was applied to assess their responses. Second, after they watched the videos, traditional questionnaires were presented. The results provided by the two techniques were then compared. The results show that there is no relationship between the emotional valence reported by questionnaires and the neurophysiological data. This reflects the two different dimensions of the experience, one cognitive and the other affective. Both facilitate the understanding of patient satisfaction.

Keywords: patient experience, patient journey, facial expression analysis, emotions, satisfaction, consumer neuroscience, customer experience

\section{INTRODUCTION}

In recent years, there has been a growing interest in the study of the customer experience, especially in terms of emotions. There has been much analysis of consumer satisfaction with services and the variables that affect it. Although satisfaction is a generally well-understood concept, there is no consensus on its nature, nor on its evaluation (Giese and Cote, 2000; Villodre et al., 2014).

While it is necessary for any organization to have satisfied customers, it is a priority objective in the health sector. Healthcare is a critical context due to its unpredictable situations, demanding clients, workload, and intrinsic organizational complexity. The need for healthcare quality improvement in a period of increasing financial and service pressures requires for financial performance and productivity not to negatively impact on service quality (Bruno et al., 2017). 
Private entities have shown that satisfied customers are more likely to be loyal to the supplier of the service that gave the satisfaction (Bendall-Lyon and Powers, 2004; Sofaer and Firminger, 2005; Rundle-Thiele and Russell-Bennett, 2010), and to recommend that service provider (Bendall-Lyon and Powers, 2004). Satisfaction also influences clinical outcomes. Studies have shown that patients who reported themselves as being more satisfied with their care are more positive, compliant, cooperative, and more likely to increase their participation in prescribed medical and pharmaceutical treatments (Dubé and Menon, 1998; Sofaer and Firminger, 2005).

According to some authors, service quality is mainly cognitive, whereas satisfaction is a more complex concept that includes both cognitive and affective components (Oliver, 1993). It is possible that both aspects might be defined by examining more closely recognized quality dimensions, cognitive satisfaction and affective satisfaction (Cronin and Taylor, 1992; Vinagre and Neves, 2008).

\section{CONCEPTUAL FRAMEWORK}

\section{Patient Experience}

There has been a rapid acceptance of the use of the term "patient experience": as evidence, it is now a top priority for healthcare management (Wolf et al., 2014). In a sector, such as healthcare, in which the internal perspective has predominated in terms of designing work processes and assessing service quality, knowing how the patient experiences the process is an opportunity to improve this experience.

The Beryl Institute (2015) defined patient experience as "the sum of all interactions, shaped by an organization's culture, that influence patient perceptions across the continuum of care." This definition reflects the multidimensional nature of patient experience previously included in the healthcare literature (Gentile et al., 2007; The King's Fund, 2010), comprising sensory, cognitive, and emotional components (Fulbright et al., 2001).

Patient satisfaction is a commonly used indicator for measuring patient experience in healthcare. However, there are methodological weaknesses regarding the techniques used to address the issue of experience (Sofaer and Firminger, 2005), as the individual is considered to be eminently rational and capable of processing all the data from the experience to express his or her opinion at a given time. For this reason, it is believed that there is currently no reliable method for collecting data on patient experience (Coulter et al., 2014).

\section{Double Dimension of Satisfaction}

The complexity of the process leading to satisfaction with health services involves diverse phenomena associated with both the cognitive and emotional domains (Vinagre and Neves, 2008). Several authors have confirmed that satisfaction has a double dimension:

(1) First, there is a cognitive evaluation side, which is a result of a cognitive process in which the patient considers the positive and negative aspects of different components of a service, either evaluating the perceived result alone, or comparing it against a standard (Liljander and Strandvik, 1997). From this perspective, satisfaction with a healthcare experience is the result of the accumulation of independent evaluations of different factors, such as medical staff, environment, service, etc. (Westbrook and Oliver, 1991).

(2) A second, affective side, considers subjective elements by capturing feelings or emotions generated in the relationship between the patient and the healthcare provider (Cronin and Taylor, 1992; Oliver, 1993; Liljander and Strandvik, 1997; Gill and White, 2009) that are beyond the patient's conscious control.

Healthcare organizations today focus on cognitive assessments and neglect the emotions experienced by the patient. However, it has been demonstrated that emotional aspects not only have an impact on patient satisfaction, they also influence clinical outcomes (Dubé and Menon, 1998; Sofaer and Firminger, 2005).

For these reasons, in recent years some researchers have advocated the need to address satisfaction from a dual cognitiveaffective approach (Westbrook and Oliver, 1991; Wirtz and Bateson, 1999; Villodre et al., 2014), considering cognitive and affective responses as distinct, since each has a separate influence on satisfaction formation (Oliver, 1993; Liljander and Strandvik, 1997). It is also likely that this approach will help to define the concepts of service quality and satisfaction (Cronin and Taylor, 1992; Vinagre and Neves, 2008).

It is possible that the measurement of the affective-subjective component of the patient satisfaction construct still lacks precision (Crow et al., 2002), which would render the studies undertaken into the subject purely exploratory (Gill and White, 2009).

\section{Satisfaction Measurement}

The literature review shows that the concept of emotion has attracted the interest of researchers in understanding the background and results of customer satisfaction. Hunt (1977) considered satisfaction as the evaluation of an emotion. Emotions are complex phenomena that arise when judging an event, in which various factors (physiological, behavioral, expressive, and subjective feelings) intervene, and that influence the individual's decision-making and judgment.

There are two main theoretical approaches to measure emotional subjective experience: the categorical approach, which studies basic emotions, and the dimensional, which looks at emotional dimensions and the degree to which these dimensions are perceived. Researchers who take the categorical approach seek to determine which of a given set of basic emotions (e.g., fear, anger, joy, sadness, acceptance, disgust, expectancy, and surprise) a subject is feeling (Pelegrín-Borondo et al., 2005). Some researchers who take the dimensional approach believe that emotional state can be determined exclusively based on levels of arousal and pleasure. The present study takes this second line. This method of obtaining self-reports of emotional feelings is simple and straightforward and generally quite reliable (Scherer, 2005).

To examine the affective component, we used the PAD (pleasure-arousal-dominance) model developed by Mehrabian and Russell (1974). This explains that an individual experiences his or her emotions through the combination of three continuous psychophysiological bipolar variables: valence (or pleasure), activation (or excitement), and dominance (or control) (Figure 1). 


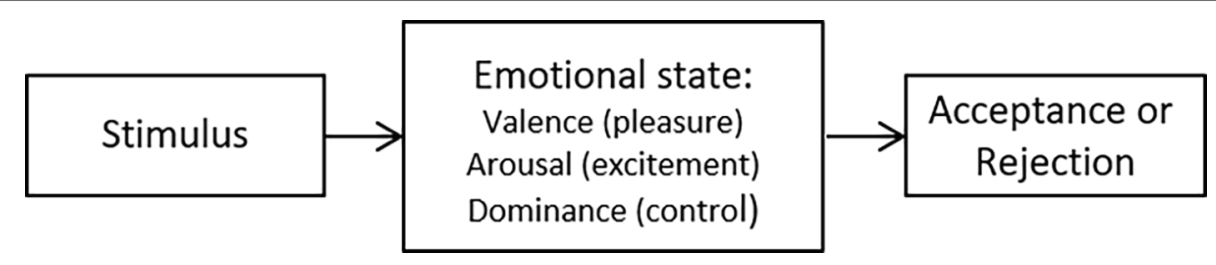

FIGURE 1 | PAD model. Source: Mehrabian and Russell (1974).

1. Valence (pleasure)

Valence refers to the subjective, emotional value evoked by the stimulus (Russell, 1980). This value classifies participants' emotions as positive (when they provoke a pleasant state), or negative (when they provoke displeasure). The former have associated approach behaviors, while the latter have been described as motivations to avoid and generate rejection or withdrawal behaviors (Cacioppo and Gardner, 1999). That is, in the case of negative valence, the behavior of the individual will not be repeated.

2. Arousal

Arousal, activation or excitation, refer to the affective experience of energy levels. When an individual experiences a high level of energy, this evokes high arousal, whereas the experience of low levels of energy is associated with low arousal. Depending on how stimulating the environment is, the individual's behavior is aimed at consciously increasing or reducing activation levels. When activation levels are low, any increase in environmental stimuli will be pleasurable, and any reduction will be unpleasant. Moderate activation levels result in a pleasant experience, while boring or stressful stimuli produce aversive experiences (Reeve, 2015).

3. Dominance

The dominance dimension refers to the degree of control exerted by the stimulus on the individual. It offers lower discrimination than valence and arousal and is not always used in research (Posner and Rothbart, 1998; Setz et al., 2009).

\section{Evaluating Patient Experience}

First, it is necessary to recognize the lack of consensus not only on a definition of satisfaction, but also on its evaluation (Giese and Cote, 2000; Villodre et al., 2014).

To collect data about patients' experiences, quantitative techniques are generally used, as are, less commonly, qualitative techniques. Quantitative techniques are based on questionnaires used to investigate patients' perceptions (Granado et al., 2007; Val-Jiménez et al., 2017). These have emerged as valid instruments for measuring the cognitive component of satisfaction, but are used less so for measuring experience and emotions or the "emotional experience" referred to by Frijda and Mesquita (1998), Granado et al. (2007), and Val-Jiménez et al. (2017).

Qualitative techniques offer a greater potential to uncover more in-depth facts about healthcare services (Ofili, 2014) and help researchers gather more customer data. For this reason, the use of qualitative research techniques is recommended to identify and understand the principal determinants of satisfaction with healthcare services (Liljander and Strandvik, 1997; Losada and Rodríguez, 2007), as quantitative research alone does not seem capable of representing patients' experiences (Lees, 2011). Some researchers argue that using combined quantitative and qualitative methodologies offers a better solution than other techniques (Losada and Rodríguez, 2007; Lees, 2011; Ofili, 2014).

There has been a progressive incorporation of neuroscience techniques into marketing research over the last decade (Ausin et al., 2017). These techniques, for example, FEA, one of the most valued methods, help to study emotions. There is no research into patient experience that applies neurophysiological data-gathering techniques of responses outside the patient's conscious control. This offers the opportunity to incorporate new methodologies capable of providing data on the emotional side of patient experience.

Against this background, the present study aims to verify the possible relationship between data reported through questionnaires, which provide a cognitive, conscious assessment, and neurophysiological data, which reflect affective processes outside the patient's conscious control.

\section{MATERIALS AND METHODS}

In order to achieve the research objective, a two-phase process was adopted: a first exploratory phase and an experimental phase. The study was approved by the internal review board of the laboratory of neuromarketing at the Universidad Rey Juan Carlos. The participants signed a written informed consent in accordance with the Declaration of Helsinki.

\section{Exploratory Stage}

In the exploratory stage, qualitative methods were used, with 3 focus groups and 14 in-depth interviews, collecting data from patients, health professionals, and health quality experts.

The objectives of this first stage were to delve into the emotional aspects of the care experience and to describe the patient journey (PJ). Specifically, we wanted to reproduce the PJ of individuals undergoing inguinal hernia surgery, the process subsequently used in the experiment. We chose this procedure because it is one of the most common in the Spanish health system and it involves different levels of care: (1) primary care (PC), (2) specialized care (SC), and (3) hospitalization and discharge $(\mathrm{H})$.

\section{Experiment}

The experiment consisted of studying the emotional value of a sample of individuals during the simulation of a surgical intervention process. We showed the participants a video of 
patients going through the process of an inguinal hernia repair surgery in a health facility, including their interactions with the healthcare professionals.

The PJ was divided into three stages on a 3-min video, in order to collect data at the end of each stage and analyze them independently. These stages correspond to each of the care process levels, $\mathrm{PC}, \mathrm{SC}$, and $\mathrm{H}$. The videos were shown to the participants to collect data on their emotions at specific moments, on the basis that the patients' would experience emotions as if the procedure was being applied to them at that moment. This design allows customer perceptions and feelings to be examined throughout a simulated event (Suomala et al., 2012).

For the emotional assessment of the experience, a double system was used: (1) a SAM questionnaire was presented to the participants after they had watched the videos; this provided data of their emotional valence and arousal and (2) their neurophysiological variables were monitored by a facial expression analysis team as they watched the videos.

Given that there is a link between the valence dimension of emotions and consumer satisfaction (Phillips and Baumgartner, 2002), the participants were asked, after watching the three videos, to assess their satisfaction with the process in a questionnaire, in order to corroborate the possible relationship.

The study design, using two types of techniques, helped meet the methodological aim of comparing the physiological measures obtained by facial expression analysis with the results from the SAM questionnaire.

In the service sector, studies frequently use self-completion questionnaires combined with data collected by neuroscience devices (Chih-Chien and Ming-Chang, 2014; Vance et al., 2014).

\section{Self-Assessment Manikin Questionnaire}

The Self-Assessment Manikin (SAM) questionnaire was used to obtain data from individuals after they watched the videos, by which means, self-reported emotional experiences at each care level (PC, SC, and $\mathrm{H}$ ) were collected.

The SAM questionnaire was developed by Bradley and Lang in 1994, based on Mehrabian's three-dimensional PAD scale (Mehrabian, 1996). The SAM questionnaire is a widely accepted tool for assessing emotional responses (Greenwald et al., 1989). It is a self-administered questionnaire that uses a non-verbal assessment scale to directly measure the pleasure and arousal associated with an individual's affective reaction to a stimulus.

The SAM measurement used consisted of a series of human figures, for each dimension, on a graduated valence-intensity scale (from a smiling to an unpleasant looking figure) and an arousal scale (from an excited to a relaxed figure) (Figure 2). Graphical evaluation techniques reduce the individual's effort in verbalizing emotions. The dominance variable was not examined in the experiment because of its lower level of discrimination and its positive correlation with valence.

The SAM questionnaire has been used in health research (Jayanti and Whipple, 2008) and has also been used to rate the affective dimensions of valence and arousal of individuals while watching videos (Setz et al., 2009; Handayani et al., 2015).

\section{Facial Expression Analysis}

As a complement to the SAM questionnaire, and in order to overcome the limitations of self-reported data, we used a neurophysiological measurement technique: facial expression analysis (FEA).

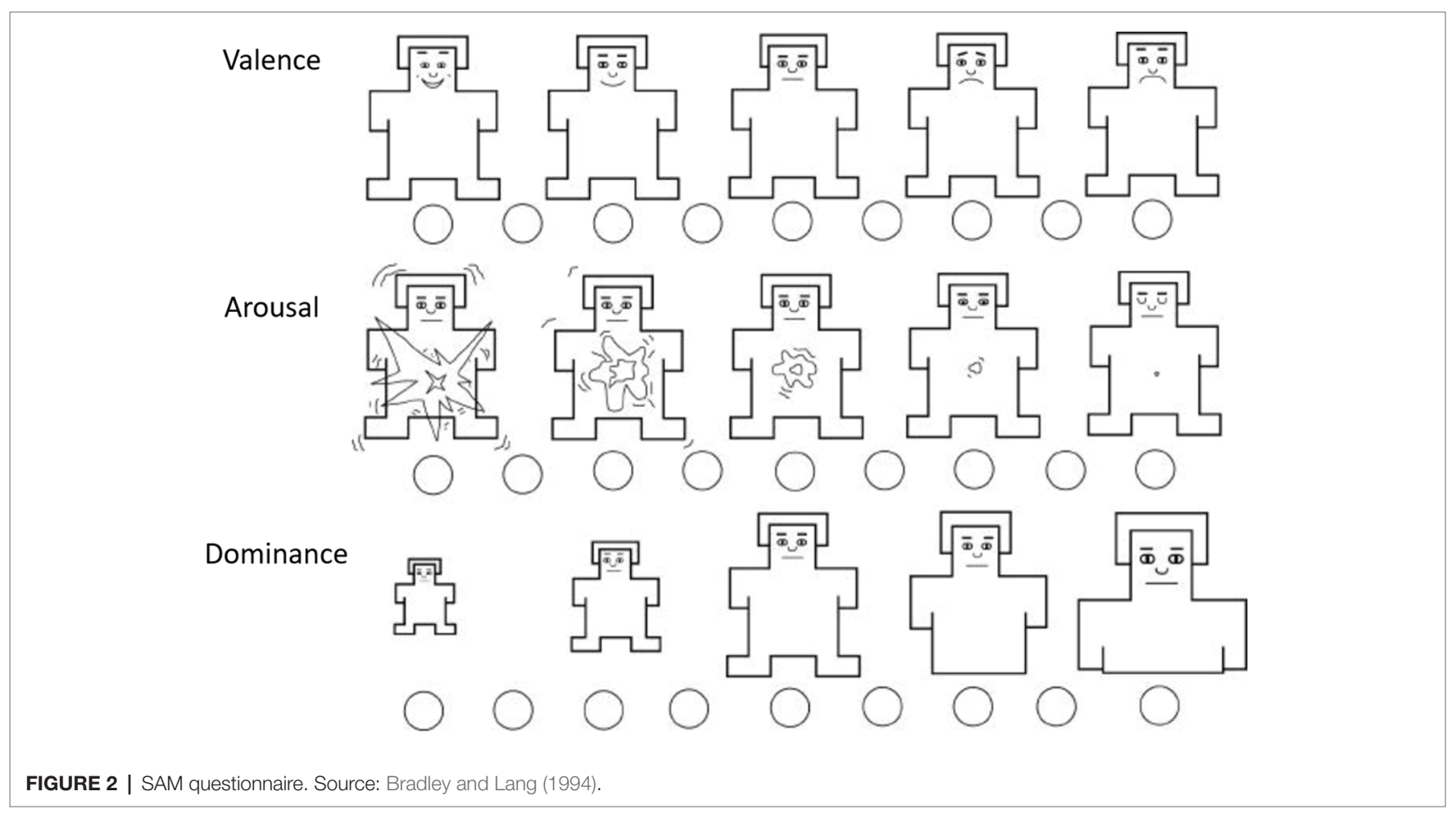


FEA captures emotions outside the patient's conscious control that have their origins in the autonomous nervous system. The technique is based on the correlation found by Ekman and Friesen (1971) between emotions and facial muscle movements. FEA identifies the visible movements of facial muscles and is a novel technique, not so much because of its origin, as the first studies into facial coding systems were developed by Ekman and Friesen (1978), but because of the incorporation of new computer applications that allow the automatic coding of expressions.

For the present study, we used Affectiva-Affdex software integrated into the iMotions platform; this identified the emotions evoked and generated the valence indicator, which measured the positive and negative nature of the individual's experience (iMotions, 2018).

The experiment was conducted in accordance with the schema shown in Figure 3. Immediately after watching the video, the SAM questionnaire was administered. Thus, each participant assessed their level of satisfaction with the entire process, as if they had been the patient.

A total of 60 people participated in the experiment (mean age: 21.7 years; SD: $2.21 ; 50 \%$ men $/ 50 \%$ women). This sample size is larger than that used in other FEA studies. The participants were between 18 and 65 years old, randomly recruited through a volunteer database encompassing all ages. The eligibility criteria were as follows: they had to be native Spanish language speakers, public health service users, not having undergone surgery in the previous 12 months, and who had never previously suffered from an inguinal hernia given that this was the reason for the PJ.

\section{RESULTS}

Data from the exploratory stage confirmed the high emotional burden that the experience of healthcare has for the patient and his or her family. The patients direct their demands towards those aspects that reduce anxiety (information) and fear (a trust relationship with the professional which may help them understand what to expect). The experience is more intense in more complex processes, in which referral to other levels is made during the hospital stay.

Although users generally expressed high levels of satisfaction with healthcare services, negative comments appeared when they referred in more detail to their experiences. Throughout the care process, negative emotions (anxiety at lack of information, fear of the results, sadness, etc.) were evident, but only in some cases did positive emotions appear (hope of a recovery of total or relative normality).

As a result, a detailed reconstruction of the patient journey of individuals undergoing inguinal hernia repair was achieved, based on 22 specific moments, from the appearance of the first symptoms of the problem, through the surgical intervention, and on to discharge (Table 1).

This PJ was the basis for developing the video materials used in the experiment, which were recorded by professional teams in real environments with the participation of healthcare professionals.

\section{Self-Assessment Manikin Questionnaire Scores}

The valence indicator showed the emotional values (positive or negative) evoked by the stimulus (Figure 4); these indicate that valence increases slightly from 5.60 to 5.68 between Stage 2 (SC) and Stage 1 (PC). It decreases considerably later, in Stage $3(\mathrm{H})$, to 3.35 , indicating an increase in patient happiness at the end of the process.

The arousal indicator, which reveals the degree of intensity with which these emotions are experienced (Figure 5), reports an increase, especially between Stages 1 (5.33) and 2 (4.02), and a decrease between Stages 2 and 3 (3.97).

The results showed a low inverse linear correlation between valence and arousal at Stage $1(r=-0.268, p=0.038)$ and at Stage $2(r=-0.261, p=0.044)$, but not at Stage 3 (Table 2). That is, arousal is less intense at higher valence levels (sadder) in Stages 1 and 2 .

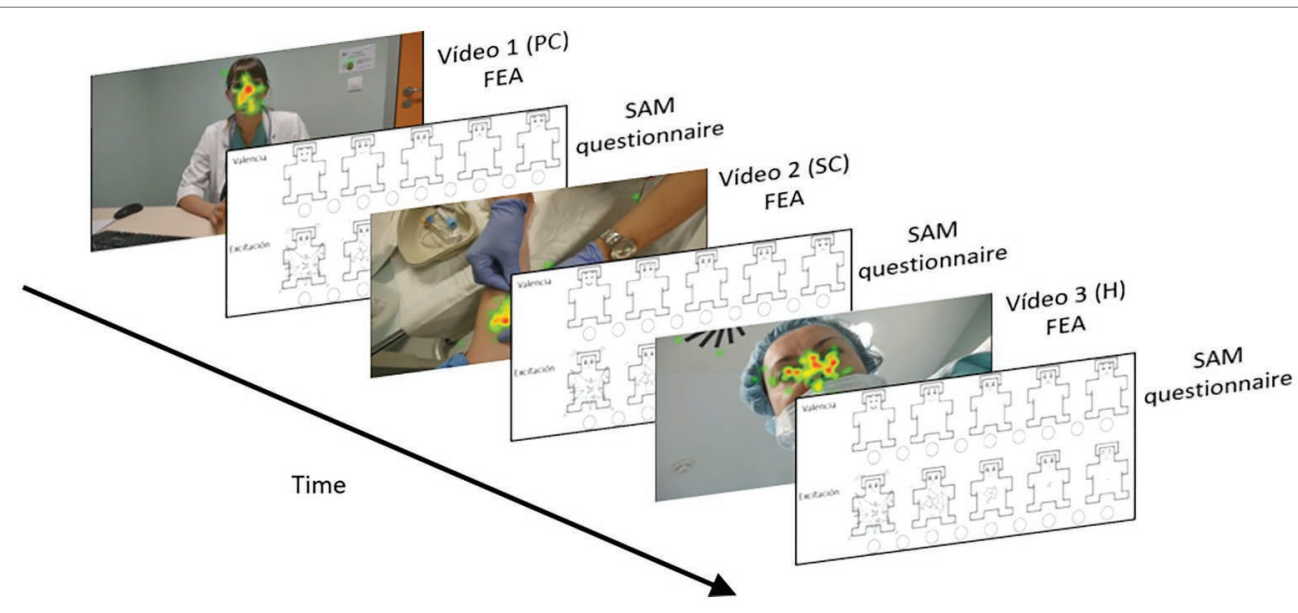

FIGURE 3 | Experimental schema. 
TABLE 1 | Patient journey, inguinal hernia repair surgery.

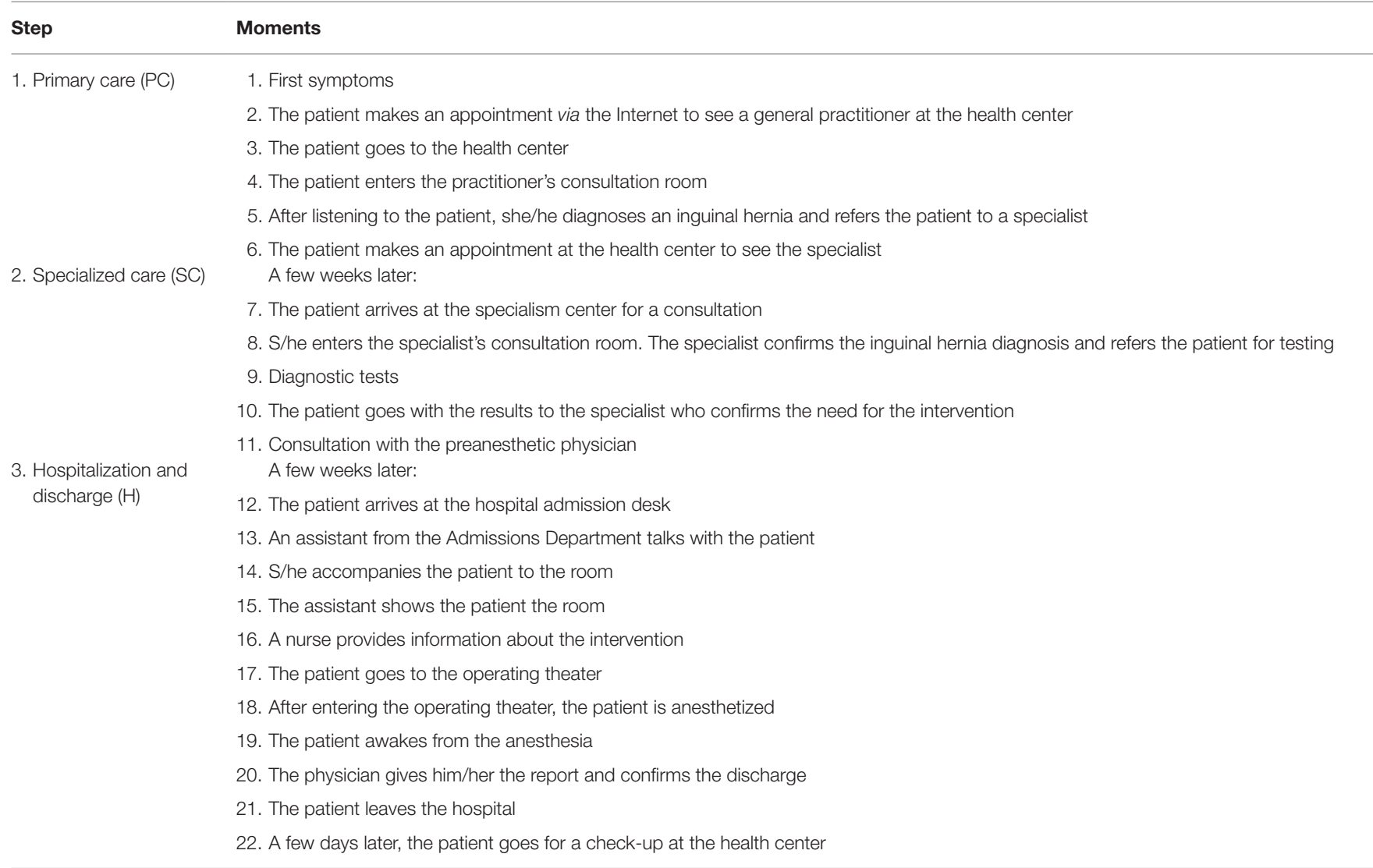

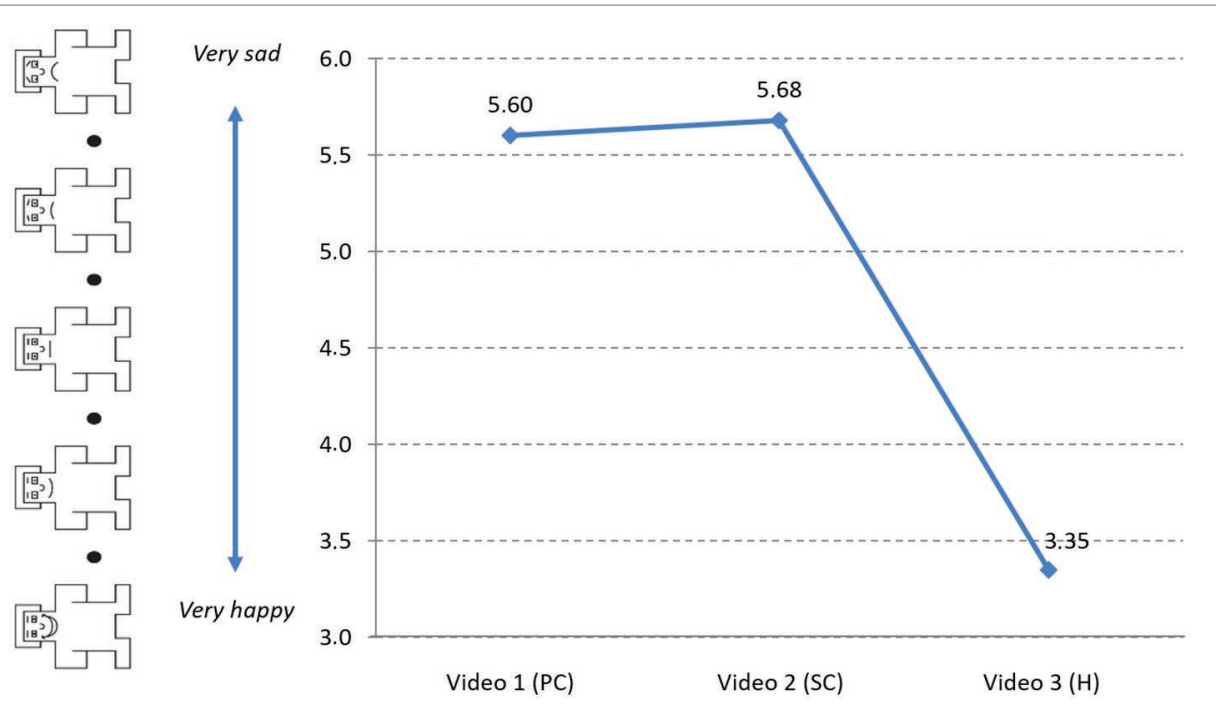

FIGURE 4 | Evolution of valence (SAM) during the PJ.

\section{Comparison Between Self-Assessment Manikin Questionnaire and Satisfaction Level} After they had watched the videos, we asked the participants to give an overall satisfaction assessment with the virtual experience. Satisfaction was measured on a numerical rating scale from 0 (not satisfied at all) to 10 (very satisfied), as used in other studies in the health sector (Aldosari et al., 2017). The overall rating was 7.45 points.

The analysis showed only a moderate inverse correlation between valence (SAM) at the end of video $3(\mathrm{H})$ and overall 


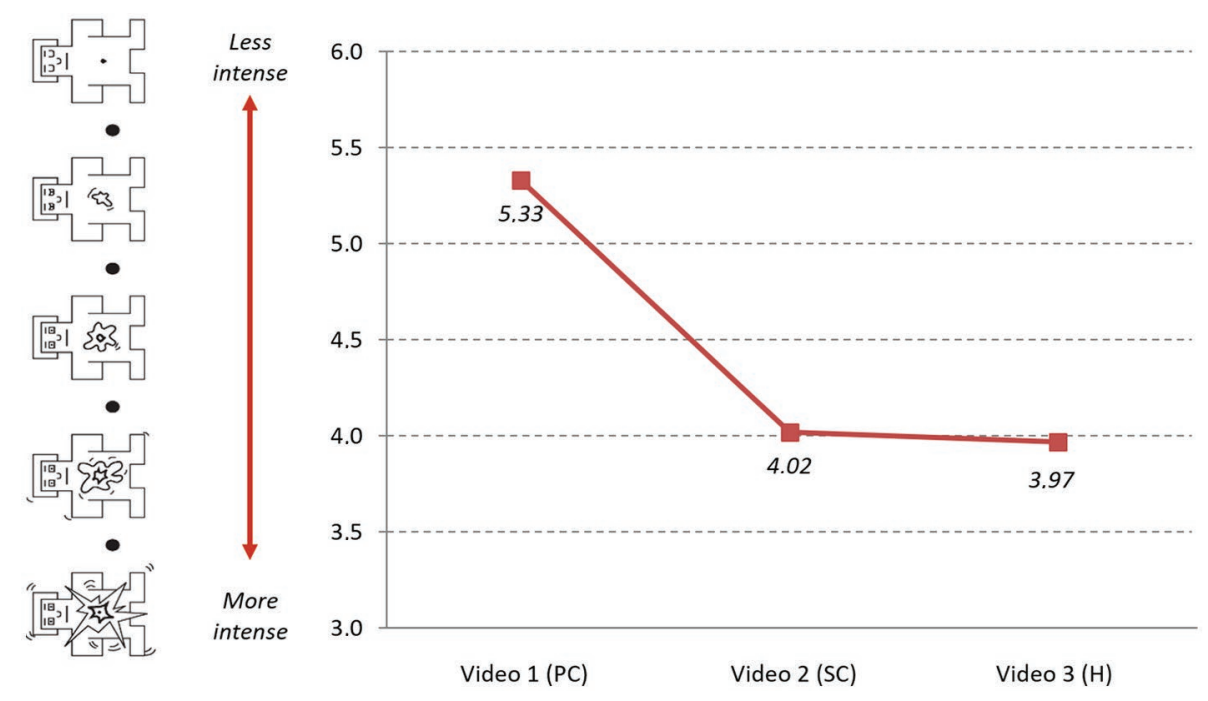

FIGURE 5 | Evolution of arousal (SAM) during the PJ.

TABLE 2 | Correlations of valence and arousal during each video (SAM).

\begin{tabular}{lcc}
\hline Correlation between & Pearson correlation & Sig. (bilateral) \\
\hline $\begin{array}{l}\text { 1. Valence and arousal } \\
\text { Stage 1 (PC) }\end{array}$ & -0.268 & $\mathbf{0 . 0 3 8}$ \\
$\begin{array}{l}\text { 2. Valence and arousal } \\
\text { Stage 2 (SC) }\end{array}$ & -0.261 & $\mathbf{0 . 0 4 4}$ \\
$\begin{array}{l}\text { 3. Valence and arousal } \\
\text { Stage 3 }(\mathrm{H})\end{array}$ & -0.013 & 0.924 \\
\hline
\end{tabular}

Bold values represent the significant difference.

satisfaction $(r=-0.408)$. That is, lower valence (more joy) when the video ended is associated with higher overall satisfaction. The means of the correlations between valences after Stages 1 (PC) and 2 (SC), and overall satisfaction, were higher than 0.05 , therefore we rejected the null hypothesis that significant differences exist (Table 3).

\section{Facial Expression Analysis Results}

The facial expression analysis (FEA) results confirmed the prevalence of negative valence in the emotional state of the participants during the $P J$. In this respect, the results of the SAM questionnaires completed by the participants coincided with the measurements obtained through the FEA (Figure 6). The valence metric derived from the FEA showed negative values at the early stages of the care process. Of the 22 specific moments/points of the $P J$, only three had positive valence: the scores became positive only after the surgical intervention was completed and up to discharge, which is consistent with the predominance of negative emotions in the healthcare experience.

At each stage, valence had more negative values but improved as the process moved forward, but access to a new care level (specialized care or hospitalization) returned emotional valence to low levels.
TABLE 3 | Correlations between valence (SAM) and overall satisfaction.

\begin{tabular}{lcc}
\hline Correlation between & Pearson correlation & Sig. (bilateral) \\
\hline $\begin{array}{l}\text { 1. Valence }(\mathrm{V} 1-\mathrm{PC}) \text { and } \\
\text { overall satisfaction }\end{array}$ & 0.009 & 0.952 \\
$\begin{array}{l}\text { 2. Valence (V2-SC) and } \\
\text { overall satisfaction }\end{array}$ & -0.109 & 0.457 \\
$\begin{array}{l}\text { 3. Valence (V3-H) and } \\
\text { overall satisfaction }\end{array}$ & -0.408 & $\mathbf{0 . 0 0 4}$ \\
\hline
\end{tabular}

Bold values represent the significant difference.

Once the need to go to the PC physician is recognized, the request for an appointment via the Internet has a negative value (-1.5). The first visual contact and the PC physician's greeting improved valence to a neutral value $(-0.175)$. The first diagnosis increased the negative value $(-1.155)$, and the appointment request reduced it again $(-0.511)$.

When attending the appointment with the specialist physician -after weeks of waiting- the entry to the center, the journey to the consultation room, and the wait to see the consultant, took valence to its most negative value $(-2.123)$. The specialist care, the testing process and the return to the physician for confirmation of the diagnosis improved the valence value, but it always remained negative. The arrival at the operating theater and the process prior to the intervention also placed the valence in negative values.

At the recovery moment, the valence for the first time reached positive values (0.651); the values were also positive during the patient's transfer to the recovery room (0.595) and at discharge from the hospital (0.568). During the subsequent PC check-up, the valence returned to the negative zone (-1.427), even lower than at the first contact with the general practitioner at the beginning of the $P J(-0.175)$.

Regarding the existence or lack thereof a correlation between the results of the valence reported by participants through the 


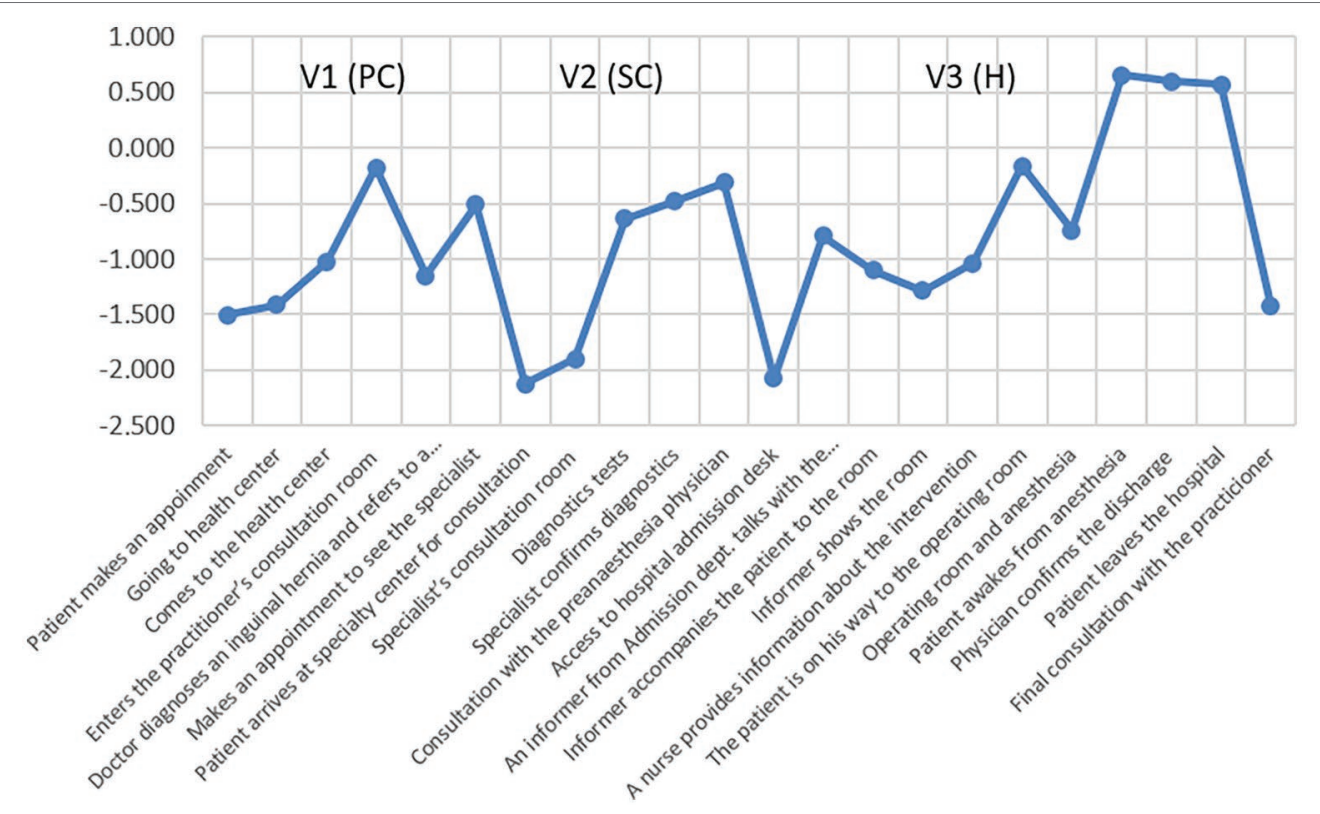

FIGURE 6 | Valence indicator (FEA) through the patient journey.

TABLE 4 | Correlation between valence (SAM) and valence (FEA).

\begin{tabular}{|c|c|c|c|c|c|c|}
\hline \multirow[b]{2}{*}{ Correlation between } & \multicolumn{2}{|c|}{ V1 (PC) } & \multicolumn{2}{|c|}{ V2 (SC) } & \multicolumn{2}{|c|}{ V3 (H) } \\
\hline & Pearson correlation & Sig. (bi-lateral) & Pearson correlation & Sig. (bi-lateral) & Pearson correlation & Sig. (bi-lateral) \\
\hline
\end{tabular}

SAM questionnaire and those provided by the facial expression analysis (FEA), the results show no correlation at the end of each stage, as the significance values are above 0.05 (Table 4).

\section{DISCUSSION AND CONCLUSIONS}

First, the results show the difference between the emotional valence of the patient's experience reported through questionnaires and the valence obtained through neurophysiological data (analysis of facial expressions). Second, the results allow a contrast to be made of the validity of a new methodology to assess the affective dimension of the patient's experience.

The present study confirms the existence of two dimensions identified in the literature on patient satisfaction: a cognitive type, demonstrated by data collected through a SAM questionnaire presented at the end of each stage of the process, and an affective type, obtained through the analysis of participants' facial expressions during the experiment. The results showed that both series of data effectively address the valence concept but show differences between the dimensions. While questionnaires collect a cognitive, or a more rational evaluation of the experience, facial expression analysis provides an affective, or emotional, assessment.
In the quantification of satisfaction, it cannot be concluded which of the two components, cognitive or emotional, is the more important. However, it is certainly true that they are distinct dimensions and, thus, must both be considered, since they contribute differently to satisfaction.

It was observed that, although patients reported high levels of satisfaction in the questionnaires, the valence shown in the FEA was negative during the almost complete PJ, and reached positive values only as the time of discharge approached. The reasons for this may be diverse, from living an unwanted experience in an unknown environment to the influence of specific factors, such as communication with the professionals or the physical aspects of the facility.

The PJ analysis showed that the moments with the most negative valence values are those related to organizational aspects, during which there was no contact with medical staff, such as accessing the center, waits or requests for appointments, or admission procedures prior to hospitalization. When there is contact with health professionals, this index improves. This result highlights the role of other aspects beyond medical care, such as communication with the physician, which contribute decisively to the emotional state of the patient.

The correlation found between the valences reported by the SAM questionnaire at the end of the hospitalization phase and final satisfaction shows that the patients did not consider 
the negative aspects of the process, such as delays, in the assessment of overall satisfaction. This effect was also seen in Redelmeier and Kahneman (1996)'s study of patients undergoing colonoscopy: they concluded that people do not perceive the sum of an experience, but rather their average experience and how the process ended. When the experience ended positively, the patient had a better assessment than when it ended negatively.

With regard to the new methodology proposed, the PJ paradigm helped to reproduce the patient's experience and collect, for the first time, neurophysiological data (facial expressions) during the care process, to achieve a broader view of the experience. This methodology can be applied in the study of other PJs, to improve specific processes and to analyze transversal issues, such as doctor-patient communication, and the influence of environmental aspects. It would be possible to apply it to other types of services.

In conclusion, it can be stated that, hitherto, the rational, or cognitive dimension has dominated in patient satisfaction assessments, and the affective or emotional dimension has been relegated to the background. For this reason, it seems appropriate now to incorporate this dimension to complete the satisfaction assessment. This will provide new ways of improving service and environmental processes and consequently increase customer satisfaction in health services.

Regarding future lines of study, it will be necessary to study in greater depth the emotional aspect of the patient's experience to complement the techniques currently used with others that help to explain the affective dimension, such as FEA. Finally,

\section{REFERENCES}

Aldosari, M. A., Tavares, M. A., Matta-Machado, A. T. A., and Abreu, M. H. (2017). Factors associated with patients' satisfaction in Brazilian dental primary health care. PLoS One 12:e0187993. doi: 10.1371/journal.pone.0187993

Ausin, J. M., Guixeres, J., Bigné, E., and Alcañiz, M. (2017). "Facial expressions to evaluate advertising: a laboratory versus living room study" in Advances in advertising research, VIII. eds. V. Zabkar, and M. Eisend (Germany: Gabler Verlag), 109-122.

Bendall-Lyon, D., and Powers, T. L. (2004). The impact of structure and process attributes on satisfaction and behavioral intentions. J. Serv. Mark. 18, 114-121. doi: $10.1108 / 08876040410528719$

Bradley, M. M., and Lang, P. J. (1994). Measuring emotion: the self-assessment Manikin and the semantic differential. J. Behav. Ther. Exp. Psychiatry 25, 49-59. doi: 10.1016/0005-7916(94)90063-9

Bruno, A., Dell'Aversana, G., and Zunino, A. (2017). Customer orientation and leadership in the health service sector: the role of workplace social support. Front. Psychol. 8:1920. doi: 10.3389/fpsyg.2017.01920

Cacioppo, J., and Gardner, W. (1999). Emotion. Annu. Rev. Psychol. 50, 191-214. doi: 10.1146/annurev.psych.50.1.191

Chih-Chien, W., and Ming-Chang, H. (2014). An exploratory study using inexpensive electroencephalography (EEG) to understand flow experience in computerbased instruction. Inf. Manag. 51, 912-923. doi: 10.1016/j.im.2014.05.010

Coulter, A., Locock, L., Ziebland, S., and Calabrese, J. (2014). Collecting data on patient experience is not enough: they must be used to improve care. BMJ 348:g2225. doi: 10.1136/bmj.g2225

Cronin, J. J., and Taylor, S. A. (1992). Measuring service quality. A reexamination and extension. J. Mark. 56, 55-68.

Crow, R., Gage, H., Hampson, S., Hart, J., Kimber, A., Storey, L., et al. (2002). The measurement of satisfaction with health care: implications for practice it is acknowledged that the present study has limitations. First, the sample size is not large, although it exceeds some used in other studies employing these types of techniques. Second, it should be noted that the proposal for a new methodology, i.e., FEA, carried out in the laboratory to analyze emotional valence, has no background use in healthcare through which to compare the results. Third, the characteristics of the chosen PJ, which cover a particular experience, mean that the results should not be generalized.

\section{DATA AVAILABILITY STATEMENT}

The datasets generated for this study are available on request to the corresponding author.

\section{ETHICS STATEMENT}

The studies involving human participants were reviewed and approved by Hospital of Alcalá de Henares, Madrid. The patients/ participants provided their written informed consent to participate in this study.

\section{AUTHOR CONTRIBUTIONS}

All authors have participated in all stages of work, including the conception and design of the research, the revision of intellectual content, and drafting the work.

from a systematic review of the literature. Health Technol. Assess. 6, 1-244. doi: $10.3310 /$ hta6320

Dubé, L., and Menon, K. (1998). Managing emotions. Mark. Health Serv. 18, $35-42$.

Ekman, P., and Friesen, W. V. (1971). Constants across cultures in the face and emotion. J. Pers. Soc. Psychol. 17, 17124-17129.

Ekman, P., and Friesen, W. V. (1978). Manual for the facial action coding system. Palo Alto, California: Consulting Psychologists Press.

Frijda, N. H., and Mesquita, B. (1998). "The analysis of emotions" in What develops in emotional development? eds. M. F. Mascolo, and S. Griffin (New York: Plenum Press), 273-295.

Fulbright, R. K., Troche, C. J., Skudlarski, P., Gore, J. C., and Wexler, B. E. (2001). Functional MR imaging of regional brain activation associated with the affective experience of pain. AJR Am. J. Roentgenol. 177, 1205-1210. doi: 10.2214/ajr.177.5.1771205

Gentile, C., Spiller, N., and Noci, G. (2007). How to sustain the customer experience: an overview of experience components that co-create value with the customer. Eur. Manag. J. 25, 395-410. doi: 10.1016/j.emj.2007.08.005

Giese, J. L., and Cote, J. A. (2000). Defining consumer satisfaction. Acad. Mark. Sci. Rev. 1, 1-34.

Gill, L., and White, L. (2009). A critical review of patient satisfaction. Leadersh. Health Serv. 22, 8-19. doi: 10.1108/17511870910927994

Granado, S., Rodríguez, C., Olmedo, M., Chacón, A., Vigil, D., and Rodríguez, P. (2007). Diseño y validación de un cuestionario para evaluar la satisfacción de los pacientes atendidos en las consultas externas de un hospital de Madrid en 2006. Rev. Esp. Salud Publica 81, 637-645. doi: 10.1590/ S1135-57272007000600007

Greenwald, M. K., Cook, E. W., and Lang, P. J. (1989). Affective judgment and psychophysiological response: dimensional covariation in the evaluation of pictorial stimuli. J. Psychophysiol. 3, 51-64. 
Handayani, D., Wahab, A., and Yaacob, H. (2015). Recognition of emotions in video clips: the self-assessment Manikin validation. Telkomnika 13, 1343-1351. doi: 10.12928/telkomnika.v13i4.2735

Hunt, H. K. (1977). "CS/D overview and future research directions" in Conceptualization and measurement of consumer satisfaction and dissatisfaction. ed. K. Hunt (Cambridge, MA: Marketing Science Institute), 455-488.

iMotions (2018). iMotions. Biometric Research. Available at: https://imotions. com/facial-expressions/ (Accessed July 20, 2018).

Jayanti, R. K., and Whipple, T. W. (2008). Like me... like me not: the role of physician likability on service evaluations. J. Mark. Theory Pract. 16, 79-86. doi: 10.2753/MTP1069-6679160106

Lees, C. (2011). Measuring the patient experience. Nurs. Res. 19, 25-28. doi: 10.7748/nr2011.10.19.1.25.c8768

Liljander, V., and Strandvik, T. (1997). Emotions in service satisfaction. Int. J. Serv. Ind. Manag. 8, 148-169. doi: 10.1108/09564239710166272

Losada, M., and Rodríguez, A. (2007). Calidad del servicio de salud: una revisión a la literatura desde la perspectiva del marketing. Cuad. Adm. 20, 237-258.

Mehrabian, A. (1996). Pleasure-arousal-dominance: a general framework for describing and measuring individual differences in temperament. Curr. Psychol. 14, 261-292. doi: 10.1007/BF02686918

Mehrabian, A., and Russell, J. A. (1974). An approach to environmental psychology. Cambridge: MIT Press.

Ofili, O. U. (2014). Patient satisfaction in healthcare delivery. A review of current approaches and methods. Eur. Sci. J. 10, 25-39.

Oliver, R. L. (1993). Cognitive, affective, and attribute bases of the satisfaction response. J. Consum. Res. 20, 418-430. doi: 10.1086/209358

Pelegrín-Borondo, J., Juaneda-Ayensa, E., González-Menorca, L., and González-Menorca, C. (2015). Dimensions and basic emotions. A complementary approach to the emotions produced to tourists by the hotel. J. Vacat. Mark. 21, 351-365. doi: 10.1177/1356766715580869

Phillips, D., and Baumgartner, H. (2002). The role of consumption emotions in the satisfaction response. J. Consum. Psychol. 12, 243-252. doi: 10.1207/ S15327663JCP1203_06

Posner, M. I., and Rothbart, M. K. (1998). "Summary and commentary: developing attentional skills" in Cognitive neuro-science of attention: A developmental perspective. ed. J. E. Richards (Mahwah, NJ: Erlbaum), 317-323.

Redelmeier, D. A., and Kahneman, D. (1996). Patients' memories of painful medical treatments: real-time and retrospective evaluations of two minimally invasive procedures. Pain 66, 3-8. doi: 10.1016/0304-3959(96)02994-6

Reeve, J. (2015). Understanding motivation and emotion. New York: Wiley.

Rundle-Thiele, S., and Russell-Bennett, R. (2010). Patient influences on satisfaction and loyalty for GP services. Health Mark. Q. 27, 195-214. doi: 10.1080/ 07359681003745162

Russell, J. A. (1980). A circumplex model of affect. J. Pers. Soc. Psychol. 39, 1161-1178. doi: 10.1037/h0077714

Scherer, K. (2005). What are emotions? And how can they be measured? Soc. Sci. Inf. 44, 695-729. doi: 10.1177/0539018405058216

Setz, C., Schumm, J., Lorenz, C., Arnrich, B., and Tröster, G. (2009). "Using ensemble classifier systems for handling missing data in emotion recognition from physiology: one step towards a practical system" in Affective computing and intelligent interaction and workshops, 2009. ACII 2009. 3rd International Conference (Amsterdam). 1-8, 10-12.

Sofaer, S., and Firminger, K. (2005). Patient perceptions of the quality of health services. Annu. Rev. Public Health 26, 513-559. doi: 10.1146/annurev. publhealth.25.050503.153958

Suomala, J., Palokangas, L., Leminen, S., Westerlund, M., Heinonen, J., and Numminen, J. (2012). Neuromarketing: understanding customers' subconscious responses to marketing. Technol. Innov. Manag. Rev. 2, 12-21. doi: 10.22215/ timreview/634

The Beryl Institute (2015). State of patient experience 2015: A global perspective on the patient experience. Available at: http://www.theberylinstitute. org/?page=Mission (Accessed June 12, 2015).

The King's Fund (2010). A high performing NHS? A review of Progress 1997-2010. London: The King's Fund.

Val-Jiménez, C. L., López-Torres, J., García-Atienza, E. M., Navarro-Ruiz, M. S., Hernández-Cerón, I., and Moreno de la Rosa, L. (2017). Satisfacción con el tratamiento en pacientes de Atención Primaria con artrosis. Rev. Esp. Salud Publica 91, e1-e10.

Vance, A., Eargle, D., Anderson, B. B., and Kirwan, C. B. (2014). Using measures of risk perception to predict information security behavior: insights from electroencephalography (EEG). J. Assoc. Inf. Syst. 15, 679-722. doi: $10.17705 / 1$ jais.00375

Villodre, R., Calero, R., and González-Gallarza, M. (2014). La satisfacción del cliente como indicador de calidad en neurorehabilitación. Cuad. Estud. Empres. 24, 131-147. doi: 10.5209/rev_CESE.2014.v24.48614

Vinagre, M. H., and Neves, J. (2008). The influence of service quality and patients' emotions on satisfaction. Int. J. Health Care Qual. Assur. 21, 87-103. doi: 10.1108/09526860810841183

Westbrook, R. A., and Oliver, R. L. (1991). The dimensionality of consumption emotion patterns and consumer satisfaction. J. Consum. Res. 18, 84-91. doi: $10.1086 / 209243$

Wirtz, J., and Bateson, J. (1999). Consumer satisfaction with services: integrating the environment perspective in services marketing into the traditional disconfirmation paradigm. J. Bus. Res. 44, 55-66. doi: 10.1016/S01482963(97)00178-1

Wolf, J. A., Niederhauser, V., Mashburn, D., and LaVela, S. L. (2014). Defining patient experience. Patient Exp. J., 17-19. doi: 10.35680/2372-0247.1004

Conflict of Interest: The authors declare that the research was conducted in the absence of any commercial or financial relationships that could be construed as a potential conflict of interest.

Copyright (C) 2019 Reinares-Lara, Rodríguez-Fuertes and Garcia-Henche. This is an open-access article distributed under the terms of the Creative Commons Attribution License (CC BY). The use, distribution or reproduction in other forums is permitted, provided the original author(s) and the copyright owner(s) are credited and that the original publication in this journal is cited, in accordance with accepted academic practice. No use, distribution or reproduction is permitted which does not comply with these terms. 


\title{
Archeological Tourist Destination Image Formation: Influence of Information Sources on the Cognitive, Affective and Unique Image
}

\author{
Nuria Huete-Alcocer ${ }^{*}$, Maria Pilar Martinez-Ruiz²*, Víctor Raúl López-Ruiz ${ }^{\text {* }}$ and \\ Alicia Izquiedo-Yusta ${ }^{3 *}$
}

1 Department of Spanish and International Economics, Econometrics, History and Economic Institutions, University of Castilla-La Mancha, Ciudad Real, Spain, ${ }^{2}$ Department of Economy and Business Administration, University of Castilla-La Mancha, Ciudad Real, Spain, ${ }^{3}$ Department of Economy and Business Administration, University of Burgos, Burgos, Spain

\section{OPEN ACCESS}

Edited by:

Giulio Arcangeli,

University of Florence, Italy

Reviewed by:

Luigi Isaia Lecca,

University of Cagliari, Italy

Jorge Pelegrín-Borondo,

University of La Rioja, Spain

${ }^{*}$ Correspondence:

Nuria Huete-Alcocer Nuria.Huete@uclm.es

Maria Pilar Martinez-Ruiz MariaPilar.Martinez@uclm.es Víctor Raúl López-Ruiz Victor.lopez@uclm.es Alicia Izquiedo-Yusta aliciaiz@ubu.es

Specialty section: This article was submitted to

Organizational Psychology, a section of the journa Frontiers in Psychology

Received: 12 July 2019 Accepted: 07 October 2019 Published: 22 October 2019

Citation: Huete-Alcocer N, Martinez-Ruiz MP, López-Ruiz VR and Izquiedo-Yusta A (2019) Archeological Tourist Destination Image Formation: Influence of Information Sources on the Cognitive, Affective and Unique Image. Front. Psychol. 10:2382. doi: 10.3389/fpsyg.2019.02382
A destination's image is a critical factor in tourists' perceptions and evaluations of said destination. This paper analyzes the formation of the tourist destination image of Segóbriga Archeological Park, a cultural destination located in the province of Cuenca (Spain) that holds great heritage value. To this end, the paper adopted a multidimensional approach and used PLS-SEM to analyze the destination image, taking into account not only its cognitive and affective components, but also the unique image component. The latter has received less attention in the literature and is a novel factor among cultural destinations. The results show that this component is essential to the overall image of an archeological destination, but is not influenced by information sources.

Keywords: information sources, tourism destination image, cognitive image, affective image, unique image

\section{INTRODUCTION}

With international tourism on the rise, destinations are locked in an increasingly intense competition for people's attention. In order to survive in today's global market, it is necessary for destinations to offer and manage a positive, yet differentiated image (Qu et al., 2011). Indeed, destination image is a fundamental factor in travelers' selection of and behavior toward a destination (Gunn, 1972; Gartner, 1994; Bigné et al., 2001; Millet, 2010; Carballo et al., 2015; Elliot and Papadopoulos, 2016). This image is a mental concept formed from a set of impressions drawn from numerous information sources (Beerli and Martín, 2004); it is traditionally delineated into the cognitive and affective image. The former is created in the minds of tourists and depends on the quality and quantity of available information. The latter, by contrast, comprises the characteristics of the destination itself (Baloglu and Brinberg, 1997), since the information about this image is not only obtained from different sources, but also depends on the characteristics of each individual (Stern and Krakover, 1993; Beerli and Martín, 2004). Tourists can also form a third image - known as the unique image - when their experience with a destination leads them to find it distinct from all other destinations (Qu et al., 2011).

In this regard, information sources serve as an important antecedent of destination image (i.e., in the formation of this image), since travelers' perceptions of a destination can be influenced by the information they receive from different sources. The literature has widely studied the 
connection between the use of information sources and destination image formation (e.g., Li et al., 2009; Coromina and Camprubí, 2016; Draper, 2016). However, what truly matters is how consumers process the information, which can depend on the type of message they receive (Rodríguez-Molina et al., 2015).

In light of the above, the present study aims to develop and test a theoretical model of destination image formation that addresses the influence of information sources on the formation of a cultural destination's overall image - and specifically its different components (i.e., the cognitive, affective image, and unique images). Our aim is to study these image types more exhaustively and determine their role in the formation of a destination's overall image. At the same time, this conceptual model seeks to fill a gap in the literature regarding the unique image - namely, what role it plays in the overall image and how it is affected by information sources. Researchers have not previously considered the unique image dimension in relation to the image formation process for a cultural destination such as an archeological site. We collected our data at the Segóbriga Archeological Park in the province of Cuenca (Spain), an archeological heritage destination that is regarded as one of the best-preserved Roman cities in the Western Roman Empire. Park visitors can first take a tour of all the best-preserved structures at the heritage site (walls, thermal baths, theater, amphitheater, basilica, circus, forum, necropolis, etc.). They can then supplement the tour with a visit to the interpretation center, which offers tourists an idea of what the ancient city was like. The site was granted the status of archeological park in order to promote tourism in the area and, by extension, boost the local economy.

\section{CONCEPTUAL FRAMEWORK}

\section{Destination Image}

The concept of destination image has been extensively researched in tourism studies (Stepchenkova and Mills, 2010; Stepchenkova and Li, 2012; Cherifi et al., 2014; Sun et al., 2015; Fu et al., 2016), as well as in other disciplines such as sociology, environmental management and psychology (Tang, 2014), and marketing and consumer behavior (Sirakaya and Woodside, 2005; Stepchenkova and Morrison, 2008). There has also been a growing body of research on tourist destinations themselves (Gallarza et al., 2002), much of which builds on the work of Hunt (1971) (Witter, 1985; Gartnerand and Hunt, 1987; Embacher and Buttle, 1989; Reilly, 1990; Echtner and Ritchie, 1991; Fakeye and Crompton, 1991). These myriad studies speak to the fact that image is fundamental to tourism destination promotion (Hudson et al., 2011), since the ways a destination differentiates itself is key to its success (Cai, 2002; Qu et al., 2011; Carballo et al., 2015).

The last four decades have produced a large body of research that illuminates the magnitude or significance of a destination's image from different perspectives (Deng and Li, 2014). Destination image has been approached in terms of its dimension and conceptualization (Hunt, 1971, 1975; Gunn, 1972; Crompton, 1979; Gartner, 1989; Echtner and Ritchie, 1991; Baloglu and McCleary, 1999; Cai, 2002; Tasci et al., 2007; Tasci and Gartner, 2007; Stepchenkova and Morrison, 2008; Lai and Li, 2012,2016), its evaluation and measurement
(Gartner, 1989; Echtner and Ritchie, 1991, 1993, 2003; Fakeye and Crompton, 1991; Baloglu, 1998; Baloglu and McCleary, 1999; Beerli and Martín, 2004; Chen and Tsai, 2007; Stepchenkova and Morrison, 2008; Yang et al., 2012), changes in the image over time (e.g., Gartnerand and Hunt, 1987; Ahmed, 1991; Fakeye and Crompton, 1991; Kim and Morrsion, 2005), its management (e.g., Goodrich, 1978; Gartner, 1989; Baloglu, 1998; Konecnik and Gartner, 2007; Pike, 2009), its effect on tourists' behavior (Chaudhary, 2000; Sirakaya and Woodside, 2005; Tasci and Gartner, 2007), and its formation (Gartner, 1989; Chon, 1990; Echtner and Ritchie, 1991; Beerli and Martín, 2004; Royo-Vela, 2009). In all these approaches, the importance of image in a destination's tourism development is paramount (MartínSantana et al., 2017). However, destination image formation is probably the most important of these issues (Deng and Li, 2014), as it underlies all the others (Gallarza et al., 2002).

One of the first studies on image formation was conducted by Gunn (1972), which looked at only two dimensions of the formation process: the organic image and the induced image. The organic image is understood as that arising from non-commercial or uncontrolled information sources, such as the opinions of friends, magazines, newspapers, news, reports, etc. (i.e., sources not intended to promote the destination). In contrast, the induced image arises from commercial information sources (i.e., marketing efforts of various commercial agents to publicize a destination, such as travel brochures; Tasci and Gartner, 2007). According to Gunn (1972, 1988), an individual's image of a destination is constantly being reformed and renewed.

As a destination's tourism image is essential to attracting tourists, it is important that said image be as real and current as possible. Indeed, the destination image clearly influences tourists' behavior (Deng and Li, 2014), as it directly reflects visitors' perceived quality of a place, as well as their satisfaction (evaluation of the stay) with, intention to return to (future behavior) and recommend (attitudinal loyalty) the destination (Bigné et al., 2001).

\section{Components of the Destination Image}

Each tourist's individual perceptions can produce a relative and personal image a destination (Bigné et al., 2001; Gallarza et al., 2002; San Martín and del Bosque, 2008). In other words, tourists' opinions are highly subjective, formed around very different antecedents based on their individual thoughts and emotions. As a result, many authors have generally investigated tourism destination image on the basis of its cognitive and affective components. For tourists, the cognitive image represents their knowledge of and beliefs regarding a place, while the affective image refers to their feelings or emotional responses toward it (Gartner, 1994; Baloglu, 1998; Beerli and Martín, 2004; Pike and Ryan, 2004; Royo-Vela, 2009; San Martín and del Bosque, 2008, 2011; Maher and Carter, 2011; Smith et al., 2015). The combination of the affective and cognitive images gives rise to the overall image (Baloglu and McCleary, 1999). Notably, the overall image reflects not only the common or shared aspects, but also the unique images that render a place distinctive (Echtner and Ritchie, 2003). The unique characteristics of a destination include both tangible attributes (e.g., beaches or historical sites) and intangible ones (e.g., customs, culture, and 
history) (Qu et al., 2011). Therefore, the unique image helps to sharpen destinations' identities and thereby improve their competitive positioning (Lin and Kuo, 2018). However, few authors have examined this unique image component (e.g., Qu et al., 2011; Llodrà Riera, 2013; Lin and Kuo, 2018). The most important research on the topic has looked at only the two main components, i.e., the cognitive and affective images (Baloglu and Brinberg, 1997; Baloglu and McCleary, 1999; Kim and Richardson, 2003; Beerli and Martín, 2004; Hsu et al., 2004; Pike and Ryan, 2004; San Martín and del Bosque, 2008, 2011; Gutiérrez and del Bosque, 2010; Smith et al., 2015; Tan and Wu, 2016; Molinillo et al., 2018).

The present study will account for all three images types, with a special emphasis on the unique image. In this way, we hope to supplement the scant number of authors who have considered this third component in their work on destination image formation (e.g., Echtner and Ritchie, 1991; Qu et al., 2011; Llodrà Riera, 2013; Lin and Kuo, 2018). Below, we will briefly outline the research on all three image types before proceeding to discuss the role of each of them in the general image of Segóbriga.

(a) Cognitive image: Most studies have specifically considered the cognitive component of the image (Echtner and Ritchie, 1991; Echtner and Ritchie, 2003; Beerli and Martín, 2004; Chi and Qu, 2008; Sun et al., 2013). In fact, Pike (2002) found that of 142 papers published between 1973 and 2000, only six included the affective (or psychological) component. As noted, this dimension of the image refers to tourists' knowledge or beliefs about the destination's attributes (Baloglu and McCleary, 1999). The literature shows that this dimension arises from other elements, such as the natural environment, cultural resources, infrastructure, and quality. However, scholars differ on the importance they assign to these latter four factors (Baloglu and McCleary, 1999; Gallarza et al., 2002; Beerli and Martín, 2004; Chi and Qu, 2008; San Martín and del Bosque, 2008; Stylos et al., 2016; Stylidis et al., 2017). Some authors argue that these cultural and natural resources include particularities such as landscape beauty, cultural activities, or traditions and customs (e.g., Beerli and Martín, 2004; Stylos et al., 2016; Stylidis et al., 2017). Others maintain that these resources merely refer to attractions (e.g., Baloglu and McCleary, 1999).

(b) Affective image: To measure the affective image, many authors (e.g., Baloglu and McCleary, 1999; Bigné et al., 2001; Kim and Richardson, 2003; Beerli and Martín, 2004; Pike and Ryan, 2004; Chi and Qu, 2008; Nadeau et al., 2008; Alcañiz et al., 2009; Chen et al., 2016), have drawn on the work of Russell and Pratt (1980). Although the literature has spent less time addressing the affective component, it is particularly important for improving tourists' perception of the destination image (Moreno-Gil et al., 2012), as it reflects their feelings toward a destination (Chen et al., 2016). In line with feelings-as-information theory, which explains how individuals make use of their emotions and impressions in ways that predispose them toward a destination (Kock et al., 2016). Stylos et al. (2016) found that advertisements featuring emotional content (e.g., words such as exciting, pleasant and relaxing) convey a destination's affective image.

(c) Unique image: Considering that the tourism industry is marked by high competition and a relatively undifferentiated supply, Qu et al. (2011) found that it is necessary to identify the attributes that define a destination and make it unique in tourists' minds. Other authors (e.g., Lin and Kuo, 2018) have only considered this component in order to study the overall image. Specifically, they concluded that the unique image is important for marketing differentiation strategies and, by extension, improving a place's competitiveness. Thus, it appears that the unique image partly explains the influence of the affective image, meaning that the latter exerts a weaker effect on the overall image compared to the other two dimensions (cognitive and unique) (Qu et al., 2011). Hence, in the midst of increasing competition among tourist destinations, it is important to identify the attributes that characterize a cultural destination as unique and encourage tourists to perceive it as such.

\section{Information Sources in Image Formation}

In reviewing the literature on destination image, it becomes clear that information sources are important antecedents to all three image components. Some researchers have suggested that these sources influence the formation of the cognitive image, but not the affective one (Woodside and Lysonski, 1989; Gartner, 1994; Baloglu and McCleary, 1999). In other words, external sources more strongly affect cognitive beliefs regarding a destination (Um and Crompton, 1990). Likewise, Beerli and Martín (2004) found that both organic sources (family members and friends) and autonomous sources (travel guides, news, articles, reports or documentaries) influence certain cognitive factors of the positive image. However, other authors (e.g., Jeong et al., 2012) have found that the information route is one of the primary factors influencing the cognitive image or overall image of a destination.

In recent years, academics and professionals have come to realize the importance of the Internet in shaping destination image. The Internet has transformed traditional WOM into eWOM. The communication of opinions is no longer done interpersonally (i.e., person-to-person or face-to-face), but rather is mediated by ICT (Huete-Alcocer, 2017). Although previous studies have shown that the Internet influences both the cognitive and affective dimensions of the destination image, most of the literature has focused solely on the cognitive dimension (Alcázar and Sicilia, 2015). In this regard, it is important to note that constructing a tourist destination image online is a more dynamic social process than traditional methods of image projection (e.g., through printed brochures and guides). The online image is instead generated by other tourists posting photographs, comments, perceptions, and experiences related to the destination (Hunter, 2016). For example, Kim et al. (2017) found that social media are a source of emerging information in tourism destination marketing. However, the issue of tourism destination image formation on social media remains relatively unexplored, especially empirically (Kim et al., 2017). Some authors (e.g., Prats et al., 2016) have suggested that an official website positively influences cognitive evaluations, since the information offered through such sites must be provided in a practical way to enable preparation of the trip. By contrast, guides influence affective evaluations due to appealing mainly to tourists' emotions. Similarly, Martín-Santana et al. (2017) showed that the cognitive image is positively affected by high levels of online participation among tourists. Other authors (e.g., Molinillo et al., 2018) have found that tourist participation in online platforms 
positively impacts both the cognitive and affective images, and by extension, the intention to visit. Of course, image formation and the intention to visit vary according to the platform that travelers use to access the information (Molinillo et al., 2018). In general, most of the research agrees that the cognitive image somewhat informs the affective aspect, but the latter is also more difficult to change through external information (Li et al., 2009).

To our knowledge, no previous literature has sought to evaluate how information sources influence the unique image - and specifically that of an archeological destination. The present study aims to fill this gap, while also incorporating the cognitive and affective components.

\section{Proposed Model and Hypotheses}

Drawing on the literature review, this study analyzed the image of a particular cultural destination as a reflective, multidimensional concept (Jarvis et al., 2003). The proposed model was developed based on previous studies showing that a destination's image is fundamentally influenced by the cognitive and affective components, which are themselves influenced by the information sources that tourists utilize. The present study also analyzed the influence of the unique image component, in relation to both information sources and the overall image of an archeological heritage destination. We also considered the degree to which the cognitive and unique images influence the affective image. To this end, we propose the following conceptual model (Figure 1) and hypotheses:

Hypotheses $\mathrm{H} 1$ and $\mathrm{H} 2$ were formulated by drawing on Beerli and Martín (2004), Qu et al. (2011), and Llodrà Riera (2013). Hypothesis H1 aims to verify the influence of information sources on the formation of the different images: cognitive, affective, and unique. Its first source is the model proposed in Beerli and Martín (2004), which examined the role of information sources in the formation of cognitive and affective images. It second source is Qu et al. (2011), which included the unique image. Finally, it incorporates the study by Llodrà Riera (2013), which is one of the few other studies (outside of Echtner and Ritchie, 1991; Qu et al., 2011) to consider the unique image. Llodrà Riera (2013) also examined the role of information sources in the formation of the

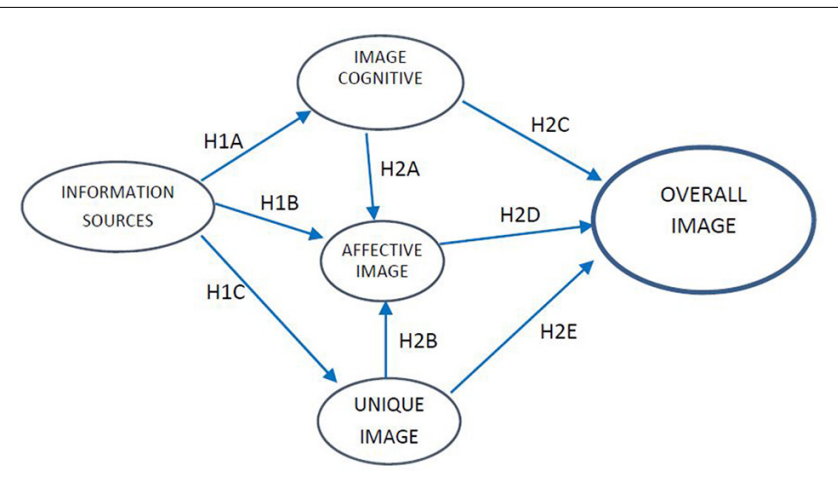

FIGURE 1 | Model for the formation of the image of a cultural destination. three types of images; however, that study referred to a sunand-sand destination. In light of these considerations, we propose the following hypothesis alongside three sub-hypotheses (H1A, H1B, and $\mathrm{H} 1 \mathrm{C})$ :

Hypothesis 1: The information sources used by tourists have a positive and significant influence on the cognitive, affective, and unique image.

H1A: Information sources positively and significantly influence the cognitive image.

H1B: Information sources positively and significantly influence the affective image.

H1C: Information sources positively and significantly influence the unique image.

In keeping with the above considerations and our objective (i.e., to analyze the formation of a cultural destination image), we relied on previous research (Beerli and Martín, 2004; Qu et al., 2011; Llodrà Riera, 2013) to formulate the second hypothesis $(\mathrm{H} 2)$, which consists of five sub-hypotheses ( $\mathrm{H} 2 \mathrm{~A}, \mathrm{H} 2 \mathrm{~B}, \mathrm{H} 2 \mathrm{C}$, $\mathrm{H} 2 \mathrm{D}$, and $\mathrm{H} 2 \mathrm{E})$. The aim of these sub-hypotheses was to analyze, first, how the cognitive image and unique image affect the affective image, and second, how each of these images (cognitive, affective, and unique) influences the destination's overall image.

Hypothesis 2: With regard to the positive and significant influence of the cognitive and unique image on the affective image of a destination, and to the positive and significant influence of each of these images (cognitive, affective, and unique) on the overall image of a destination:

H2A: the cognitive image positively and significantly influences the affective image.

$H 2 B$ : the unique image positively and significantly influences the affective image.

H2C: the cognitive image positively and significantly influences the overall image.

$H 2 D$ : the affective image positively and significantly influences the overall image.

H2E: the unique image positively and significantly influences the overall image.

\section{METHODOLOGY}

Of the many procedures used by various authors to analyze tourism destination images, we chose to use structural equation modeling (SEM) for this study. To this end, we found the PLS method to be the most efficient means of executing the SEM to test the proposed hypotheses.

\section{Data Collection Procedure}

We first designed a questionnaire for the purpose of collecting information from site visitors following their visit. We devised the questions based on a thorough review of the literature 
and the specific characteristics of the destination under study. We conducted a pilot test with the questionnaire in order to ensure the tool's clarity and relevance; only a few minor changes were made based on the results. The finalized survey was then administered to site visitors over a period of four consecutive weekends during the months of April and May 2017. A total of 598 questionnaires were given out to tourists aged 18 and over, resulting in a final sample of 511 valid responses.

A researcher handed out the questionnaires to the participants, gathered their consent, informed them about the study and procedure, and explained the meaning of some items. Participants were assured that their responses would remain anonymous and could be withdrawn from the study whenever they wanted. The authors will make the raw data available, without undue reservation, to any qualified researcher. With regard to ethics, the study was approved on March 15, 2017 by the Research Ethics Commission of the University of Castilla-La Mancha (chairperson: José Julian Garde López - Brea. Vice-chancellor's office for Research and Scientific Policy; secretary: Isabel Turégano Mansilla, Cuenca Faculty of Social Sciences; members: Inés Martínez Galán, Christian Gortázar Schmidt and Jorge Laborda Fernández).

\section{Variables and Measurement Scales}

Most of the constructs used in the present research are multidimensional concepts, each comprising several items. For all items, we employed a 5-point Likert scale as the measurement method. We analyzed a total of 32 items concerning information sources, including 19 about traditional sources and 13 about online ones (Tables 1, 2, respectively).

When carrying out the CFA for the information sources (traditional and online), only seven factors emerged, which grouped several items eliminating those whose value of lambda was less than 0.5: SOURINF1 (scientific articles of Segóbriga, news, reports and documentaries and books), SOURINF2 (media specialized in tourism, media specialized in archeological heritage, travel guides, fairs and TV series and movies), SOURINF3 (only WOM), SOURINF4 (promotion agencies, Web of the Diputación of Cuenca, Web JCCM and Web tourism of Castilla-La Mancha), SOURINF5 (Webs with user ratings and forums) SOURINF6 (blogs and Webs of tourism business Cuenca) and SOURINF7 (Internet browser and Google Maps).

Table 3 shows the variables used to measure the cognitive dimension, which were based on Beerli and Martín (2004) and $\mathrm{Qu}$ et al. (2011). While numerous studies clearly signal that this dimension comprises the natural environment, cultural resources, infrastructure, and quality, the importance assigned to each varies (e.g., Baloglu and McCleary, 1999; Gallarza et al., 2002; Beerli and Martín, 2004; Chi and Qu, 2008; San Martín and del Bosque, 2008). For example, while some authors (e.g., Beerli and Martín, 2004) suggest that cultural resources are features of landscape beauty, traditions, customs or cultural activities themselves, others (e.g., Baloglu and McCleary, 1999) consider such resources to be mere attractions.

On the other hand, the CFA for the cognitive image only revealed six factors after we eliminated items whose lambda value was less than 0.5: COGNITIVE1 corresponds to the
TABLE 1 | Traditional information sources construct.

\begin{tabular}{|c|c|c|}
\hline Questionnaire question & Item & Acronym \\
\hline \multirow{4}{*}{$\begin{array}{l}\text { 1. Indicate the extent to } \\
\text { which you have used the } \\
\text { following traditional } \\
\text { information sources to } \\
\text { obtain information about } \\
\text { Segóbriga Archeological } \\
\text { Park. }\end{array}$} & Tourist brochures & TSOURCE1 \\
\hline & $\begin{array}{l}\text { Travel agencies or tour operator } \\
\text { tour }\end{array}$ & TSOURCE2 \\
\hline & $\begin{array}{l}\text { Public figures with a recognized } \\
\text { audience }\end{array}$ & TSOURCE3 \\
\hline & Scientific papers on Segóbriga & TSOURCE4 \\
\hline \multirow{15}{*}{$\begin{array}{l}\text { SCALE: } 1=\text { I did not use it } \\
\text { at all. } 5 \text { = It was one of my } \\
\text { main sources of } \\
\text { information. } \\
\text { Authors: Gunn, 1988; } \\
\text { Gartner, 1994; Bigné et al., } \\
\text { 2001; Beerli and Martín, } \\
\text { 2004; Llodrà Riera, } 2013\end{array}$} & News, reports and documentaries & TSOURCE5 \\
\hline & $\begin{array}{l}\text { Tourist information from agencies } \\
\text { that promote the destination (e.g., } \\
\text { ADESIMAN, Ministry of Education, } \\
\text { Culture and Sports, Ministry of } \\
\text { Tourism, Trade and Crafts) }\end{array}$ & TSOURCE6 \\
\hline & $\begin{array}{l}\text { Schools (primary schools, } \\
\text { universities, vocational schools) }\end{array}$ & TSOURCE7 \\
\hline & $\begin{array}{l}\text { Nearby accommodations, } \\
\text { supplementary offer }\end{array}$ & TSOURCE8 \\
\hline & Specialized tourism media & TSOURCE9 \\
\hline & $\begin{array}{l}\text { Specialized archeological heritage } \\
\text { media }\end{array}$ & TSOURCE10 \\
\hline & Books & TSOURCE11 \\
\hline & Travel guides & TSOURCE12 \\
\hline & Fairs & TSOURCE13 \\
\hline & TV shows and movies & TSOURCE14 \\
\hline & Radio & TSOURCE15 \\
\hline & The Internet & TSOURCE16 \\
\hline & Friends and family & TSOURCE17 \\
\hline & Local residents & TSOURCE18 \\
\hline & $\begin{array}{l}\text { The sign located on the A-3 } \\
\text { highway: Madrid - Valencia - } \\
\text { Alicante. }\end{array}$ & TSOURCE19 \\
\hline
\end{tabular}

measured variable of natural resources (climate and richness of the landscape); COGNITIVE2 with tourist infrastructures (restaurants, hotels and accommodation); COGNITIVE3 with elements of the culture, history and art (monuments, museum and pieces, historical constructions, customs and ways of life); COGNITIVE4 includes another five items of the variable culture, history and art (gastronomy, theater festivals, concerts, crafts and folklore); COGNITIVE5 corresponds to the variable natural environment, measured by the maintenance and conservation of the deposit; and finally, COGNITIVE6 reflects the social environment (hospitality and friendliness of local residents and quality of life in the area).

We drew on several studies, most of them built on the findings of Russel and Pratt, to measure the affective image (e.g., Baloglu and McCleary, 1999; Bigné et al., 2001; Kim and Richardson, 2003; Beerli and Martín, 2004; Pike and Ryan, 2004; Chi and Qu, 2008; Nadeau et al., 2008; Alcañiz et al., 2009; Chen et al., 2016; Stylos et al., 2016; Stylidis et al., 2017). These studies, in turn, built on the findings of Russell and Pratt (1980). Table 4 shows the attributes that we considered.

With regard to measuring the unique image dimension, we drew on three previous studies: namely, Echtner and Ritchie 
TABLE 2 | Online information sources construct.

\begin{tabular}{|c|c|c|}
\hline Questionnaire question & Item & Acronym \\
\hline \multirow{4}{*}{$\begin{array}{l}\text { 2. Indicate the extent to } \\
\text { which you used the } \\
\text { following online information } \\
\text { sources to obtain } \\
\text { information about } \\
\text { Segóbriga Archeological } \\
\text { Park. }\end{array}$} & $\begin{array}{l}\text { Official website of the site } \\
\text { (www.segóbriga.org) }\end{array}$ & ONSOURCE1 \\
\hline & $\begin{array}{l}\text { Official website of the site } \\
\text { (www.spaincenter.org) }\end{array}$ & ONSOURCE2 \\
\hline & $\begin{array}{l}\text { Social media (Facebook, Twitter, } \\
\text { Instagram, etc.) }\end{array}$ & ONSOURCE3 \\
\hline & Blogs & ONSOURCE4 \\
\hline \multirow{2}{*}{$\begin{array}{l}\text { SCALE: } 1=\text { I did not use it } \\
\text { at all. } 5=\text { It was one of my } \\
\text { main sources of information }\end{array}$} & $\begin{array}{l}\text { Websites with user ratings } \\
\text { (TripAdvisor) }\end{array}$ & ONSOURCE5 \\
\hline & $\begin{array}{l}\text { Websites of tourism companies in } \\
\text { Cuenca that offer it }\end{array}$ & ONSOURCE6 \\
\hline \multirow{7}{*}{$\begin{array}{l}\text { Authors: Llodrà Riera, } \\
\text { 2013; Zeng and Gerritsen, } \\
\text { 2014; Llodrà-Riera et al., } \\
\text { 2015; Tseng et al., 2015; } \\
\text { Coromina and Camprubí, } \\
2016\end{array}$} & $\begin{array}{l}\text { Website of the Provincial } \\
\text { Government of Cuenca }\end{array}$ & ONSOURCE7 \\
\hline & $\begin{array}{l}\text { Website of the Regional } \\
\text { Government of Castilla-La Mancha } \\
\text { (www.patrimoniohistoricoclm.es) }\end{array}$ & ONSOURCE8 \\
\hline & $\begin{array}{l}\text { Official Castilla-La Mancha tourism } \\
\text { website } \\
\text { (www.turismocastillalamancha.es) }\end{array}$ & ONSOURCE9 \\
\hline & $\begin{array}{l}\text { Internet search engines (Google, } \\
\text { Bing, Yahoo, etc.) }\end{array}$ & ONSOURCE10 \\
\hline & $\begin{array}{l}\text { Maps (Google Maps, ViaMichelín, } \\
\text { Guía Repsol, etc.) }\end{array}$ & ONSOURCE11 \\
\hline & Forums (Los Viajeros, TripAdvisor) & ONSOURCE12 \\
\hline & Video-sharing apps (YouTube) & ONSOURCE13 \\
\hline
\end{tabular}

(1991), Qu et al. (2011), and Llodrà Riera (2013) (Table 5). This variable captures the characteristics of the site that visitors regard as unique relative to other archeological parks. The associated CFA revealed only three factors for the unique image (all except UNIMA 1).

The CFA of the affective image revealed only three factors: AFFIMA1, AFFIMA3, and AFFIMA5 (Table 6).

Finally, we measured the site's overall image using a single question based on Baloglu and McCleary (1999): "After your visit, rate the site's overall image." Respondents had to score the question on a 5-point Likert scale ( $1=$ Very bad/5 = Very good).

The survey concluded with a final set of questions related to respondents' demographics, such as age, income level, gender, education, overnight stay in the area, place of origin, etc. Based on this data, we verified the profile of the typical tourist to Segóbriga: a middle-aged (between 40 and 59 years old) person, most often a woman, who works for someone else, has a higher education, and earns a rather high income.

\section{ANALYSIS OF RESULTS}

\section{Evaluation of the Measurement Model: Validity and Reliability}

Before testing the proposed hypotheses, we evaluated the measurement model with PLS (Barclay et al., 1995). Specifically, we employed SmartPLS 3.0 software to analyze the individual reliability of each item, the reliability of the scale, and the convergent and discriminant validity. We obtained the
TABLE 3 | Cognitive image construct.

\begin{tabular}{|c|c|c|c|}
\hline $\begin{array}{l}\text { Questionnaire } \\
\text { question }\end{array}$ & Variable & Item & Acronym \\
\hline $\begin{array}{l}\text { 3. Rate the quality } \\
\text { of each of these } \\
\text { elements: }\end{array}$ & $\begin{array}{l}\text { Natural } \\
\text { resources }\end{array}$ & $\begin{array}{l}\text { Weather } \\
\text { Richness of the landscape }\end{array}$ & COGIMA2 \\
\hline $\begin{array}{l}\text { SCALE: } 1=\text { Most } \\
\text { negative score }\end{array}$ & $\begin{array}{l}\text { General } \\
\text { infrastructure }\end{array}$ & $\begin{array}{l}\text { Ability to access the } \\
\text { archeological park by } \\
\text { public transport }\end{array}$ & COGIMA3 \\
\hline $\begin{array}{l}5=\text { Most positive } \\
\text { score }\end{array}$ & & $\begin{array}{l}\text { Ability to access the } \\
\text { archeological park by } \\
\text { private transport }\end{array}$ & COGIMA4 \\
\hline $\begin{array}{l}\text { Authors: Beerli } \\
\text { and Martín, 2004; } \\
\text { Qu et al., 2011; } \\
\text { Stylos et al., 2016; } \\
\text { Stylidis et al., 2017 }\end{array}$ & $\begin{array}{l}\text { Tourism } \\
\text { infrastructure }\end{array}$ & $\begin{array}{l}\text { Accessibility inside the site } \\
\text { Restaurants } \\
\text { Hotels and } \\
\text { accommodations }\end{array}$ & $\begin{array}{l}\text { COGIMA5 } \\
\text { COGIMA6 } \\
\text { COGIMA7 }\end{array}$ \\
\hline
\end{tabular}

\section{Ease of obtaining tourist} information at the archeological park

Leisure and
recreation
tourism

Activities within the archeological park (educational and leisure activities, sports events such as races, photography contests, exhibitions)

Culture, history
and art

$$
\text { Monuments }
$$

Museum and pieces

Historical constructions Customs and ways of life Food

Theater festivals

Concerts

Crafts

Folklore

Guided tours of the archeological park

\begin{tabular}{|c|c|}
\hline \multirow[t]{4}{*}{$\begin{array}{l}\text { Natural } \\
\text { environment }\end{array}$} & $\begin{array}{l}\text { Maintenance and } \\
\text { conservation }\end{array}$ \\
\hline & Cleaning \\
\hline & $\begin{array}{l}\text { Security service at the } \\
\text { archeological park }\end{array}$ \\
\hline & Attractiveness of the site \\
\hline \multirow[t]{2}{*}{$\begin{array}{l}\text { Social } \\
\text { environment }\end{array}$} & $\begin{array}{l}\text { Hospitality and friendliness } \\
\text { of local residents }\end{array}$ \\
\hline & Local quality of life \\
\hline $\begin{array}{l}\text { Political and } \\
\text { economic } \\
\text { factors }\end{array}$ & $\begin{array}{l}\text { Value for money of the } \\
\text { admission to the } \\
\text { archeological park }\end{array}$ \\
\hline
\end{tabular}

COGIMA10 COGIMA11 COGIMA12 COGIMA13 COGIMA14 COGIMA15 COGIMA16 COGIMA17 COGIMA18 COGIMA19 COGIMA20 COGIMA21 COGIMA22

COGIMA23 COGIMA24

COGIMA25

COGIMA26 economic admission to the significance of the parameters through bootstrapping, which assesses the accuracy of the PLS estimates (Hair et al., 2011).

\section{The Individual Reliability of Each Item}

The individual reliability of each indicator was calculated, and the simple correlations of the means with their constructs were analyzed. Those items with a factor loading greater than or equal to 0.707 (meaning that more than $50 \%$ of the observed variable's variance was shared with the construct) were considered reliable (Carmines and Zeller, 1979). 
TABLE 4 | Affective image construct.

\begin{tabular}{|c|c|c|c|}
\hline $\begin{array}{l}\text { Questionnaire } \\
\text { question }\end{array}$ & Authors & Item & Acronym \\
\hline \multirow{6}{*}{$\begin{array}{l}\text { 4. Indicate the degree } \\
\text { to which you agree or } \\
\text { disagree with the } \\
\text { following statements. } \\
\text { Segóbriga } \\
\text { Archeological Park is: }\end{array}$} & \multirow{2}{*}{$\begin{array}{l}\text { Hosany et al., 2007; Qu et al., } \\
2011\end{array}$} & Beautiful & AFFIMA1 \\
\hline & & Ugly & AFFIMA2 \\
\hline & \multirow{8}{*}{$\begin{array}{l}\text { Baloglu and McCleary, 1999; } \\
\text { Bigné et al., 2001; Kim and } \\
\text { Richardson, 2003; Beerli and } \\
\text { Martín, 2004; Pike and Ryan, } \\
\text { 2004; Chi and Qu, 2008; } \\
\text { Nadeau et al., 2008; Alcañiz } \\
\text { et al., 2009; Chen et al., } \\
\text { 2016; Stylos et al., 2016; } \\
\text { Stylidis et al., } 2017\end{array}$} & Nice & AFFIMA3 \\
\hline & & Unpleasant & AFFIMA4 \\
\hline & & Relaxing & AFFIMA5 \\
\hline & & Stressful & AFFIMA6 \\
\hline \multirow{4}{*}{$\begin{array}{l}\text { SCALE: } 1 \text { = Strongly } \\
\text { disagree } 5 \text { = Strongly } \\
\text { agree }\end{array}$} & & Fun & AFFIMA7 \\
\hline & & Boring & AFFIMA8 \\
\hline & & Exciting & AFFIMA9 \\
\hline & & Depressing & AFFIMA10 \\
\hline
\end{tabular}

TABLE 5 | Unique image construct.

\begin{tabular}{|c|c|c|c|}
\hline $\begin{array}{l}\text { Questionnaire } \\
\text { question }\end{array}$ & Authors & Item & Acronym \\
\hline $\begin{array}{l}\text { 5. Would you say that } \\
\text { Segóbriga } \\
\text { Archeological Park } \\
\text { offers a unique } \\
\text { experience in the }\end{array}$ & $\begin{array}{l}\text { Echtner and } \\
\text { Ritchie, 1991; } \\
\text { Qu et al., 2011; } \\
\text { Llodrà Riera, } \\
2013\end{array}$ & $\begin{array}{l}\text { When sports } \\
\text { activities are } \\
\text { held there. }\end{array}$ & UNIMA1 \\
\hline $\begin{array}{l}\text { following cases? } \\
\text { SCALE: } 1 \text { = Strongly } \\
\text { disagree } 5 \text { = Strongly } \\
\text { agree }\end{array}$ & & $\begin{array}{l}\text { When cultural } \\
\text { activities are } \\
\text { held there (e.g., } \\
\text { conferences, } \\
\text { plays, etc.) }\end{array}$ & UNIMA2 \\
\hline $\begin{array}{l}\text { 6. Do you agree that } \\
\text { the visit to the } \\
\text { archeological park's } \\
\text { interpretation center } \\
\text { offered a unique } \\
\text { experience? }\end{array}$ & & & UNIMA3 \\
\hline \multicolumn{4}{|l|}{$\begin{array}{l}\text { SCALE: } 1 \text { = Strongly } \\
\text { disagree } 5 \text { = Strongly } \\
\text { agree }\end{array}$} \\
\hline $\begin{array}{l}\text { 7. Do you agree that } \\
\text { the visit to Segóbriga } \\
\text { Archeological Park was } \\
\text { a unique experience } \\
\text { compared to other } \\
\text { parks? }\end{array}$ & & & UNIMA4 \\
\hline $\begin{array}{l}\text { SCALE: } 1 \text { = Strongly } \\
\text { disagree } 5 \text { = Strongly } \\
\text { agree }\end{array}$ & & & \\
\hline
\end{tabular}

\section{Composite Reliability}

Next, we calculated the composite reliability using Cronbach's alpha (Cronbach, 1951), which assesses whether the indicators measure the construct to which they are assigned. Table 7 shows that all the constructs met the threshold for reliability (i.e., a Cronbach's alpha value equal to or greater than 0.7 ).

\section{Convergent and Discriminant Validity}

First, we assessed the convergent validity by calculating the average variance extracted (AVE) for each construct (Fornell and Larcker, 1981). According to Fornell and Larcker (1981), this measure reflects a construct's amount of variance due to its indicators versus mere measurement error. Its value should be equal to or greater than 0.5 , which indicates that each construct explains at least $50 \%$ of the assigned indicators' variance. We also calculated rho_A, which is another of the most important reliability measures for PLS (Dijkstra and Henseler, 2015; Table 8).

Subsequently, we checked the discriminant validity, which captures the extent to which a given construct is different from the others in the model. This validity requires that

TABLE 6 | Measurement instrument: individual reliability.

\begin{tabular}{lcc}
\hline Factor & Indicator & Loading \\
\hline INFORMATION SOURCES & SOURINF1 & 0.998 \\
& SOURINF2 & 0.998 \\
& SOURINF3 & 0.708 \\
& SOURINF4 & 0.997 \\
& SOURINF5 & 0.996 \\
& SOURINF6 & 0.999 \\
COGNITIVE IMAGE & SOURINF7 & 0.953 \\
& COGNITIVE1 & 0.889 \\
& COGNITIVE2 & 0.960 \\
AFFECTIVE IMAGE & COGNITIVE3 & 0.977 \\
& COGNITIVE4 & 0.964 \\
& COGNITIVE5 & 0.972 \\
UNIQUE IMAGE & COGNITIVE6 & 0.880 \\
OVERALL IMAGE & AFFIMA1 & 0.868 \\
N/A, Not applicable to these variables as they were measured with a single item & \\
and thus would have a value of 1. & AFFIMA3 & 0.880 \\
& AFFIMA5 & 0.744 \\
& UNIMA2 & 0.701 \\
& UNIMA3 & 0.873 \\
& UNIMA4 & 0.855 \\
& N/A & N/A \\
\hline
\end{tabular}

TABLE 7 | Measurement instrument: composite reliability.

\begin{tabular}{lcc}
\hline Factor & Cronbach's alpha & Composite Reliability \\
\hline Information sources & 0.983 & 0.986 \\
Cognitive image & 0.974 & 0.979 \\
Affective image & 0.780 & 0.871 \\
Unique image & 0.733 & 0.849 \\
Overall image & 1.000 & 1.000 \\
\hline
\end{tabular}

TABLE 8 | Measurement instrument: convergent validity.

\begin{tabular}{lcc}
\hline Factor & AVE & Rho_A \\
\hline Information sources & 0.912 & 1.000 \\
Cognitive image & 0.886 & 0.992 \\
Affective image & 0.694 & 0.810 \\
Unique image & 0.654 & 0.764 \\
Overall image & 1.000 & 1.000
\end{tabular}


TABLE 9 | Measurement instrument: discriminant validity (Fornell-Larcker criterion).

\begin{tabular}{lccccc}
\hline & $\begin{array}{c}\text { Information Cognitive } \\
\text { sources }\end{array}$ & $\begin{array}{c}\text { Affective } \\
\text { image }\end{array}$ & $\begin{array}{c}\text { Unique } \\
\text { image }\end{array}$ & $\begin{array}{c}\text { Overall } \\
\text { image }\end{array}$ \\
\hline Information sources & $\mathbf{0 . 9 5 5}$ & & & & \\
Cognitive image & 0.073 & $\mathbf{0 . 9 4 1}$ & & & \\
& $(0.055)$ & & & & \\
Affective image & -0.072 & 0.359 & $\mathbf{0 . 8 3 3}$ & & \\
Unique image & $(0.079)$ & $(0.415)$ & & & \\
& 0.029 & 0.339 & 0.403 & $\mathbf{0 . 8 0 9}$ & \\
Overall image & $(0.055)$ & $(0.351)$ & $(0.477)$ & & $\mathbf{1 . 0 0 0}$ \\
& -0.048 & 0.337 & 0.525 & 0.570 & \\
& $(0.044)$ & $(0.357)$ & $(0.582)$ & $(0.650)$ & \\
\hline
\end{tabular}

Bolded values on the diagonal are the square root of the AVE of the corresponding construction.

the variance shared by a variable and its indicators must be greater than the variance shared with the model's other variables (Barclay et al., 1995). There are two evaluation methods: an analysis of the cross-loadings or through the correlations of the latent variables (AVE). The present research used the latter method, as can be seen in Table 9, which shows the data from the correlation matrix between the model's constructs (Table 9). The diagonal of the matrix shows the value of the square root of the AVE of the corresponding construct (bolded values in Table 9). As can be seen, the correlations between the constructs were less than the square root of the AVE. Therefore the constructs met the requirement for discriminant validity. Additionally, to check that measuring instrument, we also calculated the HTMT values: As Table 9 evidences, the values were consistently less than 0.9 (Gold et al., 2001).

\section{Evaluation of the Structural Model}

Table 10 displays the results of the structural analysis carried out with PLS. The path coefficients $(\beta)$ indicate the relationships between the structures, as well as the significance of these relationships. In order to study the stability and significance of the estimated parameters, we applied the aforementioned nonparametric resampling technique: bootstrapping. This technique involves creating a number of bootstrap samples through a randomized repeated sampling of the original sample (Hair et al., 2011).

As Table 10 indicates, all the accepted direct effects held true at a significance level of 99\%. These results allowed us to draw the following conclusions: First, we found support for sub-hypothesis H1A, which sought to verify whether information sources had a positive and significant influence on the cognitive image $(\beta=0.073, p<0.001)$. However, the support for sub-hypothesis $\mathrm{H} 1 \mathrm{~B}$ - which sought to confirm the influence and significance of information sources with regard to the affective image - diverged from our expectations $(\beta=-0.1, p<0.001)$. As can be seen, the data were significant, but the sign of the coefficient was negative. In other words, the influence of one variable on the other was negative. This may be because the relationship between the two variables is very weak or is being impacted by a mediating variable. Finally, we found no support for sub-hypothesis H1C, which sought to test the positive and significant influence of information sources on the unique image $(\beta=0.029, p>0.001$, $p>0.01, p>0.05)$. Specifically, the coefficient was not significantly different from zero, since the empirical value of $t$ was less than the critical value of $t$ for significance levels of $0.90,0.95$, and 0.99 .

With regard to the second hypothesis ( $\mathrm{H} 2)$, we found support for all five sub-hypotheses (H2A, H2B, H2C, H2D, and H2E). Thus, we confirmed that the cognitive image has a positive and significant influence on the affective image $(\mathrm{H} 2 \mathrm{~A})(\beta=0.259$, $p<0.001)$, as does the unique image $(\mathrm{H} 2 \mathrm{~B})(\beta=0.318, p<0.001)$. Meanwhile, the cognitive (H2C) $(\beta=0.080 ; p<0.001)$, affective (H2D) $(\beta=0.331 ; p<0.001)$, and unique image $(\mathrm{H} 2 \mathrm{E})$ $(\beta=0.409 ; p<0.001)$ all exerted a significant effect on the overall image.

In order to assess the structural model, we calculated R2 (Table 11). According to Falk and Miller (1992), the explained variance of the endogenous variables (R2) should be equal to or greater than 0.1 . However, an increasingly common alternative to solely considering R2 is the predictive relevance criterion Q2, proposed by Chin (1998): 318: Q2 measures how well the studied values can be reconstructed by the model and its parameters. If Q2 is greater than zero, the model has predictive relevance; if it is less than or equal to zero, it does not. But this is a rule-ofthumb that does not take into account the sampling distribution

\begin{tabular}{|c|c|c|c|c|}
\hline Hypothesis & $\begin{array}{l}\text { Structural } \\
\text { relationship }\end{array}$ & $\begin{array}{l}\text { Standardized } \\
\text { path }(\beta)\end{array}$ & $\begin{array}{c}\text { Bootstrap } \\
t \text {-value }\end{array}$ & $\begin{array}{l}\text { Support for } \\
\text { hypothesis }\end{array}$ \\
\hline $\mathrm{H} 1 \mathrm{~A}$ & $\begin{array}{c}\text { Information } \\
\text { sources } \rightarrow \text { Cognitive } \\
\text { image }\end{array}$ & 0.073 & 5,293 & SUPPORTED \\
\hline $\mathrm{H} 1 \mathrm{~B}$ & $\begin{array}{l}\text { Information sources } \\
\rightarrow \text { Affective image }\end{array}$ & -0.100 & 5,255 & SUPPORTED (-) \\
\hline $\mathrm{H} 1 \mathrm{C}$ & $\begin{array}{c}\text { Information } \\
\text { sources } \rightarrow \text { Unique } \\
\text { image }\end{array}$ & 0.029 & 1,493 & $\begin{array}{c}\text { NOT } \\
\text { SUPPORTED }\end{array}$ \\
\hline $\mathrm{H} 2 \mathrm{~A}$ & $\begin{array}{c}\text { Cognitive } \\
\text { image } \rightarrow \text { Affective image }\end{array}$ & 0.259 & 19,537 & SUPPORTTED \\
\hline $\mathrm{H} 2 \mathrm{~B}$ & $\begin{array}{l}\text { Unique image } \rightarrow \\
\text { Affective image }\end{array}$ & 0.318 & 20,731 & SUPPORTED \\
\hline $\mathrm{H} 2 \mathrm{C}$ & $\begin{array}{l}\text { Cognitive image } \\
\rightarrow \text { Overall image }\end{array}$ & 0.080 & 5,729 & SUPPORTED \\
\hline $\mathrm{H} 2 \mathrm{D}$ & $\begin{array}{l}\text { Affective image } \\
\rightarrow \text { Overall image }\end{array}$ & 0.331 & 22,641 & SUPPORTED \\
\hline $\mathrm{H} 2 \mathrm{E}$ & $\begin{array}{c}\text { Unique image } \rightarrow \text { Overall } \\
\text { image }\end{array}$ & 0.409 & 27,841 & SUPPORTED \\
\hline
\end{tabular}

TABLE 11 | Predictive relevance of the model.

\begin{tabular}{lcc}
\hline Factor & $\boldsymbol{R}^{\mathbf{2}}$ & $\boldsymbol{Q}^{\mathbf{2}}$ \\
\hline Information sources & 0.000 & 0.000 \\
Cognitive image & 0.005 & 0.002 \\
Affective image & 0.229 & 0.145 \\
Unique image & 0.001 & 0.001 \\
Overall image & 0.434 & 0.410
\end{tabular}


of Q2 (Shmueli et al., 2016; Arias-Oliva et al., 2019). As shown in Table 11, the R2 values were greater than 0.1 for all the variables except the cognitive image and the unique image. Likewise, all the Q2 values were greater than zero. Therefore, we can confirm that the model has predictive relevance.

Finally, we calculated the value of the standardized root mean square residual (SRMR) (Henseler et al., 2015) in order to measure the model's fit and compare the difference between the observed and predicted correlations. Values less than 0.08 are considered acceptable. Our proposed model achieved a value of 0.048 and thus had an appropriate fit. Figure 2 below illustrates the resulting SEM model.

\section{DISCUSSION}

Like other authors (e.g., Beerli and Martín, 2004; Llodrà Riera, 2013), we could only verify that information sources have a positive and significant influence on the cognitive image (sub-hypothesis H1A). Meanwhile, information sources had a significant negative impact on the affective image (H1B) and no significant impact on the unique image (H1C). These results are largely contrary to those obtained by Llodrà Riera (2013), who found support for all three sub-hypotheses.

In line with previous reports (e.g., Baloglu and McCleary, 1999; Beerli and Martín, 2004; Qu et al., 2011; Llodrà Riera, 2013), the results showed that cognitive image positively influences the overall image (H2C). Likewise, the influence of the cognitive image on the affective image ( $\mathrm{H} 2 \mathrm{~A})$ was consistent with previous findings (Baloglu and McCleary, 1999; Beerli and Martín, 2004). The fact that the affective image clearly influenced the overall image (H2D) confirms the findings of Baloglu and McCleary (1999), Beerli and Martín (2004), Ekinci and Hosany (2006), Qu et al. (2011), and Papadimitriou et al. (2015). Collectively, these findings suggest that the affective image can have a very significant direct effect on the overall image. Additionally, we found that the unique image influences both the affective (H2B) and overall image (H2E). Interestingly, its effect on the overall image was even greater than that of the affective image, although the latter has received considerably more attention in the literature. This is consistent with the findings of $\mathrm{Qu}$ et al. (2011), but not of Llodrà Riera (2013), the latter of whom was unable to confirm the relationships between the unique, affective, and overall images.

\section{CONCLUSION}

This study sought to examine the image formation of a particular cultural and tourism destination, Segóbriga Archeological Park. Both the theoretical review of the concept and the accompanying quantitative studies revealed that the overall image of this destination is a multidimensional phenomenon consisting of cognitive, affective, and unique dimensions. In other words, tourists form perceptions of Segóbriga based on not only their individual knowledge and beliefs regarding the site's characteristics, but also their feelings toward and perceptions of the destination as a unique experience. The results also illuminate that the unique image influenced the affective image more than the cognitive one. Additionally, the unique image had the greatest influence on the overall image (followed by affective and then cognitive). The fact that the unique image significantly influenced the overall image is consistent with the findings of Echtner and Ritchie (1993), who noted that the unique image is an excellent source of differentiation that can help improve the overall image.

Likewise, our study verified the role played by information sources in image formation. By analyzing the influence of these sources on the three dimensions of the image (cognitive, affective, and unique), we found that they positively and significantly influence the cognitive image, negatively influence the affective image, and do not seem to significantly influence the unique image.

The results also underscore the information sources most often used by tourists who visit this type of site: The top-ranking one was the Internet (an induced source), followed by word of mouth (WOM) from friends and family (an organic source). These sources thus carry the greatest weight in the destination image formation process. Consequently, tourism promotion and management would be best served by leveraging online sources (social media, websites, etc.) that allow users to post-comments (eWOM) that might be seen by potential future tourists. In short, eWOM is a powerful means of promoting tourism.

\section{Practical and Theoretical Implications}

The above findings constitute a novel contribution to the literature. First, the present study highlights the importance of the affective image. This stands in contrast to most research to date, which has placed more emphasis on the cognitive image. Second, we provide a test of the unique image dimension, which has largely been ignored in the literature. To this end, we confirmed that the unique image is an essential component of the overall image for an archeological destination. These practical implications align with those of Qu et al. (2011), who argued that tourists form a unique image impression following their visits, which helps to distinguish a destination in their minds. Thus, it appears that the unique image can bolster marketing differentiation strategies and make a destination more competitive (Lin and Kuo, 2018). Consequently, academics should continue researching this image component in relation to other tourist destinations.

Moreover, destination managers should take into account that potential and actual tourists are increasingly using the Internet to find information or post-comments on social media. In our study, respondents assigned the highest scores to the destination's website, to search engines (such as Google, Bing, or Yahoo), and to online map services (such as Google Maps, ViaMichelín, or Repsol Guide). Based on these results and the prior literature, we can safely conclude that information sources can be leveraged as promotional tools to positively influence a destination's image formation.

In conclusion, this research analyzed the factors that influence tourists' perceived images of an archeological park. In aiming to improve the future management of such sites, our results 


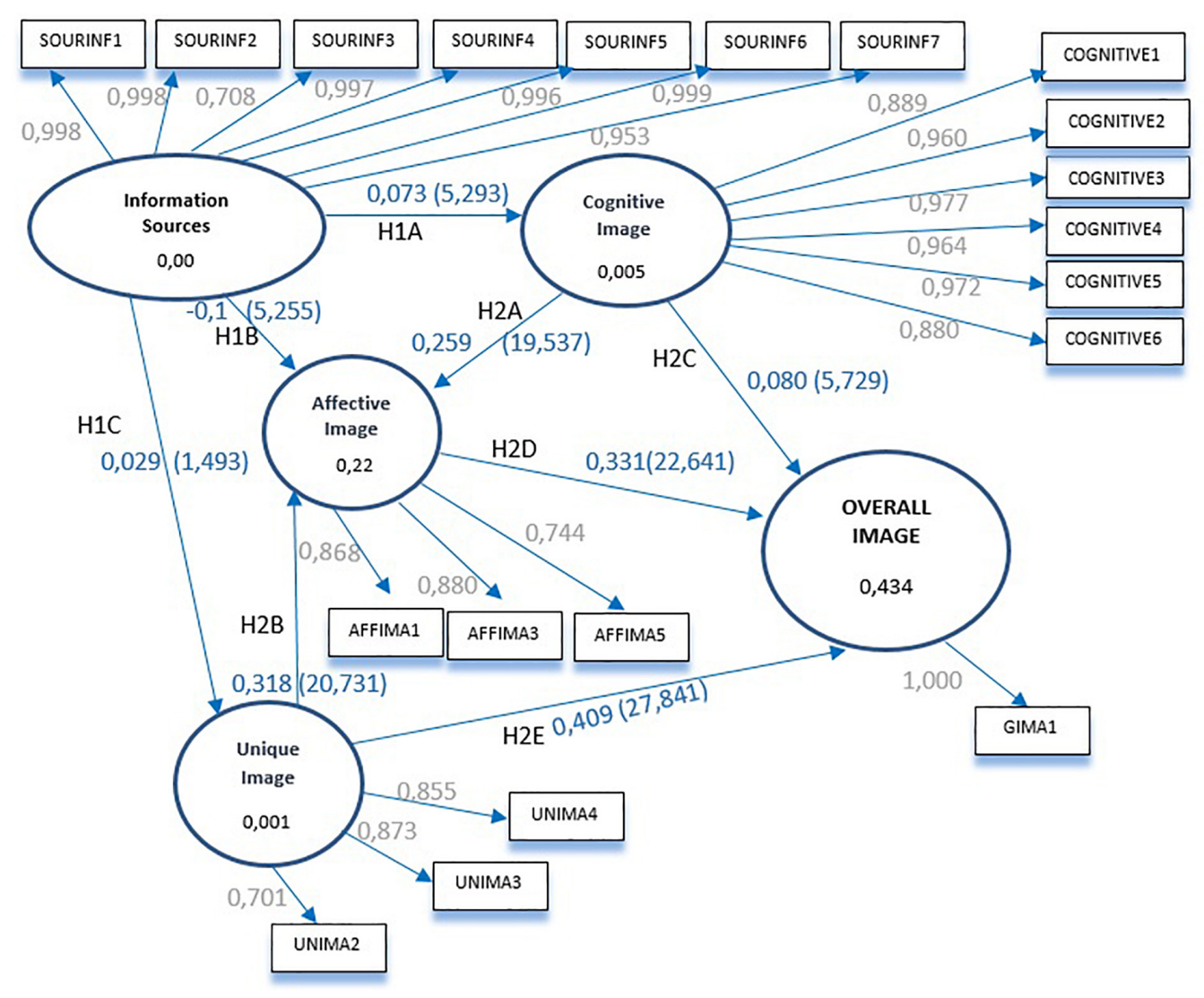

FIGURE 2 | Result of the model SEM.

highlight ways of attracting potential tourists, encouraging recommendations, and increasing the intention to return.

\section{Limitations and Further Research}

The present study features several limitations worth highlighting. For practical purposes, we measured the constructs from before and after the visit at the same time (i.e., following respondents' visit to the site). Consequently, it was not possible to gauge respondents' assessments of the site's image prior to their tourism experience. Additionally, we discarded several constructs, and the relationships between them, when constructing the proposed conceptual model. Future research should explore some of these variables and relationships. For example, it would be useful to analyze what motivates tourists' to finally decide to visit this destination and see how these factors influence each of the image components (cognitive, affective and unique). It may be that tourists develop different perceptions about this type of destination's overall image based on their motivation (or lack thereof). Future studies should also explore how these socio-demographic characteristics (age, residence, work, level of studies, etc.) relate to people's willingness to visit such archeological destinations.

Possibly, a limitation may be the cognitive effect might not influence of the overall image, due to the existence of an indirect effect through the affective image.
Other avenues for future research include assessing how tourists' perceptions of a destination change before, during, and after the visit, as well as analyzing the role that local residents play in the formation of the different image components.

\section{DATA AVAILABILITY STATEMENT}

The raw data supporting the conclusions of this manuscript will be made available by the authors, without undue reservation, to any qualified researcher.

\section{ETHICS STATEMENT}

The studies involving human participants were reviewed and approved by Research Ethics Commission of the University of Castilla-La Mancha. The patients/participants provided their written informed consent to participate in this study.

\section{AUTHOR CONTRIBUTIONS}

All authors listed have made a substantial, direct and intellectual contribution to the work, and approved it for publication. 


\section{REFERENCES}

Ahmed, Z. U. (1991). The influence of the components of a state's tourist image on product positioning strategy. Tour. Manag. 12, 331-340. doi: 10.1016/02615177(91)90045-u

Alcañiz, E. B., Garcia, I. S., and Blas, S. S. (2009). The functional-psychological continuum in the cognitive image of a destination: a confirmatory analysis. Tour. Manag. 30, 715-723. doi: 10.1016/j.tourman.2008.10.020

Alcázar, C. H., and Sicilia, M. (2015). How web interactivity influences the image of a tourist destination. J. Urban Regeneration Renewal 8, 356-366.

Arias-Oliva, M., Pelegrín-Borondo, J., and Matías-Clavero, G. (2019). Variables influencing cryptocurrency use: a technology acceptance model in spain. Front. Psychol. 10, 1-13. doi: 10.3389/fpsyg.2019.00475

Baloglu, S. (1998). An empirical investigation of attitude theory for tourist destinations: a comparison of visitors and nonvisitors. J. Hospital. Tour. Res. 22, 211-224. doi: 10.1177/109634809802200301

Baloglu, S., and Brinberg, D. (1997). Affective images of tourism destinations. J. Travel Res. 35, 11-15. doi: 10.1177/004728759703500402

Baloglu, S., and McCleary, K. W. (1999). A model of destination image formation. Ann. Tour. Res. 26, 868-897. doi: 10.1016/s0160-7383(99)00030-4

Barclay, D. W., Higgins, C., and Thompson, R. (1995). The partial least squares approach to causal modeling: personal computer adoption and use as illustration. Technol. Stud. 2, 285-309.

Beerli, A., and Martín, J. D. (2004). Factors influencing destination image. Ann. Tour. Res. 31, 657-681. doi: 10.1016/j.annals.2004.01.010

Bigné, J. E., Sanchez, M. I., and Sanchez, J. (2001). Tourism image, evaluation variables and after purchase behaviour: inter-relationship. Tour. Manag. 22, 607-616. doi: 10.1016/s0261-5177(01)00035-8

Cai, L. A. (2002). Cooperative branding for rural destinations. Ann. Tour. Res. 29, 720-742. doi: 10.1016/s0160-7383(01)00080-9

Carballo, M. M., Araña, J. E., León, C. J., and Moreno-Gil, S. (2015). Economic valuation of tourism destination image. Tour. Econom. 21, 741-759. doi: $10.5367 /$ te.2014.0381

Carmines, E. G., and Zeller, R. A. (1979). Reliability and Validity Assessment. Thousand Oaks, CA: Sage publications.

Chaudhary, M. (2000). India's image as a tourist destination-a perspective of foreign tourists. Tour. Manag. 21, 293-297. doi: 10.1016/s0261-5177(99) 00053-9

Chen, C. C., Lai, Y. H. R., Petrick, J. F., and Lin, Y. H. (2016). Tourism between divided nations: an examination of stereotyping on destination image. Tour. Manag. 55, 25-36. doi: 10.1016/j.tourman.2016.01.012

Chen, C. F., and Tsai, D. (2007). How destination image and evaluative factors affect behavioral intentions? Tour. Manag. 28, 1115-1122. doi: 10.1016/j. tourman.2006.07.007

Cherifi, B., Smith, A., Maitland, R., and Stevenson, N. (2014). Destination images of non-visitors. Ann. Tour. Res. 49, 190-202. doi: 10.1016/j.annals.2014.09.008

Chi, C. G. Q., and Qu, H. (2008). Examining the structural relationships of destination image, tourist satisfaction and destination loyalty: an integrated approach. Tour. Manag. 29, 624-636. doi: 10.1016/j.tourman.2007.06.007

Chin W. W. (1998). The partial least squares approach to structural equation modeling. Modern Methods Bus. Res. 295, 295-336.

Chon, K. S. (1990). The role of destination image in tourism: a review and discussion. Tour. Rev. 45, 2-9. doi: 10.1108/eb058040

Coromina, L., and Camprubí, R. (2016). Analysis of tourism information sources using a Mokken Scale perspective. Tour. Manag. 56, 75-84. doi: 10.1016/j. tourman.2016.03.025

Crompton, J. L. (1979). An assessment of the image of mexico as a vacation destination and the, influence of geographical location upon that image. J. Travel Res. 17, 18-23. doi: 10.1177/004728757901700404

Cronbach, L. J. (1951). Coefficient alpha and the internal structure of tests. Psychometrika 16, 297-334. doi: 10.1007/bf02310555

Deng, Q., and Li, M. (2014). A model of event-destination image transfer. J. Travel Res. 53, 69-82. doi: 10.1177/0047287513491331

Dijkstra, T. K., and Henseler, J. (2015). Consistent partial least squares path modeling. MIS Q. Manag. Inf. Syst. Q. 39, 297-316.

Draper, J. (2016). An exploratory study of the differences in prior travel experience and tourist information sources. Tour. Hospital. Res. 16, 133-143. doi: 10.1177/ 1467358415600216
Echtner, C. M., and Ritchie, J. B. (1993). The measurement of destination image: an empirical assessment. J. Travel Res. 31, 3-13. doi: 10.1177/ 004728759303100402

Echtner, C. M., and Ritchie, J. R. (2003). The meaning and measurement of destination image [Reprint of original article published in v. 2, no. 2, 1991: 2-12.]. J. Tour. Stud. 14:37.

Echtner, C. M., and Ritchie, J. R. B. (1991). The meaning and measurement of destination image. J. Tour. Stud. 2, 2-12.

Ekinci, Y., and Hosany, S. (2006). Destination personality: an application of brand personality to tourism destinations. J. Travel Res. 45, 127-139. doi: 10.1177/ 0047287506291603

Elliot, S., and Papadopoulos, N. (2016). Of products and tourism destinations: an integrative, cross-national study of place image. J. Business Res. 69, 1157-1165. doi: 10.1016/j.jbusres.2015.08.031

Embacher, J., and Buttle, F. (1989). A repertory grid analysis of austria's image as a summer vacation destination. J. Travel Res. 27, 3-7. doi: 10.1177/ 004728758902700302

Fakeye, P. C., and Crompton, J. L. (1991). Image differences between prospective, first-time, and repeat visitors to the lower rio grande valley. J. Travel Res. 30, 10-16. doi: 10.1177/004728759103000202

Falk, R. F., and Miller, N. B. (1992). A Primer for Soft Modeling. Akron, OH: University of Akron Press.

Fornell, C., and Larcker, D. F. (1981). ). Evaluating structural equation models with unobservable variables and measurement error. J. Market. Res. 18, 39-50. doi: $10.1177 / 002224378101800104$

Fu, H., Ye, B. H., and Xiang, J. (2016). Reality TV, audience travel intentions, and destination image. Tour. Manag. 55, 37-48. doi: 10.1016/j.tourman.2016.01.009

Gallarza, M. G., Saura, I. G., and García, H. C. (2002). Destination image: towards a conceptual framework. Ann. Tour. Res. 29, 56-78.

Gartner, W. C. (1989). Tourism image: attribute measurement of state tourism products using multidimensional scaling techniques. J. Travel Res. 28, 16-20. doi: $10.1177 / 004728758902800205$

Gartner, W. C. (1994). Image formation process. J. Travel Tour. Market. 2, 191216.

Gartnerand, W. C., and Hunt, J. D. (1987). An analysis of state image change over a twelve-year period (1971-1983. J. Travel Res. 26, 15-19. doi: 10.1177/ 004728758702600204

Gold, A. H., Malhotra, A., and Segars, A. H. (2001). Knowledge management: an organizational capabilities perspective. J. Manag. Inf. Syst. 18, 185-214. doi: 10.1080/07421222.2001.11045669

Goodrich, J. N. (1978). The relationship between preferences for and perceptions of vacation destinations: application of a choice model. J. Travel Res. 17, 8-13. doi: 10.1177/004728757801700202

Gunn, C. A. (1972). Vacationscape: Designing Tourist Regions. Austin, TX: University of Texas.

Gunn, C. A. (1988). Vacationscape: Designing Tourist Regions. New York, NY: Van Nostrand Reinhold.

Gutiérrez, H. S. M., and del Bosque, I. R. (2010). Los factores estímulo y personales como determinantes de la formación de la imagen de marca de los destinos turísticos: un estudio aplicado a los turistas que visitan un destino vacacional. Cuadernos de Economía y Dirección de la Empresa 13, 37-63. doi: 10.1016/ s1138-5758(10)70009-8

Hair, J. F., Ringle, C. M., and Sarstedt, M. (2011). PLS-SEM: indeed a silver bullet. J. Market. Theory Pract. 19, 139-152. doi: 10.2753/mtp1069-6679190202

Henseler, J., Ringle, C. M., and Sarstedt, M. (2015). A new criterion for assessing discriminant validity in variance-based structural equation modeling. J. Acad. Market. Sci. 43, 115-135. doi: 10.1007/s11747-014-0403-8

Hosany, S., Ekinci, Y., and Uysal, M. (2007). Destination image and destination personality. Int. J. Cult. Tour. Hospital. Res. 1, 62-81.

Hsu, C. H., Wolfe, K., and Kang, S. K. (2004). Image assessment for a destination with limited comparative advantages. Tour. Manag. 25, 121-126. doi: 10.1016/ s0261-5177(03)00062-1

Hudson, S., Wang, Y., and Gil, S. M. (2011). The influence of a film on destination image and the desire to travel: a cross-cultural comparison. Int. J. Tour. Res. 13, $177-190$.

Huete-Alcocer, N. (2017). A literature review of word of mouth and electronic word of mouth: implications for consumer behavior. Front. Psychol. 8:1256. doi: $10.3389 /$ fpsyg.2017.01256 
Hunt, J. D. (1971). Image: A Factor in Tourism. Ph.D. Dissertation, Fort Collins: Colorado State University.

Hunt, J. D. (1975). Image as a factor in tourism development. J. Travel Res. 13, 1-7. doi: $10.1177 / 004728757501300301$

Hunter, W. C. (2016). The social construction of tourism online destination image: a comparative semiotic analysis of the visual representation of Seoul. Tour. Manag. 54, 221-229. doi: 10.1016/j.tourman.2015.11.012

Jarvis, C. B., MacKenzie, S. B., and Podsakoff, P. M. (2003). A critical review of construct indicators and measurement model misspecification in marketing and consumer research. J. Consum. Res. 30, 199-218. doi: 10.1086/376806

Jeong, C., Holland, S., Jun, S. H., and Gibson, H. (2012). Enhancing destination image through travel website information. Int. J. Tour. Res. 14, 16-27. doi: $10.1002 /$ jtr. 827

Kim, H., and Richardson, S. L. (2003). Motion picture impacts on destination images. Ann. Tour. Res. 30, 216-237. doi: 10.1016/s0160-7383(02)00062-2

Kim, S. E., Lee, K. Y., Shin, S. I., and Yang, S. B. (2017). Effects of tourism information quality in social media on destination image formation: the case of sina weibo. Inf. Manag. 54, 687-702. doi: 10.1016/j.im.2017.02.009

Kim, S. S., and Morrsion, A. M. (2005). Change of images of south korea among foreign tourists after the 2002 FIFA World Cup. Tour. Manag. 26, 233-247. doi: 10.1016/j.tourman.2003.11.003

Kock, F., Josiassen, A., and Assaf, A. G. (2016). Advancing destination image: the destination content model. Ann. Tour. Res. 61, 28-44. doi: 10.1016/j.annals. 2016.07.003

Konecnik, M., and Gartner, W. C. (2007). Customer-Based Brand Equity for a Destination. Ann. Tour. Res. 24, 400-421. doi: 10.1016/j.annals.2006.10.005

Lai, K., and Li, X. (2016). Tourism destination image: conceptual problems and definitional solutions. J. Travel Res. 55, 1065-1080. doi: 10.1177/ 0047287515619693

Lai, K., and Li, Y. (2012). Core-periphery structure of destination image: concept, evidence and implication. Ann. Tour. Res. 39, 1359-1379. doi: 10.1016/j.annals. 2012.02.008

Li, X., Pan, B., Zhang, L., and Smith, W. W. (2009). The effect of online information search on image development: insights from a mixed-methods study. J. Travel Res. 48, 45-57. doi: 10.1177/0047287508328659

Lin, C. H., and Kuo, B. Z. L. (2018). The moderating effects of travel arrangement types on tourists' formation of taiwan's unique image. Tour. Manag. 66, 233243. doi: 10.1016/j.tourman.2017.12.001

Llodrà Riera, B. (2013). Gestión De la Imagen Del Destino En El Contexto Del Turismo 2.0: Recomendaciones Estratégicas Para Las Organizaciones de Marketing de Los Destinos (OMD). Ciudad Real: UCLM.

Llodrà-Riera, I., Martínez-Ruiz, M. P., Jiménez-Zarco, A. I., and Izquierdo-Yusta, A. (2015). A multidimensional analysis of the information sources construct and its relevance for destination image formation. Tour. Manage 48, 319-328. doi: 10.1016/j.tourman.2014.11.012

Maher, A. A., and Carter, L. L. (2011). The affective and cognitive components of country image: perceptions of american products in kuwait. Int. Market. Rev. 28, 559-580. doi: 10.1108/02651331111181411

Martín-Santana, J. D., Beerli-Palacio, A., and Nazzareno, P. A. (2017). Antecedents and consequences of destination image gap. Ann. Tour. Res. 62, 13-25. doi: 10.1016/j.annals.2016.11.001

Millet, O. F. (2010). La imagen De un Destino Turístico Como Herramienta de Marketing. Olga, PI: B-Olga Femenía Millet.

Molinillo, S., Liébana-Cabanillas, F., Anaya-Sánchez, R., and Buhalis, D. (2018). DMO online platforms: image and intention to visit. Tour. Manag. 65, 116-130. doi: 10.1016/j.tourman.2017.09.021

Moreno-Gil, S., Beerli-Palacio, A., and de León Ledesma, J. (2012). Entender la imagen de un destino turístico: factores que la integran y la influencia de las motivaciones. Criterio Libre 10, 115-142.

Nadeau, J., Heslop, L., O'Reilly, N., and Luk, P. (2008). Destination in a country image context. Ann. Tour. Res. 35, 84-106. doi: 10.1016/j.annals.2007. 06.012

Papadimitriou, D., Kaplanidou, K. K., and Apostolopoulou, A. (2015). Destination image components and word-of-mouth intentions in urban tourism: a multigroup approach. J. Hospital. Tour. Res. 5, 1-21.

Pike, S. (2002). Destination image analysis-a review of 142 papers from 1973 to 2000. Tour. Manag. 23, 541-549. doi: 10.1016/s0261-5177(02)00005-5
Pike, S. (2009). Destination brand positions of a competitive set of near-home destinations. Tour. Manag. 30, 857-866. doi: 10.1016/j.tourman.2008.12.007

Pike, S., and Ryan, C. (2004). Destination positioning analysis through a comparison of cognitive, affective, and conative perceptions. J. Travel Res. 42, 333-342. doi: 10.1177/0047287504263029

Prats, L., Camprubí, R., and Coromina, L. (2016). Examining the role of familiarity, information sources, length of stay and satisfaction to the image perception model. Eur. J. Tour. Res. 13:5.

Qu, H., Kim, L. H., and Im, H. H. (2011). A model of destination branding: integrating the concepts of the branding and destination image. Tour. Manag. 32, 465-476. doi: 10.1016/j.tourman.2010.03.014

Reilly, M. D. (1990). Free elicitation of descriptive adjectives for tourism image assessment. J. Travel Res. 28, 21-26. doi: 10.1177/004728759002800405

Rodríguez-Molina, M. A., Frías-Jamilena, D. M., and Castañeda-García, J. A. (2015). The contribution of website design to the generation of tourist destination image: the moderating effect of involvement. Tour. Manag. 47, 303-317. doi: 10.1016/j.tourman.2014.10.001

Royo-Vela, M. (2009). Rural-cultural excursion conceptualization: a local tourism marketing management model based on tourist destination image measurement. Tour. Manag. 30, 419-428. doi: 10.1016/j.tourman.2008. 07.013

Russell, J. A., and Pratt, G. (1980). A description of the affective quality attributed to environments. J. Pers. Soc. Psychol. 38:311. doi: 10.1037//0022-3514.38. 2.311

San Martín, H., and del Bosque, I. (2011). Un enfoque de gestión de la imagen de marca de los destinos turísticos basado en las características del turista. Revista de Análisis Turístico 9, 5-13.

San Martín, H., and del Bosque, I. A. R. (2008). Exploring the cognitiveaffective nature of destination image and the role of psychological factors in its formation. Tour. Manag. 29, 263-277. doi: 10.1016/j.tourman.2007. 03.012

Shmueli, G., Ray, S., Estrada, J. M. V., and Chatla, S. B. (2016). The elephant in the room: predictive performance of PLS models. J. Bus. Res. 69, 4552-4564. doi: 10.1016/j.jbusres.2016.03.049

Sirakaya, E., and Woodside, A. G. (2005). Building and testing theories of decision making by travellers. Tour. Manag. 26, 815-832. doi: 10.1016/j.tourman.2004. 05.004

Smith, W. W., Li, X. R., Pan, B., Witte, M., and Doherty, S. T. (2015). Tracking destination image across the trip experience with smartphone technology. Tour. Manag. 48, 113-122. doi: 10.1016/j.tourman.2014.04.010

Stepchenkova, S., and Li, X. R. (2012). Chinese outbound tourists' destination image of america: part II. J. Travel Res. 51, 687-703. doi: 10.1177/ 0047287512451137

Stepchenkova, S., and Mills, J. E. (2010). Destination image: a meta-analysis of 2000-2007 research. J. Hospital. Market. Manag. 19, 575-609. doi: 10.1080/ 19368623.2010.493071

Stepchenkova, S., and Morrison, A. M. (2008). Russia's destination image among American pleasure travelers: revisiting echtner and ritchie. Tour. Manag. 29, 548-560. doi: 10.1016/j.tourman.2007.06.003

Stern, E., and Krakover, S. (1993). The formation of a composite urban image. Geograph. Anal. 25, 130-146. doi: 10.1111/j.1538-4632.1993.tb00285.x

Stylidis, D., Shani, A., and Belhassen, Y. (2017). Testing an integrated destination image model across residents and tourists. Tour. Manag. 58, 184-195. doi: 10.1016/j.tourman.2016.10.014

Stylos, N., Vassiliadis, C. A., Bellou, V., and Andronikidis, A. (2016). Destination images, holistic images and personal normative beliefs: predictors of intention to revisit a destination. Tour. Manag. 53, 40-60. doi: 10.1016/j.tourman.2015. 09.006

Sun, M., Ryan, C., and Pan, S. (2015). Using chinese travel blogs to examine perceived destination image the case of new zealand. J. Travel Res. 54, 543-555. doi: 10.1177/0047287514522882

Sun, X., Chi, C. G. Q., and Xu, H. (2013). Developing destination loyalty: the case of Hainan Island. Ann. Tour. Res. 43, 547-577. doi: 10.1016/j.annals.2013.04.006

Tan, W. K., and Wu, C. E. (2016). An investigation of the relationships among destination familiarity, destination image and future visit intention. J. Destinat. Market. Manag. 5, 214-226. doi: 10.1016/j.jdmm.2015. 12.008 
Tang, L. R. (2014). The application of social psychology theories and concepts in hospitality and tourism studies: a review and research agenda. Int. J. Hospital. Manag. 36, 188-196. doi: 10.1016/j.ijhm.2013.09.003

Tasci, A. D., and Gartner, W. C. (2007). Destination image and its functional relationships. J. Travel Res. 45, 413-425. doi: 10.1177/004728750729 9569

Tasci, A. D., Gartner, W. C., and Cavusgil, S. T. (2007). Conceptualization and operationalization of destination image. J. Hospital. Tour. Res. 31, 194-223. doi: 10.1177/1096348006297290

Tseng, C., Wu, B., Morrison, A. M., Zhang, J., and Chen, Y. C. (2015). Travel blogs on china as a destination image formation agent: a qualitative analysis using Leximancer. Tour. Manag. 46, 347-358. doi: 10.1016/j.tourman.2014.07.012

Um, S., and Crompton, J. L. (1990). Attitude determinants in tourism destination choice. Ann. Tour. Res. 17, 432-448. doi: 10.1016/0160-7383(90)90008-f

Witter, B. S. (1985). Attitudes about a resort area: a comparison of tourists and local retailers. J. Travel Res. 24, 14-19. doi: 10.1177/004728758502400103

Woodside, A. G., and Lysonski, S. (1989). A general model of traveler destination choice. J. Travel Res. 27, 8-14. doi: 10.1177/004728758902700402
Yang, J., He, J., and Gu, Y. (2012). The implicit measurement of destination image: the application of implicit association tests. Tour. Manag. 33, 50-52. doi: 10.1016/j.tourman.2011.01.022

Zeng, B., and Gerritsen, R. (2014). What do we know about social media in tourism? a review. Tour. Manag. Persp. 10, 27-36. doi: 10.1016/j.tmp.2014. 01.001

Conflict of Interest: The authors declare that the research was conducted in the absence of any commercial or financial relationships that could be construed as a potential conflict of interest.

Copyright (C) 2019 Huete-Alcocer, Martinez-Ruiz, López-Ruiz and Izquiedo-Yusta. This is an open-access article distributed under the terms of the Creative Commons Attribution License (CC BY). The use, distribution or reproduction in other forums is permitted, provided the original author(s) and the copyright owner(s) are credited and that the original publication in this journal is cited, in accordance with accepted academic practice. No use, distribution or reproduction is permitted which does not comply with these terms. 


\section{OPEN ACCESS}

Edited by:

Ana Jiménez-Zarco, Open University of Catalonia, Spain

Reviewed by: Francesco Schiavone, Università degli Studi di Napoli

Parthenope, Italy

Francisco Simões Pinto, University of Algarve, Portugal

*Correspondence: Maria Yolanda Salinero yolanda.salinero@uclm.es

Specialty section: This article was submitted to

Organizational Psychology, a section of the journa Frontiers in Psychology

Received: 09 July 2019 Accepted: 22 October 2019 Published: 06 November 2019

Citation: Muñoz RM, Fernández MV and Salinero MY (2019) Assessing Consumer Behavior in the Wine Industry and Its Consequences for Wineries: A Case Study of a

Spanish Company.

Front. Psychol. 10:2491 doi: 10.3389/fpsyg.2019.02491

\section{Assessing Consumer Behavior in the Wine Industry and Its Consequences for Wineries: A Case Study of a Spanish Company}

\author{
Rosa M. Muñoz ${ }^{1}$, M. Valle Fernández ${ }^{2}$ and Maria Yolanda Salinero ${ }^{2 *}$ \\ ${ }^{1}$ Business Management Department, Group for Research in Organizational Knowledge, Innovation and Strategy, University \\ of Castilla-La Mancha, Ciudad Real, Spain, ${ }^{2}$ Cofinanciación de la Unión Europea a Través del Fondo Europeo de Desarrollo \\ Regional, Ciudad Real, Spain
}

The widening gap between production and domestic consumption has led Spain to become the country with the largest volume of wine exports, of which it has a global market share of $20.5 \%$. Wineries in Spain have, in recent years, undergone important transformation and modernization processes, while their customers have simultaneously acquired more power than ever before owing to both the availability of information and the technological means required to access that information. The objectives of this paper are the following. We first wish to analyze current wine consumer behavior in an attempt to discover indicators associated with exploratory behavior, i.e., the willingness to try new and innovative products for the first time. We also attempt to understand the extent of wine consumers' demands in this new digital and technological world. The second goal is to analyze the changes that have taken place in the wine industry, which have come about as a result of the evolution of consumers' expectations and demands. The customer accordingly now plays a new role in this new quick change scenario, which involves aspects such as the intensive use of technology, advances in communication, digital transformation, etc. We consider that this could affect some aspects of business and have, therefore, chosen to analyze one of the most advanced Spanish wineries in order to examine its entrepreneurial orientation, strategy and level of technological and digital transformation when linked to adaptation to this new consumer behavior. The results and conclusions obtained will allow us to apply our findings in future research, during which we intend to expand our studies to wineries from other regions and countries.

Keywords: wine industry, consumer behavior, technology, digital transformation, case study

\section{INTRODUCTION}

Wine is a product with an immediate effect on the consumer and a high level of differentiation, so customer orientation is a fundamental determinant of the competitive advantage of a company. Moreover, improving performance in markets for differentiated customer goods has been recognized as a major challenge for the European Union countries (Zaharieva et al., 2004). 
The wine sector has, in recent years, undergone an evolution marked by an increase in market competition. In 2017, global wine production fell to 250 million hectoliters (mhl), a decline of $23.6 \mathrm{mhl}$ when compared with 2016 production, while consumption increased a little to 243 mhl (OIV, 2018). A more detailed analysis shows that the difference between production and consumption is noticeable in traditional wine-producing countries (Lorenzo et al., 2018). For example, production in Italy, France and Spain in 2017 was 42.5, 36.7, and $32.1 \mathrm{mhl}$, respectively, while consumption was 22.6, 27.0, and $10.3 \mathrm{mhl}$. This important difference between production and domestic consumption has changed the way of competing in these countries, which have started to export in order to sell their products on international markets (Lorenzo et al., 2018). This widening gap between production and domestic consumption has made Spain the country with the largest volume of wine exports $(22.1 \mathrm{mhl})$, with a global market share of $20.5 \%$ (OIV, 2018). Wineries in Spain have developed important processes of modernization and transformation during the last years. It is estimated that, since 2000, more than 130,000 hectares have been restructured and converted, with investments of more than 800 million euros (Lorenzo et al., 2018). Customers have simultaneously acquired more power than ever before owing to the availability of both information and the technological means required to access that information. It is, therefore, imperative to understand why and how consumers interact in this new environment (Szolnoki et al., 2014).

The objectives of this paper are the following. We first wish to analyze current wine consumer behavior in an attempt to discover indicators associated with exploratory behavior, i.e., the willingness to try new and innovative products for the first time. We also attempt to understand the extent of wine consumers' demands in this new digital and technological world. The second goal is to analyze the changes that have taken place in the wine industry, which have been fostered by the evolution of consumers' expectations and demands. The customer accordingly now plays a new role in this new quick change scenario, which involves aspects such as the intensive use of technology, advances in communication, digital transformation, etc. We consider that some aspects of business could be affected and have, therefore, chosen to analyze one of the most advanced Spanish wineries in order to examine its entrepreneurial orientation, strategy and level of technological and digital transformation when linked to adaptation to this new consumer behavior.

This paper is organized as follows. The following section draws from literature in the field, after which the methodology is explained. The "Case Study" section provides a description of the history of the firm and its main characteristics, along with an explanation of the strategy adopted, and the company's technology and digital strengths, paying particular attention to its effect on the consumer-company relationship. Finally, the last section presents the main conclusions and implications extracted from the case study.

\section{CONSUMER BEHAVIOR IN THE WINE INDUSTRY AND ITS CONSEQUENCES FOR WINERIES}

In the following sections, we present the main characteristics of wine consumer behavior and the company's features that we consider most closely linked to them.

\section{Exploratory Consumer Behavior and Wine Consumption}

The special characteristics of the wine industry create an ideal context in which to analyze exploratory consumer behavior. This concept emerged over six decades ago from the theory of optimum stimulation level. According to this theory, consumers seek to get an optimal level of stimulation from the environment, so that it is not too low that leads to boredom, nor so high that it becomes upsetting (Orth and Bourrain, 2005). Exploratory behavior occurs when consumers seek more stimulation by trying different or unusual products and find this exploration process enjoyable and rewarding. This could be denominated as innovativeness, i.e., when consumers expose to the risk of using a previously unknown product, variety seeking or switching behavior, i.e., when they avoid the boredom that might occur as a result of repeatedly consuming the same product; and curiositymotivated, when motivates consumer's information search about new or unfamiliar products. We focus on the first form of exploratory behavior, which is to say, the search for new wines for personal consumption (Schaefer et al., 2018). One of the studies related to this issue found that consumers who showed an exploratory behavior, tended to buy greater quantities of wine, drank wine more frequently, were more highly interested in the wine category, and had greater knowledge of this sector (d'Hauteville and Goldsmith, 1998).

\section{Entrepreneurial Orientation}

Entrepreneurial orientation (EO) is a company decision-making proclivity that favors entrepreneurial initiatives and there is an agreement that it represents a continuous variable in which all enterprises can be positioned (Lumpkin and Dess, 2001). Some authors explore how this concept has been studied and assessed in prior research (Covin and Wales, 2012). They state that authors are free to choose whichever measurement approach best serves their research objectives. In this respect, some researchers have considered $\mathrm{EO}$ as a variable composed of three sub-dimensions: innovativeness, risk taking and proactiveness (Miller, 1983; Covin and Slevin, 1989).

\section{Company Strategy}

One of the models that has been used in an attempt to capture the typology of the competitive strategy is that developed by Robinson and Pearce (1988), and it has been used in several studies (Ibrahim et al., 2001; Spanos and Lioukas, 2001; Ruiz Ortega, 2010). This model was developed on the basis of previous studies by Dess and Davis (1984) and looks for expanding the generic strategies of Michael Porter, thus favoring their characterization in empirical business studies. This business 
strategy proposal consists of 22 indicators assessed using a fivepoint Likert scale, on which firms evaluate themselves with respect to different company development efforts, from 1 "not considered" to 5 "major, constant emphasis."

\section{Technology}

In the case of the technology employed in this industry, wineries have started to develop innovative traceability tools to protect their image against the negative consequences of counterfeit wines and to strengthen their brand equity (Wang et al., 2017). There are various kinds of voluntary traceability in the wine sector, such as the ISO 22005 and the private standards that are adopted by operators like wineries or retailers (Stranieri et al., 2018). With regard to the motivations leading wineries' decisions to develop voluntary quality standards, most of the studies identify firm internal efficiency, and external business factors, such as customer requirements (Corsinovi and Gaeta, 2017). Heightened customer demand for higher quality and standardized products is a primary driver of this (Matthew Rendleman et al., 2016). The implementation of a quality control program results in an increased reputation and production value. The objective of supply chain traceability is to identify the economic agents of the supply chain. This system is mandatory in Europe. However, it does not allow the traced information to be associated with a specific product, and does not provide a reconstruction of the product history. Supply chain and traceability of products entails more complex systems. They are characterized by the management of products and raw materials in separate lots and by procedures that assign specific information to each of said lots (Stranieri et al., 2018).

With regard to technology, we also wish to examine the adoption of intelligent automation (IA), which makes the consumer-companies relationships easier. It includes: robotic process automation (RPA), artificial intelligence (AI), machine learning (ML), cognitive computing (CC) and smart analytics (KPMG, 2018). IA can give companies a competitive advantage in all aspects of business.

\section{Digital Transformation}

Digital transformation is another relevant issue. The adoption of the Internet has become an important aspect of the renewal process required by the wine industry. It has moved rapidly into a new step of consumer interaction and influence via social networks, blogs, podcasts, and online virtual communities. This fact has implications for many sectors, but the wine industry is one that is particularly suited to this new tendency (Thach, 2009).

Social media have grown dramatically over the past decade, signifying that it is important for firms to learn how to interact with consumers via these new channels. This phenomenon has significantly altered the way in which customers communicate and interact with each other and with companies (Siamagka et al., 2015). This is particularly problematic in the consumer product sector, because consumers communicate about brands online, regardless of whether those brands respond or not. A lack of response in public social media can harm companies (Szolnoki et al., 2018). Social media have consequently led to a shift in power to consumers, as they move from passive receivers of marketing strategies to active participants in the brand message (Mangold and Faulds, 2009). Social media usage has been found to have a positive effect in brand performance and customer loyalty (Rapp et al., 2013).

The global wine industry is one of the industries whose brand is the subject of global online conversations (Mueller et al., 2010). Earlier literature has suggested that wineries that have a presence in social media will achieve low-cost benefits such as increased sales through word of mouth, loyalty and ongoing relationships with customers (Humphrey et al., 2017). The socialization aspect of social media allows consumers to exchange information and encourage others to try different wines, signifying that it is a key channel as regards influencing and affecting the purchase of wine (Wilson and Quinton, 2012).

Wineries, along with most other major industries, began to incorporate the Internet into their business strategies in the 1990s. The questions that should be addressed are, however, how effective is their communication with consumers online? And are wineries adopting the new Wine 2.0 philosophy of reaching out to consumers and actively engaging with them? (Thach, 2009).

The term Wine 1.0 refers to wine being featured on the Internet in a passive fashion, such as on a basic non-interactive website that includes general information on the company, its products, and contact data. The term Wine 2.0 refers to using the Internet to engage with wine consumers on their terms, in a time and manner of their choosing, and tools usually include social networking sites, blogs, message boards, and interactive components (Olsen and Hermsmeyer, 2008). Wine 3.0 is a phenomenon that includes virtual reality wine tasting, avatars, or wine reviews that are accessible via cell phones and bar codes on wine bottles (Thach, 2009). Certain product categories, such as wine, require knowledge and information in order to decide to buy them, and recommendations work well. Therefore, components such as blogs and social networking sites may influence wine purchasers. Nowak and Newton also found that "website quality, defined as a professional-looking website with user-friendly menus and prompts, was a significant predictor of increased trust in the winery and perceptions of the quality of the wine" (Nowak and Newton, 2008).

\section{METHODOLOGY}

The wine sector has been studied from different points of view in literature. Studies regarding the United States wine industry are focused on the relationship between differentiation strategies and performance (Newton et al., 2015). In terms of strategy, there is research concerning the marketing strategy and performance in the French wine sector (Hammervoll et al., 2014), while in Spain, some authors have analyzed the strategies, environmental variables, and economic performance (Simon-Elorz et al., 2015). Other works have focused on the internationalization capacity in the Italian wine sector (Galati et al., 2016), or on cluster resources and performance in the Brazilian wine industry (Fensterseifer and Rastoin, 2013). This paper adopts an exploratory perspective and employs a qualitative approach through a case study. It was used to gain 
deeper insights into a complex issue within its real-life context. The objective of case-based research is to produce a refined theory based on an in-depth understanding of a particular context (Gerring, 2007). The single case setting limits the applicability of the research to other institutions. However, the framework and model that are developed, along with the overall approach, are valuable contributions to an important and emerging research area. The "how" and "what" questions are asked about a contemporary set of events over which the investigator has little or no control (Whitehead and Yin, 2003). This study investigates "how" wine consumers behave nowadays and "what" changes are observed in wineries as a result. As the paper seeks to address research questions, this suggests the adoption of an exploratory approach, in the sense that the main objective is to refine a research idea in order to facilitate further research. Study conducted within the qualitative paradigm is characterized by its commitment to collecting data from the context in which social phenomena naturally occur and to generating an understanding that is grounded on the perspectives of research participants (Marshall and Rossman, 1995).

The qualitative approach and exploratory nature of the research question influenced the data-collection method. It was consequently collected using desk and field research. Desk research, which is based on studying internal company documents, served to provide a detailed understanding of the company's situation, while the field research included a tour of the company visiting all departments, a questionnaire and an in-depth interview with the company's Managing Director. The interview took place in April-May 2019. It lasted 90 min and was tape-recorded, immediately transcribed and then sent back to the interviewee for review to ensure "truth value."

We have included the following dimensions in our research: exploratory consumer behavior, EO, company strategy and technological and digital transformation. Robinson and Pearce (1988), Covin and Slevin (1989), and Schaefer et al. (2018) scales were chosen in order to analyze the exploratory consumer behavior, the EO and the company strategy in our case study (see Appendix, the Managing Director's answers indicated with $\mathrm{x})$. Besides the information in the Appendix, the interview included questions related to the company adoption of intelligent automation and its Wine 2.0 components. In the following section, we describe the winery, its activity and its most recent innovations. We then explain the principal ideas extracted from the data analyzed, the interview and the questionnaire.

\section{CASE STUDY}

Vinícola de Castilla S.A. is a Spanish winery located in the city of Ciudad Real whose activity started in 1976. Its products are sold in 42 countries around the world. Some data related to the company are shown in Table $\mathbf{1 .}$

These data show that the firm has a healthy financial and economic situation with good levels of growth and profit. The decrease observed in the ratios is a consequence of the strong investments in technology and digitalization that the company is carrying out in recent years.
TABLE 1 | Data regarding Vinícola de Castilla.

\begin{tabular}{lccc}
\hline Variable & $\mathbf{2 0 1 5}$ & $\mathbf{2 0 1 6}$ & $\mathbf{2 0 1 7}$ \\
\hline Turnover (mill. €) & 4.6 & 5.2 & 4.2 \\
Number of employees & 30 & 28 & 27 \\
Solvency ratio \% & 23 & 17 & 17 \\
Liquidity ratio \% & 17 & 12 & 10 \\
\hline
\end{tabular}

Vinícola de Castilla's Annual Reports.

With a speed of 15,000 bottles/hour and in a continuous updating and optimization process, the bottling line has the most advanced machinery with which to attain the safest presentation that is of the highest quality. The boxing and palletizing systems, which are completely customizable, provide many possibilities as regards the final packaging process of products. All the area systems are controlled by Programmable Logic Controllers (PLCs) and industrial computers. The facilities are airy, wellequipped and illuminated for industry-leading machines. A team of enologists monitors the entire elaboration process, from harvesting to bottling, thus ensuring that the product has the best characteristics. Traditional and modern methods coexist, and a full range of tools is available for monitoring, traceability and strict quality control. Vinícola de Castilla has its own vineyards, which are divided mainly into two types: bush vines and espalier. The quality and high food security procedures are certified by very prestigious authorities under the most demanding standards.

\section{Exploratory Consumer Behavior}

As has occurred in other recent studies (Thach et al., 2015), exploratory consumer behavior was measured using the variety seeking scale that (Schaefer et al., 2018) adapted for wine (see Appendix). We have adapted the questions in order to enable them to be answered by the manager of the company. That is to say, we wished to discover his perceptions of Vinícola de Castilla consumers' exploratory behavior. All seven items used were measured on a five-point Likert type scale. The individual items on the scale best capture aspects of exploratory behavior, including curiosity and innovativeness.

The Vinícola de Castilla consumers have low levels of exploratory behavior: they do not try unusual or exotic wines; they prefer the wines they are used to, and they do not like to try wines from different countries.

\section{Entrepreneurial Orientation}

According to the Covin and Slevin scale (Covin and Slevin, 1989) it is possible to consider that the firm has an EO, i.e., it has high levels of innovativeness, proactiveness, and risk taking. We can, in general terms, summarize that the company has, over the last few years, marketed many new lines of products and has placed a particularly strong emphasis on the marketing of tried-and-true products. When dealing with its competitors, it typically starts actions to which competitors then respond, and it is very often the first firm to introduce new products, processes and operating technologies, adopting a competitive posture. The company's top 
managers claim that, owing to the nature of the environment, bold, aggressive acts are necessary to achieve the firm's objectives.

\section{Company Strategy, Technology, and Digital Transformation}

When considering the items included in the business's company scale (see Appendix), the company appears to have a remarkable orientation toward the market as a source of its competitive advantage, and this is integrated into a clear strategy of differentiation. The winery focuses on the marketing function in an attempt to achieve an identifiable brand and a reputation in the market. It relies heavily on innovation in methods and marketing techniques. In this respect, the company has developed a marketing plan with which to enhance its online presence. It participates in trade journeys and commercial fairs to a significant extent, and has received more than 700 prestigious national and international awards and recognitions (one of its best products has recently been recognized with the prestigious Golden Bacchus 2019), and this is the best form of publicity for the company.

Differentiation through the recognition of its brand image is the result of its tradition and image of quality, which are reflected in its commitment to the continuous improvement of its processes and products and the great efforts made to obtain the best raw materials. Its Methods and Quality Control Department applies a policy of maximum quality.

The company has the best and most innovative technicalenological endowment, thanks to its heavy investment in technology and innovation that allows it to compete, simultaneously, via quality and via costs.

Customers service is another of the significant aspects of the winery's business strategy, since it attempts to provide its customers with after-sales service and support, in addition to offering them high food safety, which is certified by entities of recognized prestige under the most demanding standards. The company has a complete traceability system: it has had ISO 9001 records for more than twenty years. Its scope of certification is: the design, elaboration, aging, bottling and commercialization of wines, and it also has the BRC Global Standard for Food Safety maximum level certifications and the International Featured Standard (IFS) Food for the safety and quality of food products and production processes. With regard to the consumer, the BRC Global Standard establishes customer focus and communication, that is to say, the need to ensure that customer requirements are met and that these requirements are communicated to relevant suppliers.

Flexibility and adaptation are also remarkable company characteristics. The winery has the capability to create new specialized products, i.e., the company has been the first winery in Castilla-La Mancha to produce certain special products, such as distilled beverages made from wine (Olimpo Holanda) or natural drinks derived from wine (Dlavid).

In the case of intelligent automation, Vinícola de Castilla is starting to develop certain processes, such as RPA and artificial intelligence (specifically, predictive and prescriptive analysis), but they are still in the first stage.
Upon examining its digital transformation we discovered that the company utilizes the majority of the components of Wine 2.0: a website with an e-commerce engine that is expanded to include interactive components, a wine blog, social networking sites (Twitter, Pinterest, and Facebook linked to the website), and winevlogs, that is, a video placed on its website in order to entertain customers and educate them about the company and its products.

\section{CONCLUSION}

Marketing literature suggests that a company's long-term success and survival is dependent on a firm's ability to become consumer rather than product-oriented (Greenley et al., 2003). This paper analyses a winery's efforts to achieve consumer orientation by means of strategy and technology. The main ideas and suggestions extracted from the analysis are shown as follows.

With regard to the first objective, that is to say, the analysis of current wine consumer behavior, we can conclude that the Vinícola de Castilla consumers have low levels of exploratory behavior, which is possibly related to the fact that $50 \%$ of the company sales are in the national market and $25 \%$ are in the European Union. That is to say, only $25 \%$ are in the rest of the world. The consumers who are most likely to engage in exploratory behavior value creativity, risk taking and also have a more global outlook, as they are more likely to purchase wine from other countries (Schaefer et al., 2018). We suggest that the company focuses on consumers with an exploratory behavior in line with its advances in technology and digitalization which entails a greater internationalization. The company should keep in mind the two main trends that will influence the wine sector in the future and characterize consumers' choices: most of them will still look for the best value for money and the best deals, but there will be a growing group of sophisticated and expert wine customers who will want experience more and look for high quality products and brands with high-end attributes (KPMG, 2014). Vinícola de Castilla should consider ways in which to expand its brand portfolio to reach more sophisticated wine drinkers both in Spain and worldwide.

In the case of the second objective, that is to say, the analysis of the business changes linked to the adaptation to consumer behavior, we present some suggestions. With regard to new technologies, Vinícola de Castilla is not exploiting all its intelligent automation potential. It is now starting to employ RPA and artificial intelligence, but it should also consider the future implantation of certain technologies such as computer vision or machine learning. These technologies enable systems to automatically learn and improve from experience without being explicitly programed. Computer vision is concerned with the theory behind artificial intelligence that extracts information from images. Machine learning focuses on the development of computer programs that can access data and use it to learn for themselves. All these technologies are appropriate for the wine sector and could improve both the processes in wineries and their relationships with consumers. 
The Vinícola de Castilla digital transformation is in line with consumers' current demands. In this respect, the company has developed most of the components of Wine 2.0., but it should also start paying attention to the most advanced components of Wine 3.0, such as wine reviews that are accessible via cell phones and bar codes on wine bottles, virtual reality wine tasting and avatars. Some possibilities include, for example, creating an avatar that looks like the winemaker, and incorporating professional wine critic ratings with customer ratings of the wine brand. This could give the company a competitive advantage as a first mover.

Vinícola de Castilla has several strengths that have placed it in a good competitive position in the last few years:

- an entrepreneurial orientation characterized by high levels of innovativeness, proactiveness, and risk taking;

- a differentiation strategy;

- consumer service orientation;

- well-established quality and traceability systems, along with the latest technological trends as regards processing and communication.

Besides these strengths, the company should, considering the future scenario, concentrate on some important issues such as exploratory consumer behavior, new technologies related to intelligent automation, and Wine 3.0.

This paper has several limitations that show possible lines for further research. It has developed an in-depth case study to a company. Case studies are a detailed contextual analysis of a limited number of events or situations and their relationships. The findings should, therefore, be treated with caution and should be checked and validated in other companies and other regions and countries. Various future research opportunities may, therefore, be possible. Despite these limitations, the results are relevant and provide some key implications for managers and

\section{REFERENCES}

Corsinovi, P., and Gaeta, D. (2017). European wine policies and their consequences on the global wine trade. Econ. Agro Aliment. 19, 59-88. doi: 10.3280/ecag2017001004

Covin, J. G., and Slevin, D. P. (1989). Strategic management of small firms in hostile and benign environments. Strat. Manag. J. 10, 75-87. doi: 10.1002/smj. 4250100107

Covin, J. G., and Wales, W. J. (2012). The measurement of entrepreneurial orientation. Entrepreneur. Theor. Pract. 36, 677-702. doi: 10.3389/fpsyg.2019. 01125

Dess, G. G., and Davis, P. S. (1984). Porter (1980) generic strategies as determinants of strategic group membership and organizational performance. Acad. Manag. J. 27, 467-488. doi: 10.5465/256040

d'Hauteville, F., and Goldsmith, R. E. (1998). Heavy wine consumption: empirical and theoretical perspectives. Br. Food J. 100, 184-190. doi: 10.1108/ 00070709810207865

Fensterseifer, J. E., and Rastoin, J. L. (2013). Cluster resources and competitive advantage a typology of potentially strategic wine cluster resources. Int. J. Wine Bus. Res. 25:267. doi: 10.1108/ijwbr-04-2011-0007

Galati, A., Crescimanno, M., Tinervia, S., and Siggia, D. (2016). Website quality and internal business factors an empirical investigation in the Italian wine industry. Int. J. Wine Bus. Res. 28, 308-326. doi: 10.1108/ijwbr-08-20150026

Gerring, J. (2007). Case Study Research: Principles and Practices. Cambridge: Cambridge University Press. researchers and new issues for future studies. In relation to what is learned from this study, we can ask ourselves, to what extent are these results applicable to other organizations in the wine industry? We can affirm that the analyzed company is one of the most advanced in its sector and most wineries are also smaller. They have to catch up on issues such as digitalization and technology if they really want to respond to the consumer behavior as Vinícola de Castilla is doing.

\section{DATA AVAILABILITY STATEMENT}

All datasets generated for this study are included in the article/Supplementary Material.

\section{AUTHOR CONTRIBUTIONS}

RM has made the theoretical review and empirical study. MF has developed the interviews with the company's CEO and made the empirical study. MS has made the empirical study.

\section{FUNDING}

This work was supported by the Cofinanciación de la Unión Europea a Través del Fondo Europeo de Desarrollo Regional.

\section{SUPPLEMENTARY MATERIAL}

The Supplementary Material for this article can be found online at: https://www.frontiersin.org/articles/10.3389/fpsyg. 2019.02491/full\#supplementary-material

Greenley, G., Snoj, B., Hooley, G., Beracs, J., Fahy, J., and Fonfara, K. (2003). Market orientation in the service sector of the transition economies of central Europe. Eur. J. Mark. 37, 86-106. doi: 10.1108/03090560310453975

Hammervoll, T., Mora, P., and Toften, K. (2014). The financial crisis and the wine industry: the performance of niche firms versus mass-market firms. Wine Econ. Policy 3, 108-114. doi: 10.1016/j.wep.2014.11.001

Humphrey, W. F. Jr., Laverie, D. A., and Rinaldo, S. B. (2017). Brand choice via incidental social media exposure. J. Res. Interact. Mark. 11, 110-130. doi: 10.1108/jrim-04-2016-0025

Ibrahim, B., Dumas, C., and McGuire, J. (2001). Strategic decision making in small family firms: an empirical investigation. J. Small Bus. Strat. 12, 80-90.

KPMG (2014). The Alcoholic Beverages Market in Poland. Amstelveen: KPMG.

KPMG (2018). The State of Intelligent Automation. Easing the Pressure Points. Amstelveen: KPMG.

Lorenzo, J. R., Maza, M. T., and Abella, S. (2018). The competitive advantage in business, capabilities and strategy. What general performance factors are found in the spanish wine industry? Wine Econ. Policy 7, 94-108. doi: 10.1016/j.wep. 2018.04.001

Lumpkin, G. T., and Dess, G. G. (2001). Linking two dimensions of entrepreneurial orientation to firm performance: the moderating role of environment and industry life cycle. J. Bus. Ventur. 16, 429-451. doi: 10.1016/s0883-9026(00) 00048-3

Mangold, W. G., and Faulds, D. J. (2009). Social media: the new hybrid element of the promotion mix. Bus. Horiz. 52, 357-365. doi: 10.1016/j.bushor.2009.03.002

Marshall, C., and Rossman, G. B. (1995). Designing Qualitative Research. Thousand Oaks, CA: Sage. 
Matthew Rendleman, C., Hoemmen, G. A., Altman, I., Taylor, T., Moon, W., and Smith, S. (2016). wine industry competitiveness: a survey of the shawnee hills american viticultural area. Wine Econ. Policy 5, 4-13. doi: 10.1016/j.wep.2016. 03.002

Miller, D. (1983). The correlates of entrepreneurship in three types of firms. Manag. Sci. 29, 770-791. doi: 10.1287/mnsc.29.7.770

Mueller, S., Lockshin, L., and Louviere, J. J. (2010). What you see may not be what you get: asking consumers what matters may not reflect what they choose. Mark. Lett. 21, 335-350. doi: 10.1007/s11002-009-9098-x

Newton, S. K., Gilinsky, A., and Jordan, D. (2015). Differentiation strategies and winery financial performance: an empirical investigation. Wine Econ. Policy 4, 88-97. doi: 10.1016/j.wep.2015.10.001

Nowak, L. I., and Newton, S. (2008). Using winery web sites to launch relationships with millennials. Int. J. Wine Bus. Res. 20, 53-67. doi: 10.1108/ 17511060810864615

OIV (2018). State of the Vitiviniculture World Market. Paris: OIV.

Olsen, J., and Hermsmeyer, J. (2008). "Direct wine sales and wine 2.0," in Wine: A Global Business, eds L. Thach, and T. Matz, (New York, NY: Miranda Press).

Orth, U. R., and Bourrain, A. (2005). Optimum stimulation level theory and the differential impact of olfactory stimuli on consumer exploratory tendencies. Adv. Consum. Res. 32, 613-619.

Rapp, A., Beitelspacher, L. S., Grewal, D., and Hughes, D. E. (2013). Understanding social media effects across seller, retailer, and consumer interactions. J. Acad. Mark. Sci. 41, 547-566. doi: 10.1007/s11747-013-0326-9

Robinson, R. B., and Pearce, J. A. (1988). Planned patterns of strategic behavior and their relationship to business-unit performance. Strateg. Manag. J. 9, 43-60. doi: $10.1002 /$ smj.4250090105

Ruiz Ortega, M. J. (2010). Competitive strategies and firm performance technological capabilities' moderating roles. J. Bus. Res. 63, 1273-1281. doi: 10.1016/j.jbusres.2009.09.007

Schaefer, R., Olsen, J., and Thach, L. (2018). Exploratory wine consumer behavior in a transitional market: the case of Poland. Wine Econ. Policy 7, 54-64. doi: 10.1016/j.wep.2018.01.003

Siamagka, N. T., Christodoulides, G., Michaelidou, N., and Valvi, A. (2015). Determinants of social media adoption by $\mathrm{B} 2 \mathrm{~B}$ organizations. Ind. Mark. Manag. 51, 89-99. doi: 10.1016/j.indmarman.2015.05.005

Simon-Elorz, K., Castillo-Valero, J. S., and Garcia-Cortijo, M. C. (2015). Economic performance and the crisis: strategies adopted by the wineries of castilla-la mancha (Spain). Agribusiness 31, 107-131. doi: 10.1002/agr.21392

Spanos, Y. E., and Lioukas, S. (2001). An examination into the causal logic of rent generation: contrasting porter's competitive strategy framework and the resource-based perspective. Strateg. Manag. J. 22, 907-934. doi: 10.1002/ smj.174

Stranieri, S., Cavaliere, A., and Banterle, A. (2018). The determinants of voluntary traceability standards. The case of the wine sector. Wine Econ. Policy 7, 45-53. doi: 10.1016/j.wep.2018.02.001

Szolnoki, G., Dolan, R., Forbes, S., Thach, L., and Goodman, S. (2018). Using social media for consumer interaction: an international comparison of winery adoption and activity. Wine Econ. Policy 7, 109-119. doi: 10.1016/j.wep.2018. 07.001

Szolnoki, G., Taits, D., Nagel, M., and Fortunato, A. (2014). Using social media in the wine business an exploratory study from Germany. Int. J. Wine Bus. Res. 26, 80-96. doi: 10.1108/ijwbr-09-2013-0031

Thach, L. (2009). Wine 2.0-the next phase of wine marketing? exploring us winery adoption of wine 2.0 components. J. Wine Res. 20, 143-157. doi: 10.1080/ 09571260903169548

Thach, L., Atkin, T., Cuellar, S. S., and Olsen, J. E. (2015). Variety seeking by wine consumers in the southern states of the US. Int. J. Wine Bus. Res. 27, 260-280. doi: 10.1108/ijwbr-08-2014-0036

Wang, J., Yue, H., and Zhou, Z. (2017). An improved traceability system for food quality assurance and evaluation based on fuzzy classification and neural network. Food Control 79, 363-370. doi: 10.1016/j.foodcont.2017. 04.013

Whitehead, D., and Yin, R. (2003). Case study research design and methods. J. Adv. Nurs. 44, 108-108.

Wilson, D., and Quinton, S. (2012). Let's talk about wine: does Twitter have value? Int. J. Wine Bus. Res. 24, 271-283.

Zaharieva, E., Gorton, M., and Lingard, J. (2004). An evaluation of marketing practices and market orientation in the Bulgarian wine industry. Post Communist Econ. 16, 229-243. doi: 10.1080/14631370420002 23903

Conflict of Interest: The authors declare that the research was conducted in the absence of any commercial or financial relationships that could be construed as a potential conflict of interest.

Copyright (c) 2019 Muñoz, Fernández and Salinero. This is an open-access article distributed under the terms of the Creative Commons Attribution License (CC BY). The use, distribution or reproduction in other forums is permitted, provided the original author(s) and the copyright owner(s) are credited and that the original publication in this journal is cited, in accordance with accepted academic practice. No use, distribution or reproduction is permitted which does not comply with these terms. 


\title{
Consumer Motivation in Developed Economies With Secular Stagnation
}

\author{
Fernando Evaristo Callejas-Albiñana ${ }^{1 *}$, Irene Martín de Vidales Carrasco ${ }^{2}$, \\ Isabel Martínez-Rodríguez ${ }^{1}$ and Ana Isabel Callejas-Albiñana ${ }^{3}$ \\ ${ }^{1}$ Department of Spanish and International Economy, Econometrics, History and Economic Institutions, University \\ of Castilla-La Mancha, Ciudad Real, Spain, ${ }^{2}$ Department of Political Economy and Public Finance, Economic Statistics, \\ Business and Economic Policy, University of Castilla-La Mancha, Ciudad Real, Spain, ${ }^{3}$ Department of Psychology, \\ University of Castilla-La Mancha, Ciudad Real, Spain
}

OPEN ACCESS

Edited by:

Alicia Izquierdo-Yusta University of Burgos, Spain

Reviewed by: Antonio Calvo,

CEU San Pablo University, Spain Antonio Sánchez,

University of Valencia, Spain

*Correspondence: Fernando Evaristo Callejas-Albiñana Fernando.Callejas@uclm.es

Specialty section: This article was submitted to

Organizational Psychology, a section of the journa Frontiers in Psychology

Received: 29 October 2019 Accepted: 15 November 2019 Published: 02 December 2019

Citation:

Callejas-Albiñana FE, Martín de Vidales Carrasco I,

Martínez-Rodríguez I and Callejas-Albiñana Al (2019) Consumer Motivation in Developed Economies

With Secular Stagnation.

Front. Psychol. 10:2697.

doi: 10.3389/fpsyg.2019.02697
In recent years, the slow pace of economic growth, high indebtedness, and high unemployment registered in most developed economies since 2009 have revived the debate over the "secular stagnation hypothesis" first formulated by the Keynesian economist Alvin Hansen in 1938. This return of the secular stagnation hypothesis occurred in November 2013, when Lawrence Summers postulated that the global economy was facing a scenario of low growth, low inflation, and a reduction in GDP per capita due to a chronic insufficiency of aggregate demand. The causes should be sought not only in cyclical factors associated with a long financial cycle and excessive accumulated public and private debt, but also in structural changes in the central economies in recent decades, linked to the rapid slowdown in population growth and the gradual aging of the population. Finally, other factors also depress demand, such as the progressive exhaustion of the globalization process and the consolidation of new labor models. In light of these developments, this paper's aim is twofold: first, to perform an econometric panel-data study in order to determine the influence of each of these factors in explaining secular stagnation in recent years for the selected sample of countries; and, second, to lay out proposals for reorienting the government intervention strategies adopted since the onset of the financial crisis to promote consumption and achieve sustained growth, job creation, and poverty reduction.

Keywords: secular stagnation, consumer motivation, financial cycle, technological innovation, social inequality

\section{INTRODUCTION}

In November 2013, Lawrence Summers revived the "secular stagnation hypothesis" first formulated by Keynesian economist Alvin Hansen in 1938. In doing so, he initiated an interesting debate on the state of developed country economies after the Great Recession, asserting that the global economy faced a scenario of low growth, low inflation, and a reduction in per capita GDP due to chronic insufficiency of aggregate demand.

This scenario is the starting point for the present research, which has a twofold objective. The first is to identify the short-term and structural factors that explain secular stagnation and perform an econometric panel-data study to analyze the influence of each one in recent years for the selected sample of countries. The second is to lay out proposals to reorient the government intervention strategies adopted since the onset of the financial crisis to promote sustained growth, job creation, 
and poverty reduction. To achieve these goals, one strategy to be taken into account is that of examining motivations for entrepreneurship, not only in terms of how the internal or external incentives provided by companies might contribute, as discussed in the classic organizational psychology theories of McClelland (1961) and Herzberg (1970), but also because of the interest of producing entrepreneurs to contribute to economic growth and job creation.

\section{MATERIALS AND METHODS}

\section{The Secular Stagnation Hypothesis: Origins and Explanatory Factors}

The secular stagnation hypothesis was first formulated by the economist and Keynes disciple Alvin Harvey Hansen (1887-1975) in his famous speech to the American Economic Association at its annual meeting in December 1938. ${ }^{1}$ Hansen argued that, due to certain structural characteristics (such as the declining population growth rate and scant technological advances), economies tended to show a greater propensity to save than to invest, slowing down economic growth (Sandoval and Morales, 2017: 58).

Precisely 1 year earlier, in 1937, the American economy had entered into a strong recession following a period of dynamism achieved through the implementation of the New Deal. Franklin Delano Roosevelt had adopted that plan in the spring of 1933 to overcome the serious effects of the Great Depression of 1929 (spectacular increase in unemployment, contraction of international trade, decline in wages, and a notable loss of purchasing power).

In keeping with the postulates of Keynesian theory, the New Deal defended the need for government intervention in the economy, that is, for the mobilization of public money to generate economic activity and purchasing power. It had two main dimensions, economic and social (Lozano, 2004; Serrano, 2010: 25-128).

(a) The economic dimension addressed the major problems in three key sectors:

- The financial system, by increasing government control over banking institutions in order to ensure their solvency, stimulates the granting of credits for business investment, and protects investors from possible fraud. In particular, two important regulations were enacted to restore confidence in the financial system:

○ "The Emergency Banking Act" (March 9, 1933) formulated a program to clean up the banking sector by which only those entities that proved to be sufficiently solvent were allowed to operate, granting them a guarantee from the Federal Reserve that insured 100\% of bank deposits (Federal Reserve, 2019b).

- "The Banking Act" (June 16, 1933), better known as the Glass Steagall Act, created the Federal Deposit Insurance Corporation; consolidated the limitations on

\footnotetext{
${ }^{1}$ For more detailed information, see Hansen (1939).
}

branch opening regulated in the McFadden Act of 1927; prohibited commercial banking from participating in the investment banking business; and provided for the elimination of interest on bank deposits (Federal Reserve, 2019a).

- Industry, by encouraging subsidies to industry to encourage its recovery ("National Industrial Recovery Act" of June 16, 1933), in addition to the undertaking of gigantic public works projects with a view to industrializing certain areas of the country (mainly the Tennessee River Valley) and creating millions of jobs.

- The agricultural sector, through the granting of compensation, with the primary aim of reducing the overproduction that had caused the prices of agricultural products and farmers' profits to plunge ("Agricultural Adjustment Act" of May 12, 1933).

(b) The social dimension encompassed intervention in two major areas:

- Labor, by regulating employer-worker relations, the minimum wage, and maximum working hours ("National Labor Relations Act" of July 6, 1935).

- Welfare, by promoting the creation of the first federal system of unemployment insurance and pensions, aimed at correcting the considerable existing social inequalities ("Social Security Act" of August 14, 1935).

However, as noted, most of the gains made during the economic recovery process beginning in 1934 were lost in late 1937, when the Roosevelt administration began to gradually reduce public spending and rein its expansionary monetary policies. The precarious state of the economy became apparent when, as these government support measures were withdrawn, unemployment rose from 14 to $19 \%$, affecting $>7$ million citizens, industrial production fell by $37 \%$, and family incomes fell by 15\% (Jones, 1980; Redondo, 2015). That was when Hansen put forward his hypothesis that there had not been a normal economic cycle, but rather a depression that could become "secular" if decisive action were not taken.

Indeed, this Keynesian economist claimed that the reduced possibilities of internal geographic expansion, the observed decline in population growth (probably due to the severity of the crisis), and the tendency for new technologies to use less capital than in the early stages of capitalist development would explain the inability of investment to generate the demand that would ensure full employment and the corresponding real output. As a result, savings would accumulate unused, and economic growth would plummet unless governments borrowed and spent to reactivate aggregate demand.

However, Hansen qualified his thesis, considering that the real cause of economic stagnation was the scarcity of profitable investment opportunities compared to earlier periods. Therefore, the solution would not be simply to stimulate demand through public spending and cheap financing. In other words, it was not only a problem of demand, but also supply, which the private sector alone was not capable of solving (Navascués, 2016). 
In short, according to his theory, demand had to be stimulated, but very selectively, to prevent any public spending from being diverted to superfluous objectives. To this end, nothing could be better than a public investment program that would generate positive side-effects for consumer spending and private investment, with a view, in particular, to improving the standard of living of lowincome social groups. At the same time, this spending program would have to be combined with a flexible tax program, allowing the basic rates on revenue to be adjusted within the limits set by the government, i.e., the adoption of a compensatory fiscal policy, enabling a corrective synchronization of public spending and taxes with the economic cycle (Antonelli, 1957).

Additionally, the supply side shortcomings would have to be corrected by improving education and training and promoting technological innovation. However, Hansen was quite skeptical of the government's management capacity, arguing, "We have not yet learned to make the Government an effective, flexible and sensitive instrument in a fluctuating and highly complex society, in a private enterprise society in which the State must take on the role not only of counterweight, compensating for the shortcomings of private investment, but also as a provider of very important public services and as an advocate of basic development programs" (Antonelli, 1957: 24).

The truth is that the economic recession that began in 1937 was short-lived, thanks largely to the immediate and forceful response of the Roosevelt administration. Disregarding the Treasury Department's recommendations to continue the efforts to balance the budget, it launched a $\$ 5$ billion spending program in the spring of 1938 to increase purchasing power.

This change in the orientation of the economic policy measures implemented enabled the rapid recovery of industrial production, which grew again to $30 \%$. The economic reactivation was also later linked to the expenses generated by the Second World War, which was an important stimulus factor and kept the level of activity very high.

So, time proved Hansen profoundly wrong, not only because of the fairly high birth rate of the baby boomers, but above all because of the high investment accompanied by unprecedented global growth. ${ }^{2}$ The secular stagnation hypothesis thus fell into oblivion for a long period of time.

\footnotetext{
${ }^{2}$ Specifically, the war industry became a dynamizing factor in the postwar American economy, with large companies such as General Electric and Westinghouse in atomic power plants, IBM in computers, and Boeing in civil aviation and space programs. This large industrial growth required more labor force, which contributed to the creation of millions of jobs and a significant increase in the volume of production. In addition, after World War II, President Harry S. Truman promoted a program aimed at the gradual suppression of state control in the economy, which established an ambitious reform of social expenditure to make it more efficient and less costly. In this way, a welfare state was built that made it possible to reduce social inequalities, thanks to the approval of a plan for social housing for families with lower incomes, the control of rents and agricultural subsidies, and improvements in civil rights, employment, education, public health, and social benefits. For a detailed analysis of the role of the public sector in economic activity and its contribution to growth and technological innovation, see Galbraith (1984) and Mazzucato (2014).
}

\section{The Current Economic Debate on Secular Stagnation}

However, in recent years, the slow pace of economic growth, the high level of indebtedness, and the high unemployment registered in most developed economies since 2009, due to both the serious damage caused by the Great Recession and structural changes the economy has been facing for several decades, have revived the debate over the secular stagnation hypothesis, in both the financial press and mainstream academic economics circles.

Indeed, in the summer of 2007, the global economy entered into a major financial crisis, including the collapse of the housing market, a sharp fall in asset prices, deleveraging of the domestic and financial sector, strict credit conditions, and a high degree of political uncertainty and instability. This state of affairs subsequently triggered a severe economic recession, indeed, the most intense, problematic, and prolonged of any experienced in the last 80 years. The crisis was especially harsh for the countries on the periphery of the euro zone, due to the excessive accumulated debt (Costas and Arias, 2015; Nash-Stacey and Karp, 2015).

Nevertheless, as noted, the fragile economic situation that has prevailed in industrialized countries since 2009 is not due solely to the effects of the recent systemic financial crisis and the persistence of large volumes of public and private off-balance-sheet debt. It is also due to structural changes that have been underway since 1980, such as the slowdown in population growth, the falling price of capital goods, and increasing income concentration, which hinder sustained longterm growth, i.e., a rate of economic growth compatible with full employment. The combined action of all these factors (cyclical and structural) results in excess savings over aggregate investment, which ultimately leads to a stagnation in economic activity, accompanied by strong deflationary tendencies (Pérez and Delbianco, 2015: 53).

Therefore, the return of the secular stagnation hypothesis in late 2013, at the hands of Summers, a Harvard economist and former U.S. Treasury Secretary under President Bill Clinton, took place in a context and in conditions similar to those that Hansen and other authors of the Keynesian school tried to explain and understand eight decades ago.

Speaking at the November 2013 International Monetary Fund (IMF) academic conference in honor of Stanley Fischer, Summers hypothesized that the world economy was in a situation of "secular stagnation," launching an interesting debate on the state of developed country economies after the Great Recession. ${ }^{3}$

According to his thesis, in their current structural configuration, central economies are incapable of simultaneously achieving satisfactory economic growth and minimum conditions of financial stability (Summers, 2014a: 29). In other words, the global economy is facing a scenario of low growth, low inflation, and a reduction in per capita GDP due to a chronic insufficiency of aggregate demand. The most visible manifestation of this phenomenon is the downward trend in interest rates, reflecting a greater propensity to save

\footnotetext{
${ }^{3}$ For a detailed study, see Summers (2013).
} 
than to invest, which inevitably translates to a loss of economic dynamism. In addition, the term "secular" used to qualify this situation implies a process of indefinite duration or, at least, a very long stagnation (Quirós, 2015).

This structural imbalance between aggregate savings and investment gives rise to the chronic insufficiency of demand and, thus, provides support for the secular stagnation hypothesis. It is basically due to the following long-term changes registered in central economies in recent decades (Pérez, 2015):

(a) The rapid slowdown in population growth since 1960, in the United States, Europe, and Japan, which has logically been accompanied by a reduction in the workforce. This, in turn, has had a negative impact on capital accumulation.

In addition, the notable change in the population's age structure, due to the declining birth rate and higher life expectancy, is a very important factor that could be driving savings up in the world, to the detriment of consumption, and, consequently, aggregate demand down. Specifically, the last 30 years have seen a significant increase in the size of the population group between the ages of 45 and 64 years. This group's economic behavior is strongly conditioned by the need to maintain a certain standard of living after retirement and it thus tends to save more. The current existence of very weak or even non-existent public or pay-as-you-go pension systems must also be taken into account in this regard.

In short, demographic variables are clearly hampering aggregate demand, not only because of lower population growth in the main developed countries, but also because of the significant expansion of the population strata that are more likely to save (Martí, 2017a).

(b) The fall in total factor productivity (TFP) ${ }^{4}$ caused by a paralysis in technological innovation, especially following the onset of the financial crisis in 2007, and/or because new information technologies and digitization do not have as significant an impact on real economic activity as the manufacturing technologies of the twentieth century did (e.g., internal combustion, electricity, automobiles, aviation, telephony, television, lasers, the Internet, or mobile telephony).

In contrast to this "pessimism" regarding future technological progress, highlighted by neo-Keynesian economists such as Gordon (2012), ${ }^{5}$ other authors, such as the University of California economic historian Eichengreen (2014) and Eichengreen et al. (2015), argue that the reasons for the stagnation of production and

\footnotetext{
${ }^{4}$ According to the Spanish National Statistics Institute (INE), TFP is the difference between the production growth rate and the average growth rate of the factors used to obtain it, which are weighted by the share of national income that each factor accounts for. In other words, the sum of the contributions of productive factors (labor and capital) and TFP is the same as the rate of change of GDP.

${ }^{5}$ In addition to the paralysis in technological innovation, Gordon (2014) argues that economic growth will continue to be slow over the next 25-40 years because of four "headwinds": an aging population; lower secondary school and university completion rates, coupled with greater difficulties for university graduates to find jobs suited to their education; inequality in income distribution; and high public indebtedness.
}

total productivity should be sought in the failure of some developed countries, such as the United States, to invest in infrastructure, education, and training, rather than in the scarcity of potentially revolutionary innovations. ${ }^{6}$ In other words, to achieve sustained economic growth, it is not enough to increase investment in R\&D; it is also necessary to ensure that the economy is capable of reallocating production factors to their most efficient uses.

Additionally, one widespread argument notes that the service sector, where productivity growth is significantly slower than in the industrial sector, tends to account for an increasing share of advanced economies, in terms of both real output and job creation (Bach, 2016).

(c) The growing inequality in income and wealth distribution ${ }^{7}$ is another key explanatory factor for the greater aggregate marginal propensity to save witnessed in developed countries in recent years. Indeed, because the economic actors with the highest incomes are more likely than the poorest ones to save money rather than spend it, increasing inequality will dampen consumption, the financial position of the middle class, and, ultimately, the growth of aggregate demand (Guillén and Ontiveros, 2014).

Summers also recognized that this structural imbalance between aggregate savings and investment is further explained by the increase in gross corporate savings, due to the rising share of profits in the income of major industrialized countries since the mid-1970s and early 1980s. In particular, this is the result of rising globalization since 1980 and the increase in technological progress over this period (Summers, 2014b).

Although they do not explicitly adhere to the secular stagnation thesis, other authors, including the French economist Thomas Piketty, argue that the strong increase in social inequality registered in developed countries over the last three decades, with the large-scale implementation of free-market postulates and financial deregulation, will inevitably translate to continued low economic growth accompanied by low population growth in the coming decades (Piketty, 2015).

(d) Other factors depressing aggregate demand, including the gradual exhaustion of the globalization process, which, after accelerating dramatically over the last 20 years, especially as a result of the Uruguay Round of the GATT-WTO ${ }^{8}$ and,

${ }^{6}$ In fact, some authors, such as Mokyr (2014), professor of economics and history at Northwestern University, argue that technological progress, particularly in areas such as computing, materials, and genetic engineering, has significant indirect effects on productivity growth via the tools that scientific research provides.

${ }^{7}$ The degree of inequality in a country is usually determined based on the available monetary income. Specifically, the distribution of this income is usually measured by defining population segments, starting with those with the lowest income, and determining what proportion of income corresponds to each one. To this end, the most commonly used indicator is the so-called Gini coefficient, which measures income inequality among the citizens of a given territory, usually a country. This index ranges from 0 to 1 , where 0 is the maximum equality (all citizens have the same income) and 1 is the maximum inequality (all income is owned by a single individual). Thus, the closer the coefficient is to 0 , the less inequality there will be; conversely, the closer it is to 1 , the more the inequality will grow (Torres, 2016).

${ }^{8}$ The eighth round of multilateral trade negotiations (Uruguay Round) resulted in the largest reform of the world trading system since the creation of the General 
above all, China's entry into the Organization on December $11,2001,{ }^{9}$ has come to a virtual halt. As a consequence, the world stock of productive capital is already largely adapted to the current scheme of comparative and competitive advantages in the international trade system. This will probably be associated with lower rates of economic growth due to the progressive exhaustion of this source of generation of new investments (Martí, 2018).

Finally, another factor that could currently be contributing decisively to the increase in savings worldwide and, therefore, to the stagnation of aggregate demand is the consolidation of new employment models. These models are largely characterized by less employment stability, i.e., an erosion of permanent employment coupled with a strong trend toward temporary employment. These temporary contracts are being used by entrepreneurs not only to cover companies' short-term needs, but also as an instrument for providing external and internal flexibility to their productive organizations.

The intensely precarious nature of this new employment (the so-called "gig economy") has had a clearly negative impact on public social security systems and, more specifically, on unemployment protection systems, unbalancing them financially. One immediate consequence of the greater labor risks assumed by a good number of workers would be an increase in the level of savings, in order to cope with any contingencies that might arise and, thus, weaker consumption. This behavior might also be more likely to manifest among workers with higher salaries, since, in their case, public sector insurance would cover a smaller part of their previous labor income (Cavas-Martínez, 2005; Martí, 2017b).

In short, although the international economic situation has improved comparatively in recent years, and has done so quite generally across countries and geographical areas, all these structural factors, coupled with the more typically short-term factors associated with the effects of the recent global financial crisis and the previously high levels of indebtedness (Koo, 2014), have considerably reduced domestic and corporate investment, significantly weakening aggregate demand (Table 1).

On the other hand, in recent years many economists have defended the effectiveness of actions on aggregate supply to increase the productive potential of economies and achieve sustainable long-term growth. Thus, as mentioned at the beginning, it is possible to mitigate the current weakness of aggregate demand by considering the relevance of personal

Agreement on Tariffs and Trade (GATT) in 1948. It began in Punta del Este (Uruguay) in 1986 and concluded in Marrakech (Morocco) on December 15, 1993. Despite the challenges to be overcome, the Uruguay Round made significant efforts to establish a more open and transparent global trading system, both because of the large number of participants (123) and because of the importance of the issues addressed: the negotiation agenda on the access of goods to international markets; the first steps in the liberalization of international trade in services; the drafting of principles to guarantee the intellectual property incorporated in the goods and services exchanged and foreign investments in any country; and, finally, institutional agreements to replace the GATT with the World Trade Organization (WTO) (Zapata and Gabriele, 1994).

${ }^{9}$ For detailed information, see Adhikari and Yang (2002).
TABLE 1 | Explanatory factors of secular stagnation.

\begin{tabular}{lc}
\hline Short-term factors & Structural factors \\
\hline - Long-term financial cycle, & • Demographic factors: \\
accompanied by banking & $\checkmark$ Rapid slowdown in world population growth. \\
crises and growing tensions & $\checkmark$ Gradual aging of the world population. \\
in global financial markets. & • Declining TFP \\
- Excessive accumulated & - Increasing inequality in income and wealth \\
public and private debt & distribution \\
(balance sheet recession). & - Other factors depressing aggregate demand: \\
& $\checkmark$ Gradual exhaustion of the globalization \\
& process. \\
& $\checkmark$ Consolidation of new employment models: \\
& less job stability. \\
\hline
\end{tabular}

factors of entrepreneurship, as the motivation of achievement, being a characteristic of the personality that allows to relate with the success of the created companies (Barba and Atienza, 2011).

As noted at the start of this paper, certain factors related to individual entrepreneurship can partially mitigate this effect, such as the motivation of achievement characteristic of personalities associated with the success of created companies (Barba and Atienza, 2011).

In this context, Shapero (1985) considers that the decision to start a company depends on two types of personal perceptions having to do with values related to culture, socioeconomic status, family, education, and influential people: the perceived feasibility and the perceived desirability of starting one.

Many theories of human motivation have sought to identify the factors that define the entrepreneurial behavior that improves a country's economy and that drive successful behaviors in this regard, using the personality of entrepreneurs as a source. For example, Paturel (1997) identifies three factors: the future entrepreneur's aspirations, his or her skills and resources, and the opportunities afforded by the market.

These types of incentivized strategies (to encourage entrepreneurs) work on several fronts: the decline in productivity, which they slow, albeit moderately, since the entrepreneur him or herself is the beneficiary of the work's results; supply (direct for this worker profile); and demand, since rental income increases and so, thus, will consumption.

\section{RESULTS}

\section{Empirical Analysis}

The main objective of this empirical study is to determine which factors explain a possible secular stagnation of the economy. To this end, the impact of such factors on economic growth is quantified using the statistical method of panel data analysis ${ }^{10}$ with a sample of 12 countries (sufficient statistical information) around the world ${ }^{11}$ and time series from 1998 to 2017.

\footnotetext{
${ }^{10}$ The econometric modeling software used has been Stata.11 (Statacorp, 2009).

${ }^{11}$ The 12 selected countries are those that the World Bank considered global powers in 2017, as they had registered the highest level of GDP per capita over the period: Brazil, China, Canada, France, Germany, India, Italy, Japan, Korea, Spain, the United Kingdom, and the United States.
} 
An econometric panel-data model includes a sample of economic agents or stakeholders (individuals, firms, banks, cities, countries, etc.) for a given period of time, i.e., it combines both short-term and structural data (Mayorga and Muñoz, 2000). Specifically, here this model is used to study the impact of a set of short-term and structural variables on the economic growth of the 12 selected countries. The countries selected for the model lend themselves to the fixed-effects estimation method.

With panel sectional time series data, the most commonly estimated models are probably fixed effects (FEs) and random effects models, so is important to establish which of them is the most adequate. ${ }^{12}$ Several considerations affect the choice between a FE and a random effects model (see Allison, 2009) but, in this case three points have been considered.

Firstly, the nature of the variables that have been omitted from the model are correlated with the variables in the model so, FE models may provide a means for controlling for omitted variable bias. Secondly, the subjects (countries, in this case) change across time and there is within-subject variability in the variables, so a FE model is more convenient. Thirdly, the subjects are not randomly selected, but they are selected with a specific criterion. Specifically, those considered as world powers by the World Bank in 2017 (by registering a higher level of GDP per capita). So, the preliminary choice of countries determines that the FEs be the most appropriate method.

In short, for all that, the estimation must be made with FE.

The variables were selected to represent the short-term and structural factors explaining secular stagnation shown in Table 1. In all, 18 variables were selected (Supplementary Table 1):

- Variables representing short-term factors. Initially, a total of four variables representing the financial cycle and excessive public and private debt were considered, of which two were significant for the final models: stocks traded (total value as $\%$ of GDP $)^{13}$ and total debt (current euros) (Table 2).

- Variables representing structural factors. Initially 10 variables were considered, representing demographic factors, factors depressing aggregate demand, growing inequality in income and wealth distribution, and TFP.

\footnotetext{
${ }^{12}$ The Hausman test is used to determine the most appropriate estimation method - FEs or random effects (REs) - in order to obtain the most robust parameters in each case. In this analysis no test has been made because of an algebraical problem. However, the characteristics of the sample mentioned determine that the FEs be the most appropriate method.

${ }^{13}$ The value of the stocks traded is the total number of shares traded, both domestic and foreign, multiplied by their respective matching prices. Only part of the transaction is considered. Companies admitted to listing and admitted to trading are included in the data. Data are year-end values.
}

Of these, five were ultimately significant for the final models: total unemployment (\% of total workforce), population aged 65 years or over ( $\%$ of total), TFP growth (original), TFP growth (adjusted), and TFP at current prices (USA $=1$ ) (Table 3$)$.

- Variables representing economic growth (and thus secular stagnation). Initially, a total of four representative variables were considered, of which three were ultimately significant for the final models: GDP growth (annual \%), GDP growth per capita (annual \%), and GDP per capita (US\$ at current prices) (Table 4).

As seen in the correlation matrix (Supplementary Dataset 1), there is no serious multicollinearity among the independent variables because the most variables correlate from very slight to moderate $(0.004 \leq r \geq 0.5)$. This indicates that the different measurement scale of the independent variables does not affect the relation among them. However, following the guidelines by Afifi et al. (2012), the indicators with a correlation $>0.5$ are not included in the same econometric model.

The regression model results (Supplementary Dataset 2) by using panel data estimation are shown in Table 5. These models suggest that it is valid $(P=0.05$ or $P=0.01)$ to study and analyze GDP (measured by GDP growth, GDP growth per capita, and GDP per capita) through the structural and short-term factors considered (Tables 2, 3).

Next, three exploratory models of GDP were proposed because three variables representative of GDP were finally significant for the definitive models: GDP_P (Model 1), GDP_PCP (Model 2), and GDP_PC_N (Model 3) (Table 4). Furthermore, considering that the aim of this empirical study is to demonstrate which factors explain a possible secular stagnation of the economy, GDP is the most appropriate endogenous variable.

Based on an analysis of these estimates of the most representative models, the following can be concluded:

- Model 1: $\widehat{\mathrm{GDP} \_P}=6.488-\left(0.167 * \mathrm{P} 65 \_\mathrm{P}\right)-(0.263 * \mathrm{UNE})$ $+(1.28 *$ TFPO): The percentage of annual GDP growth is directly explained, to a greater or lesser extent, by the total productivity growth of the original factors, ${ }^{14}$ directly, and

\footnotetext{
${ }^{14}$ The Total Economy Database (TED) is structured in two parts: TED1, containing output, labor, and productivity data, and TED2, containing growth data. This latter part, in turn, includes two versions of the data: (1) The Conference Board (TCB) Adjusted: For the calculation of the adjusted version of data, GDP growth rates are adjusted for several countries. More specifically, GDP deflators are used for three countries with significant ICT production and trade: China, Japan, and the United States. This translates to higher real GDP growth rates for these countries compared to the original data version. (2) The Conference Board (TCB) Original: Based on official GDP data for the period after 1990 that do not reflect the rapid declines in ICT goods.
}

TABLE 2 | Variables corresponding to the short-term factors explaining secular stagnation.

\begin{tabular}{llll}
\hline Indicator & Factor & Database & Acronym \\
\hline Stocks traded, total value (\% of GDP) & Financial cycle & World Federation of Exchanges database \\
Stocks traded, total value (current US\$) & Financial cycle & World Federation of Exchanges database \\
Total debt & Excessive debt & Datosmacro.com & ST_P \\
Total debt (per capita) & Excessive debt & Datosmacro.com & ST
\end{tabular}


TABLE 3 | Variables corresponding to the structural factors explaining secular stagnation.

\begin{tabular}{|c|c|c|c|}
\hline Indicator & Factor & Database & Acronym \\
\hline Unemployment, total (\% of total workforce) & Aggregate demand & International Labour Organization, ILOSTAT database (updated 2017) & UNE \\
\hline Gini index & Inequality & World Bank, Development Research Group & GINI \\
\hline Population growth (annual \%) & Demographics & $\begin{array}{l}\text { (1) United Nations Population Division: World Population Prospects; (2) Census } \\
\text { reports and other statistical publications by national statistics bureaus; (3) } \\
\text { Eurostat: Demographic Statistics; (4) United Nations Statistical Division: } \\
\text { Population and Vital Statistics Report (various years); (5) U.S. Census Bureau: } \\
\text { International Database; and (6) Secretariat of the Pacific Community: Statistics } \\
\text { and Demography Programme. }\end{array}$ & PG_P \\
\hline Population aged 65 years and over (total) & Demographics & $\begin{array}{l}\text { World Bank. Based on the United Nations Population Division's World } \\
\text { Population Prospects age/sex distribution (updated 2017) }\end{array}$ & P65 \\
\hline Population aged 65 years and over (\% of total) & & & P65_P \\
\hline Population aged 0-14 (\% of total) & & & P14 \\
\hline TFP at current prices $(U S A=1)$ & TFP & Penn World Table, version 9.0 & CTFP \\
\hline TFP at constant national prices $(2011=1)$ & & & RTFPNA \\
\hline TFP growth (adjusted) & & The Conference Board (TCB). Total Economy Database. & TFPA \\
\hline TFP growth (original) & & & TFPO \\
\hline
\end{tabular}

aFeenstra et al. (2015).

TABLE 4 | Variables corresponding to indicators of secular stagnation.

\begin{tabular}{lll}
\hline Indicator & Database & Acronym \\
\hline GDP growth (annual \%) & $\begin{array}{l}\text { World Bank national } \\
\text { accounts data and OECD } \\
\text { national accounts data }\end{array}$ & GDP_P \\
GDP growth per capita (annual \%) & & GDP_PCP \\
$\begin{array}{l}\text { GDP per capita (current US\$) } \\
\text { GDP per capita (constant local } \\
\text { currency) }\end{array}$ & GDP_PC_N \\
\hline
\end{tabular}

indirectly by the unemployment rate and the percentage of the population aged 65 years or older.

- Model 2: GD $\widehat{\text { P_P_PCP }}=6.316+(1.63 e-07 * \mathrm{TD})-$ $(0.168 * \mathrm{UNE})-\left(0.255 * \mathrm{P} 65 \_\mathrm{P}\right)+(1.244 * \mathrm{TFPA}):$ The second model, the percentage growth of annual GDP per capita is explained, gradually from a greater to a lesser extent, by the adjusted TFP growth, directly, and indirectly by the percentage of the population aged 65 years or over and the unemployment rate. Total debt had a positive impact.

- Model 3: GDP_PC_N $=82772.01+(30.846 *$ ST_P $)-$ $(71329 *$ CTFP $)-(499.877 *$ UNE): In the third model, the total value of stocks traded (as a percentage of GDP) has a direct impact on changes in nominal GDP per capita and counteracts the negative effect exerted by unemployment and TFP (at current prices).

Additionally, the interpretation of the standardized coefficients $^{15}$ obtained in three models (Table 5) makes it possible to conclude which structural and short-term

${ }^{15}$ When measurement scale of the independent variables is different (Tables 2, 3), standardized coefficients must be used to interpret and compare their effects on your dependent variable. The standardized coefficients obtained in the three models are not an output of Stata software, but have been calculated directly from the unstandardized coefficients along with the standard deviations of the variables factors explain the behavior of GDP (and, consequently the economic secularization of developed economies) for the established period to the greatest extent. The interpretation is simple: the higher the value of standardized coefficients, the bigger the effect of the factor on GDP. It can thus be concluded from these models that the short-term and structural factors explaining the economic secularization of developed economies could be summarized, in order of relevance $\left(^{*}\right)$, as follows (Table 6).

If these models are considered as a whole, clear conclusions can be drawn:

(1) Except for the income and wealth inequality factor (GINI), the other indicators (financial cycle, excessive debt, demographic characteristics, fall in TFP, and other factors depressing aggregate demand such as unemployment) seem to significantly explain secular stagnation in advanced economies.

(2) TFP is the factor that most positively affects GDP growth, except in Model 3, where the endogenous variable to be explained is not the growth rate but the nominal value of GDP per capita.

(3) The structural factors explain secular stagnation to a greater extent than the short-term ones. Two of the structural factors are of particular importance: the unemployment rate (UNE) and the aging of the population (P65_P).

\section{Economic Policies to Combat Secular Stagnation}

The econometric panel-data study performed indicates the influence of each explanatory factor with regard to secular stagnation in recent years for the selected sample of countries. Based on these findings, some proposals can be made to enable the government intervention strategies adopted since the onset

$$
\widehat{\beta}_{\mathrm{J}}^{*}=\widehat{\beta}_{\mathrm{J}} * \frac{\mathrm{SD}\left(\mathrm{X}_{\mathrm{j}}\right)}{\mathrm{SD}(\mathrm{Y})}
$$


TABLE 5 | Regression results: estimation with panel data.

\begin{tabular}{|c|c|c|c|c|c|}
\hline \multirow[t]{4}{*}{ Variable } & & & \multicolumn{3}{|c|}{ Dependent variable } \\
\hline & & \multirow[b]{3}{*}{ (1) } & \multicolumn{2}{|r|}{ GDP growth per capita (annual \%) } & \multirow[t]{2}{*}{ GDP per capita (US\$ at current prices) } \\
\hline & & & \multicolumn{2}{|c|}{ Standardized coefficients (Student's $t$-values) } & \\
\hline & & & Model 1: GDP_P & Model 2: GDP_PCP & Model 3: GDP_PC_N \\
\hline $\begin{array}{l}\text { Stocks traded, total value } \\
\text { (\% of GDP) }\end{array}$ & (ST_P) & $(\mathrm{SH})$ & & & $0.118(2.62)^{* *}$ \\
\hline Total debt & (TD) & $(\mathrm{SH})$ & & $0.159(2.23)^{* *}$ & \\
\hline Unemployment rate & (UNE) & (ST) & $-0.312(-7.27)^{* * *}$ & $-0.206(-4.30)^{* * *}$ & $-0.123(-2.59)^{* *}$ \\
\hline $\begin{array}{l}\text { Population aged } 65 \text { years } \\
\text { and over (\% of total) }\end{array}$ & (P65_P) & $(\mathrm{ST})$ & $-0.273(-3.28)^{* * *}$ & $-0.418(-3.85)^{* * *}$ & \\
\hline $\begin{array}{l}\text { TFP at current prices } \\
(U S A=1)\end{array}$ & $(\mathrm{CTFP})$ & $(\mathrm{ST})$ & & & $-1.045(-9.96)^{* * *}$ \\
\hline $\begin{array}{l}\text { Total productivity growth } \\
\text { (adjusted factors) }\end{array}$ & (TFPA) & $(\mathrm{ST})$ & & $0.743(19.86)^{* * *}$ & \\
\hline $\begin{array}{l}\text { Total productivity growth } \\
\text { (original factors) }\end{array}$ & (TFPO) & $(\mathrm{ST})$ & $0.739(23.19)^{* * *}$ & & \\
\hline Statistical models & & & $n=228 F=200.18^{* * *} R^{2}$ set $=0.78$ & $n=219 F=108.71^{* * *} R^{2}$ set $=0.73$ & $n=196 F=34.33^{* * *} R^{2}$ set $=0.49$ \\
\hline
\end{tabular}

(1) Factor the variable represents: $(S H)$, short-term factor; (ST), structural factor. $* * P=0.05, * * * P=0.01$.

of the financial crisis by the main developed economies to be reoriented toward the pursuit of sustained growth, job creation, and poverty reduction.

The worsening of the financial crisis in 2008 included the fall of large financial institutions in the United States and Europe, increased government support of the financial system, and an increasingly clear reflection of the turbulence of the financial markets in real economic activity. This situation prompted the G20 leaders to meet for a summit in Washington, held on November 15 , to analyze the situation jointly, testimony to the international cooperation effort to implement mechanisms to emerge from the crisis.

In this first phase of the crisis (2008-2009) the G20 action plan was based mainly on the following measures (G20, 2008):

(a) Implementation of expansionary macroeconomic (monetary and fiscal) policies to rapidly stimulate domestic demand:

- At the monetary level, the central banks of the main economies slashed interest rates to encourage household and business consumption and investment in order to boost economic activity and inflation. Additionally, some central banks, especially the U.S. Federal Reserve (Fed), implemented unconventional monetary policy instruments (Boards of Governors of the Federal Reserve System, 2019): forward guidance strategies, indicating the orientation of monetary policy with respect to the future evolution of official interest rates, conditional on the prospects for price stability; and quantitative easing (QE), i.e., purchase of medium- and long-term bonds, making it possible to raise their prices and, thus, reduce their market interest rates.

- At the fiscal level, discretionary measures were adopted to stimulate the economy, mainly based on increased public
TABLE 6 | Explanatory power of factors with regard to secular stagnation.

\begin{tabular}{lccc}
\hline Variable & Model 1 & Model 2 & Model 3 \\
\cline { 2 - 4 } & GDP_P & GDP_PCP & GDP_PC_N \\
\hline TFPO & ST*** & & \\
TFPA & & $\mathrm{ST}^{* * * *}$ & \\
CTFP & & & $\mathrm{ST}^{* * *}$ \\
UNE & $\mathrm{ST}^{* *}$ & $\mathrm{ST}^{* *}$ & $\mathrm{ST}^{* *}$ \\
P65_P & $\mathrm{ST}^{*}$ & $\mathrm{ST}^{* * *}$ & \\
TD & & $\mathrm{SH}^{*}$ &
\end{tabular}

ST_P

$\mathrm{SH}^{*}$

ST, structural factor; SH, short-term factor. The number of asterisks (*) before a structural (ST) or short-term (SH) factor identifies the degree of relevance in explaining the endogenous variable of each model: one asterisk (*) means the minimum degree, two asterisks $\left.{ }^{* *}\right)$ mean a greater degree, three asterisks, $\left.{ }^{* * *}\right)$ mean a greater degree, and four asterisks ${ }^{(* * *)}$ mean the maximum degree.

spending, tax cuts, and aid for the groups and economic sectors hit hardest by the crisis.

(b) Approval of programs to bail out the financial system intended to increase its strength and solvency and thus facilitate the flow of credit to businesses and consumers in order to reactivate the real economy.

(c) Reform of the international financial architecture, with the priority of strengthening the regulation, oversight, and risk management of the international financial system in order to avoid new systemic crises and mitigate their global impact should they occur.

As a result of these actions, world GDP entered into a phase of mild recovery in 2009, with a return to positive growth in the second half of the year that reached a high rate $(5.4 \%$ in real terms) in 2010. Furthermore, 
TABLE 7 | Economic policy measures to combat secular stagnation.

\begin{tabular}{|c|c|}
\hline Time scope & Economic policy measures and recommendations \\
\hline $\begin{array}{l}\text { 1st phase of the } \\
\text { crisis (2008-2009) }\end{array}$ & $\begin{array}{l}\text { - Expansive macroeconomic (monetary and fiscal) policies } \\
\text { to stimulate aggregate demand } \\
\text { - Financial system rescue programs } \\
\text { - Reform of the international financial architecture }\end{array}$ \\
\hline $\begin{array}{l}\text { 2nd phase of the } \\
\text { crisis (2010-2013) }\end{array}$ & $\begin{array}{l}\text { (a) United States } \\
\text { 2010-2011: } \\
\text { - Unconventional monetary stimulus measures } \\
\text { - Budgetary stimulus measures. } \\
\text { 2012-2013: } \\
\text { - New monetary stimulus programs } \\
\text { - Fiscal policy aimed at reducing high levels of } \\
\text { indebtedness } \\
\text { (b) Euro zone } \\
\text { - Expansive monetary policy } \\
\text { - Contractive fiscal policy aimed at correcting the strong } \\
\text { imbalances in public accounts (fiscal consolidation) } \\
\text { - Structural reform programs } \\
\text { - Reform of European economic governance (six-pack, } \\
\text { two-pack, Budgetary Pact, reform of financial } \\
\text { supervision, and creation of the ESM) }\end{array}$ \\
\hline $\begin{array}{l}\text { Recovery phase } \\
\text { (2014-2017) }\end{array}$ & $\begin{array}{l}\text { (a) United States } \\
\text { - Monetary policy normalization process } \\
\text { - Fiscal expansion plans } \\
\text { (b) Euro zone } \\
\text { - Expansive orientation of monetary policy } \\
\text { - Advances in the institutional design of the EMU: } \\
\text { creation of the European Banking Union }\end{array}$ \\
\hline $\begin{array}{l}\text { Future prospects } \\
\text { (euro zone) }\end{array}$ & $\begin{array}{l}\text { (a) More active fiscal policy } \\
\text { - Increases in public investment at the heart of the euro } \\
\text { zone } \\
\text { - Fiscal consolidation policies and more structural } \\
\text { measures on the periphery (rebalancing the tax burden } \\
\text { and improving public-sector efficiency) } \\
\text { (b) Structural reform policies: Europe } 2020 \text { Strategy (smart, } \\
\text { sustainable, and inclusive growth): } \\
\text { - Jobs and careers } \\
\text { - Research and development } \\
\text { - Climate change and energy } \\
\text { - Education } \\
\text { - Poverty and social exclusion }\end{array}$ \\
\hline Future prospects & (a) Fiscal policy \\
\hline (United States) & $\begin{array}{l}\text { - Public infrastructure } \\
\text { - Education } \\
\text { - R\&D } \\
\text { (b) Redistributive policies } \\
\text { - Combat inequality } \\
\text { (c) Structural reforms } \\
\text { - Improving the Social Security network } \\
\text { - Human capital formation }\end{array}$ \\
\hline
\end{tabular}

international financial markets stabilized, volatility and risk aversion markedly declined, asset prices rebounded, and some segments of the capital markets gradually reopened (Banco de España, 2017b: 71).

However, in Europe, and especially in the peripheral countries of the euro zone, due to their greater fiscal and financial vulnerability and worse prospects for economic growth, this recovery process was derailed in early 2010 by the emergence of the first episodes of the sovereign debt crisis, caused by the distrust surrounding the state of Greek public finances.

The origin of this new phase of the crisis was the accumulation by these peripheral countries of significant macroeconomic and financial imbalances during the previous period of economic expansion (1996-2006). These imbalances were mainly associated with the high indebtedness of the private sector, soaring home prices, the excessive concentration of credit in the construction sector and real estate development, overdependence on external financing, and the accumulation of competitiveness losses in their economies (Banco de España, 2017a).

This instability in the euro zone's sovereign debt markets, which resulted in higher yields on the peripheral countries' public debt and a considerable increase in the risk premium, hampered their capacity for budgetary adjustment and the recovery of economic activity.

In this environment, the economic policies implemented from 2010 on in the United States and Europe became markedly divergent:

(a) In the United States, the Fed continued to adopt unconventional monetary stimulus measures, based on the expansion of the QE program. QE2 was announced on November 3, 2010 and lasted until June 2011. It consisted of the purchase of 600 billion dollars in Treasury bonds, with the aim of keeping interest rates low, making real estate more affordable, and slightly increasing inflation. New fiscal stimulus measures were also implemented in the area of fiscal policy.

The worsening of the economic crisis in 2012 and 2013 led to the approval of two more programs in the area of monetary policy: Operation Twist, an extension of QE2, consisting of the purchase of Treasury notes to influence the economy's long-term interest rates; and $Q E 3$, consisting of new purchases of mortgage-backed securities and Treasury bonds.

However, there was an important change in the direction of fiscal policy strategy during this period, basically geared toward reducing the high levels of public deficit and public debt generated by the weakness of real economic activity.

(b) In the euro zone, especially since mid-2012, due to the serious relapse of economic activity, an expansive monetary policy has continued to be implemented. This policy has mainly been based on reductions in the official interest rates by the European Central Bank, auctions of long-term loans to credit institutions, and reductions in the cash ratio (European Central Bank, 2018).

However, fiscal policy took a clearly contractive turn beginning in 2010, due to the growing instability and uncertainty in sovereign debt markets. During this period, the main priority of government budgetary strategies, especially those of governments that had required external financial assistance, given the explicit conditionality of those programs, was to correct the heavy imbalances 
recorded in the public accounts (Costas and Arias, 2015). In addition to fiscal consolidation measures aimed at reducing the public deficit and redirecting public debt toward a sustainable path, multiple structural reform programs were also implemented covering many areas, including the labor and product market and the public and financial sectors.

In short, this package of fiscal austerity and reform measures sought to achieve more competitive and efficient economies in order to boost sustained growth and job creation, sound public finances geared toward sustainability, a less indebted private sector, and a banking system with a greater capacity to provide credit to the real economy and support recovery (MontoriolGarriga, 2015; Rosnick and Weisbrot, 2015).

In addition, from 2010 onward, in order to ensure the stability of the European Economic and Monetary Union, an in-depth reform of European economic governance was carried out, based mainly on initiatives aimed at strengthening the surveillance of budgetary policies. The main objectives were (a) to achieve an appropriate balance between the sustainability of public accounts and the need to maintain the stabilization function of fiscal policy, (b) to reform the structure of financial supervision in the Union, and (c) to create a permanent mechanism for safeguarding financial stability of the Eurozone (European Stability Mechanism) (Subdirección General de Economía Internacional, 2012; Eur-Lex, 2014; European Commission, 2019; Callejas et al., 2017; Ministerio de Economía Industria y Competitividad, 2019).

All the measures implemented since 2010 allowed for increased deleveraging of the private sector, improved labor markets, increased confidence, and reduced instability in financial markets, which translated to a significant change in growth dynamics by the end of 2013 .

Thus, in 2014, the world economy embarked on a path of gradual recovery, with the developed economies receiving a particular boost, thanks to the recent strong performance of international trade, linked to the greater strength of investment (European Central Bank, 2015-2018).

This favorable outlook is also supported by three fundamental factors (Banco de España, 2018):

(a) In contrast to the normalization process followed by the Fed's monetary policy, the European Economic and Monetary Union has maintained an expansive orientation in this area. Indeed, since spring 2014, the Governing Council of the European Central Bank has been deploying a broad package of measures to avoid the risks to real economic activity arising from the prolongation over time of an excessively low inflation rate.

These actions focus on four basic strategic lines (Banco de España, 2016): the establishment of a negative interest rate for the deposit facility ${ }^{16}$; the communication and publicity policy for future monetary policy orientations;

\footnotetext{
${ }^{16}$ The Eurosystem's standing facility, which counterparts (the euro zone credit institutions with which the Eurosystem conducts certain monetary policy operations) may use to make overnight deposits with a national central bank remunerated at a pre-specified interest rate (Banco de España, 2019).
}

the implementation of specific programs aimed at favoring the proper functioning of transmission mechanisms through banking intermediaries and credit supply; and the implementation of a QE program, consisting of the largescale purchase of private and public assets.

(b) The approval of fiscal expansion plans in the United States, which include a tax cut and increased infrastructure spending.

(c) Important advances in the institutional design of the European Economic and Monetary Union with the creation of the European Banking Union, which emerged as a step toward financial integration, i.e., toward the single market in financial services, and, in short, toward perfecting the construction of the euro, by restoring the proper functioning of euro zone monetary policy and confidence in the European banking sector (European Central Bank, 2019).

However, despite recent improvements in the international macroeconomic situation, there are still major pockets of risk, especially in the euro zone economies. This risk is mainly associated with uncertainty about the economic policies implemented in the United States and the process of the United Kingdom's exit from the European Union, in a context marked by persistently high unemployment in some countries (19\% in Greece and $15.3 \%$ in Spain in 2018), low growth rates (1.9\% in the eurozone in 2018), weaknesses in some financial institutions, and an expected rate of medium-term inflation $<2 \%$, despite the recent upturn in energy prices ( $1.8 \%$ in the euro zone in 2018). In addition, population aging is more pronounced in European economies, and productivity growth and fiscal consolidation are progressing at a much slower pace than in the United States (Crafts, 2014: 93).

For this reason, and especially as monetary policies are brought back to normal, a process that, as noted, has already begun in the United States, since it is in a more advanced stage of the economic cycle, it is necessary to consider the role that a more active fiscal policy could play in reactivating economic activity within the European Economic and Monetary Union (Wolff, 2014: 149).

In this regard, in keeping with Hansen's initial approach, increased public investment in the countries at the heart of the eurozone, which now have more budgetary room for maneuver, could have positive effects for all Member States. Additionally, although peripheral countries must continue with fiscal consolidation policies to ensure the mediumand long-term sustainability of public accounts, they can also adopt more structural measures aimed at rebalancing the tax burden toward less distorting figures for private activity and, in particular, to enhance public-sector efficiency and synergy with the private sector (by better matching wages to the sector's productivity, modernizing government through the incorporation of new digital technologies, and increasing collection efficiency) (Aspachs et al., 2016; Banco de España, 2017c). 
Furthermore, given the importance of structural factors in explaining the sluggishness of global economic activity in recent years, as seen in the empirical analysis above, to promote sustained and sustainable long-term growth, it is essential to continue implementing structural reform policies in different economic sectors, aimed at boosting productivity growth and adequately complementing shortterm stabilization policies (monetary and fiscal measures) (Jimeno et al., 2014).

In this regard, it is worth highlighting the need to continue making progress on meeting the different objectives established in the European Union's growth and employment agenda for the current decade, i.e., the Europe 2020 Strategy. The strategy highlights "intelligent, sustainable and inclusive growth as a way of overcoming the structural deficiencies of the European economy, improving its competitiveness and productivity and sustaining a sustainable social market economy" (European Commission, 2019).

In particular, the action lines of the Europe 2020 Strategy focus on five main areas (Eur-Lex, 2017):

(a) Employment: achieve a minimum employment rate of $75 \%$ for the population aged 20-64 years.

(b) Research and development (R\&D): invest $3 \%$ of GDP in R\&D.

(c) Climate change and energy: reduce greenhouse gas emissions by at least $20 \%$, increasing the share of renewable energy sources in our final energy consumption to $20 \%$ and energy efficiency by $20 \%$.

(d) Education: reduce the drop-out rate to $<10 \%$ and increase the rate of higher-education qualifications to at least $40 \%$.

(e) Poverty and social exclusion: reduce the number of people living below the poverty line or at risk of social exclusion by 20 million.

At the same time, in order to continue boosting the real economy, the United States should implement a fiscal policy aimed at promoting public infrastructure, education, and R\&D with a view to improving productivity, boosting potential economic growth, increasing the employability of groups that have lost their jobs, and reducing possible sources of financial instability. Furthermore, redistributive policies aimed at reducing inequality in income and wealth distribution (Berganza and L'Hotellerie-Fallois, 2017), coupled with structural reforms to improve the social safety net and human capital formation, would be needed to reduce the secular increase in the number of unemployed adults over the last four decades (Glaeser, 2014).

Table 7 offers a summary of the most relevant economic policy measures adopted at the international level since the onset of the economic and financial crisis, as well as the main proposals to reactivate real economic activity.

\section{DISCUSSION}

In addition to the more typically short-term factors associated with the effects of the recent global financial crisis and the previously high levels of public and private debt, the chronic insufficiency of aggregate demand, which would support the secular stagnation hypothesis, can be explained, mainly in the central economies, by long-term or structural changes in recent decades. These changes include: the rapid deceleration of demographic growth and gradual aging of the population; the fall in TFP; growing inequality in income and wealth distribution; the gradual exhaustion of the globalization process; and the consolidation of new labor models that undermine employment stability, among others.

The empirical analysis carried out in the present research quantified the impact of these short-term and structural factors on economic growth by means of an econometric panel-data study. The sample consisted of the 12 countries around the world that the World Bank considered powers in 2017, as they had the highest level of GDP per capita over a 20-year time horizon (1998-2017).

Tests were carried out, and three final valid models were selected, all of which explain economic growth.

Of the two groups of factors analyzed, the structural ones (demographic, TFP, income and wealth distribution, and employment) had a stronger influence on secular stagnation than the short-term ones (financial cycle and excessive accumulated public and private debt).

More specifically, in the three proposed models, TFP proved to be the most significant variable and the one to most greatly affect the evolution of growth in the economies under consideration. In contrast, the unequal distribution of income (as measured by the Gini index) did not seem to influence secular stagnation, as it was not significant in any of the proposed models.

Although the cyclical factors, quantified in the behavior of financial markets and in excessive public and private debt, did influence economic growth in two of the three proposed models, their influence was much smaller.

Consequently, given the importance of structural factors in explaining the sluggishness of economic activity in recent years, to promote sustained and sustainable growth in the long term, economic stabilization policies (monetary and fiscal) must be adequately complemented by structural reform policies.

In view of the difficulty of adopting policies to increase the birth rate and combat the problem of the rapid slowdown in the growth of the world population and its gradual aging, these structural measures should be aimed, in particular, at improving the employability of the most disadvantaged groups in the labor market, promoting $\mathrm{R} \& \mathrm{D}$, curbing climate change and encouraging energy savings, implementing training and education programs, and combating poverty and social exclusion.

Certainly, environmental factors and economic policies are determinant; human motivation also plays a critical role in the entrepreneurial process (Shane et al., 2003).

Measures and motivational factors must be offered to support the behavior of people with an entrepreneurial drive (Ajzen, 1991).

In short, all these policies will ultimately translate to improved productivity and competitiveness innovation and entrepreneurship, as key factors in promoting job creation, raising the potential growth of economies and economic and 
social cohesion. Consumers would thus perceive favorable expectations and secular stagnation would be avoided.

\section{DATA AVAILABILITY STATEMENT}

All datasets generated for this study are included in the article/Supplementary Material.

\section{AUTHOR CONTRIBUTIONS}

All authors listed have made a substantial, direct and intellectual contribution to the work, and approved it for publication.

\section{FUNDING}

This work was financed by group grants from the University of Castilla-La Mancha and co-financed by the European

\section{REFERENCES}

Adhikari, R., and Yang, Y. (2002). What will WTO membership mean for China and its trading partners? Finan. Dev. 39, 22-25.

Afifi, A., May, S., and Clark, V. A. (2012). Practical Multivariate Analysis. Boca Raton, FL: CRC Press.

Ajzen, I. (1991). The theory of planned behavior. Org. Behav. Hum. Decis. Process. 50, 179-211.

Allison, P. D. (2009). Fixed Effects Regression Models. Thousand Oaks, CA: Sage Publications.

Antonelli, M. (1957). La Política Fiscal y el Desarrollo Económico. Buenos Aires: University of Buenos Aires.

Aspachs, O., Campos, A., Gual, J., and Montoriol, J. (2016). La eficiencia del sector público, clave para la consolidación fiscal. Documentos de Economía CaixaBank 29.

Bach, P. (2016). Estancamiento secular, fundamentos y dinámica de la crisis. Estrategia Int. 29, 1-24.

Banco de España, (2016). El Efecto de las Políticas Monetarias del BCE en el Período Reciente. 79-107. Annual Report 2015. Banco de España, Madrid.

Banco de España, (2017a). Comparecencia del Gobernador del Banco de España ante la Comisión de Investigación de la crisis financiera de España y el programa de asistencia financiera en el Congreso de los Diputados. Available at: https://www.bde.es/f/webbde/GAP/Secciones/SalaPrensa/IntervencionesPubli cas/Gobernador/Arc/Fic/linde120717.pdf (accessed October 8, 2019).

Banco de España, (2017b). Informe Sobre la Crisis Financiera y Bancaria en España, 2008-2014. Madrid: Banco de España.

Banco de España (2017c). La política fiscal en la UEM. Ann. Rep. 2016, 123-152.

Banco de España (2018). Informe trimestral de la economía española. Econ. Bull. 2018, 3-51.

Banco de España (2019). Glosario de Política Monetaria. Available at: https:// www.bde.es/bde/es/utiles/glosario/glosarioPolt/indexF.html (accessed October $8,2019)$.

Barba, V., and Atienza, C. (2011). Reasons to create a new venture: a determinant of entrepreneurial profiles. Afr. J. Bus. Manag. 5, 11497-11504.

Berganza, J. C., and L'Hotellerie-Fallois, P. (2017). El impacto de las políticas económicas de Donald Trump. Cuadernos de Inform. Econ. 256, 97-107.

Boards of Governors of the Federal Reserve System, (2019). Monetary Policy. Available at: https://www.federalreserve.gov/monetarypolicy.htm (accessed October 8, 2019).

Callejas, F. E., Martínez, I., Callejas, A. I., Martín, and de Vidales, I. (2017). Assessing the growth of ethical banking: some evidence from Spanish customers. Front. Psychol. 8:782. doi: 10.3389/fpsyg.2017.00782
Union through the European Regional Development Fund. Research Group: Observatory of Innovation in Commercial Distribution (OIDC).

\section{ACKNOWLEDGMENTS}

The authors acknowledge and are grateful for the financial support provided. Financed by group grants from the University of Castilla-La Mancha and co-financed by the European Union through the European Regional Development Fund. Research Group: Observatory of Innovation in Commercial Distribution (OIDC).

\section{SUPPLEMENTARY MATERIAL}

The Supplementary Material for this article can be found online at: https://www.frontiersin.org/articles/10.3389/fpsyg. 2019.02697/full\#supplementary-material

Cavas-Martínez, F. (2005). El principio de estabilidad en el empleo: crisis y claves para su recuperación. Rev. Minist. Trabajo Asuntos Soc. 58, 113-133.

Costas, A., and Arias, X. C. (2015). Economía europea: ¿hacia el estancamiento secular? Instituto Universitario de Análisis Económico y Social. Working Document 06/2015. Spain: IAES.

Crafts, N. (2014). "Secular stagnation: US hypochondria, European disease?," in Secular Stagnation: Facts, Causas and Cures, eds C. Teulings, and R. Baldwin, (London: Centre for Economic Policy Research), 91-97.

Eichengreen, B. (2014). "Secular stagnation: a review of the issues," in Secular Stagnation: Facts, Causas and Cures, eds C. Teulings, and R. Baldwin, (London: Centre for Economic Policy Research), 41-46.

Eichengreen, B., Park, D., and Kwanho, S. (2015). “The global productivity slump: common and country-specific factors," in Proceedings of the National Bureau of Economic Research Working Paper Series 21556, (Cambridge, MA: National Bureau of Economic Research).

Eur-Lex, (2014). Tratado de Estabilidad, Coordinación y Gobernanza en la Unión Económica y Monetaria. Available at: https://eur-lex.europa.eu/ legal-content/ES/TXT/?uri=LEGISSUM\%3A1403_3 (accessed October $8,2019)$.

Eur-Lex, (2017). Europa 2020: la Estrategia de la Unión Europea Para el Crecimiento y la Ocupación. Available at: https://eur-lex.europa.eu/legal-content/ES/TXT/ ?uri=LEGISSUM\%3Aem0028 (accessed October 8, 2019).

European Central Bank (2018). Monetary Policy. Available at: https://www.ecb. europa.eu/mopo/html/index.en.html (accessed October 8, 2019).

European Central Bank (2019). Supervisión bancaria. La Unión Bancaria. Available at: https:/www.bankingsupervision.europa.eu/about/bankingunion/ html/index.es.html (accessed October 8, 2019).

European Central Bank, (2015-2018). Eurosistema. Annual Report. European Central Bank, Frankfurt am Main.

European Central Bank, (2014). The Governance of the European Union in Detail. Press Release. Available at: http://europa.eu/rapid/press-release_MEMO-13979_es.htm (accessed October 8, 2019).

European Commission (2019). Estrategia Europa 2020. Available at: https://ec.europa.eu/info/business-economy-euro/economic-and-fiscalpolicy-coordination/eu-economic-governance-monitoring-preventioncorrection/european-semester/framework/europe-2020-strategy_es (accessed October 8, 2019).

Federal Reserve (2019a). Federal Reserve History. Banking Act of 1933 (Glass Steagall). Available at: https://www.federalreservehistory.org/essays/ glass_steagall_act (accessed October 8, 2019). 
Federal Reserve (2019b). Federal Reserve History. Emergency Banking Act of 1933. Available at: https://www.federalreservehistory.org/essays/emergency_ banking_act_of_1933 (accessed October 8, 2919).

Feenstra, R., Inklaar, R., and Timmer, M. (2015). "The next generation of the penn world table," in Proceeding of the National Burearu of Economic Research. Working Paper Series 19255, (Cambridge, MA: National Bureau of Economic Research)

G20, (2008). Declaration. Summit on Financial Markets and the World Economy. Available at: http://www.g20.utoronto.ca/2008/2008declaration 1115. html (accessed October 8, 2019).

Galbraith, J. K. (1984). El Nuevo Estado Industrial. Madrid: Sarpe.

Glaeser, E. L. (2014). "Secular joblessness," in Secular Stagnation: Facts, Causas and Cures, eds C. Teulings, and R. Baldwin, (London: Centre for Economic Policy Research), 69-80.

Gordon, R. J. (2012). "Is U.S. economic growth over? Faltering innovation confronts the six headwinds," in Proceddings of the National Bureau of Economic Research. Working Paper Series 18315, (Cambridge, MA: National Bureau Of Economic Research).

Gordon, R. J. (2014). "The turtle's progress: secular stagnation meets the headwinds," in Secular Stagnation: Facts, Causas and Cures, eds C. Teulings, and R. Baldwin, (London: Centre for Economic Policy Research), 47-59.

Guillén, M., and Ontiveros, E. (2014). Retos para la economía internacional en un mundo cambiante. Estudios de Economía Aplicada 32, 871-884.

Hansen, A. H. (1939). Economic progress and declining population growth. Am. Econ. Rev. 29, 1-15.

Herzberg, F. (1970). "The motivation-hygiene theory," in Management and Motivation, eds. V. H. Vroom and E. L. Deci (Tennessee: Penguin Book), 86-90.

Jimeno, J. F., Smets, F., and Yiangou, J. (2014). "Secular stagnation: a view from the Eurozone," in Secular Stagnation: Facts, Causas and Cures, eds C. Teulings, and R. Baldwin, (London: Centre for Economic Policy Research), $153-164$.

Jones, B. L. (1980). Lauchlin Currie and the causes of the 1937 recession. Hist. Polit. Econ. 12, 303-315. doi: 10.1215/00182702-12-3-303

Koo, R. C. (2014). "Balance sheet recession is the reason for secular stagnation", in Secular Stagnation: Facts, Causas and Cures, eds C. Teulings, and R. Baldwin, (London: Centre for Economic Policy Research), 131-142.

Lozano, J. J. (2004). El Período de Entreguerras. El New Deal. Revista Digital de Historia y Ciencias Sociales. Available at: http://www.claseshistoria.com/ entreguerras/solucionesnewdeal.htm (accessed October 8, 2019).

Martí, L. (2017a). Apuntes Sobre Estancamiento Secular (III): Factores Depresores de la Demanda: la Demografía. Available at: http://blognewdeal.com/luismarti/apuntes-sobre-estancamiento-secular-iii-factores-depresores-de-lademanda-la-demografia/ (accessed October 8, 2019).

Martí, L. (2017b). Apuntes Sobre Estancamiento Secular (VII): Otros Factores Depresores de la Demanda. Available at: http://blognewdeal.com/luis-marti/ apuntes-sobre-estancamiento-secular-vii-otros-factores-depresores-de-lademanda/ (accessed October 8, 2019).

Martí, L. (2018). Estancamiento Secular: Epílogo. Available at: http://blognewdeal. com/luis-marti/estancamiento-secular-epilogo/ (accessed October 8, 2019).

Mayorga, M., and Muñoz, E. (2000). La técnica de datos de panel. Una Guía Para su uso e Interpretación. San Jose: Banco Central de Costa Rica.

Mazzucato, M. (2014). El Estado Emprendedor. Mitos del Sector Público Frente al Privado. Barcelona: RBA.

McClelland, D. (1961). The Achieving Society. New York, NY: A Free Press Paperback.

Ministerio de Economía, Industria y Competitividad, (2019). Instrumentos Financieros en la UE. Available at: http://www.mineco.gob.es/portal/ site/mineco/menuitem.b6c80362d9873d0a91b0240e026041a0/?vgnextoid= e32f7cb59784c310VgnVCM1000001d04140aRCRD (accessed October 8, 2019).

Mokyr, J. (2014). "Secular stagnation? Not in your life," in Secular Stagnation: Facts, Causas and Cures, eds C. Teulings, and R. Baldwin, (London: Centre for Economic Policy Research), 83-89.
Montoriol-Garriga, J. (2015). La Recuperación en la Periferia y el Papel de las Reformas. Valencia: CaixaBank, 32-33.

Nash-Stacey, B., and Karp, N. (2015). Transición Hacia un Entorno que Premia la Productividad Sobre el Crecimiento. Mexico: BBVA Research.

Navascués, M. (2016). Alvin Hansen, "Inventor" of the secular Stagnation. The Decadence of the West. Available at: http://www.miguelnavascues.com/2016/02/ alvin-hansen-inventor-del-estancamiento.html (accessed October 8, 2019).

Paturel, R. (1997). Pratique du Management Straégique. Grenoble: Presses Universitaires de Grenoble.

Pérez, F. (2015). Una mirada crítica del actual debate sobre estancamiento secular. Cuadernos de Economía Crítica 2, 15-48.

Pérez, R., and Delbianco, F. (2015). ¿Estancamiento secular? Causas estructurales del exceso de ahorro corporativo en países desarrollados. Trayectorias 17, $52-83$.

Piketty, T. (2015). La Crisis del Capital en el Siglo XXI: Crónicas de Los Años en los Que el Capitalismo se Volvió loco. Barcelona: Anagrama.

Quirós, L. B. (2015). Estancamiento Secular. Available at: http://www.elmundo.es/ economia/2015/05/10/554cealce2704e50308b4571.html (accessed October 8, 2019).

Redondo, A. (2015). La Crisis de 1937 se Repite. Available at: https://inversorglobal. es/2015/05/la-crisis-de-1937-se-repite/ (accessed October 8, 2019).

Rosnick, D., and Weisbrot, M. (2015). ¿Ha funcionado la austeridad en España?. Washington, DC: Center for Economic and Policy Research.

Sandoval, J. K., and Morales, S. Y. (2017). ¿Por qué las tasas de interés son tan bajas? Econ. Inform. 405, 46-63.

Serrano, M. (2010). La crisis económica de 1929: roosevelt y el New Deal. Revista de la Facultad de Ciencias Sociales y Jurídicas de Elche 1, 112-130.

Shane, S., Locke, E. A., and Collins, C. J. (2003). Entrepreneurial motivation. Hum. Resour. Manag. Rev. 13, 257-279.

Shapero, A. T. (1985). The Entrepreneurial Event. Columbus, OH: Ohio State University.

Statacorp, (2009). Stata Statistical Software: Release 11. College Station, TX: StataCorp LP.

Subdirección General de Economía Internacional, (2012). Ministerio de Economía y Hacienda (2012). El Six-Pack de la reforma del gobierno económico en la Unión Europea. Boletín Económico de ICE 3022, 3-13.

Summers, L. H. (2013). IMF Fourteenth Annual Research Conference in Honor of Stanley Fischer. Available at: http://larrysummers.com/imf-fourteenth-annualresearch-conference-in-honor-of-stanley-fischer/ (accessed October 8, 2019).

Summers, L. H. (2014a). "Reflections on the new secular stagnation hypothesis," in Secular Stagnation: Facts, Causas and Cures, eds C. Teulings, and R. Baldwin, (London: Centre for Economic Policy Research), 27-38.

Summers, L. H. (2014b). U.S. economic prospects: secular stagnation, hysteresis, and the zero-lower bound. Bus. Econ. 49, 65-73. doi: 10.1057/be.2014.13

Torres, A. (2016). Coeficiente de Gini, el Detector de la Desigualdad Salarial. Mexico: BBVA Research.

Wolff, G. B. (2014). "Monetary policy cannot solve secular stagnation alone," in Secular Stagnation: Facts, Causas and Cures, eds C. Teulings, and R. Baldwin, (London: Centre for Economic Policy Research), 143-150.

Zapata, R., and Gabriele, A. (1994). La conclusión de la Ronda de Uruguay: resultados e implicaciones. Rev. Comercio Exterior. 1994, 524-537.

Conflict of Interest: The authors declare that the research was conducted in the absence of any commercial or financial relationships that could be construed as a potential conflict of interest.

Copyright (C) 2019 Callejas-Albiñana, Martín de Vidales Carrasco, MartínezRodríguez and Callejas-Albiñana. This is an open-access article distributed under the terms of the Creative Commons Attribution License (CC BY). The use, distribution or reproduction in other forums is permitted, provided the original author(s) and the copyright owner(s) are credited and that the original publication in this journal is cited, in accordance with accepted academic practice. No use, distribution or reproduction is permitted which does not comply with these terms. 
OPEN ACCESS

Edited by:

Gabriela Topa

National University of Distance

Education (UNED), Spain

Reviewed by:

Mercedes Martos-Partal,

University of Salamanca, Spain

Mario Arias-Oliva,

University of Rovira i Virgili, Spain

*Correspondence:

Maria Pilar Martinez-Ruiz

MariaPilar.Martinez@uclm.es

†These authors have contributed equally to this work

Specialty section:

This article was submitted to

Organizational Psychology,

a section of the journal

Frontiers in Psychology

Received: 30 September 2019 Accepted: 19 November 2019

Published: 03 December 2019

Citation:

Martinez-Ruiz MP and Moser KS (2019) Studying Consumer Behavior

in an Online Context: The Impact of the Evolution of the World Wide Web

for New Avenues in Research.

Front. Psychol. 10:2731.

doi: 10.3389/fpsyg.2019.02731

\section{Studying Consumer Behavior in an Online Context: The Impact of the Evolution of the World Wide Web for New Avenues in Research}

\author{
Maria Pilar Martinez-Ruiz ${ }^{1 * \dagger}$ and Karin S. Moser ${ }^{2 \dagger}$ \\ ${ }^{1}$ Department of Business Administration, University of Castilla La Mancha, Albacete, Spain, ${ }^{2}$ Business School, London \\ South Bank University, London, United Kingdom
}

Keywords: consumer behavior, online context, new research agenda, World Wide Web evolution, Web 5.0, decision making, sensory experience, emotions

\section{INTRODUCTION}

There is no denying that the increasing use of the internet by end consumers has presented numerous challenges in the field of marketing research, and more specifically in the field of consumer behavior (Pomirleanu et al., 2013) as evidenced by a growing number of studies (Cummins et al., 2014).

Understanding the psychology behind online consumer behavior is key to compete in today's markets which are characterized by ever increasing competition and globalization. In an online context, consumer responses are no longer dependent on the physical environment while at the same time entirely new factors come into play such as the device through which consumers interact, and the way products and services are sold and presented online which often differs significantly from traditional offline marketing strategies. It is for this reason that research into online consumer behavior has increasingly started looking to other disciplines, including psychological approaches and concepts.

Several examples of cornerstone reviews highlight this trend. For example, Cummins et al. (2014) observed in their literature review how research on online consumer behavior often uses psychological and social networks theories. The authors found a much greater focus on aspects related to the relationships that consumers develop with companies over the internet and connected to that, the analysis of the attitudes, beliefs and feelings that consumers develop as part of their online experiences, thus moving the relationship from the physical into the virtual sphere. Similarly, Yadav and Pavlou (2014) did a review of marketing literature in computermediated environments (CME) and proposed a structured framework around four key interactions in CME to summarize their findings: consumer-firm interactions, firm-consumer interactions, consumer-consumer interactions, and firm-firm interactions. Both reviews support our suggestion that understanding consumer behavior in a digital world relates to important psychological aspects of behavior that are best understood by using psychological concepts and methods.

Despite this evidence there are surprisingly still some important avenues of research that have received little attention. One area that we propose is central to understanding online consumer behavior concerns the impact of the different stages of internet evolution, the World Wide Web (WWW). This has received some attention in general management research and from practitioners but there is hardly any research in marketing and consumer behavior. The WWW is omnipresent in business today, and almost all work-related communications and interactions are at least partially 
supported by digital media (Moser and Axtell, 2013). It has transformed business operations and relations (Benito-Osorio et al., 2013; Kambil, 2008) and it is time to extend this to customer relations and marketing.

It is the aim of this article to highlight the importance of studying the impact of the evolution of the WWW on consumer behavior. Especially in the most recent WWW developments, psychological aspects of consumer behavior have gained in importance, namely individual preferences, emotions, and sensory experiences. In order to analyse these transformations, it is important to briefly consider what each stage in the evolution of the WWW has brought about.

\section{THE EVOLUTION OF THE WORLD WIDE WEB AND ITS IMPACT ON CONSUMER BEHAVIOR}

The first stage in the evolution of the WWW was the Web 1.0 (usually referred to as the Basic Web). This type of WWW was suitable mainly for sharing information on a new platform, such as publishing corporate information online and conducting basic business transactions. It was the first opportunity for businesses to develop an online presence and was mainly used by large international companies (BernersLee et al., 1992; Benito-Osorio et al., 2013). Only a fraction of consumers used it to stay informed and so its reach was restricted to the early adopters of the new technology. Its limited reach and suitability for large companies and basic tasks only meant that the Web 1.0 was mainly used for transactional marketing. Web 1.0 already showed the potential for online relationship marketing (for example, the possibility for consumers to access a greater breadth of information about products and brands than was physically available on the ground). Mostly, online consumer behavior was still seen as only complementary to traditional consumer behavior. Just a few pioneering publications highlighted the enormous potential of the WWW as information and communication channel that could completely reconfigure the ways in which consumers seek information and compare knowledge about products and services (Choo et al., 2000).

The Web 2.0 (known as the Social Web) was a big step forward by evolving into a platform for collaboration. The WWW was no longer a repository of information but an enabler of social interaction and collaboration on a global scale, with potentially anyone across the globe who had internet access. Hence, the Web 2.0 was qualitatively completely different from the previous Web 1.0 technologies as it began to facilitate information sharing between users, employed usercentered design technology, and supported interoperability and collaboration. This also meant that the online platforms were now open to a much wider range of users, not just the large multinationals with their own IT departments, but also to SMEs, independents, and individual consumers. Typical examples of the Social Web are Web-based communities, social network services, video hosting services, wikis, and blogs (BenitoOsorio et al., 2013). The internet could now be used to organize individuals for collective action, initiate trends, promote views, and take influence. This opened up the possibility of generating extraordinary value by creating new movements and communities that hadn't existed before and that could only be reached via the new digital technologies. The Web 2.0 fostered the building of bidirectional relations between consumers and providers of goods and services. With this, we posit that the WWW entered the next stage as the key medium for relationship marketing which in turn became central for business success.

The third step in the evolution of the WWW was the Web 3.0, the Semantic Web. Although there is still some debate over the significance and most appropriate definition of the Web 3.0, it is indisputable that one of its key features was the combination of human and artificial intelligence. This allowed to provide more relevant and more easily accessible information that was specifically targeted to groups of consumers and based on their real time online behavior thanks to nonbrowser-based applications and AI technologies (Benito-Osorio et al., 2013). It further increased the amount and breadth of available information, in real time and in an interactive way that took into account which decisions consumers made when browsing online and responding to prompts and targeted information. Companies and internet service providers could now gather detailed information about consumers' online decision making, with the possibility to be highly adaptive and respond to consumer decisions by offering products and services, for example sales offers or comparisons with similar products in real time. From a research perspective, it was now possible to obtain detailed information about consumer decision making for psychological variables that previously were almost impossible to study in real time: individual perceptions, judgements, attitudes, and intentions toward products, services and people could now be observed at each step in the decision process.

The fourth step in WWW evolution was the development of the Web 4.0 based on wireless communication and mobile devices. The Web 4.0 is usually referred to as the Symbiotic Web, because of its capability to connect people, places and objects whenever and wherever they might be, both in the physical and the virtual world, and in real time. For example, the GPS systems that guide cars and help drivers to improve route planning will in the next step save them from having to drive at all with the introduction of self-driving vehicles. The Web 4.0 is where we currently stand, with its next steps ready to take off and prototypes such as the self-driving vehicles soon ready for mass production. However, we would like to propose that for consumer behavior research we should not stop here but already look to the next evolutionary stage of the WWW, the Web 5.0.

\section{THE FUTURE OF CONSUMPTION WITH THE WEB 5.0}

This next step in web evolution is already hard on the heels of the Web 4.0 (Kambil, 2008), with the Web 5.0 currently 
being in development and referred to as the Sensory Web or the Emotive Web. With these latest and most current developments comes another exponential increase in web-based interactions via multiple channels with responses in real time and adaptive technologies that are immediately predicting and shaping the next interaction. This further evolution of the WWW marks a considerable qualitative difference compared to the Web 4.0 similar in significance to the milestone of moving from the Basic Web 1.0 to the Social Web 2.0 two decades ago. This is in line with the Marketing 4.0, which emphasized the relevance of individual customer experiences and customer journeys for consumer behavior and decision making, adding entirely new aspects to consumer research (Lemon and Verhoef, 2016; Kotler et al., 2017).

Various futuristic terms are currently in use for the Web 5.0, the Sensory and Emotive Web. The aim is to develop computers that interact with human beings and become part of daily consumer and customer relationships for many if not all people. Although the current Web technologies are not yet "emotionally sensitive" or able to read human emotions, these technologies are in development and rapidly advancing. In some very recent studies, computers have already been shown to be able to more accurately judge human emotions and personality attributes from facial expressions in photographs and videos than human observers (Khambatta et al., 2019). A current commercial example already in use is www.wefeelfine.org which tracks emotional phrases on the Web, categorizes them and registers the frequency and location of clusters of expressed sentiments. Another example is the company EmotiveSystems that developed a new neurotechnology using headphones where users can interact with content that responds to their emotions and changes the facial expression of their avatars in real time. These new technologies of the future Web 5.0 will undoubtedly and radically change the way we study and understand consumer behavior.

\section{DISCUSSION}

This short account of the evolution of the WWW shows the multifaceted and massive implications and possibilities for the field of consumer behavior research. We strongly believe that this research is still in its beginning, and that greater efforts should be devoted to research that takes the WWW evolution into account for different sectors, products, services, people, and the increasing importance of consumer perceptions

\section{REFERENCES}

Benito-Osorio, D., Peris-Ortiz, M., Rueda-Armengot, C., and Colino, A. (2013). Web 5.0: the future of emotional competences in higher education. Glob. Bus. Persp. 1, 274-287. doi: 10.1007/s40196-0130016-5

Berners-Lee, T. J., Cailliau, R., and Groff, J. F. (1992). The World-Wide Web. Electr. Netw. 2, 52-58. and emotions, and thus inherently psychological aspects of behavior.

Examples are emotions that consumers experience when shopping online and the micro-interactions in consumer decision-making when each choice in the purchase decision process is immediately followed by an individualized response based on AI algorithms, such as offering additional color or size options, which in turn then influence the consumer perception and their next decision and so on. With the further development of the Web 5.0 this will not only be the case for purchasing decisions which are mainly based on cognitive information processing but increasingly also for emotions that consumers experience and express while shopping online, many of which they may not be conscious of. The new emotionally sensitive AI technologies can read (unconscious) emotions based on verbal and facial expressions (from text, speech, photographic, and video data) but in future possibly also based on body sensors measuring heart rate, skin resistance, bodily secretions (sweat), and pupil dilatation. These are established measures in psychological research studying emotional and physiological arousal and this type of data could be obtained via cameras, smart glasses and contact lenses and smart watches.

This will bring a host of new methods into consumer research that are drawn from psychology and can only be developed in an interdisciplinary approach. Given that any decision-making process is highly complex and given that the role of emotions and sensory experiences become ever more prominent with the Web 4.0 and the forthcoming Web 5.0, it is important to start developing adequate methods and theoretical models to study these new developments in consumer behavior.

\section{AUTHOR CONTRIBUTIONS}

All authors listed have made a substantial, direct and intellectual contribution to the work, and approved it for publication.

\section{FUNDING}

This research has been financed by Research Groups Grants from the University of Castilla-La Mancha. Co-financed by the European Union through the European Regional Development Funds. Research Group: Observatory of Innovation in Commercial Distribution (OIDC). Seeking and Knowledge Work on the World Wide Web. Dordrecht, NL: Kluwer.

Cummins, S. W., Peltier, J. A., Schibrowsky, J., and Nill, A. (2014). Consumer behavior in the online context. J. Res. Inter. Mark. 8, 169-202. doi: 10.1108/JRIM-04-2013-0019

Kambil, A. (2008). What is your Web 5.0 strategy? J. Bus. Strategy 29, 56-58. doi: $10.1108 / 02756660810917255$ 
Khambatta, P., Dai, H., Logg, J. M., and Newman, D. T. (2019). The Future of Work: How People Respond to Digital Actors and Algorithms. Boston, MA: Symposium, Academy of Management Meeting 2019.

Kotler, P., Kartajayan, H., and Setiawan, I. (2017). Marketing 4.0: Moving from Traditional to Digital. Hoboken, NJ: Wiley.

Lemon, K. N., and Verhoef, P. C. (2016). Understanding customer experience throughout the customer journey. J. Mark. 80, 6, 69-96. doi: $10.1509 / \mathrm{jm} .15 .0420$

Moser, K. S., and Axtell, C. M. (2013). The role of norms in virtual work: a review and agenda for future research. J. Person. Psychol. 12, 1-6. doi: 10.1027/1866-5888/a000079

Pomirleanu, N., Schibrowsky, J. A., Peltier, J., and Nill, A. (2013). A review of internet marketing research over the past 20 years and future research direction. J. Res. Inter. Mark. 7, 166-181. doi: 10.1108/JRIM-01-201 $3-0006$
Yadav, M. S., and Pavlou, P. A. (2014). Marketing in computer-mediated environments: research synthesis and new directions. J. Mark. 78, 20-40. doi: 10.1509/jm.12.0020

Conflict of Interest: The authors declare that the research was conducted in the absence of any commercial or financial relationships that could be construed as a potential conflict of interest.

Copyright (c) 2019 Martinez-Ruiz and Moser. This is an open-access article distributed under the terms of the Creative Commons Attribution License (CC BY). The use, distribution or reproduction in other forums is permitted, provided the original author(s) and the copyright owner(s) are credited and that the original publication in this journal is cited, in accordance with accepted academic practice. No use, distribution or reproduction is permitted which does not comply with these terms. 


\title{
Dealing With Human Resources in the Age of Consumer 4.0: Aiming to Improve Service Delivery
}

\author{
Juan Jose Blazquez-Resino ${ }^{*}$, Santiago Gutiérrez-Broncano ${ }^{1}$, Pablo Ruiz-Palomino ${ }^{2}$ and \\ Pedro Jimenez-Estevez ${ }^{3}$ \\ 'Department of Business Administration, University of Castilla La Mancha, Talavera de la Reina, Spain, ${ }^{2}$ Department of \\ Business Administration, University of Castilla La Mancha, Cuenca, Spain, ${ }^{3}$ Department of Business Administration, \\ University of Castilla La Mancha, Toledo, Spain
}

Keywords: Industry 4.0, Marketing 4.0, Customer 4.0, human resources, service, I.O.T, business ecosystems, skills and competences 4.0

\section{INTRODUCTION}

The evolution of information and communication technologies (ICTs) has produced seismic, global shifts in recent decades. The development of ICTs, coupled with the progressive digitization processes they drive, has helped to create new opportunities for growth-as well as new challenges for decision-making. For instance, companies in today's environment must contend with, among other things, large databases and the need to increase the productivity of different tasks and operations. At the same time, ICTs allow new business models wherein consumers can become active co-producers in the value creation process (Dellaert, 2019). However, in order to shift innovation from the company to the customer, firms need to achieve a different kind of coordination between various organizational areas, including marketing (Ardito et al., 2019).

In this sense, firms face several hurdles, such as training employees to handle more strategic, cooperative, and creative tasks that entail greater responsibilities. Employees must not only acquire the necessary skills to participate in virtual work; they must also be able to engage the co-production and value generation processes with consumers. On this basis, this opinion piece aims to highlight some changes that companies should implement in order to properly train, qualify, and manage employees in the current context of Industry 4.0-especially if they want to meet the needs of today's consumers.

\section{CHANGES IN CONSUMER BEHAVIOR IN THE MODERN ERA}

Consumer behavior is currently characterized by the growing demand for technology. Customers are hyper-connected through different technologies, including not only the well-known mobile technologies, but also those like Internet of Thing (IOT), nanotechnology, or artificial intelligence. These technologies underlie several defining activities of Consumer 4.0, such as the co-design and recommendation of products; participating in the distribution and sale of products; co-producing and sharing experiences; and offering peer support, revision, and innovation (Dellaert, 2019). Consumers also have the opportunity to access a huge amount of information, which allows them to compare offers from a wide variety of suppliers. Consumers not only look for products that meet their needs; they also want to be part of the product through active participation in co-production and value generation. Thus, consumers need to feel tethered to the product by participating in its creation, interacting with it and sharing their experiences (Martínez-Cañas et al., 2016).

The notion of meeting consumer needs through co-production (Wu and Liu, 2018) is indispensable in the current context of Marketing 4.0. This new approach of Marketing combines online and offline interactions between customers and businesses, to achieve a better way to serve their products and generate value, establishing more flexible and adaptive processes. Therefore, 
companies should not simply transmit their own values and contributions; they should also develop a deep co-construction process, based on offline and online interactions and partnerships with customers and followers. In this vein, several studies from the last decade (e.g., Payne et al., 2008; Edvardsson et al., 2011; Martínez-Cañas et al., 2016) have highlighted the need for new theories to better understand consumer co-creation processes, especially in coordination with ICTs. After all, consumers can provide online communities with more valuable information than producers by sharing their experiences through social networks (Kotler et al., 2016).

In order to remain competitive, companies must undergo a digital transformation that affects not only the areas of value, but also the ways in which they interact with their operational environment. The following section will discuss the implications of this transformation for human resource training.

\section{IMPLICATIONS FOR HUMAN RESOURCES FORMATION AND MANAGEMENT}

An organization's performance and competitiveness depend largely on how its employees are trained and managed. Developing and maintaining a highly committed and qualified workforce means investing in proper training and human resource management processes (Hecklau et al., 2016). Beyond the selection, hiring and dismissal of employees, the management of human resources must be focused on employees' development through education and training. Despite the importance of human resource management in achieving a company's objectives, there are few scientific papers that try to generate knowledge on developing human resource strategies within Industry 4.0 (Hecklau et al., 2016; Benešová and Tupa, 2017; Longo et al., 2017). This new context routinely blurs the lines between personal and professional activities, as well as the forms of employing people who participate in value creation systems (Dellaert, 2019).

This "fourth industrial revolution" is characterized by a paradigm shift oriented toward the decentralization of production processes, facilitating the integration of different company functionalities and members of the distribution channel. As Schrauf and Berttram (2016, p. 4) stated, "the chain becomes a completely integrated ecosystem that is fully transparent to all the players involved." The ultimate goal must be to meet customized market demands in a short period of time while using the least amount of energy and resources. Companies must be closer to their customers and more reactive when interpreting their needs, which they can achieve by involving customers in the design and development of product processes (Bettiol et al., 2017). As a result, and parallel with previous industrial revolutions, some professions and jobs may disappear (Benešová and Tupa, 2017) in the wake of improved procedural efficiency and employee training.

In this regard, it should be clarified that Industry 4.0 is a new phenomenon aimed at changing the economic rules in all industries, albeit with special attention to manufacturing (c.f., Kagermann et al., 2013; Weyer et al., 2015; Stock and
Seliger, 2016). The peculiar feature of this industrial revolution is its greater degree of complexity compared to previous ones. The underlying idea of Industry 4.0 leaves aside the traditional paradigms of production and management. Instead, it considers the digitization of the company and the entire value chain, based on the adoption of digital technologies that can help companies establish real-time connections between people, objects and systems (Hecklau et al., 2016). The relevant literature has revealed interesting findings about the beneficial effects of Industry 4.0 , such as companies' increasing productivity and customers' growing role in productive processes (Bettiol et al., 2017).

In this framework, the so-called Smart Factories of the future will allow employees to work alongside customers and suppliers in a digital ecosystem in ways that improve value chain management and marketing functions (Ardito et al., 2019). In this sense, the concept of Industry 4.0 is related to other technological terms such as radio frequency identification (RFID), Internet of Things (IoT), cloud computing, decisionmaking/supporting systems, computational intelligence, and data mining (Wang et al., 2017), which can be used to bolster the company's knowledge of customer needs (Porter and Heppelmann, 2015).

In short, the growing implementation of ICT entails a need to significantly improve employees' training and qualification with regard to new technologies and smart media. Benešová and Tupa (2017) noted that the development of technologies has an important impact on education systems, where only qualified and highly trained employees will be able to control these technological tools. In order to meet consumers' needs in terms of functionality, quality and service, Industry 4.0 may need to be accompanied by an Education 4.0 system that combines both real and virtual information (Benešová and Tupa, 2017). Indeed, Industry 4.0 involves tasks of greater complexity that require human operators with more experience or adaptive capabilities (Longo et al., 2017).

\section{DISCUSSION}

This opinion article has primarily highlighted, among other issues, the need to establish a coordination between Industry 4.0 and Marketing 4.0, based on the study of the processes of educating, training and management of human resources to offer better performance to Consumer 4.0. Undoubtedly, Industry 4.0 is helping to create many new opportunities for companies; nonetheless, increasing automation and digitization introduce several critical challenges. Faced with an increasing amount of virtual and flexible work topics, employees need to adopt a higher volume of responsibilities that involve strategic, cooperative, and creative thinking. To this end, human resource management processes must be geared toward training employees to not only use new technologies, but also understand and adapt to customers' new role in the process. Therefore, it is important to focus attention on human resource management in relation to the latest marketing approaches inherent to Marketing 4.0. The need 
to strengthen the union of human resources management from a marketing perspective, established through Internal Marketing, is not surprising.

Obviously, industry has undergone several revolutions that ultimately changed not only production, but also the labor market and education system. In this latest iteration, employees need training on how to develop their activities in relation to their direct and continuous contact with customers. Going forward, customers' perceptions of products-their quality, variety, and delivery-will be strongly influenced by information technologies and social media networks. In this context, companies should try to be flexible and quickly adapt their structures, products and brands to changing social trends. Production processes must be efficient enough to meet customers' needs, but also flexible enough to adapt swiftly to changes in customer demand. In this regard, the ability to perform timely analysis of market data is a key element of flexible production. Thus, companies need to invest in communication channels that facilitate the continuous exchange of information on individual needs and situations in real time.

\section{REFERENCES}

Ardito, L., Petruzzelli, A. M., Panniello, U., and Garavelli, A. C. (2019). Towards Industry 4.0: mapping digital technologies for supply chain management-marketing integration. Bus. Process Manage. J. 25, 323-346. doi: 10.1108/BPMJ-04-2017-0088

Benešová, A., and Tupa, J. (2017). Requirements for education and qualification of people in Industry 4.0. Proced. Manuf. 11, 2195-2202. doi: 10.1016/j.promfg.2017.07.366

Bettiol, M., Capestro, M., and Di Maria, E. (2017). "Industry 4.0: the strategic role of marketing," in Proceedings of the XIV Convegno Annuale SIM (Bergamo), 26-27.

Dellaert, B. G. (2019). The consumer production journey: marketing to consumers as co-producers in the sharing economy. J. Acad. Market. Sci. 47, 238-254. doi: 10.1007/s11747-018-0607-4

Edvardsson, B., Tronvoll, B., and Gruber, T. (2011). Expanding understanding of service exchange and value co-creation: a social construction approach. J. Acad. Market. Sci. 39, 327-339. doi: 10.1007/s11747-010-0200-y

Hecklau, F., Galeitzke, M., Flachs, S., and Kohl, H. (2016). Holistic approach for human resource management in Industry 4.0. Proced. Cirp 54, 1-6. doi: 10.1016/j.procir.2016.05.102

Kagermann, H., Wahlster, W., and Helbig, J. (2013). Recommendations for Implementing the Strategic Initiative Industrie 4.0. Final report of the Industrie 4.0 Working Group, April, 1-82.

Kotler, P., Kartajaya, H., and Setiawan, I. (2016). Marketing 4.0: Moving From Traditional to Digital. Hoboken, NJ: John Wiley and Sons.

Longo, F., Nicoletti, L., and Padovano, A. (2017). Smart operators in industry 4.0: a human-centered approach to enhance operators' capabilities and competencies within the new smart factory context. Comput. Indus. Eng. 113, 144-159. doi: 10.1016/j.cie.2017.09.016

Martínez-Cañas, R., Ruiz-Palomino, P., Linuesa-Langreo, J., and Blázquez-Resino, J. J. (2016). Consumer participation in co-creation: an enlightening model of causes and effects based on ethical values and transcendent motives. Front. Psychol. 7:793. doi: 10.3389/fpsyg.2016.00793
In sum, companies must strive to understand their customers more intimately and involve them in the design and development of products. That said, co-production is a great challenge for human resource training and management. Employees need to acquire the skills necessary for virtual work and be cognizant of the blurring lines between personal and professional activities in value creation systems.

\section{AUTHOR CONTRIBUTIONS}

All authors listed have made a substantial, direct and intellectual contribution to the work, and approved it for publication.

\section{FUNDING}

This research has been financed by Research Group Grants from the University of Castilla-La Mancha. Co-financed by the European Union through the European Regional Development Funds. Research Group: Observatory of Innovation in Commercial Distribution (OIDC).

Payne, A. F., Storbacka, K., and Frow, P. (2008). Managing the co-creation of value. J. Acad. Market. Sci. 36, 83-96. doi: 10.1007/s11747-007-0070-0

Porter, M. E., and Heppelmann, J. E. (2015). How smart, connected products are transforming companies. Harvard Bus. Rev. 93, 96-114. Available online at: https://hbr.org/2015/10/how-smart-connected-productsare-transforming-companies

Schrauf, S., and Berttram, P. (2016). Industry 4.0: How digitization makes the supply chain more efficient, agile, and customer-focused. Strategy\& 1-32.

Stock, T., and Seliger, G. (2016). Opportunities of sustainable manufacturing in industry 4.0. Proced. Cirp 40, 536-541. doi: 10.1016/j.procir.2016. 01.129

Wang, Y., Ma, H. S., Yang, J. H., and Wang, K. S. (2017). Industry 4.0: a way from mass customization to mass personalization production. Adv. Manuf. 5, 311-320. doi: 10.1007/s40436-017-0204-7

Weyer, S., Schmitt, M., Ohmer, M., and Gorecky, D. (2015). Towards Industry 4.0 - Standardization as the crucial challenge for highly modular, multi-vendor production systems. IFAC Pap. Online 48, 579-584. doi: 10.1016/j.ifacol.2015.06.143

Wu, L., and Liu, H. (2018). "Tracing fake-news footprints: Characterizing social media messages by how they propagate," in Proceedings of the Eleventh ACM International Conference on Web Search and Data Mining (New York, NY: ACM), 637-645.

Conflict of Interest: The authors declare that the research was conducted in the absence of any commercial or financial relationships that could be construed as a potential conflict of interest.

Copyright (C) 2020 Blazquez-Resino, Gutiérrez-Broncano, Ruiz-Palomino and Jimenez-Estevez. This is an open-access article distributed under the terms of the Creative Commons Attribution License (CC BY). The use, distribution or reproduction in other forums is permitted, provided the original author(s) and the copyright owner(s) are credited and that the original publication in this journal is cited, in accordance with accepted academic practice. No use, distribution or reproduction is permitted which does not comply with these terms. 


\title{
Impact of Shopping Tourism for the Retail Trade as a Strategy for the Local Development of Cities
}

\author{
Ana Isabel Muro-Rodriguez ${ }^{1 *}$, Israel Roberto Pérez-Jiménez ${ }^{1}$ and \\ Jesús Antonio Sánchez-Araque ${ }^{2}$ \\ ${ }^{1}$ Econometrics Area, Department of Spanish and International Economy, Econometrics, History and Economic Institutions. \\ University of Castilla-La Mancha, Ciudad Real, Spain, ${ }^{2}$ Department of Business Administration. University of Castilla-La \\ Mancha, Ciudad Real, Spain
}

Keywords: tourism and retail, shopping tourism, tourist behavior, differentiation of tourist destinations, local development

\section{INTRODUCTION}

Shopping Tourism is a recent concept that is defined as a contemporary form of tourism carried out by individuals for whom the acquisition of goods, outside their place of residence, is a determining

OPEN ACCESS

Edited by:

Ana Jiménez-Zarco,

Open University of Catalonia, Spain

Reviewed by:

Héctor Hugo Pérez-Villarreal, Universidad Popular Autónoma del

Estado de Puebla, Mexico

Inés González-González,

Universidad Internacional De La

Rioja, Spain

*Correspondence:

Ana Isabel Muro-Rodríguez

Analsabel.Muro@uclm.es

Specialty section

This article was submitted to

Organizational Psychology,

a section of the journal

Frontiers in Psychology

Received: 12 November 2019 Accepted: 10 January 2020 Published: 31 January 2020

Citation:

Muro-Rodríguez Al, Pérez-Jiménez IR and Sánchez-Araque JA (2020) Impact of Shopping Tourism for the

Retail Trade as a Strategy for the Local Development of Cities.

Front. Psychol. 11:67.

doi: 10.3389/fpsyg.2020.00067 factor in their decision to travel (WTO, 2014, p.13).

Shopping tourism is currently one of the main strategic lines of countries to promote sustainable and quality tourism (Yu and Littrell, 2003; Tosun et al., 2007; WTO, 2014, 2017, 2018; The Shopping Quality Tourism Institute, 2015, 2017; Tourspain, 2015, 2018). This tourism is the one that generates wealth and distributes it equitably, is environmentally sustainable and has a positive impact on the environment (The Shopping Quality Tourism Institute, 2015, 2017; MINCOTUR, 2019b). It implies an important economic and employment impact for the cities and countries in which it takes place, and favors deseasonalization and diversification (The Shopping Quality Tourism Institute, 2015, 2017).

The impact that this commercial tourism has on employment and economic growth in the countries is considerable, making it a key strategic industry (Jansen-Verbeke, 1991; Yu and Littrell, 2003; Tugcu, 2014; Webster and Ivanov, 2014; Tourspain, 2015; Albayrak et al., 2016).

Spain has become one of the most important tourist powers in the world (Tourspain, 2018). In 2017, it was the second country in the world in number of tourists and in income from international tourism with nearly 87,000 million euros (WTO, 2018; MINCOTUR, 2019b). Then in 2018 the tourism sector closed with a new record of 82.6 million international tourists and a volume of 89,678 million euros (MINCOTUR, 2019a).

Given these figures, it is necessary to take advantage of this potential market and bet on the quality and diversification of the offer of tourism products, as a key element of the National and Integral Tourism Plan, and this will be achieved by promoting quality tourism and shopping as an engine of economic and social growth (Tourspain, 2015).

This strategic line of exploiting the relationship between trade and tourism and taking advantage of the existing synergies between the two (Getz, 1993; Ryan et al., 1999; Global Blue, 2015), can help the city retail sector to adapt to new consumption habits. Also, it can open new horizons and avoid the disappearance of city centers as places of commerce due to the closure of businesses (Tourspain, 2015; MINECO, 2017). Additionally, the tourism sector can avoid its main weaknesses such as the typical tourist offer of the sun and beach, the concentration of demand in time and territory, or the strong dependence of certain issuing countries (Tourspain, 2015; MINCOTUR, 2019b).

This tourism is an increasingly attractive alternative for improving local commercial activity and, at the same time, shopping can be an active potential for the city to differentiate itself as a 
chosen destination (Tourspain, 2015; The Shopping Quality Tourism Institute, 2017; MINCOTUR, 2019b).

In this sense, there are different specific initiatives to promote cities as shopping tourism destinations, both in the city center and for other areas, most of which are centered on Madrid and Barcelona, since both occupy the second position among the best European cities as shopping destinations (Travé, 2019). In order to establish strategies, destinations must have a high level of knowledge about the socio-economic profile of tourists, their main motivations for traveling and the choice of destination (Žabkar et al., 2010; Choi et al., 2016a), especially because this knowledge can influence the competitive capacity of tourist destinations as shopping destinations (Kim et al., 2011; Cohen et al., 2014).

The aim of this research is to highlight the importance of shopping tourism for cities: (1) need for the commercial and tourism sectors to exploit the interrelationships between the two, (2) socio-economic impact on local trade, (3) identify differentiation strategies for cities as shopping destinations and (4) establish recommendations based on the analysis of key factors for listing a city as a shopping destination.

\section{SHOPPING TOURISM AND ITS IMPACT ON CITIES}

Shopping as a tourist activity has recently been analyzed. Purchasing tourism has received little attention so there are few publications in this area (Choi et al., 2016b).

Shopping is a common and fundamental tourist activity both from the tourist's perspective and for the chosen destination (Jin et al., 2017). It is one of the most important activities for tourists (Yu and Littrell, 2003; Lloyd et al., 2011; Albayrak et al., 2016). In many cases, shopping is an important factor in the choice of destination (Moscardo, 2004) and in others, it is may be the main reason for traveling (Timothy, 2005; Lehto et al., 2014).

Therefore, it is very important to know on what attributes tourists base their decisions (Dann, 1981; Žabkar et al., 2010; Hult et al., 2017) and what valuation purchases have on their trips (Murphy et al., 2000; Oh et al., 2004; Wong and Wan, 2013). Since 2000, researchers have shown an increased interest in examining people's motives for shopping while traveling and how they are influenced by the tourist destination (Albayrak et al., 2016; Choi et al., 2016a).

From a tourist perspective, Albayrak et al. (2016) and Jin et al. (2017) show most studies that deal with the relationships between sociodemographic characteristics and purchasing attitudes (Kim and Littrell, 2001; Yazdani, 2007; Yüksel and Yüksel, 2007; Alegre and Cladera, 2012), purchasing motivation (Law and Au, 2000; Swanson and Horridge, 2006; Yüksel, 2007; Kattiyapornpong and Miller, 2012); consumer satisfaction (Heung and Cheng, 2000; Reisinger and Turner, 2002; Wong and Law, 2003; Chang et al., 2006; Tosun et al., 2007; Murphy et al., 2011a,b; Wong and Wan, 2013; Chang, 2014), shopping characteristics (Choi et al., 2008; Han et al., 2015), outdoor environment and procurement evaluation (Christiansen and Snepenger, 2002; Yüksel, 2004, 2013).
For cities, shopping can be an important source of income (Murphy et al., 2011a,b). Shopping tourism also favors the creation of job opportunities and improves the image of cities as tourist destinations (Cohen et al., 2014; Tugcu, 2014; Webster and Ivanov, 2014). In this sense, many cities use tourism shopping as a promotional strategy to differentiate themselves from the competition (Ryan et al., 1999; Snepenger et al., 2003; Coles, 2004; Rabbiosi, 2011, 2015; Hurst and Niehm, 2012; Timothy, 2014).

It must be kept in mind that in the consumer's choice not only the physical attributes of a product count. For the maximization of the usefulness of the tourist's behavior there are other attributes like visiting places and spaces where to understand the local culture and strengthen social bonds (Timothy, 2005; Saayman and Saayman, 2012). These variables are relevant for differentiating cities in terms of their attributes.

Better information on the patterns and factors that condition the behavior of shopping tourists offers opportunities to the cities' tourism industry (Jansen-Verbeke, 1991). On the one hand, it allows for better planning and management of sales and expenses (Timothy, 2014) and on the other hand, it serves as a basis for promoting alternative places of attraction, creation of spaces and brand development of a city (Kemperman et al., 2009; Rabbiosi, 2011, 2015). Thus a new strategic line emerges for areas that can base their attractiveness on shopping tourism (Murphy et al., 2011b). They are generally cities or areas with a pleasant environment marked by historical or natural features along tourist routes, in tourist destination areas or near urban centers. However, they differ from urban businesses and shopping districts because they have a specialized retail trade and a distinctive atmosphere (Getz, 1993). These relationships between shopping and tourism are based on the study of literature and some empirical results that relate shopping as a means of tourist attraction (Jansen-Verbeke, 1991, 2000).

It is important to analyze advantages and disadvantages when talking about sustainable development and quality tourism. Social and environmental costs must be balanced with economic benefits (Ryan et al., 1999; Moscardo and Murphy, 2014; The Shopping Quality Tourism Institute, 2017). Tourism is a very important sector for the achievement of Sustainable Development Goals 2030 proposed by the United Nations. The World Tourism Organization links tourism to the 17 objectives of sustainable development (WTO, 2016).

The sustainable development of tourism consists of making optimal use of the environmental resources that are a fundamental element of tourism development, maintaining essential ecological processes and helping to conserve natural resources and biological diversity (WTO, 2014). This concept is developed through five strategic axes: collaborative governance, sustainable growth, tourism space, companies and people, product, marketing and tourism intelligence, and competitive transformation (MINCOTUR, 2019b).

The competitive transformation of tourism is linked to the concept of Intelligent Tourism Systems (SIT) for the promotion of Intelligent Tourist Destinations (SEGITTUR, 2015) and the concept of Tourism 4.0. Tourism 4.0 is a term that has been mentioned since 2017 to refer to tourism that encourages 
technological changes in tourism. These changes in the tourism industry range from the digitization of establishments using the Internet to offer a service to everything related to interactions through mobile devices such as maps, GPS, information about shops, restaurants, etc. (Zupan, 2019). Examples of these strategies have been developed in Palma de Mallorca, Las Palmas de Gran Canaria, Badajoz and the island of El Hierro, considered the first smart island in the world. Las Palmas de Gran Canaria stands out with the implementation of the first model to promote shopping tourism in the city through multilingual mobile technology (SEGITTUR, 2015). In this context, different strategic questions arise regarding the socio-economic impact of shopping tourism that influence local and sustainable development (Jin et al., 2017).

Outstanding as local development strategies are "Town Centre Management" focused on downtown management models (Coca-Stefaniak et al., 2009) and the Business Improvement Districts (BIDs) used to revitalize the urban centers of British cities such as Birmingham, Plymouth and for the promotion of Tourist Shopping Villages (TSV) (Getz, 1993; Murphy et al., 2011a,b). According to the World Tourism Organization, cities as shopping destinations must take into account accessibility, available infrastructure, security, cleanliness, attractive location, destination marketing and promotion, connection with the tourism value chain, research and development, regulation and adequate training and education (WTO, 2014).

All these strategies condition the choice of tourist destination, so a collaboration is necessary between all the businessmen agents (commercial companies, transport, accommodation), tourism promoters and local institutions. In this sense, the joint participation of all agents to position Spain, or certain cities, as a destination for shopping tourism is very important.

\section{DISCUSSION}

Tourism is an increasingly attractive alternative for improving local commercial activity and, at the same time, retail trade can be an active potential for the city to differentiate itself as a chosen destination (Tourspain, 2015). With proper planning, tourism can be a part of the solution to cities' economic problems by helping to avoid closing businesses in cities that accelerate city

\section{REFERENCES}

Albayrak, T., Caber, M., and Çömen, N. (2016). Tourist shopping: the relationships among shopping attributes, shopping value, and behavioral intention. Tour. Manage. Perspect. 18, 98-106. doi: 10.1016/j.tmp.2016.01.007

Alegre, J., and Cladera, M. (2012). Tourist characteristics that influence shopping participation and expenditures. Int. J. Cult. Tour. Hospital. Res. 6, 223-237. doi: $10.1108 / 17506181211246375$

Chang, J., Yang, B. T., and Yu, C. G. (2006). The moderating effect of salespersons' selling behaviour on shopping motivation and satisfaction: Taiwan tourists in China. Tour. Manage. 27, 934-942. doi: 10.1016/j.tourman.2005.06.001

Chang, K. C. (2014). Examining the effect of tour guide performance, tourist trust, tourist satisfaction, and flow experience on tourists' shopping behavior. Asia Pacific J. Tour. Res. 19, 219-247. doi: 10.1080/10941665.2012.739189 depopulation problems and cause economic losses for families' economies. For this reason, the concept of tourist purchases (WTO, 2014; Tourspain, 2015), gains importance and is defined as an activity in which tourists buy goods during their trip (Jin et al., 2017).

In order for cities to take advantage of the synergies between tourism and trade, it is necessary to analyze the different local development strategies that can be implemented such as: “Town Centre Management" (Coca-Stefaniak et al., 2009), the Business Improvement Districts (BIDs) and the "Tourist Shopping Villages" (TSV) (Getz, 1993; Murphy et al., 2011a,b); and all the variables that cities must have in mind to differentiate themselves as destinations (WTO, 2014; SEGITTUR, 2015).

Given all the variables necessary to promote a city as a tourist shopping destination, it is necessary to establish joint strategies with the participation of all local agents, such as traders and their associations, and local institutions to establish strategies to position cities internationally as a tourist shopping destination, relating to the commercial management of retail establishments in Spain and aimed at promoting quality and sustainable shopping tourism, as one of the strategic lines to boost the competitiveness of the sector (SEGITTUR, 2015; Tourspain, 2015; MINECO, 2017; MINCOTUR, 2019b).

\section{AUTHOR CONTRIBUTIONS}

AM-R, IP-J, and JS-A contributed conception of the opinion article. AM-R wrote the first draft of the manuscript. IP-J and JS-A performed the state of the art and the conceptual framework. All authors contributed to manuscript revision, read and approved the submitted version.

\section{FUNDING}

This work was financed with group grants from the University of Castilla-La Mancha. Co-financed by the European Union through the European Regional Development Fund. Group: Observatory of Innovation in Commercial Distribution (OIDC). And the copy-edition and revision of the translation has been financed with the collaboration of the contract-program of the Faculty of Judicial and Social Sciences of Toledo. 490-501. doi: 10.1016/j.tourman.2016.01.005

Choi, T.-M., Liu, S.-C., Pang, K.-M., and Chow, P.-S. (2008). Shopping behaviors of individual tourists from the Chinese Mainland to Hong Kong. Tour. Manage. 29, 811-820. doi: 10.1016/j.tourman.2007.07.009

Christiansen, T., and Snepenger, D. J. (2002). Is it the mood or the mall that encourages tourists to Shop? J. Shopp. Cent. Res. 9, 7-26. Available online at: http://173.254.37.135/JSCR/IndArticles/Christiansen_N102.pdf

Coca-Stefaniak, J. A., Parker, C., Quin, S., Rinaldid, R., and Byrom, J. (2009). Town centre management models: a European perspective. Cities. 26, 74-80. doi: 10.1016/j.cities.2008.12.001 
Cohen, S. A., Prayag, G., and Moital, M. (2014). Consumer behavior in tourism: concepts, influences and opportunities. Curr. Issues Tour. 17, 872-909. doi: $10.1080 / 13683500.2013 .850064$

Coles, T. (2004). "Tourism, shopping, and retailing: an axiomatic relationship?" in A Companion to Tourism, eds A. A. Lew, C. M. Hall, and A. M. Williams (Blackwell Publishing Ltd.), 360-373. doi: 10.1002/9780470752272.ch29

Dann, G. M. (1981). Tourist motivation an appraisal. Ann. Tour. Res. 8, 187-219 doi: 10.1016/0160-7383(81)90082-7

Getz, D. (1993). Tourist shopping villages: development and planning strategies. Tour. Manage. 14, 15-26. doi: 10.1016/0261-5177(93)90078-Y

Global Blue (2015). Posicionamiento de España como Destino de Compras Informe 2015. Available online at: https://www.globalblue.com/business/spain/ newsroom/presentacion-del-estudio-de-global-blue-posicionamiento-deespana-como-destino-de-compras/

Han, H., Hwang, J., and Kim, Y. (2015). Senior travelers and airport Shopping: deepening repurchase decision-making theory. Asia Pacif. J. Tour. Res. 20, 761-788. doi: 10.1080/10941665.2014.929156

Heung, V. C. S., and Cheng, E. (2000). Assessing tourists' satisfaction with shopping in the Hong Kong special administrative region of China. J. Travel Res. 38, 396-404. doi: 10.1177/004728750003800408

Hult, G. T. M., Morgeson, F. V. III, Morgan, N. A., Mithas, S., and Fornell, C. (2017). Do managers know what their customers think and why? J. Acad. Market. Sci. 45, 37-54. doi: 10.1007/s11747-016-0487-4

Hurst, J. L., and Niehm, L. S. (2012). Tourism shopping in rural markets: a case study in rural Iowa. Int. J. Cult. Tour. Hospital. Res. 6, 194-208. doi: 10.1108/17506181211246357

Jansen-Verbeke, M. (1991). Leisure shopping: a magic concept for the tourism industry? Tour. Manage. 11, 9-14. doi: 10.1016/0261-5177(91)90024-N

Jansen-Verbeke, M. (2000). "Leisure shopping: a magic concept for the tourism industry?" in Tourism Management -Towards the New Millennium, eds C. Ryan and S. Page (Oxford: Elsevier Science Ltd.), 203-210.

Jin, H., Moscardo, G., and Murphy, L. (2017). Making sense of tourist shopping research: a critical review. Tour. Manage. 62, 120-134. doi: 10.1016/j.tourman.2017.03.027

Kattiyapornpong, U., and Miller, K. E. (2012). Propensity to shop: identifying who shops til they drop. J. Travel Tour. Market. 29, 552-565. doi: 10.1080/10548408.2012.703027

Kemperman, A. D. A. M., Borgers, A. W. J., and Timmermans, H. J. P. (2009). Tourist shopping behavior in a historic downtown area. Tour. Manage. 30, 208-218. doi: 10.1016/j.tourman.2008.06.002

Kim, S., and Littrell, M. A. (2001). Souvenir buying intentions for self versus others. Ann. Tour. Res. 28, 638-657. doi: 10.1016/S0160-7383(00)00064-5

Kim, S. S., Timothy, D. J., and Hwang, J. (2011). Understanding Japanese tourists' shopping preferences using the Decision Tree Analysis method. Tour. Manage. 32, 544-554. doi: 10.1016/j.tourman.2010.04.008

Law, R., and $\mathrm{Au}, \mathrm{N}$. (2000). Relationship modeling in tourism shopping: a decision rules induction approach. Tour. Manage. 21, 241-249. doi: 10.1016/S0261-5177(99)00056-4

Lehto, X. Y., Chen, S. Y., and Silkes, C. (2014). Tourist shopping style preferences. J. Vacat. Market. 20, 3-15. doi: 10.1177/1356766713484727

Lloyd, A. E., Yip, L. S. C., and Luk, S. T. K. (2011). An examination of the differences in retail service evaluation between domestic and tourist shoppers in Hong Kong. Tour. Manage. 32, 520-533. doi: 10.1016/j.tourman.2010.04.004

MINCOTUR (2019a). Balance del sector turístico 2018. Ministerio de Industria, Comercio y Turismo. Available online at: https://www.mincotur.gob.es/ es-es/gabineteprensa/notasprensa/2018/documents/20190116\%20balance \%20turismo\%202018.pdf (accessed date 01, 2019).

MINCOTUR (2019b). Directrices generales de la estrategia de turismo sostenible de España 2030. Ministerio de Industria, Comercio y Turismo. Available online at: https://turismo.gob.es/es-es/estrategia-turismo-sostenible/Documents/ directrices-estrategia-turismo-sostenible.pdf (accessed date 01, 2019).

MINECO (2017). Plan Integral de Apoyo a la Competitividad del Comercio Minorista de España 2017. Available online at: http://www.mineco.gob.es/stfls/ mineco/comercio/pdf/170908_Plan_Integral_Comercio_17.pdf (accessed date 06, 2019).

Moscardo, G. (2004). Shopping as a destination attraction: An empirical examination of the role of shopping in tourists' destination choice and experience. J. Vacat. Market. 10, 294-307. doi: 10.1177/135676670401000402
Moscardo, G., and Murphy, L. (2014). There is no such thing as sustainable tourism: re-conceptualizing tourism as a tool for sustainability. Sustainability 6, 2538-2561. doi: 10.3390/su6052538

Murphy, L., Benckendorff, P., Moscardo, G., and Pearce, P. L. (2011a). Tourist Shopping villages: Forms and Functions. New York, NY: Routledge. doi: $10.4324 / 9780203834824$

Murphy, L., Moscardo, G., Benckendorff, P., and Pearce, P. L. (2011b). Evaluating tourist satisfaction with the retail experience in a typical tourist shopping village. J. Retail. Consum. Serv. 18, 302-310. doi: 10.1016/j.jretconser.2011.02.004

Murphy, P., Pritchard, M. P., and Smith, B. (2000). The destination product and its impact on traveller perceptions. Tour. Manage. 21, 43-52 doi: 10.1016/S0261-5177(99)00080-1

Oh, J. Y. J., Cheng, C. K., Lehto, X. Y., and O'Leary, J. T. (2004). Predictors of tourists' shopping behaviour: examination of socio-demographic characteristics and trip typologies. J. Vacat. Market. 10, 308-319. doi: 10.1177/135676670401000403

Rabbiosi, C. (2011). The invention of shopping tourism. The discursive repositioning of landscape in an Italian retail-led case. J. Tour. Cult. Change 9, 70-86. doi: 10.1080/14766825.2010.549233

Rabbiosi, C. (2015). Renewing a historical legacy: tourism, leisure shopping and urban branding in Paris. Cities 42, 195-203. doi: 10.1016/j.cities.201 4.07 .001

Reisinger, Y., and Turner, L. W. (2002). The determination of shopping satisfaction of Japanese tourists visiting Hawaii and the Gold Coast compared. J. Travel Res. 41, 167-176. doi: 10.1177/004728702237417

Ryan, B., Bloms, J., Hovland, J., and Scheler, D. (1999). Tourism and Retail Development: Attracting Tourists to Local Businesses. Center for Community Economic Development. Available online at: https://learningstore.uwex.edu/ Assets/pdfs/G3713.pdf

Saayman, M., and Saayman, A. (2012). Shopping tourism or tourists shopping? Tour. Econom. 18, 1313-1329. doi: 10.5367/te.2012.0169

SEGITTUR (2015). Libro blanco de los Destinos Turísticos Inteligentes. Available online at: https://www.segittur.es/opencms/export/sites/segitur/.content/ galerias/descargas/proyectos/Libro-Blanco-Destinos-Tursticos-Inteligentesok_es.pdf (accessed date 06, 2019).

Snepenger, D. J., Murphy, L., O'Connell, R., and Gregg, E. (2003). Tourists and residents use of a shopping space. Ann. Tour. Res. 30, 567-580. doi: 10.1016/S0160-7383(03)00026-4

Swanson, K. K., and Horridge, P. E. (2006). Travel motivations as souvenir purchase indicators. Tour. Manage. 27, 671-683. doi: 10.1016/j.tourman.2005.03.001

The Shopping and Quality Tourism Institute (2015). I Summit Shopping Tourism and Economy. Turismo de calidad vs. Masificación turística. Available online at: https://issuu.com/summitshoppingtourismeconomy/docs/dossier_ completo_noticias_summit_20 (accessed date 09, 2019).

The Shopping and Quality Tourism Institute (2017). Plan estratégico para el turismo de compras y de calidad en España 2018-2020. Available online at: http://www.crones.es/pdf/Plan_Turismo_Compras.pdf (accessed date 09,2019 ).

Timothy, D. J. (2005). Shopping Tourism, Retailing, and Leisure. Brístol: Channel View Publications. doi: 10.21832/9781873150610

Timothy, D. J. (2014). "Trends in tourism, shopping, and retailing," in The Wiley Blackwell Companion to Tourism, eds A. A. Lew, C. M. Hall, and A. M. Williams (Wiley), 378-388. doi: 10.1002/9781118474648.ch30

Tosun, C., Temizkan, S. P., Timothy, D. J., and Fyall, A. (2007). Tourist shopping experiences and satisfaction. Int. J. Tour. Res. 9, 87-102. doi: 10.1002/jtr.595

Tourspain (2015). Plan de Turismo de Compras 2015, Instituto de Turismo de España, Ministerio de Industria, Energía y Turismo y Ministerio de Economía y Competitividad. Avaialble online at: http://www.tourspain.es/Documents/Plan \%20de\%20Turismo\%20de\%20Compras.pdf (accessed date 04, 2019).

Tourspain (2018). Plan Estratégico de Marketing 2018-2020. Instituto de Turismo de España, Ministerio de Industria, Energía y Turismo y Ministerio de Economía y Competitividad. Available online at: http://www.tourspain.es/es-es/VDE/ Documentos\%20Plan\%20Estratgico\%20de\%20Marketing/PEM\%2018-20.pdf (accessed date 04, 2019).

Travé, R. (2019). Turismo de compras. Centro de Investigación, Divulgación e Innovación en Turismo de Ostelea School of Tourism, and Hospitality. 
IDITUR-OSTELEA. Available online at: http://www.aept.org/archivos/ documentos/informe_ostelea_compras_0.pdf (accessed date 04, 2019).

Tugcu, C. T. (2014). Tourism and economic growth nexus revisited: A panel causality analysis for the case of the Mediterranean Region. Tour. Manage. 42, 207-212. doi: 10.1016/j.tourman.2013.12.007

Webster, C., and Ivanov, S. (2014). Transforming competitiveness into economic benefits: does tourism stimulate economic growth in more competitive destinations? Tour. Manage. 40, 137-140. doi: 10.1016/j.tourman.2013.06.003

Wong, I. A., and Wan, Y. K. P. (2013). A systematic approach to scale development in tourist shopping satisfaction: Linking destination attributes and shopping experience. J. Travel Res. 52, 29-41. doi: 10.1177/0047287512457263

Wong, J., and Law, R. (2003). Difference in shopping satisfaction levels: a study of tourists in Hong Kong. Tour. Manage. 24, 401-410. doi: 10.1016/S0261-5177(02)00114-0

WTO (2014). Global Report on Shopping Tourism, AM Reports. Madrid: UNWTO. Available online at: https://www.e-unwto.org/doi/book/10.18111/ 9789284416172

WTO (2016). El turismo y los Objetivos de Desarrollo Sostenible. Madrid: UNWTO. Available online at: https://www.e-unwto.org/doi/pdf/10.18111/ 9789284417766

WTO (2017). Tourism Highlights. Madrid: UNWTO. Available online at: https:// www.e- unwto.org/doi/pdf/10.18111/9789284419029

WTO (2018), Tourism Highlights, 2018 Edition. Madrid: UNWTO.

Yazdani, M. (2007). An investigation on influencing factors on tourists shopping attitude of iranian handmade carpet in Isfahan. Master's thesis, Luleå University of Technology, Department of Business Administration and Social Sciences, 1-85. Luleå, Sweden. Available online at: http://www.diva-portal.org/smash/ get/diva2:1017509/FULLTEXT01.pdf

Yu, H., and Littrell, M. (2003). Product and process orientations to tourism shopping. J. Travel Res. 42, 140-150. doi: 10.1177/0047287503257493
Yüksel, A. (2004). Shopping experience evaluation: a case of domestic and international visitors. Tour. Manage. 25, 751-759. doi: 10.1016/j.tourman.2003.09.012

Yüksel, A. (2007). Tourist shopping habitat: effects on emotions, shopping value and behaviours. Tour. Manage. 28, 58-69. doi: 10.1016/j.tourman.2005. 07.017

Yüksel, A., and Yüksel, F. (2007). Shopping risk perceptions: Effects on tourists' emotions, satisfaction and expressed loyalty intentions. Tour. Manage. 28, 703-713. doi: 10.1016/j.tourman.2006.04.025

Yüksel, F. (2013). The streetscape: effects on shopping tourists' product/service quality inferences and their approach behaviors. J. Qual. Assur. Hospit. Tour. 14, 101-122. doi: 10.1080/1528008X.2013.749387

Žabkar, V., Brenčič, M. M., and Dmitrović, T. (2010). Modelling perceived quality, visitor satisfaction and behavioural intentions at the destination level. Tour. Manage. 3, 537-546. doi: 10.1016/j.tourman.2009.06.005

Zupan, K. S. (2019). From Industry 4.0 to Tourism 4.0. Innov. Issues Approach. Soc. Sci. 12, 29-52. doi: 10.12959/issn.1855-0541.IIASS-2019-n o3-art3

Conflict of Interest: The authors declare that the research was conducted in the absence of any commercial or financial relationships that could be construed as a potential conflict of interest.

Copyright (C) 2020 Muro-Rodríguez, Pérez-Jiménez and Sánchez-Araque. This is an open-access article distributed under the terms of the Creative Commons Attribution License (CC BY). The use, distribution or reproduction in other forums is permitted, provided the original author(s) and the copyright owner(s) are credited and that the original publication in this journal is cited, in accordance with accepted academic practice. No use, distribution or reproduction is permitted which does not comply with these terms. 


\title{
Proposal for Lines of Research Into Consumer Behavior: Examples in the Tourism Industry
}

\author{
Juan Jose Blazquez-Resino ${ }^{1 *}$, Santiago Gutiérrez-Broncano ${ }^{1}$ and Mario Arias-Oliva ${ }^{2}$ \\ ${ }^{1}$ Department of Business Administration, Faculty of Social Science, University of Castilla La Mancha, Ciudad Real, Spain, \\ ${ }^{2}$ Department of Business Management, Faculty of Business and Economics, Rovira i Virgili University, Reus, Spain
}

Keywords: active attitudinal loyalty, passive attitudinal loyalty, behavioral loyalty, tourist destination image, tourist loyalty

\section{INTRODUCTION}

Departing from the high relevance that loyalty plays in the promotion of tourist destinations, the study of the variables that result in loyalty is key. For this reason, there are myriads of studies devoted to the analysis of the variables that result in loyalty, especially considering either or both attitudinal and behavioral loyalty; in turn, relatively less frequent are the studies that also/instead consider active and passive loyalty. Within this research line, we go one step further and propose the importance of focusing on the study of the variables that are conducive to attitudinal and behavioral loyalty; moreover, within attitudinal loyalty, we also acknowledge the distinction of two further types of loyalty, that is, active attitudinal and passive attitudinal loyalty. This opinion paper aims at adding knowledge to the field of consumer behavior in tourism, proposing the importance of studying the variables that are able to drive loyalty in a very differentiated way (active attitudinal loyalty, passive attitudinal loyalty, and behavioral loyalty).

Open University of Catalonia, Spain

Reviewed by:

Rocío Martínez Torres, University of Seville, Spain

Mercedes Rubio Andres, CEU San Pablo University, Spain

*Correspondence:

Juan Jose Blazquez-Resino Juan.Blazquez@uclm.es

Specialty section

This article was submitted to Organizational Psychology, a section of the journal Frontiers in Psychology

Received: 09 November 2019 Accepted: 10 January 2020 Published: 19 February 2020

Citation:

Blazquez-Resino JJ,

Gutiérrez-Broncano $S$ and Arias-Oliva M (2020) Proposal for Lines of Research Into Consumer Behavior: Examples in the Tourism Industry. Front. Psychol. 11:64 doi: 10.3389/fpsyg.2020.00064

\section{PROPOSING A NEW RESEARCH LINE}

Loyalty is a key variable in all economic sectors and industries, so there is no doubt that looking for loyalty is a key priority. In fact, it has been largely proven how loyalty is essential for achieving key company indicators such as long-term competition, profitability, and survival (Jacoby and Chestnut, 1978; Dick and Basu, 1994; Garbarino and Johnson, 1999; Uncles et al., 2003; RundleThiele, 2005; Kim and Li, 2009). In the tourism industry, loyalty is generally regarded as the best predictor for future tourist behavior, as well as a source of success in the market, in addition to providing competitive superiority (Kim and Brown, 2012; Sun et al., 2013; Gursoy et al., 2014; Maghsoodi et al., 2016; Almeida-Santana and Moreno-Gil, 2018; Cossío-Silva et al., 2019). Hence, a key objective for tourist destinations is to attract and retain their target market (Gursoy et al., 2014; Cossío-Silva et al., 2019). These considerations are of special relevance for countries such as Spain, where tourism is one of the main industries, and the economy relies, to a great extent, on tourism (Balaguer and Cantavella-Jorda, 2002; Camisón et al., 2016).

In the marketing literature, several research studies showed how within loyalty, a further distinction between attitudinal loyalty and behavioral loyalty could be made (e.g., Day, 1969; Jacoby, 1971; Jacoby and Kyner, 1973; Lutz and Winn, 1974; Dick and Basu, 1994; Yoon and Kim, 2000; Bowen and Chen, 2001; Chaudhuri and Holbrook, 2001; Lam et al., 2004; Söderlund, 2006). In general, while attitudinal loyalty refers to positive attitudes held by customers toward a particular brand or store, behavioral loyalty refers to repeat purchases by a customer at a specific brand or store (Day, 1969; Dick and Basu, 1994). While it is common to encourage the design of strategies to boost both types of loyalty, it has been observed how sometimes, attitudes might not necessarily lead to repeat patronage. In fact, previous research suggested that attitudinal loyalty not in the 
presence of re-patronage behavior, and re-patronage not in the presence of attitudinal loyalty, could be conceptualized (Day, 1969; Dick and Basu, 1994; Reynolds and Beatty, 1999). These latter phenomena are sometimes due to custom, chance, or other factors (Day, 1969). In either case, it is very important to refer to both types of loyalty, that is, attitudinal and behavioral loyalty, as two separate constructs, despite the fact of such constructs being inter-related (Dick and Basu, 1994; Bemmaor, 1995; Chandon et al., 2005; Liu, 2007). This perspective is also acknowledged in the tourism literature, where a vast number of studies (e.g., Faullant et al., 2008; Wang et al., 2010; Kursunluoglu, 2011; Forgas-Coll et al., 2012; Prayag and Ryan, 2012; Zhang et al., 2014; Llodrà-Riera et al., 2015) also consider loyalty as a twodimensional variable, that is, a variable that consists of two separate and inter-related constructs of both attitudinal and behavioral loyalty.

Relatively less analyzed is the further distinction between two other types of loyalty, that is to say, active loyalty and passive loyalty. One of the studies that considered this distinction in the services literature is the research of Ganesh et al. (2000). In this work, loyalty could be considered as either active or passive depending on the predisposition of clients to collaborate with the company. From this point of view, active loyalty was then conceptualized as word-of-mouth communication (WOM), requiring an active compromise reflecting the emotional bonds with the client. Sharing this perspective, Kandampully et al. (2015) suggested that active loyalty was exhibited by those clients that had both a firm compromise and a strong will to serve as ambassadors of the brand, supporting the products and services of the company with a positive WOM. In this regard, social media technologies fostered the development of research oriented to assess both active and passive loyalty. For example, Van Asperen et al. (2018) considered two types of clients' participation in social media: the consumption of social media as passive participation and contribution in social media as active participation. This differentiation could be the key to understand why a recommendation succeeded or, the other way around, failed.

There is no doubt that this proposed research line is of key importance. Departing from the high relevance that loyalty plays in the promotion of tourist destinations, given its connections to long-term profit variables such as long-term competitiveness, profitability, and survival, the study of the variables that result in loyalty is key, especially in countries such as Spain, where tourism is without a doubt the main industry, and the economy relies, to a

\section{REFERENCES}

Almeida-Santana, A., and Moreno-Gil, S. (2018). Understanding tourism loyalty: horizontal vs. destination loyalty. Tour. Manage. 65, 245-255. doi: 10.1016/j.tourman.2017.10.011

Balaguer, J., and Cantavella-Jorda, M. (2002). Tourism as a long-run economic growth factor: the Spanish case. Appl. Econ. 34, 877-884. doi: $10.1080 / 00036840110058923$

Bemmaor, A. C. (1995). Predicting behavior from intention-to-buy measures: the parametric case. J. Market. Res. 32, 176-191. doi: 10.1177/002224379503200205 greater extent, on tourism (Nowak et al., 2007). Spain's economic growth has been positively affected by the persistent expansion of inbound tourism in recent decades (Sokhanvar, 2019). For example, the results obtained in 2018 in terms of the number of foreign visitors to this country were 89,856 million, a $1.1 \%$ increase in arrivals over the previous year, which represents an increase in international tourist spending by 3.3\% (Ministerio de Energía y Turismo, 2019). These data make Spain as the second country in the world in terms of foreign tourist arrivals (World Tourism Organization, 2019).

\section{DISCUSSION}

Loyalty is often measured by the joint use of its behavioral and attitudinal components. In some markets, such as tourism, repeat visits (behavioral loyalty) may be limited due to other variables, such as "search for variety." However, a tourist who does not repeat a visit to the same destination may have an important attitudinal loyalty toward that destination and be willing to strongly recommend his visit. Therefore, this opinion paper has been aimed at showing how in the field of consumer behavior in tourism marketing, it is still possible to propose new future lines of research. One of them is to analyze the differences between active and passive attitude loyalty. Although some previous work in this area had shown differences between the active and passive behavior of consumers as opposed to the use of information sources (Ganesh et al., 2000; Kandampully et al., 2015), the difference between active and passive attitudinal loyalty had not been addressed. It is especially relevant to carry out work aimed at analyzing this line of research, especially given the relevance that the development of social networks can give to it.

\section{AUTHOR CONTRIBUTIONS}

All authors listed have made a substantial, direct and intellectual contribution to the work, and approved it for publication.

\section{ACKNOWLEDGMENTS}

This research has been financed by Research Group Grants from the University of Castilla-La Mancha. Co-financed by the European Union through the European Regional Development Funds. Research Group: Observatory of Innovation in Commercial Distribution (OIDC). and customer satisfaction. Int. J. Contemp. Hosp. Manage. 13, 213-217. doi: 10.1108/09596110110395893

Camisón, C., Puig-Denia, A., Forés, B., Fabra, M. E., Muñoz, A., and Munoz Martinez, C. (2016). The importance of internal resources and capabilities and destination resources to explain firm competitive position in the Spanish tourism industry. Int. J. Tour. Res. 18, 341-356. doi: 10.1002/jtr.2053

Chandon, P., Morwitz, V. G., and Reinartz, W. J. (2005). Do intentions really predict behavior? Self-generated validity effects in survey research. J. Market. 69, 1-14. doi: 10.1509/jmkg.69.2.1.60755 
Chaudhuri, A., and Holbrook, M. B. (2001). The chain of effects from brand trust and brand affect to brand performance: the role of brand loyalty. J. Market. 65, 81-93. doi: 10.1509/jmkg.65.2.81.18255

Cossío-Silva, F. J., Revilla-Camacho, M. Á., and Vega-Vázquez, M. (2019). The tourist loyalty index: a new indicator for measuring tourist destination loyalty? J. Innov. Knowl. 4, 71-77. doi: 10.1016/j.jik.2017.10.003

Day, G. S. (1969). A two dimensional concept of brand loyalty. J. Advertis. Res. 9, 29-36.

Dick, A. S., and Basu, K. (1994). Customer loyalty: toward an integrated conceptual framework. J. Acad. Market. Sci. 22, 99-113. doi: 10.1177/0092070394222001

Faullant, R., Matzler, K., and Füller, K. J. (2008). A positioning map of skiing areas using customer satisfaction scores. J. Hosp. Leisure Market. 16, 230-245. doi: 10.1080/10507050801946833

Forgas-Coll, S., Palau-Saumell, R., Sánchez-García, J., and Callarisa-Fiol, L. J. (2012). Urban destination loyalty drivers and cross-national moderator effects: the case of Barcelona. Tour. Manage. 33, 1309-1320. doi: 10.1016/j.tourman.2011.12.013

Ganesh, J., Arnold, M. J., and Reynolds, K. E. (2000). Understanding the customer base of service providers: an examination of the differences between switchers and stayers. J. Market. 64, 65-87. doi: 10.1509/jmkg.64.3.65.18028

Garbarino, E., and Johnson, M. S. (1999). The different roles of satisfaction, trust, and commitment in customer relationships. J. Market. 63, 70-87. doi: $10.1177 / 002224299906300205$

Gursoy, D. S., Chen, J., and Chi, C. G. (2014). Theoretical examination of destination loyalty formation. Int. J. Contemp. Hosp. Manage. 26, 809-827. doi: 10.1108/IJCHM-12-2013-0539

Jacoby, J. (1971). "Brand loyalty: a conceptual definition," in Proceedings of the Annual Convention of the American Psychological Association (Seattle, WA: American Psychological Association). doi: 10.1037/e611322012-087

Jacoby, J., and Chestnut, R. W. (1978). Brand Loyalty: Measurement and Management. New York, NY: John Wiley \& Sons.

Jacoby, J., and Kyner, D. B. (1973). Brand loyalty vs. repeat purchasing behavior. J. Market. Res. 10, 1-9. doi: 10.1177/002224377301000101

Kandampully, J., Zhang, T., and Bilgihan, A. (2015). Customer loyalty: a review and future directions with a special focus on the hospitality industry. Int. J. Contemp. Hosp. Manage. 27, 379-414. doi: 10.1108/IJCHM-03-2014-0151

Kim, A. K., and Brown, G. (2012). Understanding the relationships between perceived travel experiences, overall satisfaction, and destination loyalty. Anatolia 23, 328-347. doi: 10.1080/13032917.2012.696272

Kim, Y. G., and Li, G. (2009). Customer satisfaction with and loyalty towards online travel products: a transaction cost economics perspective. Tour. Econ. 15, 825-846. doi: 10.5367/000000009789955125

Kursunluoglu, E. (2011). Customer service effects on customer satisfaction and customer loyalty: a field research in shopping centers in Izmir City-Turkey. Int. J. Bus. Soc. Sci. 2, 52-59. doi: 10.30845/ijbss

Lam, S. Y., Shankar, V., Erramilli, M. K., and Murthy, B. (2004). Customer value, satisfaction, loyalty, and switching costs: an illustration from a business-to-business service context. J. Acad. Market. Sci. 32, 293-311. doi: $10.1177 / 0092070304263330$

Liu, Y. (2007). The long-term impact of loyalty programs on consumer purchase behaviour and loyalty. J. Market. 71, 19-35. doi: 10.1509/jmkg.71.4.19

Llodrà-Riera, I., Martínez-Ruiz, M. P., Jiménez-Zarco, A. I., and Izquierdo-Yusta, A. (2015). A multidimensional analysis of the information sources construct and its relevance for destination image formation. Tour. Manage. 48, 319-328. doi: 10.1016/j.tourman.2014.11.012

Lutz, R. J., and Winn, P. R. (1974). "Developing a Bayesian measure of brand loyalty: a preliminary report," in Combined Proceedings (Chicago, IL: American Marketing Association), 104-108.
Maghsoodi, M. J., Hedayati, M., Abdullah, A., and Bahauddin, A. (2016). Examining the influence of international tourists' destination image and satisfaction on their behavioral intention in Penang, Malaysia. J. Qual. Assurance Hosp. Tour. 17, 425-452. doi: 10.1080/1528008X.2015.10 96756

Ministerio de Energía y Turismo (2019). Available online at: https://www. mincotur.gob.es/es-es/GabinetePrensa/NotasPrensa/2019/Paginas/20190201gasto-llegadas-turistas.aspx (October 30, 2019).

Nowak, J. J., Sahli, M., and Cortés-Jiménez, I. (2007). Tourism, capital good imports and economic growth: theory and evidence for Spain. Tour. Econ. 13, 515-536. doi: 10.5367/000000007782696113

Prayag, G., and Ryan, C. (2012). Antecedents of tourists' loyalty to Mauritius: the role and influence of destination image, place attachment, personal involvement, and satisfaction. J. Travel Res. 51, 342-356. doi: $10.1177 / 0047287511410321$

Reynolds, K. E., and Beatty, S. E. (1999). Customer benefits and company consequences of customer-salesperson relationships in retailing. J. Retail. 75, 11-13. doi: 10.1016/S0022-4359(99)80002-5

Rundle-Thiele, S. (2005). Exploring loyal qualities: assessing survey-based loyalty measures. J. Serv. Market. 19, 492-500. doi: 10.1108/08876040510625990

Söderlund, M. (2006). Measuring customer loyalty with multi-item scales: a case for caution. Int. J. Serv. Indus. Manage. 17, 76-98. doi: 10.1108/09564230610651598

Sokhanvar, A. (2019). Does foreign direct investment accelerate tourism and economic growth within Europe?. Tour. Manage. Perspect. 29, 86-96. doi: 10.1016/j.tmp.2018.10.005

Sun, X., Chi, C. G. Q., and Xu, H. (2013). Developing destination loyalty: the case of Hainan Island. Ann. Tour. Res. 43, 547-577. doi: 10.1016/j.annals.2013.04.006

Uncles, M. D., Dowling, G. R., and Hammond, K. (2003). Customer loyalty and customer loyalty programs. J. Consumer Market. 20, 294-316. doi: 10.1108/07363760310483676

Van Asperen, M., de Rooij, P., and Dijkmans, C. (2018). Engagementbased loyalty: the effects of social media engagement on customer loyalty in the travel industry. Int. J. Hosp. Tour. Admin. 19, 78-94. doi: $10.1080 / 15256480.2017 .1305313$

Wang, Y. J.,Wu, K., and Yuan, J. (2010). Exploring visitors' experiences and intention to revisit a heritage destination: the case for Lukang, Taiwan. J. Qual. Assurance Hosp. Tour 11, 162-178. doi: 10.1080/1528008X.2010.483418

World Tourism Organization (2019). International Tourism Highlights. Madrid: UNWTO.

Yoon, S. J., and Kim, J. H. (2000). An empirical validation of a loyalty model based on expectation disconfirmation. J. Consumer Market. 17, 120-136. doi: 10.1108/07363760010317196

Zhang, H., Fu, X., Cai, L. A., and y Lu, L. (2014). Destination image and tourist loyalty: a meta-analysis. Tour. Manage. 40, 213-223. doi: 10.1016/j.tourman.2013.06.006

Conflict of Interest: The authors declare that the research was conducted in the absence of any commercial or financial relationships that could be construed as a potential conflict of interest.

Copyright (C) 2020 Blazquez-Resino, Gutiérrez-Broncano and Arias-Oliva. This is an open-access article distributed under the terms of the Creative Commons Attribution License (CC BY). The use, distribution or reproduction in other forums is permitted, provided the original author(s) and the copyright owner(s) are credited and that the original publication in this journal is cited, in accordance with accepted academic practice. No use, distribution or reproduction is permitted which does not comply with these terms. 


\section{OPEN ACCESS}

Edited by:

Ana Jiménez-Zarco,

Open University of Catalonia, Spain

Reviewed by:

Ye Sun,

The University of Utah, United States Ana-Belén Rio-Lanza, University of Oviedo, Spain

*Correspondence: Anne Schmitz anne.schmitz@uam.es

Specialty section: This article was submitted to

Organizational Psychology, a section of the journal

Frontiers in Psychology

Received: 20 January 2020 Accepted: 30 March 2020 Published: 24 April 2020

Citation:

Díaz-Martín AM, Schmitz A and Yagüe Guillén MJ (2020) Are Health

e-Mavens the New Patient

Influencers? Front. Psychol. 11:779.

doi: 10.3389/fpsyg.2020.00779

\section{Are Health e-Mavens the New Patient Influencers?}

\author{
Ana M. Díaz-Martín, Anne Schmitz* and María Jesús Yagüe Guillén \\ Departamento de Financiación e Investigación Comercial, Universidad Autónoma de Madrid, Madrid, Spain
}

Even though the healthcare industry is usually considered a rather traditional and slowly evolving sector, change is happening. Digitalization is transforming the way of obtaining medical advice and treatment and the Internet has become a key source for the seeking of healthcare information. It has allowed people to turn into more active collaborators in matters of their own health by enabling them to easily search and share information with other patients. Although research points out the growing importance of usergenerated content in many sectors and its positive impact on information credibility, trust, engagement, and, ultimately, customer behavior (Malthouse et al., 2016), there is a lack of attention to this topic in healthcare. In this brief review, we address this gap by analyzing the role of health e-mavens, which are a particular type of influencers that possesses both expertise and online social influence. We lastly illustrate possible benefits of their impact on other to the different parties involved and affected by this phenomenon.

Keywords: e-Mavenism, health e-Mavenism, healthcare, patient influencer, eHealth

\section{INTRODUCTION}

Traditionally, physicians have played a key role in providing health information to their patients, but, over the last few decades, there has been a considerable transformation of the forms of obtaining and retrieving medical advice. At the risk of stating the obvious, the Internet clearly is the most important disrupter and has marked a before and after for the healthcare industry. At the beginning of the 21st century, when the WWW was spreading, information provided by a personal doctor on the web and by medical universities and government sites became the most trusted sources of online health information (Dutta-Bergman, 2003). In today's media landscape, patients are turning to the Internet also to search for peer-to-peer recommendations (Lutkenhaus et al., 2019).

Therefore, whereas in the past health information was created by doctors and used by patients, nowadays these lines become blurry as patients are increasingly in charge of their own health, collaborate with healthcare professionals rather than passively receive information from them and even create their own health recommendations for other users. This shift toward more informed, empowered and enabled patients is both desired and handy and has clear implications on the ways people interact with healthcare professionals and the healthcare system itself (Chu et al., 2017).

The Internet has become a tool to support the emergence of the educated and empowered health consumer (Powell et al., 2011) and it is frequently used by people to investigate about the meaning of symptoms, tests, diagnoses and treatments or even to have access to other peoples' 
ratings, experiences, opinions or advice (O'Neill et al., 2014). Consequently, both the amount and the use of health information on the Internet are constantly growing (Dubowicz and Schulz, 2015).

In addition, new medical technologies such as electronic health records, health wearables, robotic surgery or even 3Dprinting have already become part of modern healthcare, and even more innovative applications and concepts such as artificial intelligence, virtual reality or the sharing economies are no longer seen as "strangers" in the field. According to Metwally (2017), these new healthcare related technologies and the data they generate will have the same impact on the sector as Uber has had on the transport sector or Airbnb on the tourism and hospitality industry.

Therefore, in an environment where the online world meets the offline world and where interactions among patients and between them and healthcare companies are increasingly seamless and digital, there is a need to carefully study both the content that is being generated and the way people use and interpret online health information (Cuomo et al., 2020). This could be true for any industry, but it is particularly relevant for the healthcare sector, since making decisions about health issues is more complicated than choosing a pair of shoes and not all individuals are equally qualified to generate and disseminate health information. At this particular moment, for example, the spread of pseudoscience around COVID-19 through social networks has been fast and dangerous.

In summary, when it comes to healthcare, information exchange clearly is on the rise. The voice of the customer is of paramount importance. In the following section, we will review the role of user-generated content in the healthcare setting.

\section{USER-GENERATED CONTENT IN HEALTHCARE}

The relevance of user-generated content is well established and recognized in different sectors. Industries such as fashion, tourism and beauty have already picked up on the importance and the impact of user generated content, exploiting and taking advantage of its impact and convenience for firms, brands and marketers (Lutkenhaus et al., 2019; Zhou et al., 2019). Staff (2018) even claims that people trust influencers more than they trust a brand and, additionally, a report by Nielsen (2015) revealed that about $83 \%$ of people completely or somewhat trust the recommendations of friends and family, and about $66 \%$ trust consumer opinions posted online.

Similar to other contexts, patients talk and exchange experiences about health problems, drug related issues and experiences and other aspects related to their health condition in different forums and social networks, where content is created, shared and used (Martínez et al., 2016). Lavorgna et al. (2017) confirm that many patients with a chronic illness rely on the Internet as their main source of information. A report published by patient-leader network Wegohealth (2018) has shown that patients are not only more likely to respond to content that comes from another patient "just like them", but also for about $92 \%$ of the sample, online communities such as Facebook, Twitter, blogs, discussion groups and other social media sites play a significant role in their health decisions. Serving as an example in this case, a morning sickness drug recommendation on social media by influencer Kim Kardashian boosted sales by $21 \%$ (Thomas, 2019). Recent research also shows that patients find content created by other patients to be more authentic and trustworthy than content created by healthcare companies (Kanski, 2019).

But who are those individuals that are behind the healthcare content that is being created on the Internet? Eventually, anyone could post healthcare information on the WWW, but not all users are able to engage with patients and give them significant and trustworthy information. The fact that people do actively disseminate and look for health content on the web needs to be acknowledged, but it may not be forgotten that, for some people, this new role can be overwhelming and somewhat intimidating (Parker-Pope, 2008). Patients need assistance to find reliable information and, given the declining appeal of traditional health informants, such as physicians, it is important to identify active users that provide honest online health information, who are willing to share their data in order to help other patients and whose content is perceived as useful and authentic. These knowledgeable influencers are called health e mavens. Despite their relevance, there is scarce research about market mavens in social media and their influence on other patients (Cengiz et al., 2016; Agopian, 2019). A theoretical approach to this question will be offered in the next section.

\section{HEALTH E-MAVENS AND RELATED CONCEPTS}

Feick and Price (1987) coined the term market mavens and defined them as consumers who have early awareness and possess high levels of knowledge and information about many products, brands, places to shop, and other facets of the market, initiate discussions with consumers and respond to requests for market information, and regularly influence people's consumption decisions.

Therefore, market mavens are a type of influencers who pair their social influence with expertise. Influencers have a social impact, but lack expertise. Also, while content shown by influencers on social media is often sponsored and does not necessarily require personal involvement, market mavens are not driven for profit motive, they stand out by their genuine desire to help and assist others. It is important to highlight that mavens are perceived as highly reliable by other customers, which is a trait that is particularly interesting considering that people are becoming more conscious about trusting formal marketing efforts made by companies (Kiani and Laroche, 2019).

A market maven can also be seen as an opinion leader. In fact, the terms market maven and opinion leader are sometimes used interchangeably (Agopian, 2019). Nevertheless, opinion leaders are more domain specific (Dix, 2015; Casaló et al., 2018) and may have no social influence at all.

Over the years, the growing importance of online activities has led to the term e-mavens. E-mavens are the virtual version 
of market mavens and they have become a salient topic in the last decade, due to the shift of the channel through which information is acquired and spread by consumers and firms. They are just like market mavens except for the channel they use to communicate with other people. To date, few studies have shed some light on the demographic, psychographic and behavioral profiles of market mavens on the Internet (Belch et al., 2005; Zhang, 2010; Yang, 2013). Researchers agree that demographic variables contribute little to explain e-mavenism and demonstrate that psychographic and technological factors are significant antecedents of e-mavenism.

Combining the above mentioned concepts and applying them to healthcare, Sun et al. (2016) developed the concept of health e-mavens. They define health e-mavens as "individuals who are consistently and actively involved with health information acquisition and information transmission on the web space" (Sun et al., 2016, p. 1073). So, health e-mavens are experts that have social influence and provide general information about health goods and services on the Internet. They respond to requests from patients and actively participate in online communication and discussions. Compared to other types of influencers, they have a sense of obligation to inform patients and they enjoy helping others. Above all, they are not perceived as an elite or exclusive group of opinion leaders.

According to Sun et al. (2016), the health e-maven construct consists of two factors: one known as information acquisition (it includes the tracking of health information on various devices and consulting, meaning checking online rankings or reviews of doctors, hospitals or drugs) and another one described as information transmission (it is based on people's active behavior of posting, for example, online rankings or reviews of doctors, hospitals and drugs and sharing health information on social media platforms). In this seminal research work, the authors designed a Likert-type scale to measure health e-mavenism and empirically validated its behavioral dimensions. The health e-maven construct opens interesting research opportunities to be further developed, since it promises theoretical and practical insights for health scholars and managers in the age of new and social media technologies.

\section{CONCLUSION AND DISCUSSION}

Healthcare systems all around the world are undergoing huge changes. Patients are not only more demanding, but they are also becoming familiar with new ways of dealing with healthcare information in online and offline environments. Nowadays,

\section{REFERENCES}

Agopian, G. (2019). Toward a Framework for Establishing Social Media Market Mavenism: An Expertise Presentation Approach. Doctoral dissertation, Rensselaer Polytechnic Institute, Troy, NY.

Belch, M. A., Krentler, K. A., and Willis-Flurry, L. A. (2005). 'Teen internet mavens: influence in family decision making'. J. Bus. Res. 58, 569-575.

Casaló, L. V., Flavián, C., and Ibáñez-Sánchez, S. (2018). Influencers on instagram: antecedents and consequences of opinion leadership. J. Bus. Res. (in press). markets widely acknowledge the importance of opinion leaders, influencers and market mavens as intermediaries and boosters of information exchange on the Internet.

The aim of this short review is to relate the concept of health e-mavens (Sun et al., 2016) to the framework of user-generated content in the healthcare sector and their potential to act as patient influencers. Since they combine both the potential to influence and the necessary expertise to do so, they should be considered by all stakeholders as important individuals with whom to collaborate and also an interesting research topic.

Knowing that user-generated content in healthcare is practically still in its infancy, it is important to investigate the specific profiles of health eMavens: what characteristics distinguish them? Are those antecedents similar all over the world? Are health and technology literacy relevant factors in explaining the variance in health e-mavenism? Does altruism stimulate users to engage in an e-maven like behavior?

In times where "fake news" and hoaxes spread like wildfire, it is crucial to assure the quality and the integrity of the information that is shared over the internet. Future research should monitor the content generated by health e-mavens combining data mining, machine learning and qualitative research techniques to analyze their materials. It would also be interesting to address the effects of such content on those who consume it and on healthcare professionals: does it affect their intention to spread eWOM? How do patients and physicians use the content created by e-mavens in their search of well-being? Both the patients and the health service providers' perspectives need to be better understood.

Health e-mavens represent, as well, a critical group for health promotion practitioners to recruit and mobilize in various web-based health intervention programmers or online health communication campaigns. Recognizing the decisive influence of health e-mavens and collaborating with them is crucial for healthcare organizations trying to develop a successful social media strategy. How do firms identify them? And how should they appeal to them?

In our opinion, health managers, social media administrators, health e-mavens, data scientists, marketing researchers and influencer agencies could benefit from working together on these relevant questions.

\section{AUTHOR CONTRIBUTIONS}

Authors are listed in alphabetical order and have all made a substantial contribution to this manuscript.

Cengiz, E., Akyuz, I., Omay, G. G., and Bosat, M. (2016). Defining health mavens on demographic characteristics: a pilot study in Istanbul. Eur. Sci. J. 12, 93-104. doi: 10.19044/esj.2016.v12n13p93

Chu, J. T., Wang, M. P., Shen, C., Viswanath, K., Lam, T. H., and Chan, S. S. C. (2017). How, when and why people seek health information online: qualitative study in Hong Kong. Interact. J. Med. Res. 2:e24. doi: 10.2196/ijmr.7000

Cuomo, M., Tortora, D., Giordano, A., Festa, G., Metallo, G., and Martinelli, E. (2020). User-generated content in the era of digital well-being: a netnographic analysis in a healthcare marketing context. Psychol. Mark. 37, 578-587. 
Dix, M. J. (2015). What are The Possible Futures Impacts of Patient Opinion Leaders on Healthcare and Healthcare Stakeholders?. Bachelor Thesis, Haute École de Gestion de Genève, Switzerland.

Dubowicz, A., and Schulz, P. J. (2015). Medical information on the internet: a tool for measuring consumer perception of quality aspects. Interact. J. Med. Res. 4:e8. doi: 10.2196/ijmr.3144

Dutta-Bergman, M. (2003). Trusted online sources of health information: differences in demographics, health beliefs, and health-information orientation. J. Med. Internet Res. 5:e21.

Feick, L. F., and Price, L. L. (1987). The market maven: a diffuser of marketplace information. J. Mark. 51, 83-97. doi: 10.2307/1251146

Kanski, A. (2019). Survey: Patient Influencers Trust Social Media more than Pharma Websites. Available online at: https://www.mmm-online.com/home/channel/ survey-patient-influencers-trust-social-media-more-than-pharma-websites/ (accessed September 22, 2019).

Kiani, I., and Laroche, M. (2019). From desire to help to taking action: effects of personal traits and social media on market mavens' diffusion of information. Psychol. Mark. 36, 1147-1161. doi: 10.1002/mar.21263

Lavorgna, L., Lanzillo, R., Brescia Morra, V., Abbadessa, G., Tedeschi, G., and Bonavita, S. (2017). Social media and multiple sclerosis in the posttruth age. Interact. J. Med. Res. 6:e18. doi: 10.2196/ijmr.7879

Lutkenhaus, R. O., Jansz, J., and Bouman, M. P. (2019). Tailoring in the digital era: stimulating dialogues on health topics in collaboration with social media influencers. Digital Health 5, 1-11. doi: 10.1177/2055207618821521

Malthouse, E. C., Calder, B. J., Kim, S. J., and Vandenbosch, M. (2016). Evidence that user-generated content that produces engagement increases purchase behaviours. J. Mark. Manag. 32, 427-444. doi: 10.1080/0267257X.2016.1148066

Martínez, P., Martínez, J. L., Segura-Bedmar, I., Moreno-Schneider, J., Luna, A., and Revert, R. (2016). Turning user generated health-related content into actionable knowledge through text analytics services. Comput. Ind. 78, 43-56. doi: 10.1016/j.compind.2015.10.006

Metwally, A. M. A. (2017). What Will the 'Sharing Economy' Mean for Healthcare?. Dubai: Arab Health.

Nielsen (2015). Global Trust in Advertising. New York, NY: Nielsen.

O’Neill, B., Ziebland, S., Valderas, J., and Lupiáñez-Villanueva, F. (2014). User-generated online health content: a survey of internet users in the United Kingdom. J. Med. Internet Res. 16:e118. doi: 10.2196/jmir.3187
Parker-Pope, T. (2008). You're sick. Now what? Knowledge is Power. New York, NY: The New York Times.

Powell, J., Inglis, N., Ronnie, J., and Large, S. (2011). The characteristics and motivations of online health information seekers: cross-sectional survey and qualitative interview study. J. Med. Internet Res. 13:e20. doi: 10.2196/jmir. 1600

Staff, V. (2018). Consumers trust influencers more than they trust you (VB Live) | VentureBeat. Available online at: https://venturebeat.com/2018/11/ $02 /$ consumers-trust-influencers-more-than-they-trust-you-vb-live/ (accessed June 2, 2019).

Sun, Y., Liu, M., and Krakow, M. (2016). Health e-mavens: identifying active online health information users. Health Expect 19, 1071-1083. doi: 10.1111/hex.12398

Thomas, K. (2019). Key opinion leaders supercharged by the internet: paid doctor and patient influencers on social media. BMJ 365:12336. doi: 10.1136/bmj.12336

Wegohealth (2018). Authenticity: The Value of User-Generated Content in Healthcare. Boston, MA: Wegohealth.

Yang, H. (2013). A cross-cultural study of market mavenism in social media: exploring young American and Chinese consumers' viral marketing attitudes, eWOM motives and behaviour. Int. J. Internet Mark. Advert. 8, 102-124.

Zhang, J. (2010). Exploring Antecedents and Consequences of eMavenism in their Electronic Word-of-Mouth Communication. Doctoral dissertation, The University of Texas, Austin, TX.

Zhou, S., McCormick, H., Blazquez, M., and Barnes, L. (2019). "eWOM: the rise of the opinion leaders: consumer behaviour in online environments," in Social Commerce. Consumer Behaviour in Online Environments, ed. R. Boardman (London: Palgrave Macmillan).

Conflict of Interest: The authors declare that the research was conducted in the absence of any commercial or financial relationships that could be construed as a potential conflict of interest.

Copyright (c) 2020 Díaz-Martín, Schmitz and Yagüe Guillén. This is an open-access article distributed under the terms of the Creative Commons Attribution License (CC BY). The use, distribution or reproduction in other forums is permitted, provided the original author(s) and the copyright owner(s) are credited and that the original publication in this journal is cited, in accordance with accepted academic practice. No use, distribution or reproduction is permitted which does not comply with these terms. 


\section{OPEN ACCESS}

Edited by:

Alicia Izquierdo-Yusta,

University of Burgos, Spain

Reviewed by:

Sandra Virtue,

DePaul University, United States

Alireza Nazarian,

University of Roehampton London,

United Kingdom

Ines Kuster,

University of Valencia, Spain

*Correspondence:

Jesús García-Madariaga jesgarci@ucm.es

Specialty section This article was submitted to

Organizational Psychology, a section of the journal

Frontiers in Psychology

Received: 15 January 2020

Accepted: 27 March 2020

Published: 12 May 2020

Citation:

García-Madariaga J, Moya I, Recuero N and Blasco M-F (2020) Revealing Unconscious Consumer Reactions to Advertisements That Include Visual Metaphors. A Neurophysiological Experiment. Front. Psychol. 11:760. doi: 10.3389/fpsyg.2020.00760

\section{Revealing Unconscious Consumer Reactions to Advertisements That Include Visual Metaphors. A Neurophysiological Experiment}

\author{
Jesús García-Madariaga*, Ingrit Moya, Nuria Recuero and María-Francisca Blasco \\ Management and Marketing Department, Complutense University of Madrid, Madrid, Spain
}

The main challenge of advertising is to catch consumers' attention and evoke in them positive attitudes to consequently achieve product preference and higher purchase intentions. In modern advertising, visual metaphors are widely used due to their effects such as improving advertising recall, enhancing persuasiveness, and generating consumers' positive attitudes. Previous research has pointed out the existence of an "inverted U-curve" that describes a positive relationship between the conceptual complexity of metaphors and consumers' positive reactions to them, which ends where complexity outweighs comprehension. Despite the dominance of visual metaphors in modern advertising, academic research on this topic has been relatively sparse. The inverted U-curve pattern has been validated regarding ad appreciation, ad liking, and purchase intention by using declarative methods. However, at present, there is no evidence of consumers' neurophysiological responses to visual metaphors included in advertising. Given this gap, the aim of this research is to assess consumer neurophysiological responses to print advertisements that include visual metaphors, using neuroscience-based techniques. Forty-three participants (22W-21M) were exposed to 28 stimuli according to three levels of visual complexity, while their reactions were recorded with an electroencephalogram (EEG), eye tracking (ET), and galvanic skin response (GSR). The results indicated that, regardless of metaphor type, ads with metaphors evoke more positive reactions than non-metaphor ads. EEG results revealed a positive relationship between cognitive load and conceptual complexity that is not mediated by comprehension. This suggests that the cognitive load index could be a suitable indicator of complexity, as it reflects the amount of cognitive resources needed to process stimuli. ET results showed significant differences in the time dedicated to exploring the ads; however, comprehension doesn't mediate this relationship. Moreover, no cognitive load was detected from GSR. ET and GSR results suggest that neither methodology is a suitable measure of cognitive load in the case of visual metaphors. Instead, it seems that they are more related to the attention and/or emotion devoted to the stimuli. Our empirical analysis reveals the importance of using neurophysiological measures to analyze the appropriate use of visual metaphors and to find out how to maximize their impact on advertising effectiveness.

Keywords: consumer neuroscience, cognitive load, visual metaphors, advertising, attitude toward the ad, electroencephalogram, eye tracking, galvanic skin response 


\section{INTRODUCTION}

Marketing scholars and practitioners are continuously facing the challenge to find out how to enhance advertising effectiveness. The decrease of traditional advertising media such as TV and newspapers, the rise of new ones like mobiles or videos, and the growth of interactive and targeted advertising represent a huge limitation to print advertising, characterized by a static image. Given this limitation, graphic print advertising must focus on seeking the most optimal design to catch consumers' attention and evoke positive attitudes, in order to trigger a higher preference for the products and, consequently, higher purchase intentions.

Advertisers and academics have analyzed the key factors that influence effective print advertisement such as element location (Garcia et al., 2000; Girisken and Bulut, 2014), advertisement size (Pieters and Wedel, 2004), images (Gakhal and Senior, 2008; Cook et al., 2011; Bastiaansen et al., 2016; Tomaselli Fidelis et al., 2017), exposure duration (Elsen et al., 2016) and messages (Thomsen and Fulton, 2007). However, the complexity of visual images and their impact on print advertising have been poorly studied until Phillips and McQuarrie's (2004) research, which provides a significant theoretical review on aspects of visual complexity by analyzing visual rhetoric in advertising.

Images themselves can be extremely complex, as they are "capable of representing concepts, abstractions, actions, metaphors and modifiers" (Scott, 1994, p. 253). A single image can contain many sophisticated interrelated signs and multiple meanings for viewers or readers (Bulmer and Buchanan-Oliver, 2006). Therefore, as Phillips and McQuarrie (2004) suggest, the role of images in advertising needs in-depth study, as they are not necessarily analogous to visual perception but are rather symbolic artifacts.

A rhetorical figure is an artful deviation relative to audience expectation (McQuarrie and Mick, 1996), which can comprise a variety of different forms such as rhyme, antithesis, ellipsis, metaphor, and pun. Rhetorical figures have been cataloged and studied primarily from a text perspective, although literature provides evidence that the artful deviation characteristic of figures also can be constructed out of pictorial elements in advertising (Forceville, 1994, 1996, 2005; McQuarrie and Mick, 1996; Foss, 2005; Mohanty and Ratneshwar, 2014).

Among the visual rhetoric figures, metaphors are the most commonly used because, according to the theory, they can formulate, sustain, or modify the attention, perceptions, attitudes, or behaviors of their audiences (Foss, 2005); they also provide a novel way of communicating product attributes to consumers, and they can enhance ad recall and produce more positive attitudes (McQuarrie and Mick, 2003; Norris et al., 2012).

Scholar research defines metaphors as comparisons between two things that are originally different in nature but have something in common (van Mulken et al., 2014), and where one concept is understood in terms of another (Peterson, 2019). Among the visual rhetoric literature, there are three main approaches to classify visual metaphors (Forceville, 1996, 2005, 2008; Phillips and McQuarrie, 2004, 2009; Gkiouzepas and Hogg, 2011), and although each author uses different terms to name them, it is possible to distinguish three types of metaphors: (1) a comparison based on two items that are presented separately (i.e., similes or juxtaposition); (2) a combination of two things that evoke a single concept (i.e., hybrid metaphor, synthesis, or fusion); and (3) an absent object that is evoked by an image (i.e., contextual image or replacement). All authors indicate an increasing degree of complexity going from no metaphor to juxtaposition, to fusion, and finally to replacement.

Consumer studies have concluded that advertisements with complex layouts evoke positive attitudes (McQuarrie and Mick, 1996, 2003; van Mulken et al., 2010, 2014), high appreciation (van Mulken et al., 2010), advertisement recognition (McQuarrie and Mick, 1996, 2003; Norris et al., 2012), and purchase intentions among consumers (Jeong, 2008; van Hooft et al., 2013; Myers and Jung, 2019). However, the evidences provided by these researches is all based on results from declarative studies. Thus, at present, there are no studies developed using other research methodologies. This lack of evidence of non-declarative reactions motivates the present research, which seeks to fill this gap by investigating experimentally the neurophysiological responses of consumers to visual metaphors included in advertising by applying neuromarketing techniques.

\section{CONCEPTUAL TENETS AND LITERATURE REVIEW}

\section{Visual Complexity in Advertising}

As mentioned, previous studies have consistently reported that advertisements with complex layouts result in audiences' more positive attitudes than advertisements based on standalone images (Phillips, 2000; Jeong, 2008; Pieters et al., 2010; van Mulken et al., 2010, 2014). Once a subject resolves the riddle, a positive attitude toward the advertisement emerges that consequently yields a significant improvement of ad recall, brand recognition (McQuarrie and Mick, 2003; Norrick, 2003), product perception (McQuarrie and Mick, 2009), and purchase intentions (Ang and Lim, 2006; Jeong, 2008; van Hooft et al., 2013; Myers and Jung, 2019).

It seems that decoding the message increases the subject's sense of pleasure and decreases the sense of tension, leading to the enhancement of the subject's attitude toward the ad (Aad) (Jeong, 2008) and to improve the ad persuasiveness (Burgers et al., 2015). In this respect, Hornikx and le Pair (2017) determined that a positive Aad occurs when consumers are exposed to advertisements that require higher cognitive effort than when they are presented with advertisements that do not require much cognitive effort.

According to Phillips and McQuarrie (2004), there are two determinant factors for the processing of visual rhetoric figures: the richness of the figure and its complexity. Putting those two dimensions together, visual metaphors can vary from simple and readily interpretable figures to highly complex figures open to a wide range of interpretations. Thus, excessively complex metaphors may fail to be comprehended and, consequently, cease having a positive impact (Phillips and McQuarrie, 2004). This effect is related to Berlyne's (1971) theory, which suggests that the 
relationship between complexity and pleasure could be explained by an inverted U-curve whose tipping point is reached when complexity outweighs comprehension (van Mulken et al., 2014).

The pleasure evoked by complex visual images used in advertising has been studied from different perspectives. Previous studies suggest that if metaphors demand too much or too little cognitive processing effort, consumers may opt out, and appreciation will decrease; thus, advertisement appreciation follows the pattern of the aforementioned inverted U-curve (Phillips, 2000; McQuarrie and Mick, 2003). In the same line, van Mulken et al. $(2010,2014)$ validated the inverted U-curve pattern in advertisement appreciation and pointed out that visual metaphors of moderate complexity are the most effective. Moreover, van Hooft et al. (2013) studied the inverted U-curve as a function of liking and purchase intention. They confirmed the pattern regarding preference but found only partial confirmation regarding purchase intention because, although they found that more complex metaphors lead to lower purchase intentions, there was no difference between juxtapositions and fusions regarding this variable.

Despite of the valuable findings of the aforementioned research, empirical evidence for the inverted $\mathrm{U}$-curve is still relatively scarce, and its validity has not yet been proven regarding Aad, a concept extensively examined that reveals consumers' precise perceptions and impressions toward advertisement designs (Huhmann and Limbu, 2016). Neither it has been proven on preference. Based on this lack of evidence, we will validate the presence of the inverted $\mathrm{U}$-curve pattern in those two important indicators of advertising effectiveness: Aad and preference. Besides, due to the importance of purchase intentions, we will also include it in order to find if the pattern could be validated in different product categories than that used by van Hooft et al., 2013. Hence, it is postulated:

Hypothesis 1: The effects of metaphors on (a) Aad, (b) purchase intention, and (c) preference follow the inverted U-curve pattern according to which there is a positive relationship between complexity and positive feelings until a tipping point is reached where complexity exceeds comprehension.

\section{Processing of Visual Metaphors}

According to Phillips (2003), the usage of metaphors in advertising mainly impacts four variables: attention, elaboration, pleasure, and liking. As visual metaphors are defined as artful deviations from expectations (McQuarrie and Mick, 1999), they give rise to incongruity that certainly attracts attention and prompts exploratory behaviors (Kaplan, 1990; Jeong, 2008; Mohanty and Ratneshwar, 2014). Once attention is caught, the consumer is forced to decipher the underlying message. This means that attention is retained and that the consumer must devote some time to provide a meaning for the ad and to elaborate the message. Finally, the extra effort is rewarded with the pleasure of having been able to solve the puzzle, and it leads to more positive attitudes toward the advertisement (van Hooft et al., 2013).
In cognitive psychological terms, elaboration "indicates the amount, complexity, or range of cognitive activity occasioned by a stimulus" (McQuarrie and Mick, 1999. p 39). When the viewer draws an inference or generates assumptions and integrates them with his/her prior knowledge, this launches an elaboration process where working memory is increasingly taxed to the extent that complexity increases (Peterson, 2019).

The increased elaboration of visual metaphors has been proven in previous studies (McQuarrie and Mick, 1999, 2003; Phillips, 2000; Jeong, 2008; Chang and Yen, 2013), where it is stated that more complex visual figures lead to more cognitive elaboration. Such higher elaboration is a consequence of comprehension efforts, and it manifests as an enhanced memory of the ad (Phillips and McQuarrie, 2004).

Those previous findings have been very valuable for marketing, however, their weakness lies in the fact that they are derived from declarative methodologies that are inevitably biased by subjective considerations (Hsu, 2017). To overcome this situation, in the last few years, neurophysiological techniques have begun to be applied, mainly because of their ability to provide additional insights crucial to understanding consumers' behavior (Dimofte, 2010; Gattol et al., 2011).

Due to its recent adoption in marketing, research on visual metaphors in advertising by applying neuroscientific techniques is still scarce (Bambini et al., 2016). The studies on this matter are mainly focused on the analysis of textual metaphors and are mostly restricted to semantic processing (Sotillo et al., 2004; Lachaud, 2013; Rataj, 2014).

In spite of that, we note that studies made with an electroencephalogram (EEG), and especially those based on the recording of event-related brain potentials (ERPs)-an EEG methodology that offers great insights into processing mechanisms with millisecond precision (Kappenman and Luck, 2012)-suggest a biphasic pattern of brain activity, with earlier negativity (N400) followed by later positivity (P600/LPC) (Coulson and Van Petten, 2002; Weiland et al., 2014; Bambini et al., 2016). N400 is linked to efforts in terms of lexical access and semantic representation (Kutas and Federmeier, 2011), whereas P600 is usually observed for syntactic operations (Brouwer et al., 2012).

In the same line, Pileliene and Grigaliunaite (2016) analyzed the allocation of attentional resources to process advertising with complex layouts (not metaphorical), through the use of P300, a component that provides information about the neural activity of cognitive operations (Ma et al., 2008). The obtained results revealed that a complex layout in an advertisement leads to more attentional and cognitive resources being engaged in processing the advertisement as well as to the higher emotional value to consumers.

Moreover, regarding temporal and spatial studies of the brain, the EEG study developed by Cardillo et al. (2012) found prefrontal and left posterior temporal activations in the presence of higher cognitive processes of comparison and categorization related to the elaboration of metaphorical contents. These findings are consistent with those of Anderson et al. (2011), who studied cognitive load across multiple visualization types and found that, as Klimesch (1999) suggested, EEG oscillations in the 
alpha band reflect cognitive performance and that, in particular, the movement of the individual alpha frequency outside of the 8-12 Hz band of frequencies may indicate a cognitive overload induced by a too-complex visualization task.

On the other hand, studies using eye tracking (ET) revealed that the time devoted to exploring the stimuli could be indicative of the cognitive processes involved in comprehending the metaphors, as experimental studies showed that extra time is needed to comprehend more complex metaphors (Raney et al., 2014). Besides, the implication of more visual attention when more complex advertisements are presented could be translated into longer ET fixation time (Pieters et al., 2010).

Finally, some authors have suggested that galvanic skin response (GSR) seems to be a suitable tool for measuring cognitive activity and have pointed out the correlation between GSR features and cognitive functions and more specific cognitive workload (Miller and Shmavonian, 1965; McEwen and Sapolsky, 1995; Shi et al., 2007; Nourbakhsh et al., 2012).

Based on the preceding discussion, we can identify a positive relationship between complexity and elaboration that can be represented as a higher cognitive load as metaphors increase their complexity. According to literature, the cognitive load can be measured with EEG, analyzing oscillations of alpha-theta bands; with ET, analyzing the time devoted to exploring the visual metaphor; and by analyzing GSR features. Hence, it is hypothesized:

Hypothesis 2: To the extent that a visual metaphor increases its difficulty, the subject will have a higher cognitive load. This situation will be reflected in (a) a longer time to explore the advertisement, (b) a higher index of EEG cognitive load, and (c) a higher index on GSR activation.

\section{MATERIALS AND METHODS}

\section{Participants}

Forty-three undergraduate students (22 women, 21 men) voluntarily participated in the study in June 2018. The mean age was 23.3 years with a standard deviation of 2.8 years. The participants were recruited using convenience sampling. All participants were right-handed, healthy people with normal or corrected-to-normal vision and were free of any hearing problems. All participants provided signed consent before participating and received monetary compensation at the end of the session.

\section{Measurements}

\section{Consumer Neuroscience Techniques Electroencephalograph}

The EEG is a measurement of the whole sphere of brainwave activity emerging in various cortical areas, which helps to understand the way the brain responds to various stimuli. EEG is a non-invasive instrument that provides information from areas underneath the cortex and, combined with other instruments, may provide very accurate results on a subject's response to a marketing stimulus (Du Plessis et al., 2011).

Cerebral activity was recorded using the Bitbrain Versatile EEG with 16 channels at a sampling rate of $256 \mathrm{~Hz}$, while impedances were kept below $5 \mathrm{k} \Omega$. For the experiment, we used 12 electrodes placed by following the International 10-20 system.

\section{Eye tracking}

This biometric technique is based on the relationship between human eye movements, visual attention, and information acquisition, with the latter two both being closely related to higher-order cognitive processes (Ares et al., 2014). ET has a high temporal resolution $(60-120 \mathrm{~Hz})$ and uses an optical camera to identify the position of the pupil and cornea using near-infrared light pointed at the cornea and reflected off it (Venkatraman et al., 2015). When the eye moves across a spatial stimulus, the difference between the incoming and outgoing angle of the infrared light beam changes, indicating the specific position on the stimulus to which the eye moves (Pieters and Wedel, 2004).

Consumers' behavior is measured with an ET technique by recording either the number of fixations or dwell time of the eyes during an individual or group exposure to external stimuli. The specific ET device used in the present study was a Tobii X2-30 Eye-Tracker Compact Edition, a screen-based eye tracker capturing gaze data at $60 \mathrm{~Hz}$.

\section{Galvanic skin response}

The GSR is defined as a change in the electro-physiological properties of the skin due to sweat gland function. GSR provides an indication of changes in the human sympathetic nervous system (SNS) (Shi et al., 2007) and is well known as a robust and easily captured physiological tool available at low cost (Nourbakhsh et al., 2013). The GSR measures the electrodermal response that occurs when the skin becomes a better electrical conductor due to increased activity of the sweat glands because of the exposure to a specific stimulus (Potter and Bolls, 2012). Therefore, the skin conductance amplitude provides a direct measure of subjects' arousal (Venkatraman et al., 2015). The GSR device used in the present study to get the arousal was the Bitbrain GSR ring, a wireless device for real-time monitoring of electrodermal and cardiac activity.

\section{Neurophysiological Measurements}

Neurophysiological measurements comprise cognitive load, time in AOI and arousal. These measures are described following and the instruments used to measure them are related in Table 1.

TABLE 1 | Summary of Consumer neuroscience measures.

\begin{tabular}{lc}
\hline Consumer neuroscience measures & Instrument \\
\hline Time to AOI & ET \\
Cognitive load & EEG \\
Activation & GSR
\end{tabular}

AOI, area of interest; ET, eye tracking; EEG, electroencephalogram; GSR, galvanic skin response. 


\section{Cognitive load index}

The EEG technique can be used to obtain many different psychological metrics such as cognitive workload. Studies on the area have found that EEG power in the theta and alpha frequency range is related to cognitive performance (Antonenko et al., 2010). In fact, with increasing task demands, theta synchronizes (increases), whereas alpha desynchronizes (decreases). That is the situation of visual attention and semantic tasks, primary factors that lead to a suppression (decrease) of the alpha rhythm in the prefrontal cortex (Klimesch, 1999, 2012; Gevins and Smith, 2003; Anderson et al., 2011).

Based on previous studies (Klimesch, 1999, 2012; Gevins and Smith, 2003; Antonenko et al., 2010; Anderson et al., 2011), in the present study, the cognitive load was calculated by computing the ratio between power in the theta band in frontal channels (F3, F4) and power in the alpha band in parietal channels (P3, P4).

\section{Time spent exploring stimuli (Time in Area of Interest)}

The ET technique has been used as a direct measure of attention by analyzing the number of fixations on specific areas, the viewing time, or the time that users take to reach each area (Rebollar et al., 2015) and also as a measure of the cognitive processes involved in comprehension (Raney et al., 2014). ET and pupillary responses may also provide additional insights into the cognitive load concerning with respect to visualization studies (Anderson et al., 2011). ET has great potential for objectively assessing consumers' perception of visual stimuli (Wedel and Pieters, 1989, 2008) and is being increasingly used in consumer science (Ares et al., 2013; Piqueras-Fiszman et al., 2013; Mitterer-Daltoé et al., 2014; Fenko et al., 2018).

Taking into account that there is evidence regarding "a sufficiently close connection between time spent fixating on display items and the amount of cognitive processing" (Graesser et al., 2005, p. 1237) that has been validated by previous studies (Lang et al., 2002; Graesser et al., 2005; Pieters et al., 2010; Lagerwerf et al., 2012; Raney et al., 2014), the present study employs the total time spent looking at each metaphor [time in area of interest (AOI)] as indicator of cognitive elaboration.

To get the time in AOI, we previously defined the AOIs on each image by selecting the area of the metaphor. In order to avoid the bias derived from having a different number of images according to the type of metaphor, we defined as "area of interest" the same zone (same size and shape) for all four conditions in each set.

\section{Arousal}

Previous studies have found that the GSR signal represents a suitable measure for detecting emotional responses but also for differentiating between stress and cognitive load (Shi et al., 2007; Nourbakhsh et al., 2013). Besides, Mühl et al. (2014) proved that GSR offers an unobtrusive and continuous measure sensitive to cognitive workload. Subjects' arousal was obtained by computing the skin conductance response (SCR) amplitudes taking into account that phasic SCRs are a reliable concomitant of states of arousal (Benedek and Kaernbach, 2010a).

\section{Declarative Questionnaire}

A computer-based questionnaire was also applied, through an Internet platform, to obtain declarative Aad, purchase intention, preference, and perceived complexity (see Table 2 ).

(1) Aad was measured adopting Lutz et al.'s (1983) and MacKenzie et al.'s (1986) measure, by using four semantic differential items: not interesting/very interesting, not appealing/very appealing, dislike/like, and bad/good. The response options were on a seven-point scale. Cronbach's alpha for this construct was 0.979 .

(2) Purchase intention was measured as in previous studies (Ang and Lim, 2006; Jeong, 2008; van Hooft et al., 2013), on a seven-point Likert scale that comprised the next two semantic differential items: not likely/very likely to buy and you are very likely to recommend this product/you are not likely to recommend this product. Cronbach's alpha for this construct was: 0.972 .

(3) Participants ranked their preference from 1 (the most preferred stimulus) to 4 (the least preferred stimulus).

(4) Perceived complexity was measured as in van Mulken et al. (2010), on the basis that "more complex metaphors might on average be less well understood than less complex metaphors" (van Mulken et al., 2010, p. 3425). This item was measured on a seven-point Likert scale that comprised the next two semantic differential items: unclear/straightforward and difficult to understand/easy to understand. Cronbach's alpha for this construct was: 0.981 .

\section{Stimuli}

A within-subjects research was conducted to assess consumer responses to print advertisements that include visual metaphors. Twenty-eight advertisements were developed in total, seven sets of four print advertisements for seven different product categories (see example in Figure 1). To build the metaphorical ads, the start point was a product image without any metaphorical content, also taken as the control condition. On the basis of that neutral point, we developed three metaphorical ads following the three main approaches to classify visual metaphors

TABLE 2 | Summary of declarative measures.

\begin{tabular}{|c|c|c|}
\hline $\begin{array}{l}\text { Declarative } \\
\text { measures }\end{array}$ & Instruments & \\
\hline $\begin{array}{l}\text { Attitude toward the } \\
\operatorname{ad} \alpha=0.979\end{array}$ & $\begin{array}{l}\text { 7-point } \\
\text { Likert scale }\end{array}$ & $\begin{array}{l}\text { Not interesting/very interesting, not } \\
\text { appealing/very appealing, dislike/like, } \\
\text { and bad/good }\end{array}$ \\
\hline $\begin{array}{l}\text { Purchase intention } \\
\alpha=0.972\end{array}$ & $\begin{array}{l}\text { 7-point } \\
\text { Likert scale }\end{array}$ & $\begin{array}{l}\text { Not likely/very likely to buy and you are } \\
\text { very likely to recommend this } \\
\text { product/you are not likely to } \\
\text { recommend this product }\end{array}$ \\
\hline Preference & $\begin{array}{l}\text { Ranked } \\
\text { from } 1 \text { to } 4\end{array}$ & $\begin{array}{l}1=\text { the most preferred stimulus } 4=\text { the } \\
\text { least preferred stimulus }\end{array}$ \\
\hline $\begin{array}{l}\text { Perceived } \\
\text { complexity } \\
\alpha=0.981\end{array}$ & $\begin{array}{l}\text { 7-point } \\
\text { Likert scale }\end{array}$ & $\begin{array}{l}\text { Unclear/straightforward and difficult to } \\
\text { understand/easy to understand }\end{array}$ \\
\hline
\end{tabular}


(Forceville, 1996, 2005, 2008; Phillips and McQuarrie, 2004, 2009; Gkiouzepas and Hogg, 2011) according to which there are three types of metaphors: (1) a comparison based on two items that are presented separately (i.e., similes or juxtaposition); (2) a combination of two things that evoke a single concept (i.e., hybrid metaphor, synthesis, or fusion); and (3) an absent object that is evoked by an image (i.e., contextual image or replacement).

Thus, we created seven sets of four images corresponding to three levels of complexity (juxtaposition, fusion, and replacement) and a control condition. Each set corresponded to one of the product categories (yogurt, juice, milk, tea, coffee, tomato sauce, and insecticide) selected on the basis of a focus group performed with eight people from 18 to 35 years, in which age range were found high levels of familiarity with categories of food, house, and personal care.

All images used were full-color, and product images were previously used in real printed or Internet ads. However, in order to avoid familiarization bias (Gregg and Klymowsky, 2013), although all brands and products used were real, they were not marketed in Spain.

\section{Procedure Pre-test}

Taking into account that metaphorical content could have multiple interpretations (Utsumi, 2007) a pre-test was conducted to assess the correct interpretation of metaphors to be used in the experiment. Sixty participants were invited to examine all the advertisements created and to answer whether they had recognized the concept expressed by each metaphor. To assess the metaphor comprehension, we applied the "valid/invalid" criteria of Morgan and Reichert (1999) according to which a valid interpretation of the metaphor is one in which the subject identified a relationship between the product and the concept used to create the comparison that is correctly supported by the metaphor. The obtained results showed that for each product category tested, more than $70 \%$ of participants made a correct identification of the metaphorical concept. We also checked that the complexity continuum for each set of images followed the described scale of complexity. It means that for each set of metaphors (juxtaposition, fusion, and replacement), there was an increase in complexity equal to that stated in literature.

\section{Experimental Procedure}

The study was performed at the Laboratory of Neuromarketing of Complutense University of Madrid, and its total duration was $60 \mathrm{~min}$, including both blocks to be described in the following paragraphs. All 43 participants were right-handed, healthy people with normal or corrected-to-normal vision and were free of any hearing problems. All participants provided signed consent before participating and received monetary compensation at the end of the session.

The experimental procedure had two phases, which entailed the use of neurophysiological (Block 1) and declarative (Block 2) methods. In Block 1, after briefing the protocol to the participants, they were sat in front of the computer screen where the ET was installed and were affixed with the EEG and GSR devices for collecting their brain electrical activity and skin conductance. The screen used was 21 inches with full HD resolution $(1,920 \times 1,080$ pixels $)$.

To calibrate the ET, subjects were instructed to follow the points appearing on the screen with their sight without moving their heads. Once the ET was calibrated, the researcher checked that the signal of all three devices was good and started running the experiment. It is important to highlight that in order to measure the workload, the emotional activation, and the time spent exploring each ad, we used simultaneous EEG, GSR, and ET measurements during the whole experiment. The software used to present stimuli and simultaneously record data was SensLab, developed by Bitbrain.

In this block, the 43 participants were exposed to the 28 aforementioned stimuli (7 product categories $\times 4$ complexity

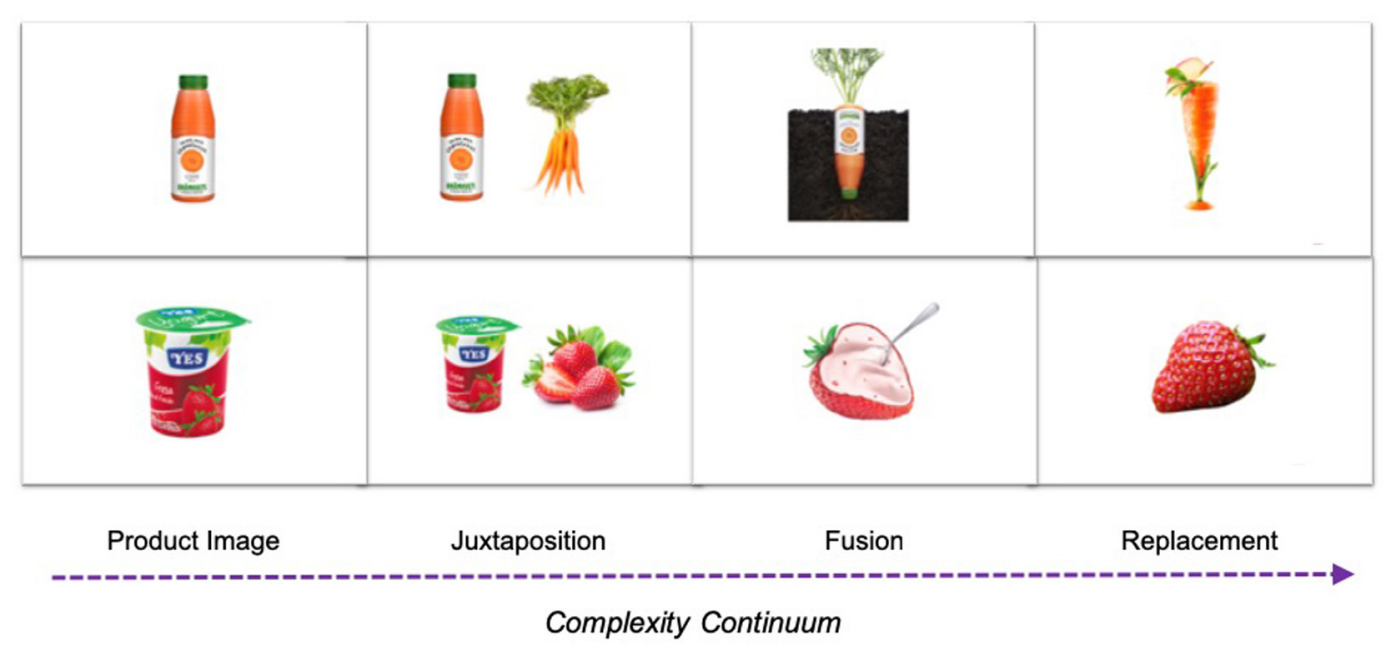

FIGURE 1 | Example of sets of four print advertisements designed for the study. 


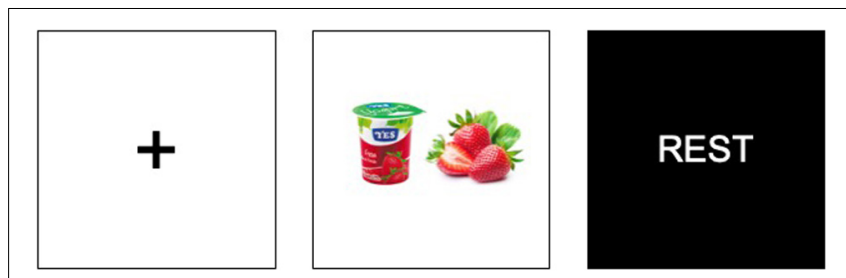

FIGURE 2 | Stimuli presentation Block 1.

modification designs), presented individually and randomly. First, a fixed cross was presented in the middle of the screen, followed by the stimulus for $5 \mathrm{~s}$, and then a black slide, with the word "Rest," so participants could take a 2 s rest (see Figure 2).

During Block 2, which entailed the declarative test phase, participants had to answer the questionnaire while they were visualizing the stimuli individually. The respondents initially answered the Aad scale for the 28 advertisements. The second scale, with the same structure, asked participants about their purchase intention. The third task was to rank the four advertisement modulations (product, fusion, juxtaposition, and replacement) from 1 to 4 , to assess their preference. Finally, the last declarative section asked about their perceived complexity. In this second block, the exposure time depended on the subject's response time instead of being standardized as in Block 1.

\section{RESULTS}

\section{Data Analysis}

All raw data coming from the neurophysiological techniques were provided by SennsLab.

Raw EEG data were first filtered using a band-pass filter between 1 and $25 \mathrm{~Hz}$ with a four-order Butterworth filter. After that, a filtering pipeline was implemented. First, an ASR (artifact subspace reconstruction) filter was used to remove big amplitude artifacts (Mullen et al., 2013). Then ICA (independent component analysis) was performed in order to separate the EEG data info into independent components (Hyvarinen, 1999) to subsequently apply MARA, which is a machine learning-based algorithm that classifies automatically ICA components as artifacts or as clean data (Winkler et al., 2011). Once the signal was clean, we computed the cognitive load as the ratio between power in the theta band in frontal channels (F3, F4) divided by power in the alpha band in parietal channels (P3, P4) (Gevins et al., 1998; Klimesch, 1999; Gevins and Smith, 2003). To get the frequency bands, we first applied the Welch method to obtain the power spectral density. Theta and alpha bands were individualized using IAF (individualized alpha frequency) analysis (Doppelmayr et al., 1998).

Skin conductance data are usually characterized by a sequence of overlapping phasic SCRs overlying a tonic component (Benedek and Kaernbach, 2010b). The extraction of the skin conductance data followed three steps: (1) the deconvolution of recorded data and the subsequent estimation

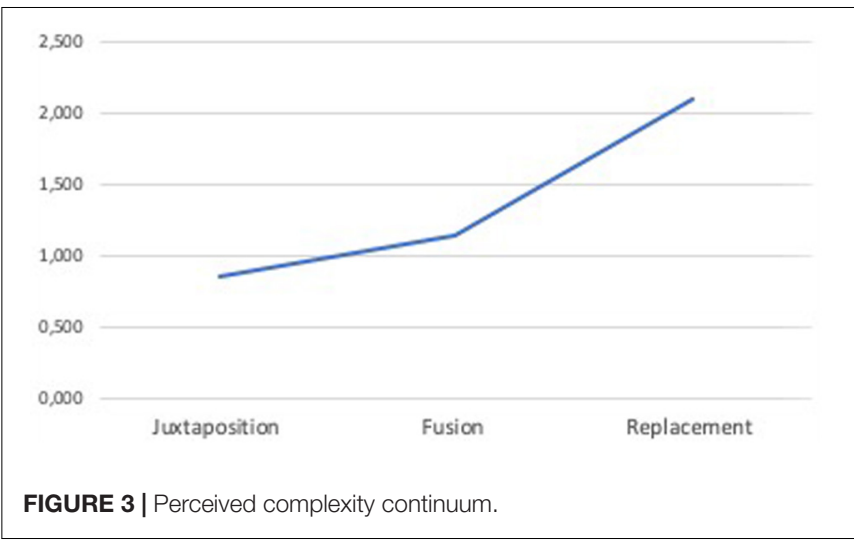

of (2) tonic and (3) phasic activity. After application of a low-pass filter to eliminate the muscle noise in order to detect more accurately the sweating peaks to the GSR signal, information on the subjects' arousal was obtained by computing the SCR amplitudes taking into account that phasic SCRs are a reliable concomitant of states of arousal (Benedek and Kaernbach, 2010a).

The post-processed EEG and GSR signals, next to the ET information about time in AOI were subsequently analyzed by using SPSS. The declarative information also was analyzed using that statistical software.

The data analysis was performed in three stages. First, we focused on the differences between advertisements with and without metaphors. To obtain those differences, a $t$-test analysis was performed. The second stage was oriented to find differences in the complexity continuum. To get those results, we applied a repeated measures ANOVA. In the third stage, all the metrics (implicit and declarative) were regressed onto conceptual complexity derived from metaphorical content, with perceived complexity as a mediating variable. Finally, a Sobel test was used to statistically investigate the effect of the proposed mediator on the predictoroutcome relationship.

\section{Self-Reported Results Perceived Complexity}

The first step to analyze Hypothesis 1 was to validate that the complexity continuum was well constructed. For this purpose, a repeated measures ANOVA was performed. It showed that the perceived complexity of the levels of the ads was statistically and significantly different, $F_{(1.641,68.941)}=39.42$, $p=0.000$. More specifically, differences were found between juxtaposition $(M=6.1)$ and replacement $(M=4.9, p=0.000)$ and between fusion $(M=5.9)$ and replacement $(M=4.9$, $p=0.000)$.

Note that in order to maintain the negativity of the scales to the left, subjects rated the images difficult to understand as 1 and those easy to understand as 7. Figure 3 shows a graphic reinterpretation to show that the complexity continuum was well perceived by the subjects.

To compare the perceived complexity between ads with and without metaphors, a paired-samples $t$-test was conducted. 
Results showed that there was a significant difference in the scores for ads without metaphors $(M=5.94, S D=0.88)$ and ads including metaphors $(M=5.64 S D=0.71)$; $t(42)=-2.71$, $p=0.010$. It means that ads without metaphors were perceived as easier to understand than those with metaphorical content.

\section{Attitude Toward the Advertisements}

In order to obtain more accurate results of the self-reported measures, we performed two types of analysis: (1) a comparison between advertisements with and without metaphors and (2) a comparison between the three levels of complexity included in the experiment.

Regarding the analysis of Aad with and without metaphors, a paired-samples $t$-test was conducted. Results revealed a significant difference between advertisements without metaphors $(M=3.4, S D=0.89)$ and those including metaphors $(M=4.5$, $S D=0.67) ; t(42)=-9.235, p=0.000$.

Subsequently, in order to test Hypothesis 1a, a repeated measures ANOVA was performed. It determined that Aad also showed statistically significant differences in the different complexity levels of the advertisement, $F(2,84)=75.877$, $p=0.000$. Regarding the level of complexity, post hoc tests using the Bonferroni correction revealed significant differences between juxtapositions $(M=4.8)$ and fusions $(M=5.4)$ and between fusions and replacement metaphors $(M=3.9)$. However, there were no significant differences between juxtaposition and replacement metaphors (see Figure 4).

Finally, in order to validate the mediator effect of comprehension (perceived complexity) described as an inverted $\mathrm{U}$-curve in the literature, a mediation analysis was performed. Statistically, mediation is often analyzed through path analytic models with one $\mathrm{X}$ variable, one mediator $\mathrm{M}$, and one outcome variable Y (Papa et al., 2015). In the present study, the complexity of visual metaphors (X) is hypothesized to indirectly affect Aad (Y). In this model, higher levels of complexity are hypothesized

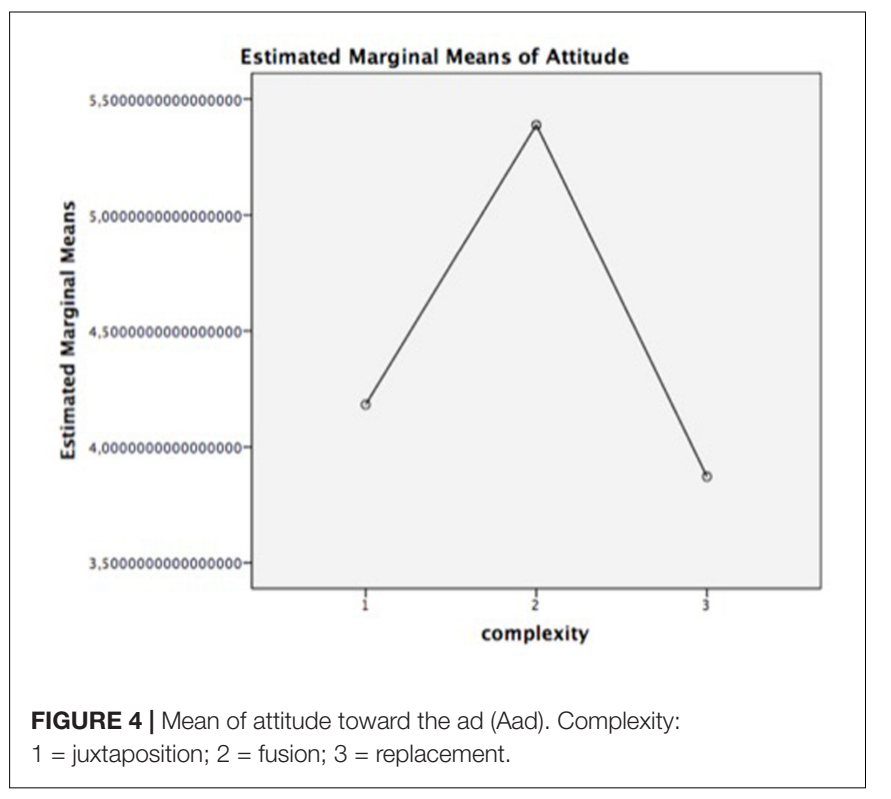

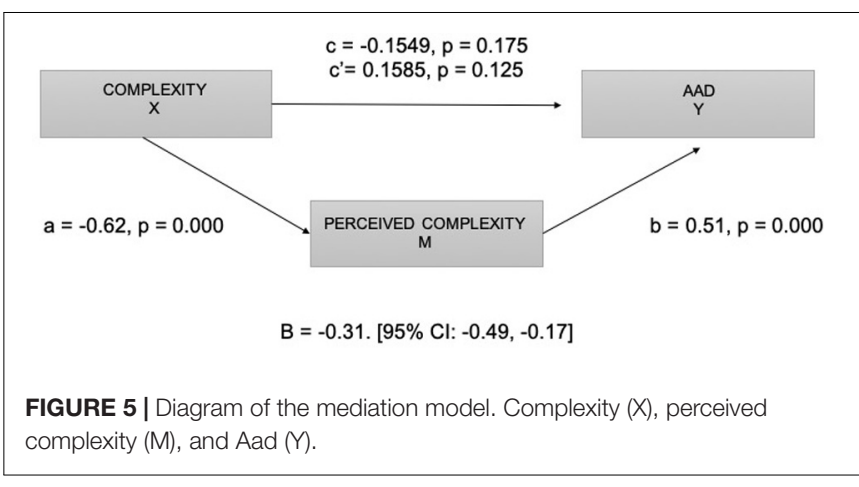

to induce higher levels of perceived complexity, which in turn increase Aad. The indirect (or mediated) effect (B) is quantified as $a \times b$ and tested for statistical significance (see Figure 5).

The results of mediation analysis indicated that complexity of metaphors was a significant predictor of perceived complexity ( $a=-0.62, p=0.000$ ) and that perceived complexity was a significant predictor of Aad $(b=0.51, p=0.000)$. These results support the mediational hypothesis. Ad complexity was not a significant predictor of Aad after controlling for the mediator (comprehension), $c^{\prime}=0.16, p=0.179$. The standardized indirect effect $(\mathrm{B})$ was a $(-0.62) \times \mathrm{b}(0.51)=-0.31$ [95\% CI: $-0.49,-0.17]$.

A Sobel test was also conducted to validate the effect of the mediator, finding full mediation $(z=-4.13, p=0.000)$. The results revealed that comprehension/perceived complexity is a significant mediator of the relationship between advertisement complexity induced by metaphors and Aad; thus, the inverted U-curve pattern is validated, and consequently, results support Hypothesis 1a.

\section{Purchase Intention}

Regarding purchase intention, a paired-sample $t$-test revealed a significant difference between advertisements without metaphors $(M=3.7, S D=0.91)$ and advertisements including metaphors $(M=4.0, S D=0.84) ; t_{(42)}=-3.395, p=0.020$.

In order to test Hypothesis $1 \mathrm{~b}$, a repeated measures ANOVA also determined that the different complexity levels of the advertisement produced statistically significant differences in purchase intention, $F_{(2,84)}=41.742, p=0.000$. Post hoc tests using the Bonferroni correction revealed significant differences between all three levels of complexity: juxtapositions $(M=4.8)$, fusions $(M=5.4)$, and replacement metaphors $(M=3.9)$.

On the other hand, the mediation analysis indicated that advertisement complexity was a significant predictor of perceived complexity $(a=-0.62, p=0.000)$ and that perceived complexity was a significant predictor of purchase intention $(b=0.43$, $p=0.000)$. Advertisement complexity induced by metaphors was no longer a significant predictor of purchase intention after controlling for the mediator $\left(c^{\prime}=-0.05, p=0.653\right)$, in consistence with a full mediation. The standardized indirect effect was a $(-0.62) \times \mathrm{b}(0.43)=-0.27$ [95\% CI: $-0.44,-0.13]$ (see Figure 6). 


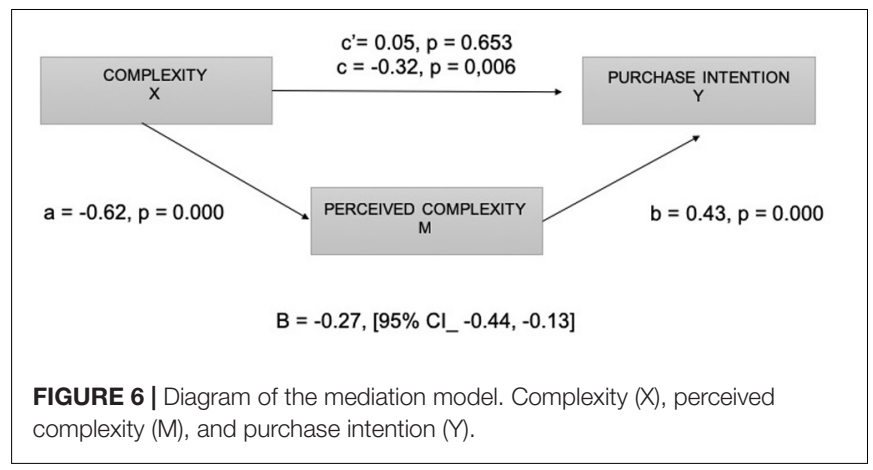

Lastly, the Sobel test found full mediation $(z=-3.64$, $p=0.000)$. Thus, it can be concluded that comprehension mediated the relationship between advertisement complexity induced by metaphors and purchase intention. Consequently, the inverted U-curve pattern is validated for this construct, and the hypothesis $1 \mathrm{~b}$ is supported, as displayed in Figure 7.

\section{Preference}

To test the preference hypothesis (H1c), due to the ordinal nature of the preference metric, a Friedman test was conducted as the non-parametric alternative to the one-way repeated measures ANOVA. The Friedman test revealed a statistically significant difference in preference depending on the complexity of the images visualized, $\chi^{2}{ }_{(2)}=40.812, p=0.000$. A post hoc analysis with a Wilcoxon signed-rank test was conducted with a Bonferroni correction, resulting in a significance level set at $p<0.000$. There were significant differences between the three levels of complexity.

To examine the effect of comprehension of different metaphors on preference, we performed a path analysis, described in Figure 8. Results indicated that complexity of visual metaphors was a significant predictor of comprehension ( $a=-0.062, p=0.000)$. To investigate how conceptual

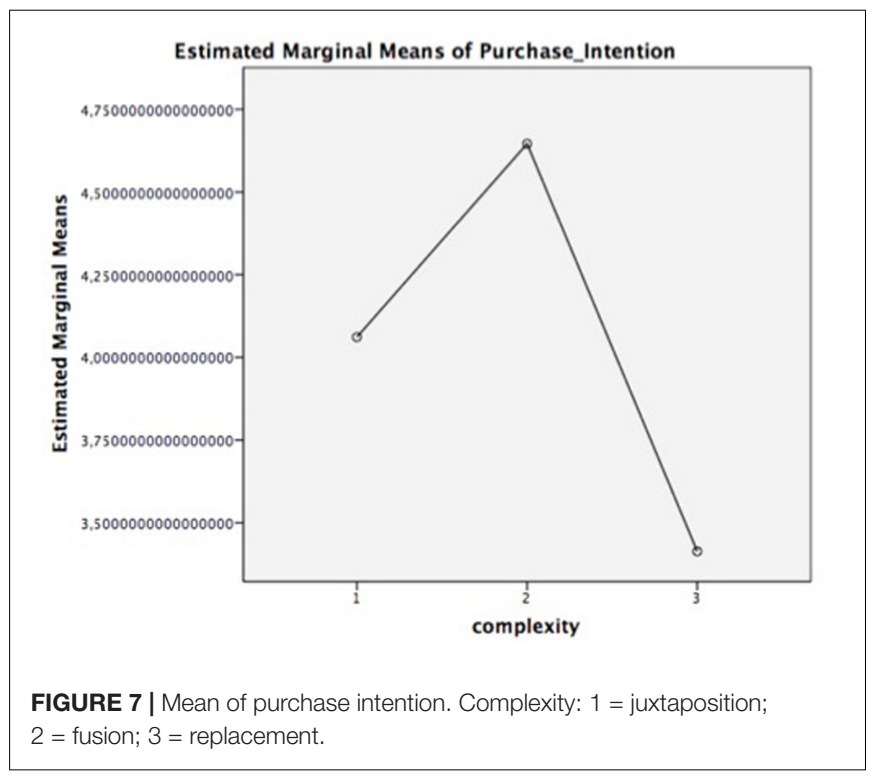

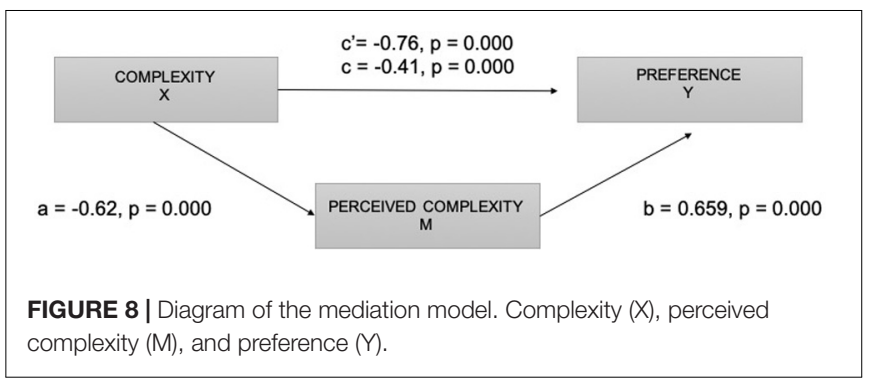

complexity of metaphors could influence the preference of ads with metaphorical content, an ordinal logistic regression analysis was conducted. The conceptual complexity was found to contribute to the model $\left[X^{2}(1)=15.053, p=0.000\right]$. The estimated odds ratio shows an inverse relationship between complexity and preference. It suggests a decreasing probability of improving the preference level with increasing complexity level of ads (complexity estimate $=-0.760, \mathrm{SD}=0.205$, Wald $=13.716$, $p=0.000)$.

On the other hand, the analysis showed that comprehension was a significant predictor in the model $\left[X^{2}(1)=16.536\right.$, $p=0.000]$. The coefficient shows that when increasing the perceived complexity, there is a predicted increase of 0.659 in the log-odds of being in a higher level of preference (comprehension estimate $=0.659, \mathrm{SD}=0.1674$, Wald $=15.103, p=0.000)$. These results support the mediational hypothesis. The standardized indirect effect was a $(-0.62) \times b(0.659)=-0.4085$.

Finally, a Wilcoxon signed-rank test was conducted to analyze the differences between ads with and without metaphorical content. Results showed statistically significant differences between (1) ads not including metaphorical images and ads including juxtapositions $(Z=-4.059$, $p=0.000)$ and (2) ads not including metaphorical images and fusions $(Z=-4.908, p=0.000)$. However, the analysis shows that there were no differences between ads including replacements and ads not including metaphorical images $(Z=-0.775, p=0.438)$.

Obtained results show that preference follows the inverted U-curve pattern according to which there is a positive relationship between complexity and positive feelings until a tipping point is reached where complexity exceeds comprehension. Thus, Hypothesis $1 \mathrm{c}$ is also supported. Table 3 shows a summary of the declarative results obtained.

TABLE 3 | Summary of declarative results.

\begin{tabular}{lll}
\hline Measure & $\begin{array}{l}\text { Differences between } \\
\text { ads with metaphor and } \\
\text { without metaphor }\end{array}$ & $\begin{array}{l}\text { Differences among the } \\
\text { three levels of } \\
\text { complexity }\end{array}$ \\
\hline $\begin{array}{l}\text { Attitude toward the } \\
\text { ad }\end{array}$ & $t_{(42)}=-9.235, p=0.000$ & $F_{(2.84)}=75.877, p=0.000$ \\
Purchase intention & $\begin{array}{l}t_{(42)}=-3.395, p=0.020 \\
\text { Preference }\end{array}$ & $F_{(2,84)}=41.742, p=0.000$ \\
& $\begin{array}{l}\text { (1) } Z=-4.059, p=0.000 \\
\text { (2) } Z=-4.908, p=0.000\end{array}$ & $\chi^{2}(2)=40.812, p=0.000$ \\
& (3) $Z=-0.775, p=0.438$ & \\
\hline
\end{tabular}




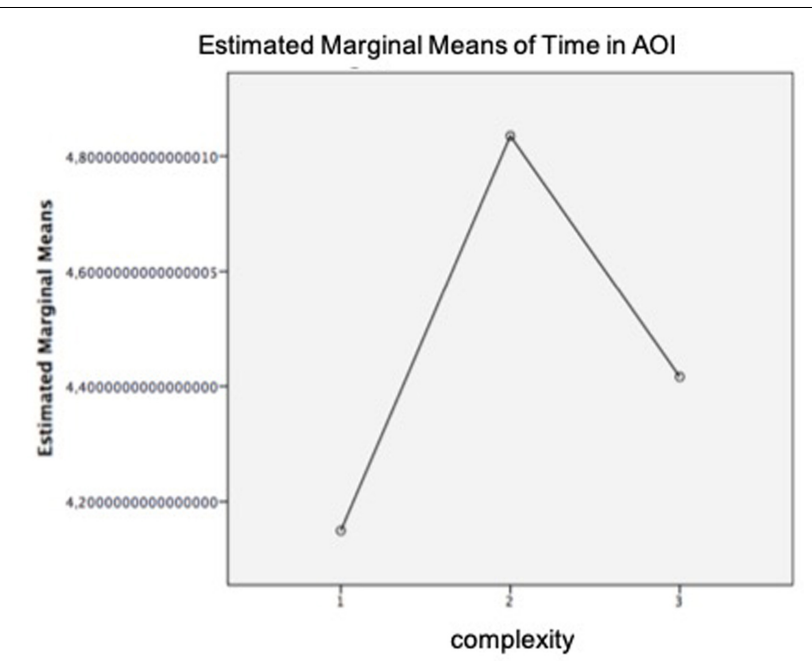

FIGURE 9 | Mean of eye tracking (ET) time in area of interest (AOI). Complexity: 1 = juxtaposition; 2 = fusion; 3 = replacement.

\section{Neurophysiological Results} Time in AOI

According to the literature, the total time spent exploring an image or an AOI (time in AOI) is a suitable indicator of comprehension (Raney et al., 2014) and cognitive load (Anderson et al., 2011) and is also a measure related to visual complexity (Henderson et al., 2003; Irwin, 2004). Therefore, in order to validate Hypothesis $2 \mathrm{a}$, we analyzed the performance of time in AOI.

First, a paired-sample $t$-test was conducted to compare the time in AOI for ads including and not including metaphorical images. Results yielded a significant difference in the time in AOI between ads without metaphors $(M=4.8, S D=0.81)$ and ads including metaphors $(M=4.5 S D=0.62) ; t_{(42)}=-3.200$, $p=0.003$. Besides, a repeated measures ANOVA determined that the different complexity levels of the ads produced statistically significant differences in time in AOI, $F_{(1.38,57.96)}=11.609$, $p=0.000$. Post hoc tests using the Bonferroni correction revealed significant differences in time in AOI between juxtapositions $(M=4.1)$ and fusions $(M=4.8)$ and between fusions and replacements $(M=4.4)$.

As shown in Figure 9, time in AOI also follows the inverted U-curve pattern. Thus, to complete the analysis, a mediation was performed. However, the results obtained showed that, although ad complexity was a significant predictor of perceived complexity ( $a=0.62, p=0.000)$, perceived complexity was not a significant predictor of time in AOI $(b=0.07, p=0.459)$, so perceived complexity did not mediate the relationship between ad complexity induced by metaphors and time in AOI $(B=-0.043$ [95\% CI: $-0.15,0.05])$. These results were also supported by results of the Sobel test $(z=-0.74, p=0.46)$.

Regarding the time spent exploring the ads, obtained results provide three interesting findings: (1) participants spent more time exploring ads without metaphors $(M=4.8)$ than ads with metaphors $(M=4.5)$; (2) the time that participants spent exploring an ad did not always increase when the ad increased in complexity (i.e., time in AOI fusion > time in AOI replacement); and (3) perceived complexity was not a significant predictor of time in AOI.

On the basis of the obtained results and since Hypothesis 2a predicted that higher levels of difficulty and, consequently, a higher index of cognitive load could be reflected by a longer time spent exploring the advertisement, we can state that Hypothesis 2a was not supported.

\section{Cognitive Load Index}

Cognitive load describes the relationship between the capacity of mental processing capability and the cognitive demands of a particular task (Mühl et al., 2014). Specifically, regarding the images, cognitive load is defined as the amount of resources needed to interpret a visualization (Anderson et al., 2011). As mentioned, the cognitive load should be reflected in physiological measurements and can be measured by various tools (GarcíaMadariaga et al., 2019), but EEG has been proven the most reliable source of information of subjects' cognitive load (Gevins et al., 1998; Antonenko et al., 2010).

In order to determine the cognitive load required by ads including and not including metaphorical images, a pairedsample $t$-test was conducted. Results revealed no significant difference in the scores for ads without metaphors $(M=27.1$, $S D=8.32)$ and ads including metaphors $(M=27.6, S D=6.84)$; $t_{(41)}=-0.503, p=0.617$. However, a repeated measures ANOVA determined that cognitive load measured through EEG yielded statistically significant differences as a function of the different complexity levels of the ads, $F_{(2,82)}=3.102, p=0.050$. Post hoc tests using Bonferroni revealed differences in cognitive load between juxtaposition $(M=26.1)$ and replacement $(M=28.4)$.

Regarding these results, it is interesting to remark that EEG results reflect a linear relationship between complexity and cognitive load, as shown in Figure 10. This means that as complexity increases, so does cognitive load.

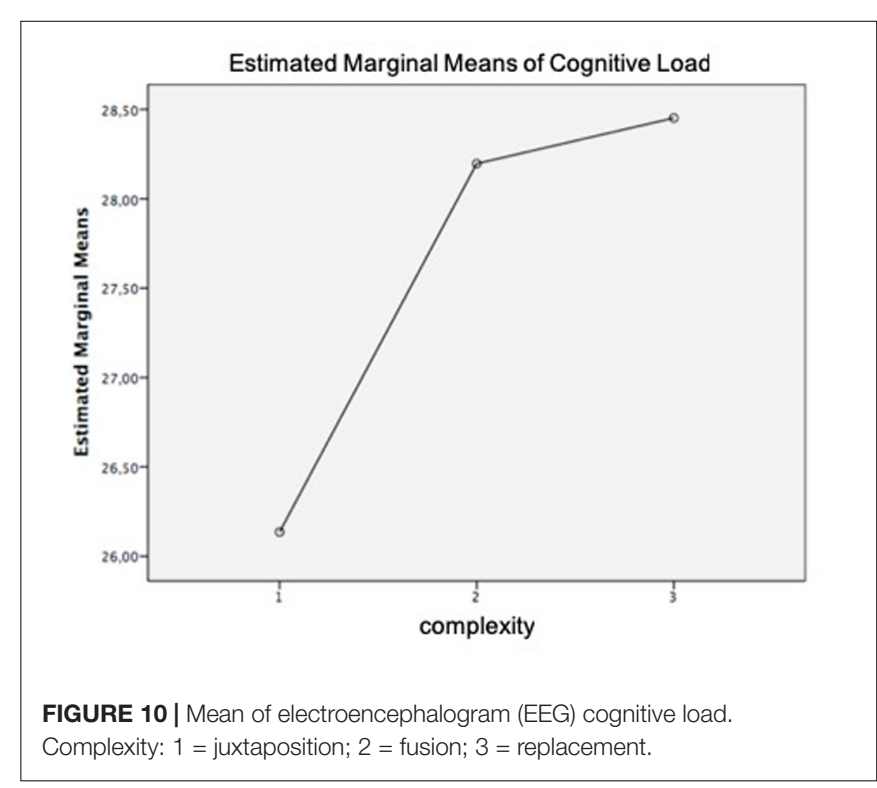




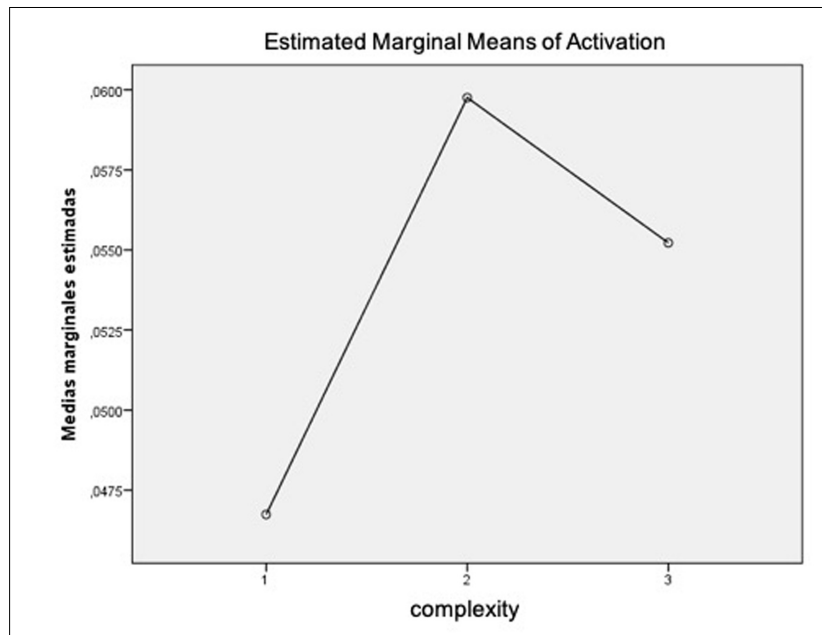

FIGURE 11 | Mean of galvanic skin response (GSR) activation. Complexity: 1 = juxtaposition; 2 = fusion; 3 = replacement.

The mediation analysis showed that comprehension did not mediate the relationship between ad complexity induced by metaphorical content and cognitive load. Although ad complexity was a significant predictor of perceived complexity ( $a=-0.61, p=0.000)$, perceived complexity was not a significant predictor of cognitive load ( $b=0.31, p=0.692)$, so perceived complexity did not mediate the relationship between ad complexity induced by metaphors and cognitive load $(B=-0.18$ [95\% CI: $-1.22,-0.74]$. These results were also supported by the Sobel test performed $(z=-0.39, p=0.692)$.

According to the obtained results: (1) ads with metaphors had a higher cognitive load index $(M=27.6)$ than ads without metaphors ( $M=27.1)$, (2) there is a linear relationship between complexity and cognitive load, and (3) perceived complexity is not a significant predictor of cognitive load. Since Hypothesis $2 b$ stated that higher levels of difficulty could be reflected on a higher index of EEG cognitive load, we can state that Hypothesis 2a was supported.

\section{Arousal}

Again, the first step was to conduct a $t$-test to compare the activation induced by ads including and not including metaphorical images. Results revealed no significant differences in activation for ads without metaphors $(M=0.06, S D=0.11)$ and ads including metaphors $(M=0.05, S D=0.08) ; t_{(38)}=0.372$, $p=0.712$. Nor was there any significant difference in activation as a function of the three levels of complexity, $F_{(1.20,45.62)}=0.288$, $p=0.636$. However, it is interesting to note that the means obtained reflect the aforementioned inverted U-curve pattern, as displayed in Figure 11.

Regarding the arousal, obtained results provide two findings: (1) participants had more arousal when they were exposed to ads without metaphors $(M=0.06)$ than when they visualized ads with metaphors $(M=0.05)$ and (2) the participants' arousal did not always increase when the ad increased in complexity (i.e., time in AOI fusion $>$ time in AOI replacement). On the basis of the obtained results and since Hypothesis $2 \mathrm{c}$ predicted that higher levels of difficulty and, consequently, a higher index of cognitive load could be reflected by higher levels of arousal, we can state that Hypothesis $2 \mathrm{c}$ was not supported. Table 4 shows a summary of the neurophysiological results obtained.

\section{DISCUSSION}

According to Phillips (2003), the usage of metaphors in advertising has an impact on attention, elaboration, pleasure, and liking. As previous studies have proven the existence of an inverted $\mathrm{U}$-curve pattern in advertisement appreciation (van Mulken et al., 2010, 2014), liking, and purchase intention (van Hooft et al., 2013), the aims of the present study were to validate previous results by testing this pattern in Aad, purchase intention, and preference, mainly because these measures are three important indicators of advertising effectiveness.

The obtained results validate previous results on purchase intentions in different product categories than used before (van Hooft et al., 2013) and provide new evidence related to preference and Aad by showing that these two metrics also follow the inverted U-curve pattern, according to which there is a positive relationship between complexity and positive feelings until a tipping point is reached where complexity exceeds comprehension (Phillips, 2000; McQuarrie and Mick, 2003; van Mulken et al., 2010, 2014; van Hooft et al., 2013). The fact that all the tested declarative constructs followed that pattern shows the importance of modulating the complexity of metaphors included in advertisements and of warning advertisers to be aware of including metaphorical content in advertisements because, instead of catching the consumers' attention, this content could lead them to ignore the message and also the brand behind it.

Moreover, the results indicated that, regardless of metaphor type, ads with metaphors evoke more positive reactions than non-metaphor ads and that medium complexity is better to get more positive Aads, preference, and purchase intentions. This finding is consistent with van Mulken et al. (2010, 2014), who ensure that the impact of a message is maximized in the medium point of the complexity continuum, because the efforts demanded of consumers match those that they are willing and able to make available.

Regarding the neurophysiological techniques applied, the results of the present study are consistent to previous studies where it was proven that complex reasoning is almost invariably accompanied by activation of broad regions of the frontal and

TABLE 4 | Summary of neurophysiological results.

\begin{tabular}{lll}
\hline Measure & $\begin{array}{l}\text { Differences between } \\
\text { ads with metaphor and } \\
\text { without metaphor }\end{array}$ & $\begin{array}{l}\text { Differences among the } \\
\text { three levels of } \\
\text { complexity }\end{array}$ \\
\hline Time in AOI (ET) & $t_{(42)}=-3.200, p=0.003$ & $\begin{array}{l}F_{(1.38,57.96)}=11.609, \\
p=0.000\end{array}$ \\
Cognitive load (EEG) & $t_{(41)}=-0.503, p=0.617$ & $\begin{array}{l}F_{(2,82)}=3.102, p=0.050 \\
\text { Activation (GSR) }\end{array}$ \\
$t_{(38)}=0.372, p=0.712$ & $\begin{array}{l}F_{(1.20,45.62)}=0.288, \\
p=0.636\end{array}$
\end{tabular}


parietal cortices that form a frontoparietal network (Stamenković et al., 2019). Besides, we provide evidence of a linear relationship between complexity and cognitive load, consistent with the idea that increases in visual complexity increase the cognitive resources needed to elaborate the metaphorical content and provide a meaning for it (McQuarrie and Mick, 1999, 2003; Phillips, 2000; Jeong, 2008; Chang and Yen, 2013). As shown in the results, there were statistically significant differences in cognitive load index as a function of the different complexity levels of the ads. This demonstrated that as complexity increases, so does cognitive load.

On the other hand, although ET has been previously used to measure cognitive load (Pieters et al., 2010; Raney et al., 2014), results on time in AOI do not correlate with those obtained with EEG. Therefore, we cannot confirm the hypothesis that extra time is required to comprehend more complex metaphors. Consequently, we couldn't confirm the hypothesis that the time spent exploring an ad is a reflection of the effort needed to comprehend it, because more complex metaphors did not necessarily require more fixation time to be understood. These findings are coincident with Wang et al. (2014) research according to which when an individual is conducting complex tasks, he/she is suffering high perceptual load, and if the load is too high, he/she might lose interest in exploring the stimuli and give up.

The same thing occurred with activation as measured by GSR. Despite that previous studies mention it as a useful tool to identify cognitive functions (Miller and Shmavonian, 1965; McEwen and Sapolsky, 1995; Shi et al., 2007; Mühl et al., 2014; Nourbakhsh et al., 2017, 2012), our experimental research results are not consistent with that idea. Instead, it turned out that our results were in line with Larmuseau et al. (2019) and Haapalainen et al. (2010), who did not obtain satisfactory results when attempting to detect cognitive load from GSR. Due to the fact that GSR is a convenient measure for indexing changes in sympathetic arousal that could be associated not only with cognition but also with emotion and attention (Vecchiato et al., 2014), our results may reflect the emotional meaning of visual metaphors (Venkatraman et al., 2015) or their attention-grabbing capacity (Critchley, 2002) instead of the cognitive load required to process them.

In this regard it is interesting that both, ET and GSR results followed the inverted U-curve pattern. This suggests that neither of the two methodologies is a suitable measures of cognitive load, at least, not in the specific case of visual metaphors. Instead, on the basis of our results, and taking into account that both metrics show the same behavior as the Aad and preference, it seems that time in AOI and arousal in this specific case are more closely related to the good feelings evoked by the ads.

\section{CONCLUSION}

This study was motivated by the lack of evidence of consumers' neurophysiological reactions to visual metaphors in advertising. In this regard, the results provide three conclusions. First, the EEG cognitive load index seems to be a suitable indicator of visual metaphors' complexity, as it reflects the amount of cognitive resources needed to process them.

According to previous studies (Klimesch, 1999, 2012; Gevins and Smith, 2003; Anderson et al., 2011), suppression (decrease) of the alpha rhythm in the prefrontal cortex could be indicative of attentional demands, task difficulty, and cognitive load. The results of the present study provide evidence along the same lines, as we found a linear relationship between complexity and cognitive load, consistent with the idea that increases in visual complexity increase the cognitive resources needed to elaborate the metaphorical content and provide a meaning for it (McQuarrie and Mick, 1999, 2003; Phillips, 2000; Jeong, 2008; Chang and Yen, 2013).

Although further research is needed on this matter, the results on cognitive load represent a step forward for consumer neuroscience research, due to the fact that this measure could be refined and may be useful in the future to analyze consumers' difficulty processing any kind of advertisement.

Second, according to the research, it turns out that both time spent exploring the stimuli and arousal follow the same "inverted U-curve" pattern as declarative constructs. This situation contradicts the previous findings that both metrics (Time in AOI and arousal) could be suitable to measure the cognitive load derived from complex tasks or contents (Miller and Shmavonian, 1965; Pieters et al., 2010; Raney et al., 2014; McEwen and Sapolsky, 1995; Shi et al., 2007; Mühl et al., 2014; Nourbakhsh et al., 2017, 2012). This conclusion supports the idea that neither of the two metrics is a suitable measure of cognitive load, at least, in the specific case of visual metaphors. Instead, in this specific context, they are more closely related to the good feelings evoked by the ads. Thus, practitioners must be careful when using GSR and ET in market research since regarding the evaluation of graphic ads, the metrics provided by those techniques are more related to attention and emotion than to cognitive load.

In advertising, visual metaphors are widely used to draw individuals' attention and entice them to buy the product (van Mulken, 2003). However, their usage is not simple. Based on the findings of the present study, researchers should be aware of the importance of comprehension in consumers' reactions. Practitioners should take care to modulate the complexity of metaphors and to prevent a lack of comprehension from reducing the effectiveness of these rhetorical figures. In any case, the study of visual metaphors in advertising should continue because only by going deeper into the understanding of consumer reactions to these resources will marketers be able to take advantage of them.

Visual metaphors are creative resources that try to provide differentiation and recognition of the brand. Our results highlight the importance of assessing the perceived complexity of ads in order to find the optimal level of complexity of the visual metaphors to achieve the desired brand awareness and advertising effectiveness (van Mulken et al., 2014; Pilelienè and Grigaliūnaitè, 2016).

Finally, the present study provides evidence on how useful the use of neuroscientific techniques can be to have an objective measure of consumer reactions to marketing stimuli and to find new and useful insights that cannot be detected with 
declarative methodologies (García-Madariaga et al., 2019). Our results suggest that EEG seems to be not only an adequate technique to discover how advertising processing can be when visual metaphors are included but also a suitable indicator of complexity, as it reflects the amount of cognitive resources needed to process stimuli. Although further research is required to deepen this issue and test the measure of cognitive load in other types of advertising and contexts, current evidence represents a step forward for consumer neuroscience research.

\section{LIMITATIONS AND FURTHER RESEARCH}

While this study provides theoretical and practical implications, some limitations must be acknowledged, mainly regarding the sample size, similarity of participants, and forced exposure to the stimuli.

Although previous studies have demonstrated that consumer neuroscience studies with small sample sizes can produce predictive results and significant insights (Berns and Moore, 2012; Smidts et al., 2014; Shen and Morris, 2016; Christoforou et al., 2017), the use of larger samples could broaden the generalizability of the findings.

Besides, the sample used is very similar because it is formed by students, and their age, education level, cultural context, and lifestyle are pretty similar. Since previous studies have proven significant cross-cultural variations in the interpretation of advertisements (Margariti et al., 2019), it would be interesting to vary the sample and to analyze how variables such as education, culture, and environment influence the processing of metaphorical content included in ads and how those variables could impact on the four variables mentioned by Phillips (2003): attention, elaboration, pleasure, and liking.

On the other hand, the present study was conducted in a laboratory, and subjects were forced to visualize the stimuli contrary to how they behave in real life, where they devote their attention voluntarily. The degree of control exerted over potential extraneous variables determines the level of internal validity of a study (Slack and Draugalis, 2001). Although the laboratory context provides that control and consequently increases the internal validity of the study, it would be interesting

\section{REFERENCES}

Anderson, E. W., Potter, K. C., Matzen, L. E., Shepherd, J. F., Preston, G. A., and Silva, C. T. (2011). A user study of visualization effectiveness using EEG and cognitive load. Comput. Graph. Forum 30, 791-800. doi: 10.1111/j.1467-8659. 2011.01928.x

Ang, S. H., and Lim, E. A. C. (2006). The influence of metaphors and product type on brand personality perceptions and attitudes. J. Advert. 35, 39-53. doi: 10.1080/00913367.2006.10639226

Antonenko, P., Paas, F., and Grabner, R. (2010). Using electroencephalography to measure cognitive load. Educ. Psychol. Rev. 22, 425-438. doi: 10.1007/s10648010-9130-y

Ares, G., Giménez, A., Bruzzone, F., Vidal, L., Antúnez, L., and Maiche, A. (2013). Consumer visual processing of food labels: results from an eye-tracking study. J. Sens. Stud. 28, 138-153. doi: 10.1111/joss.12031 to replicate the present study in more real conditions and analyze if the processing of metaphorical content varies when visualization is not forced.

Finally, on the basis of previous findings according to which advertisement appreciation follows an inverted U-curve pattern (Phillips, 2000; McQuarrie and Mick, 2003), we took comprehension as a mediation variable. Future research could consider other mediating variables such as attitude toward the brand, product category, education level, or cultural context.

\section{DATA AVAILABILITY STATEMENT}

The datasets generated for this study are available on request to the corresponding author.

\section{ETHICS STATEMENT}

Ethical review and approval was not required for the study on human participants in accordance with the local legislation and institutional requirements. The patients/participants provided their written informed consent to participate in this study.

\section{AUTHOR CONTRIBUTIONS}

All authors listed contributed to the design of the experiment, data collection, data analysis, literature review and writing and reviewing of this manuscript.

\section{FUNDING}

This work was funded by grant RTC-2016-4718-7 from the Spanish Ministry of Economy, Industry and Competitiveness.

\section{ACKNOWLEDGMENTS}

The authors would like to thank Bit-Brain S. L. for their technological assistance and support.

Ares, G., Mawad, F., Giménez, A., and Maiche, A. (2014). Influence of rational and intuitive thinking styles on food choice: preliminary evidence from an eyetracking study with yogurt labels. Food Qual. Prefer. 31, 28-37. doi: 10.1016/j. foodqual.2013.07.005

Bambini, V., Bertini, C., Schaeken, W., Stella, A., and Di Russo, F. (2016). Disentangling metaphor from context: an ERP study. Front. Psychol. 7:559. doi: 10.3389/fpsyg.2016.00559

Bastiaansen, M., Straatman, S., Driessen, E., Mitas, O., Stekelenburg, J., and Wang, L. (2016). My destination in your brain: a novel neuromarketing approach for evaluating the effectiveness of destination marketing. J. Dest. Mark. Manage. 7, 76-88. doi: 10.1016/j.jdmm.2016. 09.003

Benedek, M., and Kaernbach, C. (2010a). A continuous measure of phasic electrodermal activity. J. Neurosci. Methods 190, 80-91. doi: 10.1016/j. jneumeth.2010.04.028 
Benedek, M., and Kaernbach, C. (2010b). Decomposition of skin conductance data by means of nonnegative deconvolution. Psychophysiology 47, 647-658. doi: 10.1111/j.1469-8986.2009.00972.x

Berlyne, D. E. (1971). Aesthetics and Psychobiology, Vol. 336. New York, NY: Appleton-Century-Crofts.

Berns, G. S., and Moore, S. E. (2012). A neural predictor of cultural popularity. J. Consum. Psychol. 22, 154-160. doi: 10.1016/j.jcps.2011.05.001

Brouwer, H., Fitz, H., and Hoeks, J. (2012). Getting real about semantic illusions: rethinking the functional role of the P600 in language comprehension. Brain Res. 1446, 127-143. doi: 10.1016/j.brainres.2012.01.055

Bulmer, S., and Buchanan-Oliver, M. (2006). Visual rhetoric and global advertising imagery. J. Mark. Commun. 12, 49-61. doi: 10.1080/13527260500289142

Burgers, C., Konijn, E. A., Steen, G. J., and Iepsma, M. A. R. (2015). Making ads less complex, yet more creative and persuasive: the effects of conventional metaphors and irony in print advertising. Int. J. Advert. 34, 515-532. doi: 10.1080/02650487.2014.996200

Cardillo, E. R., Watson, C. E., Schmidt, G. L., Kranjec, A., and Chatterjee, A. (2012). From novel to familiar: tuning the brain for metaphors. Neuroimage 59, 3212-3221. doi: 10.1016/j.neuroimage.2011.11.079

Chang, C. T., and Yen, C. T. (2013). Missing ingredients in metaphor advertising: the right formula of metaphor type, product type, and need for cognition. J. Advert. 42, 80-94. doi: 10.1080/00913367.2012.749090

Christoforou, C., Papadopoulos, T. C., Constantinidou, F., and Theodorou, M. (2017). Your brain on the movies: a computational approach for predicting box-office performance from viewer's brain responses to movie trailers. Front. Neuroinform. 11:72. doi: 10.3389/fninf.2017.00072

Cook, I. A., Warren, C., Pajot, S. K., Schairer, D., and Leuchter, A. F. (2011). Regional brain activation with advertising images. J. Neurosci. Psychol. Econ. 4, 147-160. doi: 10.1037/a0024809

Coulson, S., and Van Petten, C. (2002). Conceptual integration and metaphor: an event-related potential study. Mem. Cognit. 30, 958-968. doi: 10.3758/ BF03195780

Critchley, H. D. (2002). Review: electrodermal responses: what happens in the brain. Neuroscientist 8, 132-142. doi: 10.1177/107385840200800209

Dimofte, C. V. (2010). Implicit measures of consumer cognition: a review. Psychol. Mark. 27, 921-937. doi: 10.1002/mar

Doppelmayr, M., Klimesch, W., Pachinger, T., and Ripper, B. (1998). Individual differences in brain dynamics: important implications for the calculation of event-related band power. Biol. Cybern. 79, 49-57. doi: 10.1007/s004220050457

Du Plessis, E., Leighton, J., and Dalvit, S. (2011). The branded mind: what neuroscience really tells us about the puzzle of the brain and the brand. Int. J. Advert. 30, 723-725. doi: 10.2501/IJA-30-4-723-725

Elsen, M., Pieters, R., and Wedel, M. (2016). Thin slice impressions: how advertising evaluation depends on exposure duration. J. Mark. Res. 53, 563-579. doi: 10.1509/jmr.13.0398

Fenko, A., Nicolaas, I., and Galetzka, M. (2018). Does attention to health labels predict a healthy food choice? An eye-tracking study. Food Qual. Prefer. 69, 57-65. doi: 10.1016/j.foodqual.2018.05.012

Forceville, C. (1994). Pictorial metaphor in advertisements. Metaphor Symb. Act. 1, 1-29. doi: 10.1207/s15327868ms0901_1

Forceville, C. (1996). Pictorial Metaphor in Advertising. London: Routledge.

Forceville, C. (2005). Addressing an audience: time, place, and genre in Peter van Straaten's calendar cartoons. Humor 18, 247-278. doi: 10.1515/humr.2005.18.3. 247

Forceville, C. (2008). "Pictorial and multimodal metaphor in commercials," in Go Figure! New Directions in Advertising Rhetoric, eds E. F. McQuarrie and B. J. Phillips (Armonk, NY: ME Sharpe), 272-310.

Foss, S. K. (2005). "Theory of visual rhetoric," in Handbook of Visual Communication: Theory, Methods, and Media, eds S. Ken, M. Sandra, B. Gretchen, and K. Keith (New York, NY: Routledge), 141-152.

Gakhal, B., and Senior, C. (2008). Examining the influence of fame in the presence of beauty: an electrodermal 'neuromarketing' study. J. Consum. Behav. 7, 331-341.

Garcia, C., Ponsoda, V., and Estebaranz, H. (2000). "Scanning Ads: effects of involvement and of position of the illustration in printed advertisements," in NA - Advances in Consumer Research, eds S. J. Hoch and R. J. Meyer (Provo, UT: Association for Consumer Research), 104-109.
García-Madariaga, J., López, M. F. B., Burgos, I. M., and Virto, N. R. (2019). Do isolated packaging variables influence consumers' attention and preferences? Physiol. Behav. 200, 96-103. doi: 10.1016/j.physbeh.2018.04.030

Gattol, V., Sääksjärvi, M., and Carbon, C. C. (2011). Extending the implicit association test (IAT): assessing consumer attitudes based on multidimensional implicit associations. PLoS One 6:e15849. doi: 10.1371/journal. pone.0015849

Gevins, A., and Smith, M. (2003). Neurophysiological measures of cognitive workload during human-computer interaction. Theor. Issues Ergon. Sci. 4, 113-131. doi: 10.1080/14639220210159717

Gevins, A., Smith, M. E., Leong, H., McEvoy, L., Whitfield, S., Du, R., et al. (1998). Monitoring working memory load during computer-based tasks with EEG pattern recognition methods. Hum. Factors 40, 79-91. doi: 10.1518/ 001872098779480578

Girisken, Y., and Bulut, D. (2014). How do consumers perceive a/an logotype/emblem in the advertisements: an eye tracking study. Int. J. Strateg. Innov. Mark. 01, 198-209. doi: 10.15556/IJSIM.01.04.002

Gkiouzepas, L., and Hogg, M. K. (2011). Articulating a new framework for visual metaphors in advertising. J. Advert. 40, 103-120. doi: 10.2753/JOA00913367400107

Graesser, A. C., Lu, S., Olde, B. A., Cooper-Pye, E., and Whitten, S. (2005). Question asking and eye tracking during cognitive disequilibrium: comprehending illustrated texts on devices when the devices break down. Mem. Cognit. 33, 1235-1247. doi: 10.3758/bf03193225

Gregg, A. P., and Klymowsky, J. (2013). The implicit association test in market research: potentials and pitfalls. Psychol. Mark. 30, 588-601. doi: 10.1002/mar. 20630

Haapalainen, E., Kim, S., Forlizzi, J. F., and Dey, A. K. (2010). "Psychophysiological measures for assessing cognitive load," in Proceedings of the 12th ACM International Conference on Ubiquitous Computing (New York, NY: ACM), 301-310. doi: 10.1145/1864349.1864395

Henderson, P. W., Cote, J. A., Leong, S. M., and Schmitt, B. (2003). Building strong brands in Asia: selecting the visual components of image to maximize brand strength. Int. J. Res. Mark. 20, 297-313. doi: 10.1016/j.ijresmar.2003. 03.001

Hornikx, J., and le Pair, R. (2017). The influence of high-/low-context culture on perceived Ad complexity and liking. J. Glob. Mark. 30, 228-237. doi: 10.1080/ 08911762.2017.1296985

Hsu, M. (2017). Neuromarketing: inside the mind of the consumer. Calif. Manage. Rev. 59, 5-22. doi: 10.1177/0008125617720208

Huhmann, B. A., and Limbu, Y. B. (2016). Influence of gender stereotypes on advertising offensiveness and attitude toward advertising in general. Int. J. Adv. 35, 846-863. doi: 10.1080/02650487.2016.115791

Hyvarinen, A. (1999). Fast and robust fixed-point algorithm for independent component analysis. IEEE Trans. Neural Netw. 10, 626-634. doi: 10.1109/72. 761722

Irwin, D. E. (2004). "Fixation location and fixation duration as indices of cognitive processing," in The Interface of Language, Vision, and Action: Eye Movements and the Visual World, eds J. M. Henderson, and F. Ferreira (New York, NY: Psychology Press), 105-133. doi: 10.1177/0301006615594942

Jeong, S. (2008). Visual metaphor in advertising: is the persuasive effect attributable to visual argumentation or metaphorical rhetoric? J. Mark. Commun. 14, 59-73. doi: 10.1080/14697010701717488

Kaplan, S. J. (1990). Visual metaphors in the representation of communication technology. Crit. Stud. Media Commun. 7, 37-47. doi: 10.1080/15295039009360162

Kappenman, E. S., and Luck, S. J. (eds) (2012). "ERP components: the ups and downs of brainwave recordings," in The Oxford Handbook of Event-Related Potential Components (Oxford: Oxford University), 3-30.

Klimesch, W. (1999). EEG alpha and theta oscillations reflect cognitive and memory performance: a review and analysis. Brain Res. Rev. 29, 169-195. doi: 10.1016/S0165-0173(98)00056-3

Klimesch, W. (2012). Alpha-band oscillations, attention, and controlled access to stored information. Trends Cogn. Sci. 16, 606-617. doi: 10.1016/j.tics.2012.10. 007

Kutas, M., and Federmeier, K. D. (2011). Thirty years and counting: finding meaning in the N400 component of the event-related brain potential (ERP). Annu. Rev. Psychol. 62, 621-647. doi: 10.1146/annurev.psych.093008.131123 
Lachaud, C. M. (2013). Conceptual metaphors and embodied cognition: EEG coherence reveal brain activity differences between primary and complex conceptual metaphors during comprehension. Cogn. Syst. Res. 22, 12-26. doi: 10.1016/j.cogsys.2012.08.003

Lagerwerf, L., van Hooijdonk, C. M., and Korenberg, A. (2012). Processing visual rhetoric in advertisements: interpretations determined by verbal anchoring and visual structure. J. Pragmat. 44, 1836-1852. doi: 10.1016/j.pragma.2012.08.009

Lang, S. Y., Dickinson, J., and Buchal, R. O. (2002). Cognitive factors in distributed design. Comput. Ind. 48, 89-98. doi: 10.1016/S0166-3615(02)00012-X

Larmuseau, C., Vanneste, P., Cornelis, J., Desmet, P., and Depaepe, F. (2019). Combining physiological data and subjective measurements to investigate cognitive load during complex learning. Frontline Learn. Res. 7, 57-74. doi: 10.14786/flr.v7i2.403

Lutz, R. J., MacKenzie, S. B., and Belch, G. E. (1983). "Attitude toward the ad as a mediator of advertising effectiveness: determinants and consequences," in NA - Advances in Consumer Research, Vol. 10, eds P. Richard, Bagozzi, M. Alice, and Tybout (Ann Abor, MI: Association for Consumer Research), 532-539.

Ma, Q., Wang, X., Shu, L., and Dai, S. (2008). P300 and categorization in brand extension. Neurosci. Lett. 431, 57-61. doi: 10.1016/j.neulet.2007.11.022

MacKenzie, S. B., Lutz, R. J., and Belch, G. E. (1986). The role of attitude toward the ad as a mediator of advertising effectiveness: a test of competing explanations. J. Mark. Res. 23, 130-143. doi: 10.1177/002224378602 300205

Margariti, K., Boutsouki, C., Hatzithomas, L., and Zotos, Y. (2019). Visual metaphors in food advertising: a cross-cultural study. Food Res. Int. 115, 338-351. doi: 10.1016/j.foodres.2018.11.030

McEwen, B. S., and Sapolsky, R. M. (1995). Stress and cognitive function. Curr. Opin. Neurobiol. 5, 205-216. doi: 10.1016/0959-4388(95)80028-X

McQuarrie, E. F., and Mick, D. (2009). A laboratory study of the effect of verbal rhetoric versus repetition when consumers are not directed to process advertising. Int. J. Advert. 28, 287-312. doi: 10.2501/S0265048709200576

McQuarrie, E. F., and Mick, D. G. (1996). Figures of rhetoric in advertising language. J. Consum. Res. 22, 424-438. doi: 10.1086/209459

McQuarrie, E. F., and Mick, D. G. (1999). Visual rhetoric in advertising: textinterpretive, experimental, and reader-response analyses. J. Consum. Res. 26, 37-54. doi: $10.1086 / 209549$

McQuarrie, E. F., and Mick, D. G. (2003). Visual and verbal rhetorical figures under directed processing versus incidental exposure to advertising. J. Consum. Res. 29, 579-587. doi: $10.1086 / 346252$

Miller, L. H., and Shmavonian, B. M. (1965). Replicability of two GSR indices as a function of stress and cognitive activity. J. Pers. Soc. Psychol. 2, 753-756. doi: $10.1037 / \mathrm{h} 0022680$

Mitterer-Daltoé, M. L., Queiroz, M. I., Fiszman, S., and Varela, P. (2014). Are fish products healthy? Eye tracking as a new food technology tool for a better understanding of consumer perception. LWT Food Sci. Technol. 55, 459-465. doi: 10.1016/j.lwt.2013.10.013

Mohanty, P., and Ratneshwar, S. (2014). Did you get it? factors influencing subjective comprehension of visual metaphors in advertising. J. Advert. 44, 232-242. doi: 10.1080/00913367.2014.967424

Morgan, S., and Reichert, T. (1999). The message is in the metaphor: assessing the comprehension of metaphors in advertisements. J. Advert. 28, 1-12. doi: 10.1080/00913367.1999.10673592

Mühl, C., Jeunet, C., and Lotte, F. (2014). EEG-based workload estimation across affective contexts. Front. Neurosci. 8:114. doi: 10.3389/fnins.2014.00114

Mullen, T., Kothe, C., and Chi, Y. (2013). "Real-time estimation and 3D visualization of source dynamics and connectivity using wearable EEG," in Proceedings of the Fifth International Brain-Computer Interface Meeting, San Diego, CA, 2-3. doi: 10.1109/EMBC.2013.6609968

Myers, J., and Jung, J. (2019). The interplay between consumer self-view, cognitive style, and creative visual metaphors in print advertising. J. Mark. Commun. 25, 229-246. doi: 10.1080/13527266.2016.1197296

Norrick, N. R. (2003). Issues in conversational joking. J. Pragmat. 35, 1333-1359. doi: 10.1016/S0378-2166(02)00180-7

Norris, R. L., Bailey, R. L., Bolls, P. D., and Wise, K. R. (2012). Effects of emotional tone and visual complexity on processing health information in prescription drug advertising. Health Commun. 27, 42-48. doi: 10.1080/10410236.2011. 567450
Nourbakhsh, N., Chen, F., Wang, Y., and Calvo, R. A. (2017). Detecting users' cognitive load by galvanic skin response with affective interference. ACM Trans. Interact. Intell. Syst. 7, 1-20. doi: 10.1145/2960413

Nourbakhsh, N., Wang, Y., and Chen, F. (2013). "GSR and blink features for cognitive load classification," in Proceedings of the 14th IFIP International Conference on Human-Computer Interaction, eds P. Kotze, G. Marsden, G. Lindgaard, J. Wesson, and M. Winckler (Heidelberg: Springer), 159-166. doi: 10.1007/978-3-642-40483-2_11

Nourbakhsh, N., Wang, Y., Chen, F., and Calvo, R. A. (2012). “Using galvanic skin response for cognitive load measurement in arithmetic and reading tasks," in Proceedings of the 24th Australian Computer-Human Interaction Conference, (New York, NY: ACM), 420-423. doi: 10.1145/2414536.2414602

Papa, L. A., Litson, K., Lockhart, G., Chassin, L., and Geiser, C. (2015). Analysing statistical mediation with multiple informants: a new approach with an application in clinical psychology. Front. Psychol. 6:1674. doi: 10.3389/fpsyg. 2015.01674

Peterson, M. O. (2019). Aspects of visual metaphor: an operational typology of visual rhetoric for research in advertising. Int. J. Advert. 38, 67-96. doi: 10.1080/ 02650487.2018.1447760

Phillips, B. J. (2000). The impact of verbal anchoring on consumer response to image Ads. J. Advert. 29, 15-24. doi: 10.1080/00913367.2000.10673600

Phillips, B. J. (2003). "Understanding visual metaphor in advertising," in Persuasive Imagery, eds L. M. Scott and R. Batra (Mahwah, NJ: Erlbaum), 304-317. doi: 10.4324/9781410607256-24

Phillips, B. J., and McQuarrie, E. F. (2004). Beyond visual metaphor: a new typology of visual rhetoric in advertising. Mark. Theory 4, 113-136. doi: 10. $1177 / 1470593104044089$

Phillips, B. J., and McQuarrie, E. F. (2009). Impact of advertising metaphor on consumer belief: delineating the contribution of comparison versus deviation factors. J. Advert. 38, 49-62. doi: 10.2753/JOA0091-3367380104

Pieters, R., and Wedel, M. (2004). Attention capture and transfer in advertising: brand, pictorial, and text-size effects. J. Mark. 68, 36-50. doi: 10.1509/jmkg.68. 2.36.27794

Pieters, R., Wedel, M., and Batra, R. (2010). The stopping power of advertising: measures and effects of visual complexity. J. Mark. 74, 48-60. doi: 10.1509/jmkg. 74.5.48

Pilelienè, L., and Grigaliūnaite, V. (2016). Effect of visual advertising complexity on consumers' attention. Int. J. Manage. Acc. Econ. 3, 489-501.

Piqueras-Fiszman, B., Velasco, C., Salgado-Montejo, A., and Spence, C. (2013). Using combined eye tracking and word association in order to assess novel packaging solutions: a case study involving jam jars. Food Qual. Prefer. 28, 328-338. doi: 10.1016/j.foodqual.2012.10.006

Potter, R. F., and Bolls, P. (2012). Psychophysiological Measurement and Meaning: Cognitive and Emotional Processing of Media. Abingdon, UK: Routledge.

Raney, G. E., Campbell, S. J., and Bovee, J. C. (2014). Using eye movements to evaluate the cognitive processes involved in text comprehension. J. Vis. Exp. 83:e50780. doi: 10.3791/50780

Rataj, K. (2014). Surfing the brainwaves of metaphor comprehension. Poznan Stud. Contemp. Linguist. 50, 55-73. doi: 10.1515/psicl-2014-0004

Rebollar, R., Lidón, I., Martín, J., and Puebla, M. (2015). The identification of viewing patterns of chocolate snack packages using eye-tracking techniques. Food Qual. Prefer. 39, 251-258. doi: 10.1016/j.foodqual.2014.08.002

Scott, L. M. (1994). Images in advertising: the need for a theory of visual rhetoric. J. Consum. Res. 21, 252-273. doi: 10.1086/209396

Shen, F., and Morris, J. D. (2016). Decoding neural responses to emotion in television commercials: an integrative study of self-reporting and fMRI measures. J. Advert. Res. 56, 193-204. doi: 10.2501/JAR-2016-016

Shi, Y., Ruiz, N., Taib, R., Choi, E., and Chen, F. (2007). "Galvanic skin response (GSR) as an index of cognitive load," in Proceedings of the CHI'07 Extended Abstracts on Human Factors in Computing Systems, (New York, NY: ACM), 2651-2656. doi: 10.1145/1240866.12 41057

Slack, M. K., and Draugalis, J. R. Jr. (2001). Establishing the internal and external validity of experimental studies. Am. J. Health Syst. Pharm. 58, 2173-2181. doi: 10.1093/ajhp/58.22.2173

Smidts, A., Hsu, M., Sanfey, A. G., Boksem, M. A., Ebstein, R. B., Huettel, S. A., et al. (2014). Advancing consumer neuroscience. Mark. Lett. 25, 257-267. doi: 10.1007/s11002-014-9306-1 
Sotillo, M., Carretié, L., Hinojosa, J. A., Tapia, M., Mercado, F., López-Martín, S., et al. (2004). Neural activity associated with metaphor comprehension: spatial analysis. Neurosci. Lett. 373, 5-9. doi: 10.1016/j.neulet.2004.09.071

Stamenković, D., Ichien, N., and Holyoak, K. J. (2019). Metaphor comprehension: an individual-differences approach. J. Mem. Lang. 105, 108-118. doi: 10.1016/j. jml.2018.12.003

Thomsen, S. R., and Fulton, K. (2007). Adolescents' attention to responsibility messages in magazine alcohol advertisements: an eye-tracking approach. J. Adolesc. Health 41, 27-34. doi: 10.1016/j.jadohealth.2007.02.014

Tomaselli Fidelis, B., Caldeira Oliveira, J. H., Engracia Giraldi, J., de Oliveira, R., and dos Santos, R. D. O. J. (2017). Sexual appeal in print media advertising: effects on brand recall and fixation time. Res. J. Text. Apparel 21, 42-58. doi: 10.1108/RJTA-12-2016-0033

Utsumi, A. (2007). Interpretive diversity explains metaphor-simile distinction. Metaphor Symb. 22, 291-312.

van Hooft, A., van Mulken, M., and Nedertigt, U. (2013). "Cultural differences? Visual metaphor in advertising: comprehension and tolerance of ambiguity in Four European Countries," in Advances in Advertising Research, Vol. IV, eds S. Rosengren, M. Dahlén, and S. Okazaki (Wiesbaden: Springer Gabler), 351-364. doi: 10.1007/978-3-658-02 365-2_27

van Mulken, M. (2003). Analysing rhetorical devices in print advertisements. Doc. Des. 4, 114-128. doi: 10.1075/dd.4.2.02mul

van Mulken, M., le Pair, R., and Forceville, C. (2010). The impact of perceived complexity, deviation and comprehension on the appreciation of visual metaphor in advertising across three European countries. J. Pragmat. 42, 3418-3430. doi: 10.1016/j.pragma.2010.04.030

van Mulken, M., van Hooft, A., and Nederstigt, U. (2014). Finding the tipping point: visual metaphor and conceptual complexity in advertising. J. Advert. 43, 333-343. doi: 10.1080/00913367.2014.920283

Vecchiato, G., Cherubino, P., Maglione, A. G., Ezquierro, M. T. H., Marinozzi, F., Bini, F., et al. (2014). How to measure cerebral correlates of emotions in marketing relevant tasks. Cognit. Comput. 6, 856-871. doi: 10.1007/s12559014-9304- $\mathrm{x}$

Venkatraman, V., Dimoka, A., Pavlou, P. A., Vo, K., Hampton, W., Bollinger, B., et al. (2015). Predicting advertising success beyond traditional measures: new insights from neurophysiological methods and market response modeling. J. Mark. Res. 52, 436-452. doi: 10.1509/jmr.13.0593

Wang, Q., Yang, S., Liu, M., Cao, Z., and Ma, Q. (2014). An eye-tracking study of website complexity from cognitive load perspective. Decis. Support Syst. 62, 1-10. doi: 10.1016/j.dss.2014.02.007

Wedel, M., and Pieters, R. (1989). A review of eye-tracking research in marketing. Rev. Mark. Res. 4, 123-147. doi: 10.4324/9781351550932-5

Wedel, M., and Pieters, R. (2008). Eye tracking for visual marketing. Found. Trends Mark. 1, 231-320. doi: 10.1561/1700000011

Weiland, H., Bambini, V., and Schumacher, P. B. (2014). The role of literal meaning in figurative language comprehension: evidence from masked priming ERP. Front. Human Neurosci. 8:583. doi: 10.3389/fnhum.2014. 00583

Winkler, I., Haufe, S., and Tangermann, M. (2011). Automatic classification of artifactual ICA-components for artifact removal in EEG signals. Behav. Brain Funct. 7:30. doi: 10.1186/1744-9081-7-30

Conflict of Interest: The authors declare that the research was conducted in the absence of any commercial or financial relationships that could be construed as a potential conflict of interest.

Copyright (c) 2020 García-Madariaga, Moya, Recuero and Blasco. This is an openaccess article distributed under the terms of the Creative Commons Attribution License (CC BY). The use, distribution or reproduction in other forums is permitted, provided the original author(s) and the copyright owner(s) are credited and that the original publication in this journal is cited, in accordance with accepted academic practice. No use, distribution or reproduction is permitted which does not comply with these terms 


\title{
Future-Oriented Happiness: Its Nature and Role in Consumer Decision-Making for New Products
}

\author{
Debora Bettiga*t and Lucio Lambertit \\ Department of Management, Economics and Industrial Engineering, Politecnico di Milano, Milan, Italy
}

OPEN ACCESS

Edited by:

Maria Pilar Martinez-Ruiz, University of Castilla La Mancha,

Spain

Reviewed by:

Alba García-Milon,

University of La Rioja, Spain

Rafael Anaya-Sánchez,

University of Malaga, Spain

${ }^{*}$ Correspondence:

Debora Bettiga

debora.bettiga@polimi.it

tThese authors have contributed

equally to this work

Specialty section:

This article was submitted to Organizational Psychology,

a section of the journal

Frontiers in Psychology

Received: 20 January 2020

Accepted: 14 April 2020

Published: 15 May 2020

Citation:

Bettiga D and Lamberti L (2020)

Future-Oriented Happiness: Its Nature and Role in Consumer

Decision-Making for New Products.

Front. Psychol. 11:929.

doi: 10.3389/fpsyg.2020.00929
Cognitive evaluations only partially explain the consumer purchasing patterns, especially when consumers approach a product for the first time. In such an encounter, consumers anticipate the emotions they might experience as a result of their decision, as they cannot realistically evaluate product performances. The work investigates the nature and the influence of these future-oriented emotions, namely anticipated and anticipatory happiness, in the first encounter with new products. Through a first laboratory study, adopting both physiological (micro-facial expressions analysis) and self-reported measures, we confirm the distinction between anticipated and anticipatory happiness. We further show the differential impact of these two emotional constructs on the consumer decision-making process by grounding on the Theory of Planned Behavior (TPB). Through a second study, based on a questionnaire, we further investigate the role of anticipated happiness within the TPB. We show that anticipated happiness is a pervasive emotional construct that influences all stages of the intention formation process. We discuss how these findings enrich existing knowledge on the interplay between cognitive and affective components of the decision-making process for new products. Moreover, we offer a methodological contribution to the use of physiological methods to assess emotions.

Keywords: anticipated happiness, anticipatory happiness, Theory of Planned Behavior (TPB), micro-facial expressions, decision-making process

\section{INTRODUCTION}

The first encounter with a product represents a strong determinant of product adoption (Mugge et al., 2005; Aichner, 2012; Hui et al., 2013). Positive consumer experience is essential in such a touchpoint (Kumar and Garg, 2010; Jun et al., 2019), as consumers cannot realistically evaluate product performances, but only imagining how using that product would be (Palmer and Koeniglewis, 2014). If research affirms that pure cognitive evaluations only partially explain consumer purchasing patterns (Moons and De Pelsmacker, 2012), the need for considering emotions alongside rationality is even stronger when it comes to consumers approaching products for the first time (Palmer and Koenig-lewis, 2014).

Future-oriented emotions, namely anticipated and anticipatory emotions, have been proposed in the literature as the anticipation of future emotional states that arise when consumers imagine or simulate product consumption (Chang, 2016). For instance, a consumer who envisions or feels that using a particular product will make him/her happy in the future (Baumgartner et al., 2008). 
However, the conceptualization of future-oriented emotions and their impact on the purchasing process are largely unexplored. Concerning the first issue, a still fuzzy distinction exists between anticipatory and anticipated emotions, with emotions that have not been precisely classified into one of the two categories (Baumgartner et al., 2008; Carrera et al., 2012). About the second issue, very few studies investigated future-oriented emotions effect on consumer purchasing process (Bettiga and Lamberti, 2017, 2018). Prior research mostly investigates contexts of uncertainty or risk, such as anticipated emotions of gambling or regret (Coricelli et al., 2007) or personal goals, such as losing weight or obtaining a tenure position (Perugini and Bagozzi, 2001). A third shortage of extant research refers to the kind of future-oriented emotions explored. Most researchers focused their attention on negative emotions such as regret, guilt or embarrassment (Kim et al., 2013; Onwezen et al., 2014; Turel, 2016; Londono et al., 2017; Khan et al., 2019), probably due to the evaluation of negative emotions as stronger predictors of behavioral intentions than positive emotions (Baumgartner et al., 2008).

However, recent studies recognize positive emotions, particularly happiness, as relevant drivers of decision-making process (Nicolao et al., 2009; Mogilner et al., 2011; Bhattacharjee and Mogilner, 2014; Petersen et al., 2018; Cloarec et al., 2019). This opens new space for investigation of positive emotions for which boundaries, as well as effects on the purchase process, are still unclear (De Keyser and Lariviere, 2014; Ayadi et al., 2017).

In light of these considerations, this work aims, through two exploratory studies, at deepening the understanding of the nature and the influence of future-oriented happiness in the first encounter with a new product. Such relationships are studied through both self-reported (a questionnaire) and physiological (Facial Action Coding System) methods. By doing that, the works wants to contribute to extant literature by shedding light on the still vague conceptualization of anticipated and anticipatory happiness, supporting their conceptual distinction. Furthermore, it aims to explore their effect on the consumer purchasing patterns, by extending the Theory of Planned Behavior (TPB) and enriching existing knowledge on the interplay between cognitive and affective components of the decision-making process. Finally, the study introduces the use of physiological methods to assess emotions, thus offering a methodological contribution.

\section{ANTICIPATED AND ANTICIPATORY EMOTIONS IN DECISION-MAKING}

Academic research displays a raising interest toward irrational and affective dimensions of consumer decision making, with many attempts to improve cognitive models of decision-making by including emotional constructs. Emotions spontaneously affect the decision-making process (Moons and De Pelsmacker, 2012). They may constitute pivotal mediating variables in behavioral responses (Schoefer and Diamantopoulos, 2008) or direct drivers of the purchase decisions (Di Muro and Murray, 2012). This is particularly true when it comes to consumers approaching products or services for the first time
(Palmer and Koenig-lewis, 2014; Bettiga et al., 2017). Indeed, consumers tend to evaluate new stimuli through the feelings they may elicit (Holbrook and Hirschman, 1982; George et al., 2016). Individuals, indeed, are not able to realistically evaluate product usage in the pre-consumption stage, thus they tend to rely on emotions in such decision-making process (Palmer and Koenig-lewis, 2014).

Among cognitive theories adopted to analyze the decisionmaking process, the TPB is probably the most recognized and adopted model (Ajzen, 1991). Its key concepts and relationships have been proved effective in predicting consumer intentions for a wide variety of products and behavior (Pavlou and Fygenson, 2006; Chen and Tung, 2014; Hassan et al., 2016). TPB has constituted the core theory on which to develop newer models to explain purposive behaviors (Perugini and Bagozzi, 2001; Londono et al., 2017). Comparatively to the Theory of Reasoned Action (TRA- Fishbein and Ajzen, 1975), from which it originates, it includes an additional major construct, the Perceived Behavioral Control (PBC). PBC showed to improve the prediction of behavioral intention and behavior, especially when the behavior is not completely under volitional control (Madden et al., 1992). According to the TPB, behavioral intention (I), a predictor of behavior, is influenced by attitude (A) - the overall evaluation one performs of certain behavior and its possible consequences -, subjective norms $(\mathrm{SNs})$ - the perceived social pressure - and $\mathrm{PBC}$ - the perceived ease or difficulty associated with a specific behavior.

The TPB is a widely applied theory to understand and predict human behavior (Pavlou and Fygenson, 2006; Chen and Tung, 2014; Hassan et al., 2016). However, many authors argue that its efficacy could be improved by overcoming present limitations. The first limitation regards the intention-behavior gap where, theoretically, "behavioral intentions are motivational factors that capture how hard people are willing to try to perform a behavior" (Pavlou and Fygenson, 2006, p. 117). However, the intention may not be a good predictor of the final behavior as people may fail to act on their stated intentions. The causes of this gap can sometimes be found in the methodology adopted to measure both intention and behavior (Hassan et al., 2016). The second limitation of the TPB concerns the inability of the model to predict behaviors that are not driven by intentions such as habits and impulsive buying (Wood and Neal, 2009; Verplanken and Sato, 2011). However, even for deliberate behaviors, the TPB may fail in capturing all determinants of such intentions. Indeed, the TPB is highly cognitive and relies on the assumption that most behaviors people engage in are rational and under their control. Thus, it tends to perform less efficiently for behaviors grounded on strong irrational and affective elements (Kim et al., 2013). For these reasons, various studies tried to improve the predictive power of TPB by including emotional constructs (Kim et al., 2013; Onwezen et al., 2014; Turel, 2016; Londono et al., 2017). Following prior studies, we rely on the TPB as the building block of on which to develop our model.

Emotions are the result of the appraisal of a specific situation, they are highly subjective and they depend on the person that performs this evaluation. They "have a specific referent," meaning that they arise only as a response of an "appraisals one makes 
for something of relevance to one's well-being" (Bagozzi et al., 1999, p. 185). The potential consequences of the current decision heavily influence consumers' decision making too (Bagozzi et al., 2016). Consumer anticipation, indeed, is as a mental process by which consumers envision the impact that a certain consumption decision may have on the self in the future (Vichiengior et al., 2019). Hence, when consumers imagine or simulate product consumption, they generate affective expectations about how using that product could make them feel (Chang, 2016), the so-called anticipated and/or anticipatory emotions.

Baumgartner et al. (2008) proposed a distinction between Anticipatory and Anticipated Emotions, confirmed in further studies (Carrera et al., 2012; Barsics et al., 2016; Xu and Guo, 2019). Anticipatory Emotions ( $A_{Y} E s$ ) are affective reactions that are experienced in the present "due to the prospect of a desirable or undesirable future event" (Baumgartner et al., 2008, p. 685). They consist of current and real affective responses to future events. Anticipated Emotions $\left(\mathrm{A}_{\mathrm{D}} \mathrm{Es}\right)$, instead, arise when a person project to experience certain emotions in the future, in response to an event. Even though they could be accompanied by vivid visualizations at the present, they represent predictions of future emotional states. Nevertheless, these forecasted emotions can shape present consumer behavior through a self-regulatory function.

Anticipated Emotions rely on "cognitive-evaluative dimensions" while Anticipatory Emotions are connected to “experiential-current reactions" (Carrera et al., 2012, p. 274).

Both Anticipated and Anticipatory Emotions impact behavioral intentions, where $A_{D}$ Es have stronger motivational effects than $A_{Y}$ Es. Moreover, negative emotions are stronger predictors of behavioral intentions than positive emotions (Baumgartner et al., 2008). Anticipated Negative Emotions, which include regret, shame, sadness, embarrassment, have been proved to influence cognitive evaluation, being direct predictors of behavioral intention in the TPB framework (Kim et al., 2013; Londono et al., 2017). This suggests that decision-making models such as the TPB could largely benefit by accounting emotions in intentions formation. Anticipated pride and guilt shown to impact the TPB by partially mediating the impact of attitude and subjective norms on intention (Onwezen et al., 2014). Among Anticipated Positive Emotions, happiness and hope proved to induce a more favorable attitude toward the product (Chang, 2016). Besides, the occurrence likelihood of the target future event influences the experience of $A_{Y} E s$, but it is not related to $A_{D}$ Es. This work investigates such issues in two exploratory studies. Specifically, Study 1 examines the nature and the impact of anticipated emotions and anticipatory emotions along the decision-making process. Study 2 deepens the role of anticipated happiness on individuals' decisional patterns by analyzing its role in the TPB.

\section{STUDY 1}

\section{Research Questions Development}

Research acknowledges the importance of emotions in relation to consumer behavior (Argo et al., 2006; Soscia, 2007;
Baumgartner et al., 2008; Schoefer and Diamantopoulos, 2008; Nicolao et al., 2009; Mogilner et al., 2011; Di Muro and Murray, 2012; Kim et al., 2013; Bhattacharjee and Mogilner, 2014; Onwezen et al., 2014; Sun et al., 2015; Chang, 2016; Turel, 2016; Bettiga et al., 2017; Londono et al., 2017). Despite that, a lack of knowledge is evident on the impact of positive emotions in the decision-making processes. Researchers mainly focused their attention on negative emotions such as regret, guilt, embarrassment (Kim et al., 2013; Onwezen et al., 2014; Pletti et al., 2016; Turel, 2016; Londono et al., 2017), probably because negative emotions have been recognized as stronger predictors of behavioral intentions than positive ones (Baumgartner et al., 2008). Few studies focused on positive emotions, even if they recognize them, particularly happiness, as a relevant driver of the decision-making process (Mogilner et al., 2011; Martínez-Ruiz et al., 2017).

Happiness, defined as "a state of well-being and contentment; a pleasurable or satisfying experience" (Mogilner et al., 2011, p. 430) revealed a strong positive relationship with consumption (Mogilner et al., 2011; Wang et al., 2019) making this construct particularly relevant in the study of consumer consumption processes. However, most of the studies to date focused only on the experiential and indulgent sides of purchase. Research studied happiness in relation to material vs. experiential purchases (Nicolao et al., 2009), investigate whether happiness could vary across ordinary and extraordinary experiences (Bhattacharjee and Mogilner, 2014) and analyzed the relationship between indulgent purchases and happiness (Petersen et al., 2018). The current research moves in a novel direction, by exploring happiness in the first encounter with new products, to uncover insights on this powerful but still little explored emotion. Finally, prior studies do not clearly distinguish between anticipated and anticipatory emotions and their respective impact on consumer decision-making (Baumgartner et al., 2008; Carrera et al., 2012). So, the first objective of this work is to investigate if Anticipated and Anticipatory Emotions are indeed two different constructs. More formally:

RQ1: Anticipated and Anticipatory Happiness are two distinct emotional reactions.

The second objective of the study is to investigate if Anticipatory and Anticipated happiness do have an impact on the decisionmaking process. To do that, we will explore the impact of Anticipated and Anticipatory Happiness on the three acknowledged predictors of intention (A, SNs, and $\mathrm{PBC}$ ) in the Theory of Planned Behavior. Thus:

RQ2: Anticipated and Anticipatory Happiness have a relationship with Attitude, Subjective Norms and Perceived Behavioral Control.

\section{Materials and Methods}

The study employs two different methodologies to assess Anticipated and Anticipatory Happiness elicited by the same stimulus. The former is evaluated through self-reported methods, by utilizing a questionnaire, while the latter is measured through autonomic physiological responses, by employing a microfacial 
expression reader. The choice of these two methodologies is due to the nature of Anticipated and Anticipatory Emotions. Anticipated Emotions require the individual to imagine a future consumption situation and try to envision how they would feel in that context. So, since they require a cognitive elaboration, this effort could be better captured by employing a self-reported method like a questionnaire. Anticipatory Emotions, instead, are emotional responses experienced in the present moment when one thinks about a future event, hence they are better evaluated through the affective physiological responses, the spontaneous and unconscious reactions to the stimulus. In this regard, we use the Facial Action Coding System (FACS), firstly developed by Paul Ekman and Wallace V. Friesen in 1978 and largely used in marketing researches to assess emotional responses (Teixeira et al., 2012; Hernández-Fernández et al., 2019). It can determine the emotional state of the interviewed subject through the analysis of the micro-expressions (fear, anger, surprise, disgust, happiness, and sadness), which are involuntary contractions of the facial muscle.

\section{Stimuli Selection}

The chosen stimuli were two teaser videos advertising new products, which lasted $\sim 30 \mathrm{~s}$ each. The use of two different videos guarantees the capability to accurately assess emotion intensity. Moreover, their length is recognized to be appropriate to elicit emotional responses in the subject (Ménard et al., 2015). The advertised products belonged to two different categories: a personal care product (a teeth whitening pen) and an electronic good (a laser keyboard). When choosing the products, two main constraints were set: the product had to be relatively new to the respondent to avoid being influenced by previous experiences of use. When past experiences are available, people tend to rely more on those experiences and engage less in processing information (Palmer and Koenig-lewis, 2014). This results in a weaker relationship between $\mathrm{A}, \mathrm{SNs}, \mathrm{PBC}$ and intention to purchase the product (Kidwell and Jewell, 2008). Similarly, also the brand name was left out on purpose since it works as a memory cue which pushes consumers to retrieve past information to guide their future decisions.

\section{Experimental Design and Sample}

A laboratory experiment was conducted, involving 50 Italian participants. Such sample size is more than satisfactory for physiological studies, usually grounded on $<20$ subjects (Stoll et al., 2008; Santos et al., 2012; Teixeira et al., 2012; HernándezFernández et al., 2019). The experiment lasted $10 \mathrm{~min}$ and it was carried inside a university laboratory. Participants selected did not have to carry cardiac diseases, acute visual impairments and they should not have participated in neuromarketing experiments in the previous 6 months. Subjects were invited to sign an authorization module which informed them about the purpose of the experiment, the technical equipment used to perform the experiment, the possibility to interrupt the experiment whenever they wanted and the data treatment. Then, they were invited to sit in front of a monitor, where a webcam was installed in front of them to record their expressions while watching the two product advertising videos and answering a questionnaire. The subjects were recommended to avoid touching or obscuring their face while watching the videos and to remove their hair from their face (a fringe, for example, could impede the clear recognition of the micro facial expression in the analysis phase). At the beginning of the first video, a neutral image was displayed on the screen for $20 \mathrm{~s}$, to collect the basic expression of the subject (i.e., the expression the subject has when no external stimuli are provided).

\section{Questionnaire Development}

The questionnaire was mainly developed grounding on Ajzen (2006). It consisted of three main sections: the first aimed at gathering descriptive information about the respondents such as gender, age, level of education, type of job and nationality. The other two sections were needed to collect data about the original TPB factors (A, SNs, $\mathrm{PBC}$, and I) and the extended factor $\left(\mathrm{A}_{\mathrm{D}} \mathrm{H}\right)$ for the two different products. At the beginning of each section, a brief description of the product was presented, followed by the teaser advertising video. Questions were introduced with a short instruction about how to answer them.

The questions testing the Anticipated Happiness' construct were assessed using 7-points Likert scales ranging from "not at all" to "extremely." Anticipated Happiness was assessed with four items (Laros and Steenkamp, 2005; Mogilner et al., 2011; Chang, 2016), asking participants to envision how they would feel about using the product in the future and the projected impact of the products on their lives. Specifically, we asked them to rate how pleased would they feel about using the product, if the idea of using it would make them feel better and if the product could solve annoying problems and improve their everyday life. The questions testing Attitude, Subjective Norms, Perceived Behavioral Control, and Intentions were assessed using 7-points Likert scales ranging from "strongly disagree" to "strongly agree." Attitude toward the products was assessed through five items (Ajzen, 2006). Participants had to rate how much they thought the product could be "a good idea," "pleasant," "valuable," "enjoyable," and "beneficial" for them. Subjective Norms were measures through three items (Ajzen, 2006): participants had to indicate whether their relevant others (family and friends) would agree with their purchase and then they had to rate their propensity to listen to the advice of their relevant others. Perceived Behavioral Control was measured with five items (Ajzen, 2006; Hsu et al., 2017) able to capture the perceived ability to use the product and the extent to which respondents had the resources needed to use it. The intention to buy the product was measured using three items (Ajzen, 2006) that evaluated the willingness of the respondents to acquire the product. The questionnaire was translated into Italian, the mother tongue of the participants. A preliminary test of the questionnaire was carried out on 10 subjects to gather relevant feedbacks regarding distinct aspects like syntax, easiness of comprehension and overall clarity.

\section{Microfacial Expressions Assessment}

Participants were recorded while watching the teaser videos. Each video was then analyzed using Noldus Face Reader, version 7. The software automatically assesses the intensity of a series of six emotional states of the subject: happiness, fear, anger, disgust, surprise, and sadness. The output is a temporal track where all 
the changes in the subject's expressions are analyzed and classified into emotions (changes in the subject's face are recorded every 66 $\mathrm{ms}$ ). The emotion intensity ranks from 0 to 1 and values below 0.05 are considered background noise.

\section{Results \\ Preliminary Analysis}

Two subjects for the personal care product stimulus and five for the electronic device were not considered for data analysis due to low quality of the facial expression recording (mainly subjects partially covering their faces with hands during the experiment). Once the cleaning session of the data had been performed, the emotional track of each participant was calibrated. The calibration phase is needed to remove person-specific biases, such as a facial expression naturally skewed toward anger. For each participant, it was necessary to select $2 \mathrm{~s}$ of video recording to be used as an input for the calibration analysis. This time interval was taken while the subject was staring at the neutral image at the beginning of the first video. If for some reason the expression of the subject was not considered neutral, the calibration was done considering another part of the track where the subject was as neutral as possible (e.g., when answering to the demographic questions in the questionnaire).

\section{Descriptive Analysis}

The sample was composed of $40 \%$ men and $60 \%$ women. Age distribution was the following: $2 \%$ of the respondents aged between 19 and 25 years old, 20\% between 26 and 35, 32\% between 36 and 45 and the remaining $46 \%$ aged over 45 years old. Regarding the education level, $70 \%$ of the participants attended high school, 28\% got a degree (Bachelor or Master degree) and 2\% obtained a Ph.D. Analysing the type of job, the majority of the respondents (66\%) worked as employees, $20 \%$ were entrepreneurs, $2 \%$ declared to be retired and the remaining $12 \%$ was unemployed (no students were present in the sample). All the respondents were Italian. With one exception, all respondents never used before the advertised products and this is aligned with our purpose to avoid past experiences that influence the evaluation of the products. Table 1 shows the descriptive statistics of the TPB model constructs evaluated, divided by product. Table 2 provides the descriptive statistics of the six basic emotions that were detected using the face reader. The intensity of the emotions detected in the laboratory environment resulted quite low as respondents mainly display a neutral expression during the session (mostly, the intensity of the emotions recorded scored values lower than $0.05 / 1$, not considered manifestations of emotion but a background noise). For both stimuli more than half of the participants did not manifest any emotion.

\section{RQ1 Results}

The first part of the analysis investigated whether there is a relationship between Anticipated and Anticipatory Happiness. To the best of our knowledge, there is no previous evidence that supports a specific type of association between them. Thus, three possible regression models were investigated: linear, logarithmic and polynomial. Figure 1 plots the regression lines for each tested relation: the red dotted line represents the linear
TABLE 1 | Descriptive statistics of A, SNs, PBC, and $A_{D} H$.

\begin{tabular}{lccccc}
\hline & \multicolumn{2}{c}{ Electronic device } & & \multicolumn{2}{c}{ Personal care product } \\
\cline { 2 - 3 } Construct & $\boldsymbol{M}$ & SD & & $\boldsymbol{M}$ & $\boldsymbol{S} \boldsymbol{D}$ \\
\hline $\mathrm{A}^{*}$ & 5.03 & 1.53 & & 5.37 & 1.93 \\
$\mathrm{SNS}^{\star *}$ & 21.51 & 13.25 & & 26.02 & 14.51 \\
$\mathrm{PBC}^{\star}$ & 6.18 & 0.78 & & 6.14 & 0.90 \\
$\mathrm{~A}_{D} \mathrm{H}^{*}$ & 4.81 & 1.44 & & 5.28 & 1.78
\end{tabular}

*Max value 7; ${ }^{* *}$ Max value 49.

TABLE 2 | Descriptive statistics of Anticipatory Emotions.

\begin{tabular}{lccccc}
\hline & \multicolumn{2}{c}{ Electronic device } & & \multicolumn{2}{c}{ Personal care product } \\
\cline { 2 - 3 } Anticipatory emotions* & $\boldsymbol{M}$ & S & & $\boldsymbol{M}$ & SD \\
\hline Happy & 0.029 & 0.047 & & 0.043 & 0.078 \\
Sad & 0.083 & 0.108 & & 0.105 & 0.134 \\
Angry & 0.044 & 0.063 & & 0.053 & 0.070 \\
Surprised & 0.014 & 0.034 & & 0.027 & 0.055 \\
Scared & 0.005 & 0.018 & & 0.010 & 0.026 \\
Disgusted & 0.033 & 0.057 & & 0.037 & 0.075 \\
\hline
\end{tabular}

*Values between 0 and 1.

regression; the blue and the green represent the logarithmic and the polynomial regression lines respectively. Results confirms our expectations, demonstrating that the two variables are not related $\left(R_{\operatorname{lin}}^{2}=0.011 ; R_{\log }^{2}=0.002 ; R_{\text {polinomial }}^{2}=0.070\right.$; number of observations $=93$ ).

\section{RQ2 Results}

Respondents were divided into two clusters based on the fact that they manifested the emotions of Anticipatory Happiness through their facial expression or not, at least in response to one stimulus. Following, one-way analyses of variance (Single Factor ANOVA) were run to understand if there was any difference in the intention predictors among the two clusters. Results (Table 3) revealed that subjects with higher (lower) tendency to show $\mathrm{A}_{Y} \mathrm{H}$ through facial expressions declared lower (higher) levels of PBC. Thus, more "emotional" subjects perceived on average to have less control. Conversely, high-control individuals were those who did not express $\mathrm{A}_{Y} \mathrm{H}$ through facial expressions during any of the two stimuli. Further, Anticipated Happiness was analyzed in relationship with intention antecedents. Given that these variables $\left(\mathrm{A}, \mathrm{SNs}, \mathrm{PBC}\right.$, and $\mathrm{A}_{\mathrm{D}} \mathrm{H}$ ) were assessed with the same measurement method (questionnaire), a regression analysis seems appropriate to assess relationships between $A_{D} H$ and each of the three predictors. Results show that $A_{D} H$ could qualify as a predictor of all constructs of $\mathrm{A}, \mathrm{SNs}$, and PBC. A first regression was calculated to predict $A$ based on $A_{D} H$. A significant regression equation was found $[F(1,91)=771.45$; $p<0.000$ ] with an $\mathrm{R}^{2}$ of 0.89 . A second regression analysis calculates $\mathrm{SNs}$ based on $\mathrm{A}_{\mathrm{D}} \mathrm{H}$, with results of $[F(1,91)=69.69$; $p<0.000]$ and an $\mathrm{R}^{2}$ of 0.43 . A third regression predicts $\mathrm{PBC}$ based on $A_{D} H$, with the following results: $[F(1,91)=10.29$; $p<0.002$ ] with an $\mathrm{R}^{2}$ of 0.10 . Looking at the $\mathrm{R}^{2}$ values it can 


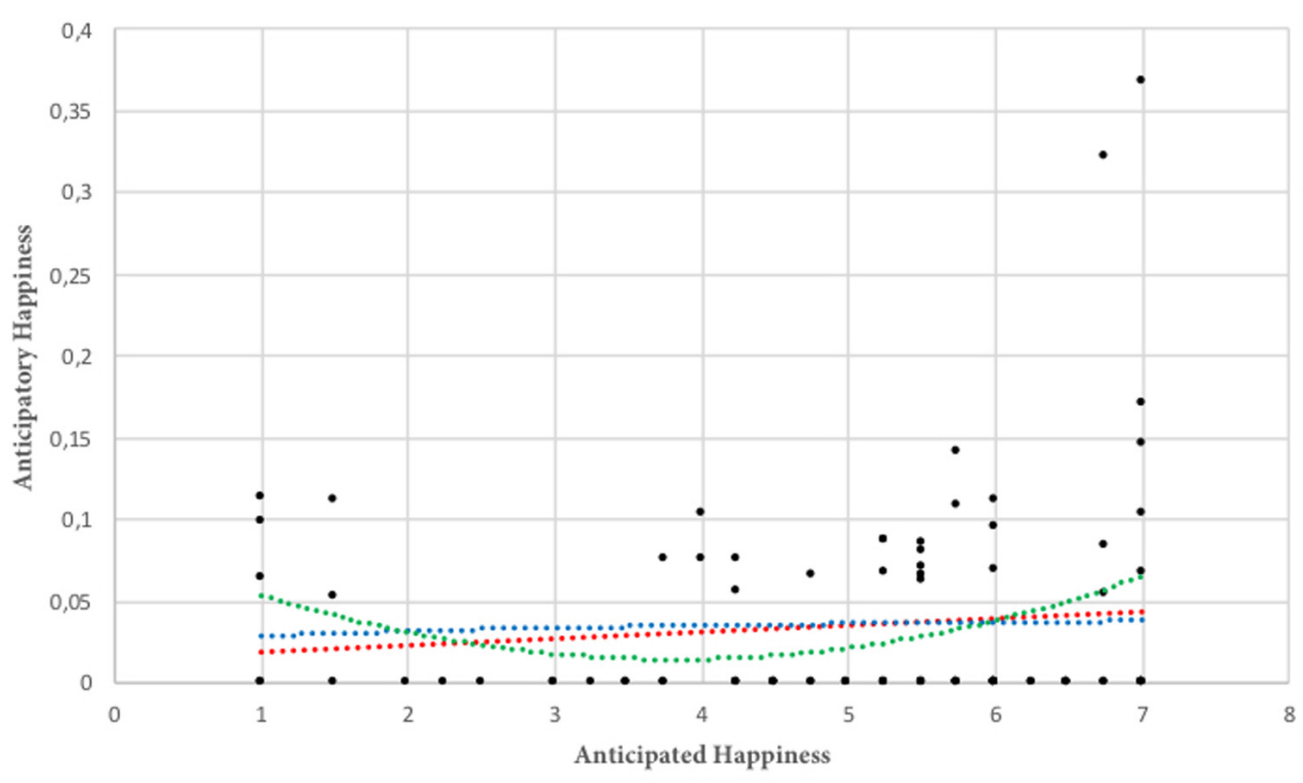

FIGURE 1 | Relationship between anticipated and anticipatory happiness.

be noticed that the stronger relationship is between $A_{D} H$ and $A$, with an explained variance of $89 \%$, while $\mathrm{A}_{\mathrm{D}} \mathrm{H}$ explains around $43 \%$ of the variance in SNs and $10 \%$ of the variance in PBC.

\section{Discussion}

This study aimed to understand whether Anticipated and Anticipatory Happiness constitute two different emotional reactions and their role in the decision-making process. The choice to investigate consumer happiness is driven by two main reasons. First, the fact that this emotion has been proven to play a crucial role in shaping consumer behavior (Nicolao et al., 2009; Bhattacharjee and Mogilner, 2014; De Keyser and Lariviere, 2014; Ayadi et al., 2017; Petersen et al., 2018). Second, the intent to expand prior literature on consumer emotions, which has traditionally focused on the role of negative emotional responses (Onwezen et al., 2014; Turel, 2016; Londono et al., 2017).

To test our first research question, two methods were employed, to account for previously proposed differences between the two categories of emotions (Baumgartner et al., 2008). Results provide support for H1, confirming that there is a distinction between Anticipated and Anticipatory Happiness, supporting Baumgartner et al. (2008) arguments of divergence between the constructs. Even more remarkably, we contribute

TABLE 3 | One-way analysis of variance and means for PBC by AyH.

\begin{tabular}{|c|c|c|c|c|}
\hline \multirow[t]{3}{*}{ Measure } & \multirow{2}{*}{\multicolumn{2}{|c|}{$\begin{array}{c}\text { Mean } \\
\text { AyH }\end{array}$}} & \multirow[t]{3}{*}{$F(1,91)$} & \multirow[t]{3}{*}{$p$-value } \\
\hline & & & & \\
\hline & Yes & No & & \\
\hline PBC & 5.93 & 6.33 & 5.303 & 0.024 \\
\hline
\end{tabular}

methodologically by measuring anticipatory emotions (more consistently to their definition) through autonomic, objective measures, and demonstrating the divergence between them and self-reported anticipated emotions. This is consistent with previous studies showing how biofeedback and self-reported scales tend to diverge as they tackle with different "mechanisms" of the human brain (e.g., Bettiga et al., 2017). The implications of these outcomes open interesting developments in conceptual terms, like the study of the interaction between $A_{D} E s$ and $A_{Y} E s$, and also in methodological terms, suggesting how biofeedback may provide a richer understanding of product adoption processes.

Furthermore, study 1 frames $A_{D} E s$ and $A_{Y} E s$ in the TPB. Results suggest that whereas higher levels of anticipatory emotions are reached, decreasing levels of self-reported PBC are observed. We find this result intriguing and somehow controversial. We interpret this phenomenon contending that $A_{Y} E s$ are somehow expressions of an individual's emotionality, where higher (lower) levels of perceived control may be associated with a weaker (stronger) tendency to show emotions and vice versa. Another possible explanation could be that control perception may inhibit the emotional reactions one has in terms of facial expressions. These two explanations find support in the literature (Biehl et al., 1997; Rhodes et al., 2005; Anggraini and Siswanto, 2016; Hofmann et al., 2019) and are suggested to be further studied in the future.

As per Anticipated Happiness, our results show that $A_{D} H$ is arguably a possible antecedent of all intention antecedents (A, SNs, and PBC), even though the strongest impact emerged with attitude. Nonetheless, such an outcome remains unclear and raises the opportunity and the relevance of deepening the relationship between anticipated emotions (and, namely $A_{Y} H$ ) and the TPB constructs, that is the object of our Study 2. Finally, 
the results of Study 1 appear consistent with the idea that $A_{D} H$, inherently more cognitive, is mostly linked with the cognitive construct of attitude. Indeed, they both require the subject a mental elaboration effort (attitude requires to evaluate the product while Anticipated Happiness requires to imagine future consumption and understand one's feeling in that situation). Conversely, $\mathrm{A}_{Y} \mathrm{H}$, which is less cognitive and more visceral, is mostly linked to the perception of control, which is a highly subjective construct, more related to subjects' perceptions than to rational assessments. To conclude, findings of Study 1 leave space for further developments on how $A_{D} E$, and more in detail $A_{D} H$, can be an important predictor in the decision-making process.

\section{STUDY 2}

\section{Research Questions Development}

Findings of Study 1 suggest to deeper investigate the role of $A_{D} E s$ and in particular $A_{D} H$ in the decision-making process, to improve the capability to explain the intention to purchase new products. Hence, we develop a second study to further explore the role of Anticipated Happiness in the TPB model of decision-making. Grounding on the findings of the first study and on prior studies that propose both empirical and theoretical evidence for supposing that Anticipated Happiness could qualify as an important additional component in the TPB framework, we formulated the following research question:

RQ3: Anticipated Happiness is a direct antecedent of Intention in the Theory of Planned Behavior.

RQ4: Anticipated Happiness is a direct antecedent of Attitude (a), Subjective Norms (b), and Perceived Behavioral Control (c) in the Theory of Planned Behavior.

RQ5: Anticipated Happiness partially mediates the impact of Attitude (a), Subjective Norms (b) and Perceived Behavioral Control (c) on Intention in the Theory of Planned Behavior.

\section{Methodology}

The self-reported method chosen to assess Anticipated Happiness in the first study is also employed in this second one. Thus, the previously stated research questions have been tested using an online questionnaire, with the same measurement scales employed in study 1 . The questionnaire has been distributed online on social platforms. The sample of participants is a nonstudent sample, for which descriptive information have been reported in paragraph Preliminary and Descriptive Analysis. This method allows reaching a larger sample size which is adequate for the objective of testing structural relationships among constructs through Structural Equation Modeling (Henseler et al., 2009).

\section{Results}

\section{Preliminary and Descriptive Analysis}

The total amount of respondents was 316. Ten subjects were not considered in the analysis due to potential disengaged answering mode (e.g., some records scored the same in all items). The sample was composed of $40 \%$ of men and $60 \%$ of women.
Most of the respondents (74\%) were equally split between two age ranges: 19-25 and over 45. Regarding the education level, $3 \%$ of the sample did a Ph.D. program, $48 \%$ own a degree, $43 \%$ did the high school and 6\% the middle school. Analysing the type of job, a great part of the population (50\%) work as an employee, $29 \%$ declared to be students, $13 \%$ entrepreneurs, $3 \%$ retired and the remaining 5\% unemployed. Most of the respondents (90\%) were Italian. The majority of the respondents didn't have previous experience with both the personal care product (only $6 \%$ of respondents already used this product) and the electronic device (2\% of respondents already used this product). Tables 4, 5 show the main descriptive statistics and the correlation coefficients of the variables postulated in the extended TPB model divided by product.

\section{Inferential Statistics}

Data were analyzed with a series of Single Factor ANOVA tests to assess whether different groups of respondents were statistically different concerning a specific variable (A, SNs, $\mathrm{PBC}, \mathrm{A}_{\mathrm{D}} \mathrm{H}$, and I). Two groups' discriminants were defined: sex (male/female) and age (the first group included all respondents $<25$ years old, the second between 26 and 45 years old and the third over 45 years old). When comparing the three age groups, ANOVA was supplemented by the Tukey-Kramer post-hoc test, to understand where the differences lied. Tables 6, 7 report the results, respectively, for the health care product and the electronic device. Concerning the personal care product, no significant differences were found between males and females. Conversely, attitude and subjective norms were found to be significantly higher between individuals below 25 years-old and individuals above 45 years-old. Likewise, for the electronic device, ANOVA tests evidence no significant difference between males and females. However, $\mathrm{A}_{\mathrm{D}} \mathrm{H}, \mathrm{A}$ and $\mathrm{SNs}$ were found to

TABLE 4 | Descriptive statistics of the extended TPB model - Personal care product.

\begin{tabular}{lccccccc}
\hline Construct & $\boldsymbol{M}$ & SD & & & & & \\
\hline $\mathrm{A}^{\star}$ & 3.48 & 1.61 & 1.00 & & & & \\
$\mathrm{SNS}^{* *}$ & 15.02 & 10.73 & 0.64 & 1.00 & & & \\
$\mathrm{PBC}^{*}$ & 5.54 & 1.17 & 0.18 & 0.20 & 1.00 & & \\
$\mathrm{~A}_{\mathrm{D}} \mathrm{H}^{*}$ & 3.30 & 1.49 & 0.87 & 0.61 & 0.13 & 1.00 & \\
$\mathrm{I}^{*}$ & 2.87 & 1.71 & 0.84 & 0.56 & 0.10 & 0.81 & 1.00 \\
\hline
\end{tabular}

*Max value 7; **Max value 49.

TABLE 5 | Descriptive statistics of the extended TPB model - Electronic device.

\begin{tabular}{lccccccc}
\hline Construct & $\boldsymbol{M}$ & $\boldsymbol{S D}$ & & & & & \\
\hline $\mathrm{A}^{*}$ & 4.00 & 1.67 & 1.00 & & & & \\
$\mathrm{SNS}^{\star *}$ & 18.20 & 12.28 & 0.66 & 1.00 & & & \\
$\mathrm{PBC}^{*}$ & 5.36 & 1.30 & 0.39 & 0.33 & 1.00 & & \\
$\mathrm{~A}_{\mathrm{D}} \mathrm{H}^{*}$ & 3.65 & 1.64 & 0.86 & 0.62 & 0.28 & 1.00 & \\
$\mathrm{I}^{*}$ & 2.90 & 1.66 & 0.77 & 0.61 & 0.27 & 0.74 & 1.00 \\
\hline
\end{tabular}

*Max value 7; **Max value 49 . 
TABLE 6 | One-way analysis of variance and means for personal care product by age.

\begin{tabular}{|c|c|c|c|c|c|}
\hline \multirow[t]{3}{*}{ Measure } & \multicolumn{3}{|c|}{ Mean } & \multirow[t]{3}{*}{$F(2,303)$} & \multirow[t]{3}{*}{$p$-value } \\
\hline & \multicolumn{3}{|c|}{ Age } & & \\
\hline & $<25$ & $26-45$ & $>45$ & & \\
\hline$A$ & 3.742 & 3.484 & 3.211 & 3.18 & 0.043 \\
\hline SNs & 16.558 & 15.459 & 13.071 & 3.19 & 0.043 \\
\hline
\end{tabular}

TABLE 7 | One-way analysis of variance and means for electronic device by age.

\begin{tabular}{|c|c|c|c|c|c|}
\hline \multirow[t]{3}{*}{ Measure } & \multicolumn{3}{|c|}{ Mean } & \multirow[t]{3}{*}{$F(2,303)$} & \multirow[t]{3}{*}{$p$-value } \\
\hline & \multicolumn{3}{|c|}{ Age } & & \\
\hline & $<25$ & $26-45$ & $>45$ & & \\
\hline$A$ & 4.295 & 3.819 & 3.813 & 3.059 & 0.048 \\
\hline SNs & 20.944 & 17.959 & 15.417 & 6.088 & 0.003 \\
\hline$A_{D} H$ & 3.971 & 3.497 & 3.415 & 3.819 & 0.023 \\
\hline
\end{tabular}

be significantly greater for individuals below 25 years-old and individuals above 45 years-old.

\section{Measurement Model}

The data were analyzed with PLS-SEM analysis carried out using SmartPLS 3.2.7. We opted for PLS-SEM being an appropriate and robust method to analyze composite models (Hwang et al., 2010; Wong, 2013). Among second- generation techniques, we opted for PLS-SEM, instead of covariance-based SEM, due to the explorative nature of the research and the complexity of the structural model - i.e., several constructs and indicators- (Hwang et al., 2010; Avkiran, 2018), that make the use of PLS-SEM more suitable (Hair et al., 2011). As suggested by Henseler et al. (2009) to achieve robust PLS estimations, the sample size should be at least 10 times the largest number of structural paths pointed to a specific construct in the inner path model. The largest number of structural paths directed to a construct in our inner model is equal to 4 making our sample size adequate.

Before assessing the causal relationships among the constructs of the proposed framework, data were analyzed through a CFA (Confirmatory Factor Analysis) to ensure both the reliability and validity of the reflective measurement model. Indicators' reliability was tested by looking at the outer loadings: acceptable values have to be above $0.6-0.7$ for each measurement item (Hulland, 1999). After this check, only one indicator was dropped since its value was found to be below 0.6. This result supports the theoretical assignment of the indicators to each construct, hypothesized during the questionnaire development.

Internal consistency reliability was evaluated through CR (Composite Reliability) measures, instead of Cronbach's alphas (Henseler et al., 2009). PLS, indeed, priorities indicators based on their reliability, achieving a more consistent composite than Cronbach's Alfa, which instead assumes that all indicators are equivalently reliable. All CR values exceed 0.7 for each latent variable, so they are considered acceptable (Henseler et al., 2009).
Convergent validity was assessed by looking at the AVE (Average Variance Extracted), which had to be $=0.5$ for each latent variable (Bagozzi and Yi, 1988), meaning that each latent variable can explain on average more than half of the variance of its block indicators. All constructs had an AVE value greater than the threshold. Discriminant validity has been tested with two approaches. Firstly, the Fornell-Larcker criterion (Fornell and Larcker, 1981), imposing the square root of AVE of each latent variable to be higher than the correlations with all other latent variables. In this way each latent variable has to share more variance with its own set of indicators than with another latent variable representing a different set of indicators. Secondly, it has been tested through the heterotrait-monotrait ratio of correlations (HTMT) based on the multitrait-multimethod matrix (Henseler et al., 2015). Tables 8, 9 present a summary of the results of constructs reliability and validity.

\section{Structural Model}

Once the suitability of the outer model was tested, it was necessary to assess the quality of the inner model and to check whether the posited relationships among the constructs were supported by the data. A PLS algorithm with 300 iterations was run to obtain the coefficients of the structural path and the variance of the dependent variable(s) explained by the independent variables ( $\mathrm{R}^{2}$ and $\mathrm{R}^{2}$ adjusted). Then the significance of the path coefficients was tested using the bootstrap approach with 5,000 re-samples (Londono et al., 2017).

Table 10 shows that all the propositions are supported. Therefore, $A_{D} H$ can play a role in the TPB both as a direct antecedent of all original constructs (A, SNs, PBC, and I) and as a partial mediator of the existing relationships among the constructs. These results highlight the pervasive role of anticipated positive emotions in intention formation, suggesting that $\mathrm{A}_{\mathrm{D}} \mathrm{H}$ does not just constitute a first emotional reaction to the perception of stimuli, but that it can also partially explain the original relationships among TPB constructs. These results further confirm that $\mathrm{A}_{\mathrm{D}} \mathrm{H}$ plays a crucial role in all aspects

TABLE 8 | Internal consistency reliability and validity results.

\begin{tabular}{lccccccc}
\hline Construct & CR & AVE & A & A $_{\mathbf{D}} \mathbf{H}$ & I & PBC & SNs \\
\hline A & 0.953 & 0.801 & $\mathbf{0 . 8 9 5}$ & & & & \\
$\mathrm{A}_{D} \mathrm{H}$ & 0.938 & 0.790 & 0.868 & $\mathbf{0 . 8 8 9}$ & & & \\
I & 0.961 & 0.891 & 0.805 & 0.768 & $\mathbf{0 . 9 4 4}$ & & \\
PBC & 0.851 & 0.592 & 0.300 & 0.229 & 0.200 & $\mathbf{0 . 7 6 9}$ & \\
SNs & 0.952 & 0.869 & 0.655 & 0.621 & 0.583 & 0.295 & $\mathbf{0 . 9 3 2}$ \\
\hline
\end{tabular}

The bold values represent the square root of AVE.

TABLE 9 | Heterotrait-Monotrait Ratio (HTMT) results.

\begin{tabular}{lcccc}
\hline Construct & $\mathbf{A}$ & $\mathbf{A}_{\mathbf{D}} \mathbf{H}$ & $\mathbf{I}$ & PBC \\
\hline $\mathrm{A}_{\mathrm{D}} \mathrm{H}$ & 0.938 & & & \\
$\mathrm{I}$ & 0.848 & 0.824 & & \\
$\mathrm{PBC}$ & 0.342 & 0.263 & 0.226 & \\
SNs & 0.703 & 0.677 & 0.621 & 0.339
\end{tabular}


TABLE 10 | Path coefficients and indirect path coefficients.

\begin{tabular}{|c|c|c|c|c|c|c|c|c|}
\hline & TPB Model & RQ3 Model & RQ4a Model & RQ4b Model & RQ4c Model & RQ5a Model & RQ5b Model & RQ5c Model \\
\hline & $\begin{array}{l}\text { Original TPB } \\
\text { model }\end{array}$ & $\begin{array}{c}\text { TPB with } A_{D} H \\
\text { as direct } \\
\text { antecedent of } \\
\text { I }\end{array}$ & $\begin{array}{c}\text { TPB with } A_{D} H \\
\text { as direct } \\
\text { antecedent of } \\
\text { A }\end{array}$ & $\begin{array}{l}\text { TPB with } A_{D} H \\
\text { as direct } \\
\text { antecedent of } \\
\text { SNs }\end{array}$ & $\begin{array}{c}\text { TPB with } A_{D} H \\
\text { as direct } \\
\text { antecedent of } \\
\text { PBC }\end{array}$ & $\begin{array}{c}\text { TPB with } A_{D} H \\
\text { as partial } \\
\text { mediator of } \\
A \rightarrow \text { I }\end{array}$ & $\begin{array}{c}\text { TPB with } A_{D} H \\
\text { as partial } \\
\text { mediator of } \\
\text { SNs } \rightarrow \text { I }\end{array}$ & $\begin{array}{c}\text { TPB with } A_{D} H \\
\text { as partial } \\
\text { mediator of } \\
\text { PBC } \rightarrow \text { I }\end{array}$ \\
\hline \multicolumn{9}{|c|}{ Path coefficients } \\
\hline$A \rightarrow 1$ & $0.753^{\star \star \star}$ & $0.544^{\star \star \star}$ & $0.753^{\star \star \star}$ & $0.753^{\star \star \star}$ & $0.755^{\star \star \star}$ & $0.547^{\star \star \star}$ & $0.546^{\star \star \star}$ & $0.549^{\star \star \star}$ \\
\hline $\mathrm{SNs} \rightarrow \mathrm{I}$ & $0.108^{\star \star \star}$ & $0.083^{\star \star}$ & $0.108^{\star \star \star}$ & $0.108^{\star \star \star}$ & $0.110^{\star \star \star}$ & $0.084^{\star \star}$ & $0.083^{\star \star}$ & $0.085^{\star \star}$ \\
\hline $\mathrm{PBC} \rightarrow 1$ & $-0.058^{\star \star}$ & $-0.047^{\star}$ & $-0.058^{\star \star}$ & $-0.058^{\star \star}$ & $-0.066^{\star \star \star}$ & $-0.047^{\star}$ & $-0.047^{\star}$ & $-0.055^{\star \star}$ \\
\hline $\mathrm{A}_{D} \mathrm{H} \rightarrow \mathrm{I}$ & & $0.255^{\star \star \star}$ & & & & $0.250^{\star \star \star}$ & $0.252^{\star \star \star}$ & $0.251^{\star \star \star}$ \\
\hline$A_{D} H \rightarrow A$ & & & $0.871^{\star \star \star}$ & & & & & \\
\hline $\mathrm{A}_{D} \mathrm{H} \rightarrow \mathrm{SNS}$ & & & & $0.623^{\star \star \star}$ & & & & \\
\hline $\mathrm{A}_{D} \mathrm{H} \rightarrow \mathrm{PBC}$ & & & & & $0.253^{\star \star \star}$ & & & \\
\hline$A \rightarrow A_{D} H$ & & & & & & $0.870^{\star \star \star}$ & & \\
\hline $\mathrm{SNs} \rightarrow \mathrm{A}_{D} \mathrm{H}$ & & & & & & & $0.622^{\star \star \star}$ & \\
\hline $\mathrm{PBC} \rightarrow \mathrm{A}_{D} \mathrm{H}$ & & & & & & & & $0.238^{\star \star \star}$ \\
\hline \multicolumn{9}{|c|}{ Indirect effect coefficients } \\
\hline$A \rightarrow 1$ & & & & & & $0.217^{\star \star \star}$ & & \\
\hline $\mathrm{SNs} \rightarrow \mathrm{I}$ & & & & & & & $0.157^{\star \star \star}$ & \\
\hline $\mathrm{PBC} \rightarrow 1$ & & & & & & & & $0.060^{\star \star}$ \\
\hline$A_{D} H \rightarrow I$ & & & $0.655^{\star \star \star}$ & $0.067^{\star \star \star}$ & $-0.017^{\star \star}$ & & & \\
\hline
\end{tabular}

and stages of the intention formation process by influencing all the TPB constructs. Moreover, results show that attitude and Anticipated Happiness are the strongest predictors of intention in this context and that they both have a positive impact on it. Same reasoning for subjective norms, which are significant as well, but with a secondary relevance. Perceived behavioral control, instead, is the weakest predictor of the intention to buy the products and it has a significant path coefficient only in RQ5c, RQ4a, RQ4b, RQ4c.

Potential collinearity among exogenous latent variables has been assessed using SPSS Statistic, through Variance Inflation Factors (VIF). To avoid multicollinearity problem, we considered as acceptable VIF values below or equal to 5 (Vercellis, 2009). Results show the absence of multicollinearity problems as all VIF values were lower than the above-mentioned threshold.

The model fit was assessed using a set of indicators, which include both relative and absolute indexes: $\chi^{2} /$ degree of freedom (df), NFI, SRMR. The reason behind the use of $\chi^{2} / \mathrm{df}$ instead of $\chi^{2}$ relies on the fact that $\chi^{2}$ is not a reliable indicator when dealing with large samples (more than 200 observations), as it tends to suggest misfit, regardless of the true situation (Coughlan et al., 2008). $\chi^{2} / \mathrm{df}$, instead, is more reliable with large samples. Hereafter, Table 11 presents the fit indexes for all the models: each model was built by incorporating each of the stated research questions in the original TPB framework. SRMR (Standardize Root Mean Square Residual) scores below 0.08 indicate an acceptable fit and NFI (Normed-Fit Index) is deemed to be acceptable when it is higher or equal to 0.95 (Coughlan et al., 2008). Even though there is no consensus about threshold values for $\chi^{2}$ /df (Coughlan et al., 2008) we considered acceptable values those lower or equal to 3 (Iacobucci, 2010).
Results indicate that RQ3, RQ4a, RQ4b, RQ4c, and RQ5a models perform slightly better in terms of model fit, compared to RQ5b and RQ5c models. Moreover, RQ3, RQ4a, RQ5a, RQ5b, and RQ5c models are aligned with previous studies that attempt to include emotional constructs within the TPB. Indeed, there is evidence that supports the inclusion of emotions as direct antecedents of intention (Londono et al., 2017), as direct antecedents of attitude (Ding et al., 2014; Chang, 2016) and as partial mediators of attitude, subjective norms and PBC on intention (Onwezen et al., 2014; Turel, 2016). RQ4b and RQ4c models, instead, enlarge previous findings by showing that Anticipated Happiness could be integrated into the TPB even as a direct antecedent of both SNs and PBC.

Since results confirmed a pervasive role of $A_{D} H$ within the TPB, we also assessed the goodness of two models in which $A_{D} H$ was simultaneously positioned as a predictor of $\mathrm{A}, \mathrm{SNs}, \mathrm{PBC}$, and I and as partial mediator of A, SNs, and PBC on I. SEM analysis was then conducted on these two models. All path coefficients of the postulated relationships were significant, and each model was able to explain $67 \%$ of the variance in intention $\left(R^{2}\right.$ modela $=0.672$; $\left.R_{\text {model b }}^{2}=0.673\right)$.

\section{Structural Model by Product}

We explored if there are any differences in the relationships between the constructs of the enlarged TPB (A, SNs, PBC, $A_{D} H$, and I) produced by the type of product. The significance of the path coefficients of the inner model was slightly different when considering the two products separately. By modeling the enlarged TPB for the personal care product, SNs and PBC were found not to be relevant predictors of intention. An analogous result is achieved for the electronic device, where PBC did not 
TABLE 11 | R-square and Model fit indicators.

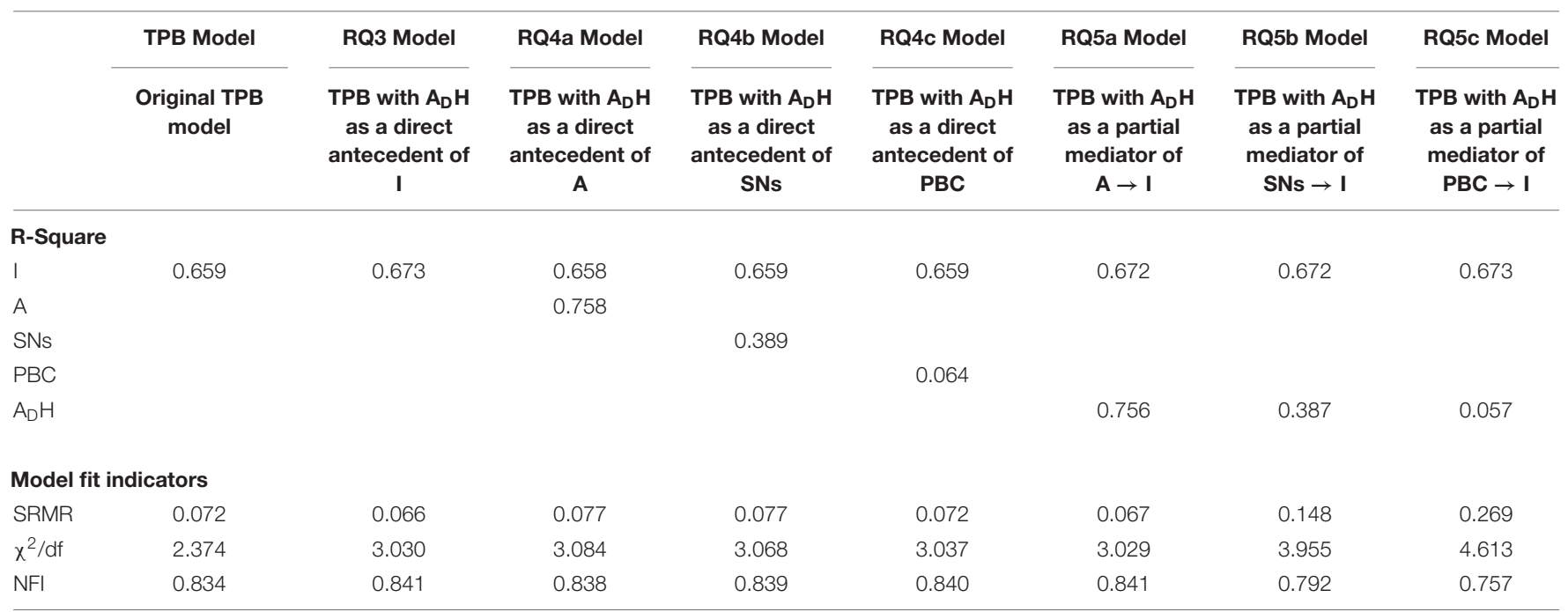

represent a predictor of the intention to buy the product. Shifting the attention on the role of $A_{D} H$ in the enlarged TPB, all the proposed relationships are supported even considering the two products separately. This means that $\mathrm{A}_{\mathrm{D}} \mathrm{H}$ was not strictly related to the product type, but it has a pervasive and strong role regardless of it.

\section{Discussion}

All the postulated relationships between $A_{D} H$ and the TPB constructs were confirmed, suggesting the possibility to position $\mathrm{A}_{\mathrm{D}} \mathrm{H}$ both as a direct antecedent of the four traditional TPB constructs and as a mediator of the relationships between intention's predictors and intention itself. More in detail, $A_{D} H$ can be a direct predictor of attitude, meaning that $A_{D} H$ could be considered as a first signal that derives from an "emotional assessment" of the stimulus, feeding the subsequent creation of a positive attitude (Baumgartner et al., 2008). $\mathrm{A}_{\mathrm{D}} \mathrm{H}$ also plays a role as a direct antecedent of SNs. A possible explanation for the underlying mechanism could be related to the projection bias (Loewenstein et al., 2003). Indeed, people who experience positive feelings about a product tend to think that their relevant others will also be pleased about it and consider purchase a good idea.

Moreover, $\mathrm{A}_{\mathrm{D}} \mathrm{H}$ is also proved to be a predictor of $\mathrm{PBC}$ : this result can be better interpreted in light of the Construal Level Theory (CLT). CLT states that when Psychological Distance (PD) is high (in our case the focal product is new, the context trial is virtual and the purchase is not happening in the near future, thus PD can be considered high), people tend to focus on the desirability aspects of the behavior and to overlook more concrete ones such as the availability of resources and capabilities needed to use the product (Goodman and Malkoc, 2012). Thus, the desirability focus may trigger $A_{D} H$ which could lead the subject to perceive more control over the behavior, since feasibility considerations are not performed.

Finally, $A_{D} H$ is not just pervasive in the TPB, but it also has a tremendous impact on purchase intention, as is suggested by
$\mathrm{A}_{\mathrm{D}} \mathrm{H}$ 's ability to explain 0.587 of variance in intention when it is the only predictor. Thus, on the one hand, in the process of intention formation, $\mathrm{A}_{\mathrm{D}} \mathrm{H}$ can be a first, immediate emotional response to the stimulus, impacting in turn on the more cognitive constructs of $\mathrm{A}, \mathrm{SNs}, \mathrm{PBC}$, and I. On the other hand, $\mathrm{A}_{\mathrm{D}} \mathrm{H}$ can, at least in part, explain the relationships between intention predictors and behavioral intention. Indirectly, the confirmation in a further study of the positive impact of $A_{D} H$ on TPB confirms the idea of $A_{D} E_{S}$ and $A_{Y} E_{S}$ as distinct constructs.

\section{GENERAL DISCUSSION}

This research shed some light on the ambiguous and fuzzy distinction between Anticipated and Anticipatory Emotions (Baumgartner et al., 2008). According to our results, Anticipatory Emotions are experienced in the present in relation to future events while Anticipated Emotions are forecasts of future emotional states, thus they occur when a person imagines a future situation and reasons about how he or she would feel in that context. Hence, Anticipatory Emotions reflect in physiological affective responses of individuals while Anticipated Emotions in the cognitive-emotional assessment. This outcome contributes to literature not only by providing further evidence to Baumgartner et al. (2008) theories, but also by offering a richer interpretation grounded onto objective autonomic measures confirming prior studies showing how physiological and self-reported measures tend to diverge as they tackle with different brain processes (e.g., Bettiga et al., 2017). The work thus proposes a strong methodological implication, suggesting a possible approach to use micro facial expressions analysis to study $A_{Y} E_{S}$.

We hence focused on the relationship between futureoriented emotions and intention to buy a new product, studying the relationships with the TPB's intention predictors (Attitude, Subjective Norms, and Perceived Behavioral Control). Results suggested that Anticipated Happiness could qualify as a relevant antecedent of attitude (Anticipated Happiness was 
found to account for $89 \%$ of the variation in attitude), while Anticipatory Happiness seems to be more linked to perceptions of control (PBC), supporting the conceptualization of Anticipated Emotions as "cognitive-evaluative dimensions" and Anticipatory Emotions as "experiential-current reactions" (Carrera et al., 2012, p. 274). In particular, results show that higher levels of Anticipatory Emotions are expressed by subjects who declare lower levels of PBC. This suggests that either control may somehow inhibit the emotional reactions one has in terms of facial expressions, or that emotional reactions are overwhelming, so they trigger feelings of loss of control.

It seems reasonable that the cognitive construct of attitude, related to rational assessments of behavior, is mostly linked with Anticipated Happiness, which requires a cognitive effort of imagining future events and reasoning about one's feelings in that hypothetical scenario. Similarly, since anticipatory emotional responses are experienced in the present (in line with Baumgartner et al., 2008), they are more overwhelming, and they are mostly related to a less cognitive construct, $\mathrm{PBC}$, which is grounded on subjective perception than on rational evaluations. Indeed, the real control one has can be experienced only when the behavior is being performed, and it is better known as Actual Behavioral Control (Hassan et al., 2016).

Furthermore, this study enlarges previous findings in two main ways. First, previously tested relationships between Anticipated Emotions and the TPB variables have been verified and confirmed with a new construct, $\mathrm{A}_{\mathrm{D}} \mathrm{H}$, which belongs to the broader category of anticipated positive emotions, that have traditionally received less attention than anticipated negative emotions. $A_{D} H$ was found to be conceptually separated from attitude. Indeed, while attitude is more focused on one's thoughts and evaluations toward a specific product, $A_{D} H$ captures the extent to which the product has a positive impact on the subject's life, eliciting feelings of pleasure, and a sense of well-being. This result is in line with prior studies, showing that happiness and attitude are two distinct constructs with a positive effect of the first on the second one (Chang, 2016). Secondly, previous literature has been expanded by finding support for a new possible role of $\mathrm{A}_{\mathrm{D}} \mathrm{H}$ as a direct antecedent of $\mathrm{SNs}$ and $\mathrm{PBC}$. These results suggest that emotional responses may have an impact also on one's perception of control over a behavior and over the perceived pressure to perform the behavior exerted by relevant others.

To conclude, Anticipated Happiness was found to have a pervasive role in all stages of the intention formation process, by qualifying at the same time as a direct antecedent of the traditional constructs and as a partial mediator of the existing relationships among the TPB constructs. These findings confirm the important role that happiness assumes in consumer choice (Mogilner et al., 2011) and the necessity to integrate emotional constructs in cognitive models, as the TPB, supporting prior studies moving in this direction (Kim et al., 2013; Onwezen et al., 2014; Turel, 2016; Londono et al., 2017). These results extend prior studies on anticipated emotions in purchasing process (Bagozzi et al., 2016) to a new context, highlighting the importance of considering emotional reactions generated in the encounter with a new product, to improve the capability to explain intention formation.

\section{MANAGERIAL IMPLICATIONS}

Results of this study could have relevant implications for marketers involved in the design of advertisements and communication campaigns for new products. Indeed, the emotional identity of the viewer is likely to play a much prominent role than the rational one, thus becoming a strong predictor of the buying intention. Moreover, marketers are increasingly seeking to connect with customers on a more simple and essential level, by promising happiness and by creating brands that cultivate happiness. So, visual product communication should be designed in a way to elicit feelings of Anticipated and Anticipatory Positive Emotions (e.g., happiness) in the viewer. Of much less relevance are considerations about the opinions of important others or the perceived control over the behavior, thus these aspects should receive less attention. This task may not be as easy as it appears since happiness has been demonstrated to be a complex emotion who's meaning often shifts among individuals.

Nevertheless, previous studies on the role of happiness in consumer research can offer interesting cues for eliciting it. For instance, it has been demonstrated that framing consumption as an experience instead of a mere purchase could create deeper connections with customers by evoking feelings of happiness (Nicolao et al., 2009; Bhattacharjee and Mogilner, 2014). Furthermore, the extent to which the experience is presented as "ordinary" or "extraordinary" has an impact on individuals' happiness level and this effect is proved to be different between younger and older subjects (Bhattacharjee and Mogilner, 2014). Thus, age can be an important factor to take into consideration when presenting marketing content that frames consumption as an experience (Petersen et al., 2018).

Finally, the identification of two different categories of futureoriented emotions, namely anticipated and anticipatory ones, may support marketers in their communication strategies. Our results, indeed, show that anticipatory happiness is particularly relevant in situations of low perceived control while anticipated happiness is more related to a cognitive reasoning. This may provide directions to marketers on how to elicit happiness in high vs. low self-control consumers and which arguments could be more effective, especially when it comes to indulgent purchases. For instance, messages which provide customers with a reason to indulge (e.g., "luxury feels better earned") resonate better with high self-control consumers, making them happier and more satisfied with the purchase. Conversely, for low self-control consumers, happiness is more likely to arise when the brand promotes spontaneous indulgence - e.g., "you don't need a reason to indulge"- (Petersen et al., 2018). These findings have important implications for marketers which could increase the effectiveness of one-to-one communication, especially online, based on consumer personality variables, inferred from their online behavior data. For example, marketers can use social networks likes or language to infer personality traits 
of agreeableness and conscientiousness, which are correlated to the self-control trait.

\section{LIMITATIONS AND FUTURE RESEARCH}

The study is subject to some limitations. The first limitation stems from the fact that, for time and resource constraints, the TPB model was just partially tested as the actual behavior of the participants was not measured. Although the behavioral intention is considered to be a good predictor of behavior (Ajzen, 1991), there is no guarantee that intention will translate into actual behaviors. Therefore, further research could address this issue by testing the relationship between actual behavior and the declared intention.

The second limitation regards the type of products used in the experiments: this research was limited to very new and innovative products presented through teaser videos. So, future research should replicate this study by using different kinds of products, to assess whether Anticipated and Anticipatory Happiness play the same role. This test could help in understanding whether Anticipated and Anticipatory Happiness are a function of the type of product and/or the purchase type. For instance, complex purchases could be characterized by a different decision-making process where emotional reactions could be offset by more rational and cognitive thoughts.

The third limitation is linked with the emotional construct under investigation. On the one hand, this study only investigates one positive emotion, happiness. Thus, further investigations could be aimed at assessing the role of other positive emotions like contentment, pleasure, and excitement, using the TPB model. On the other hand, the present study focuses only on Anticipated and Anticipatory Happiness. However, to further clarify the distinction between Anticipatory and Anticipated Emotions, other types of emotions (both positive and negative) should be considered.

The last limitation concerns the methods used to measure happiness. The construct was assessed using both self-reported and autonomic methods (micro facial expressions). However, it is

\section{REFERENCES}

Aichner, T. (2012). The zero moment of truth in mass customization. Int. J. Indus. Eng. Manag. 3, 173-178.

Ajzen, I. (1991). The theory of planned behavior. Organ. Behav. Hum. Decis. Process. 50, 179-211.

Ajzen, I. (2006). Constructing a TPB Questionnaire: Conceptual and Methodological Considerations. Available at: http://citeseerx.ist.psu.edu/viewdoc/summary; jsessionid=011E42C7D4396A688EA04E1D0DFBF6F0?doi=10.1.1.601.956

Anggraini, F. R. R., and Siswanto, F. A. J. (2016). The role of perceived behavioral control and subjective norms to internal auditors' intention in conveying unethical behavior: a case study in Indonesia. Rev. Integr. Bus. Econ. Res. 5, 141-150.

Argo, J., Dahl, D., and Morales, A. (2006). Consumer contamination: how consumers react to products touched by others. J. Mark. 70, 81-94.

Avkiran, N. K. (2018). An in-depth discussion and illustration of partial least squares structural equation modeling in health care. Health Care Manag. Sci. 21, 401-408. doi: 10.1007/s10729-017-9393-7 reasonable to presume that $\mathrm{A}_{\mathrm{Y}} \mathrm{H}$ does not only manifest through facial expressions, like changes in the lip corners and in the muscles near cheeks and eyes. Prior research (Kaklauskas et al., 2011) investigated other possible biometrical manifestations of this emotional construct, as the heart rate acceleration, the skin temperature, and blood pressure growth and the skin conductance change. So, results should be replicated with other types of autonomic measures.

\section{DATA AVAILABILITY STATEMENT}

The anonymized raw data supporting the conclusions of this article will be made available by the authors, without undue reservation, to any qualified researcher.

\section{ETHICS STATEMENT}

Ethical review and approval was not required for the study on human participants in accordance with the local legislation and institutional requirements. The patients/participants provided their written informed consent to participate in this study.

\section{AUTHOR CONTRIBUTIONS}

Both authors listed have made a substantial, direct and intellectual contribution to the work, and approved it for publication.

\section{ACKNOWLEDGMENTS}

We would like to thank Martina Lucente and Marta Pagani for their support in the development of the manuscript. This manuscript has been released as a pre-print at https://re. public.polimi.it/retrieve/handle/11311/1113716/446708/AiIG\% 202019_Bettiga\%20et\%20al.pdf (Bettiga et al., 2019).

Ayadi, N., Paraschiv, C., and Vernette, E. (2017). Increasing consumer well-being: risk as potential driver of happiness. Appl. Econ. 49, 4321-4335.

Bagozzi, R. P., Belanche, D., Casaló, L. V., and Flavián, C. (2016). The role of anticipated emotions in purchase intentions. Psychol. Mark. 33, 629-645.

Bagozzi, R. P., Gopinath, M., and Nyer, P. U. (1999). The role of emotions in marketing. J. Acad. Mark. Sci. 27, 184-206.

Bagozzi, R. P., and Yi, Y. (1988). On the evaluation of structural equation models. J. Acad. Mark. Sci. 16, 74-94.

Barsics, C., Van der Linden, M., and D'Argembeau, A. (2016). Frequency, characteristics, and perceived functions of emotional future thinking in daily life. Q. J. Exp. Psychol. 69, 217-233. doi: 10.1080/17470218.2015.1051560

Baumgartner, H., Pieters, R., and Bagozzi, R. P. (2008). Future-oriented emotions: conceptualization and behavioral effects. Eur. J. Soc. Psychol. 38, 685-696.

Bettiga, D., and Lamberti, L. (2017). Exploring the adoption process of personal technologies: a cognitive-affective approach. J. High Technol. Manag. Res. 28, 179-187.

Bettiga, D., and Lamberti, L. (2018). Exploring the role of anticipated emotions in product adoption and usage. J. Consum. Mark. 35, 300-316. 
Bettiga, D., Lamberti, L., Lucente, M., and Pagani, M. (2019). Anticipated and anticipatory happiness in product decision-making process. Available at: https://re.public.polimi.it/retrieve/handle/11311/1113716/446708/AiIG\% 202019_Bettiga\%20et\%20al.pdf

Bettiga, D., Lamberti, L., and Noci, G. (2017). Do mind and body agree? Unconscious versus conscious arousal in product attitude formation. J. Bus. Res. $75,108-117$

Bhattacharjee, A., and Mogilner, C. (2014). Happiness from ordinary and extraordinary experiences. J. Consum. Res. 41, 1-17.

Biehl, M., Matsumoto, D., Ekman, P., Hearn, V., Heider, K., Kudoh, T., et al. (1997). Matsumoto and Ekman's japanese and caucasian facial expressions of emotion (JACFEE): reliability data and cross-national differences. J. Nonverbal Behav. $21,3-21$.

Carrera, P., Caballero, A., and Munoz, D. (2012). Future-oriented emotions in the prediction of binge-drinking intention and expectation: the role of anticipated and anticipatory emotions. Scand. J. Psychol. 53, 273-279. doi: 10.1111/j.14679450.2012.00948.x

Chang, C. (2016). Before-after appeals: a dual-route effect model. Int. J. Adv. 35, 301-324.

Chen, M.-F., and Tung, P.-J. (2014). Developing an extended Theory of planned behavior model to predict consumers' intention to visit green hotels. Int. J. Hosp. Manag. 36, 221-230.

Cloarec, J., Meyer-Waarden, L., and Munzel, A. (2019). "Happiness as a driver of social exchanges," in Proceedings of the Academy of Management, Vol. 1 (Briarcliff Manor, NY: Academy of Management).

Coricelli, G., Dolan, R., and Sirigu, A. (2007). Brain, emotion and decision making: the paradigmatic example of regret. Trends Cogn. Sci. 11, 258-265. doi: 10.1016/ j.tics.2007.04.003

Coughlan, J., Mullen, M. R., and Hooper, D. (2008). Structural equation modelling: guidelines for determining model fit. Electron. J. Bus. Res. Methods 6, 53-60. doi: 10.1016/j.acap.2015.07.001

De Keyser, A., and Lariviere, B. (2014). How technical and functional service quality drive consumer happiness. J. Serv. Manag. 25, 30-48.

Di Muro, F., and Murray, K. B. (2012). An arousal regulation explanation of mood effects on consumer choice. J. Consum. Res. 39, 574-584.

Ding, T., Mullan, B., and Xavier, K. (2014). Does subjective well-being predict health-enhancing behaviour? The example of fruit and vegetable consumption. Br. Food J. 116, 598-610.

Fishbein, M., and Ajzen, I. (1975). Belief, Attitude, Intention, and Behavior: An Introduction to Theory and Research. Reading, MA: Addison-Wesley.

Fornell, C., and Larcker, D. (1981). Evaluating structural equation models with unobservable variables and measurement error. J. Mark. Res. 18, 39-50.

George, W., Ekinci, Y., Simkin, L., and Sutan, A. (2016). "Understanding the role of emotion in self-service technology adoption: a structured abstract," in Thriving in a New World Economy. Developments in Marketing Science: Proceedings of the Academy of Marketing Science, ed. K. Plangger (Cham: Springer).

Goodman, J. K., and Malkoc, S. A. (2012). Choosing here and now versus there and later: the moderating role of psychological distance on assortment size preferences. J. Consum. Res. 39, 751-768.

Hair, J., Ringle, C., and Sarstedt, M. (2011). PLS-SEM: indeed a silver bullet. J. Mark. Theory Pract. 19, 139-152.

Hassan, L., Shiu, E., and Shaw, D. (2016). Who says there is an intention-behaviour Gap? Assessing the empirical evidence of an intention-behaviour gap in ethical consumption. J. Bus. Ethics 136, 219-236.

Henseler, J., Ringle, C. M., and Sarstedt, M. (2015). A new criterion for assessing discriminant validity in variance-based structural equation modeling. J. Acad. Mark. Sci. 43, 115-135.

Henseler, J., Sinkovics, R. R., and Ringle, C. M. (2009). "The use of partial least squares path modeling in international marketing," in Advances in International Marketing, Vol. 20, eds R. R. Sinkovics, and P. N. Ghauri (Bingley: Emerald), 277-320.

Hernández-Fernández, D. A., Mora, E., and Hernández, V. (2019). When a new technological product launching fails: a multi-method approach of facial recognition and E-WOM sentiment analysis. Physiol. Behav. 200, 130-139. doi: 10.1016/j.physbeh.2018.04.023

Hofmann, W., Kotabe, H. P., and Righetti, F. (2019). How anticipated emotions guide self-control judgments. Front. Psychol. 10:1614. doi: 10.3389/fpsyg.2019. 01614
Holbrook, M. B., and Hirschman, E. C. (1982). The experiential aspects of consumption: consumer fantasies, feelings, and fun. J. Consum. Res. 9, 132-140.

Hsu, C.-L., Chang, C.-Y., and Yansritakul, C. (2017). Exploring purchase intention of green skincare products using the theory of crossmark planned behavior: testing the moderating effects of country of origin and price sensitivity. J. Retail. Consum. Serv. 34, 145-152.

Hui, S. K., Huang, Y., Suher, J., and Inman, J. J. (2013). Deconstructing the "First Moment of Truth": understanding unplanned consideration and purchase conversion using in-store video tracking. J. Market. Res. 50, 445-462.

Hulland, J. (1999). Use of partial least squares (PLS) in strategic management research: a review of four recent studies. Strat. Manag. J. 20, 195-204.

Hwang, H., Malhotra, N., Kim, Y., Tomiuk, M. A., and Hong, S. (2010). A comparative study on parameter recovery of three approaches to structural equation modeling. J. Mark. Res. 47, 699-712.

Iacobucci, D. (2010). Structural equations modeling: fit indices, sample size, and advanced topics. J. Consum. Psychol. 20, 90-98.

Jun, S. Y., Kim, K. H., and Park, H. K. (2019). The effect of the preorder strategy on consumers' product choice: the moderating role of product experience and payment timing. J. Bus. Res. 99, 80-86.

Kaklauskas, A., Zavadskas, E. K., Seniut, M., Dzemyda, G., Stankevic, V., Simkevicius, C., et al. (2011). Web-based biometric computer mouse advisory system to analyze a user's emotions and work productivity. Eng. Appl. Artif. Intell. 24, 928-945.

Khan, U., DePaoli, A., and Maimaran, M. (2019). The unique role of anger among negative emotions in goal-directed decision making. J. Assoc. Consum. Res. 41, 65-76.

Kidwell, B., and Jewell, R. D. (2008). The influence of past behavior on behavioral intent: an information-processing explaination. Psychol. Mark. 25, 1151-1166.

Kim, Y. J., Njite, D., and Hancer, M. (2013). Anticipated emotion in consumers' intentions to select eco-friendly restaurants: augmenting the theory of planned behavior. Int. J. Hosp. Manag. 34, 255-262.

Kumar, M., and Garg, N. (2010). Aesthetic principles and cognitive emotion appraisals: how much of the beauty lies in the eye of the beholder? J. Consum. Psychol. 20, 485-494.

Laros, F. J., and Steenkamp, J.-B. E. (2005). Emotions in consumer behavior: a hierarchical approach. J. Bus. Res. 58, 1437-1445.

Loewenstein, G., O’Donoghue, T., and Rabin, M. (2003). Projection bias in predicting future utility. Q. J. Econ. 118, 1209-1248.

Londono, J. C., Davies, K., Elms, J., Londono, J. C., Davies, K., and Elms, J. (2017). Extending the theory of planned behavior to examine the role of anticipated negative emotions on channel intention: the case of an embarrassing product. J. Retail. Consum. Serv. 36, 8-20.

Madden, T. J., Ellen, P. S., and Ajzen, I. (1992). A comparison of the theory of planned behavior and the theory of reasoned action. Pers. Soc. Psychol. Bull. 18, 3-9. doi: 10.1177/0145445509348055

Martínez-Ruiz, M. P., Izquierdo-Yusta, A., Olarte-Pascual, C., and Reinares-Lara, E. (2017). Do affective variables make a difference in consumers behavior toward mobile advertising? Front. Psychol. 7:2018. doi: 10.3389/fpsyg.2016. 02018

Ménard, M., Richard, P., Hamdi, H., Daucé, B., and Yamaguchi, T. (2015). "Emotions recognition based on heart rate and skin conductance," in Proceedings of the 2nd International Conference on Physiological Computing Systems, Loire Valley, 26-32. doi: 10.1016/j.concog.2017.10.013

Mogilner, C., Aaker, J., and Kamvar, S. (2011). How happiness affects choice. J. Consum. Res. 39, 429-443.

Moons, I., and De Pelsmacker, P. (2012). Emotions as determinants of electric car usage intention. J. Mark. Manag. 28, 195-237.

Mugge, R., Schifferstein, H. N., and Schoormans, J. P. (2005). "A longitudinal study of product attachment and its determinants," in European Advances in Consumer Research, Vol. 7, eds K. M. Ekstrom, and H. Brembeck (Gothenburg: Association for Consumer Research), 641-647.

Nicolao, L., Irwin, J. R., Goodman, J. K., Nicolao, L., Irwin, J. R., and Goodman, J. K. (2009). Happiness for sale: do experiential purchases make consumers happier than material purchases? J. Consum. Res. 36, 188-198. doi: 10.1177/ 0956797617736386

Onwezen, M. C., Bartels, J., and Antonides, G. (2014). The self-regulatory function of anticipated pride and guilt in a sustainable and healthy consumption context. Eur. J. Soc. Psychol. 44, 53-68. 
Palmer, N. K. A., and Koenig-lewis, N. (2014). The effects of anticipatory emotions on service satisfaction and behavioral intention. J. Serv. Mark. 28, 437-451.

Pavlou, P. A., and Fygenson, M. (2006). Understanding and predicting electronic commerce adoption: an extension of the theory of planned behavior. MIS Q. 30, $115-143$.

Perugini, M., and Bagozzi, R. (2001). The role of desires and anticipated emotions in goal-directed behaviours: broadening and deepening the theory of planned behaviour. Br. J. Soc. Psychol. 40, 79-98. doi: 10.1348/01446660116 4704

Petersen, F. E., Dretsch, H. J., and Loureiro, Y. K. (2018). Who needs a reason to indulge? Happiness following reason-based indulgent consumption. Int. J. Res. Mark. 35, 170-184.

Pletti, C., Lotto, L., Tasso, A., and Sarlo, M. (2016). Will I regret it? Anticipated negative emotions modulate choices in moral dilemmas. Front. Psychol. 7:1918. doi: $10.3389 /$ fpsyg.2016.01918

Rhodes, R. E., Courneya, K. S., and Jones, L. W. (2005). The theory of planned behavior and lower-order personality traits: interaction effects in the exercise domain. Pers. Individ. Diff. 38, 251-265.

Santos, J., Seixas, D., Brandão, S., and Moutinho, L. (2012). Neuroscience in branding: a functional magnetic resonance imaging study on brands' implicit and explicit impressions. J. Brand Manag. 19, 735-757.

Schoefer, K., and Diamantopoulos, A. (2008). The role of emotions in translating perceptions of (In)justice into postcomplaint behavioral responses. J. Serv. Res. $11,91-103$.

Soscia, I. (2007). Gratitude, delight, or guilt: the role of consumers' emotions in predicting postconsumption behaviors. Psychol. Mark. 24, 871-894.

Stoll, M., Baecke, S., and Kenning, P. (2008). What they see is what they get? An fMRI-study on neural correlates of attractive packaging. J. Consum. Behav. 7 , 342-359.

Sun, Y., Hou, Y., and Wyer, R. S. Jr. (2015). Decoding the opening process. J. Consum. Psychol. 25, 642-649.
Teixeira, T., Wedel, M., and Pieters, R. (2012). Emotion-induced engagement in internet video advertisements. J. Mark. Res. 49, 144-159.

Turel, O. (2016). Untangling the complex role of guilt in rational decisions to discontinue the use of a hedonic Information System. Eur. J. Inform. Syst. 25, 432-447.

Vercellis, C. (2009). Business Intelligence: Data Mining and Optimization for Decision Making. New York, NY: John Wiley.

Verplanken, B., and Sato, A. (2011). The psychology of impuse buying: an integrative self-regulation approach. J. Consum. Policy 34, 197-210.

Vichiengior, T., Ackermann, C. L., and Palmer, A. (2019). Consumer anticipation: antecedents, processes and outcomes. J. Mark. Manag. 35, 130-159.

Wang, H., Cheng, Z., and Smyth, R. (2019). Consumption and happiness. J. Dev. Stud. 55, 120-136.

Wong, K. (2013). Partial least squares structural equation modeling (PLS-SEM) techniques using SmartPLS. Mark. Bull. 24, 1-32.

Wood, W., and Neal, D. T. (2009). The habitual consumer. J. Consum. Psychol. 19, 579-592.

$\mathrm{Xu}, \mathrm{Z}$., and Guo, H. (2019). Advantages of anticipated emotions over anticipatory emotions and cognitions in health decisions: a meta-analysis. Health Commun. 34, 774-781. doi: 10.1080/10410236.2018.1434738

Conflict of Interest: The authors declare that the research was conducted in the absence of any commercial or financial relationships that could be construed as a potential conflict of interest.

Copyright (๑) 2020 Bettiga and Lamberti. This is an open-access article distributed under the terms of the Creative Commons Attribution License (CC BY). The use, distribution or reproduction in other forums is permitted, provided the original author(s) and the copyright owner(s) are credited and that the original publication in this journal is cited, in accordance with accepted academic practice. No use, distribution or reproduction is permitted which does not comply with these terms. 


\title{
Value Co-creation in Third-Party Managed Virtual Communities and Brand Equity
}

\author{
Natalia Rubio, Nieves Villaseñor* and $M^{a}$ Jesús Yagüe \\ Finance and Marketing Department, Universidad Autónoma de Madrid, Madrid, Spain
}

Value co-creation continues to be a key issue in the era of marketing 4.0. Despite an increasing amount of research on value co-creation, there is still a lot of ambiguity in the use of certain terms. For example, different names are used to refer to the same concept. Even though the concept of co-innovation or co-production has nearly the same meaning as co-creation, there are certain differences between them that must be clarified. In addition, another difficulty found in the literature is that the co-creation concept is frequently applied to different objects of study, such that it might be dealing with brand value co-creation, co-creation of experience, co-creation attitude, etc. In order to clarify these issues, this paper presents a brief review of the relevant literature on value co-creation.

Edited by: Maria Pilar Martinez-Ruiz, Universidad de Castilla La Mancha, Spain

Reviewed by:

Sebastian Molinillo,

Universidad de Málaga, Spain Andrea Moretta Tartaglione, University of Cassino, Italy

${ }^{*}$ Correspondence: Nieves Villaseñor nieves.villasenor@uam.es

Specialty section:

This article was submitted to Organizational Psychology, a section of the journal Frontiers in Psychology

Received: 18 January 2020 Accepted: 14 April 2020

Published: 27 May 2020

Citation:

Rubio N, Villaseñor $N$ and Yagüe MJ (2020) Value Co-creation in Third-Party Managed Virtual Communities and Brand Equity. Front. Psychol. 11:927. doi: 10.3389/fpsyg.2020.00927
Keywords: co-creation, virtual community, brand equity, co-innovation, value

\section{INTRODUCTION}

At present, profound changes are taking place in the markets that are revolutionizing the relationships between consumers and companies, among which the management of big data should be mentioned. Virtual communities are a good example of this, since they owe their success in part to the storage of large amounts of data from individuals, which companies analyze to offer products and services that best meet their needs and thus achieve a competitive advantage. Marketing 3.0 tools based on social networking sites help organizations to increase consumer engagement by analyzing changes in their behavior and promoting dialogue and interaction with them that ultimately bring about a strong bond between the consumer and brands, generating what is called brand equity (Martínez-Cañas et al., 2016). However, according to a recent study based on a series of in-depth interviews with marketing leaders, organizational success will require engaging more deeply with digital transformations to maintain their level of competitiveness. For example, one of these key transformations is represented by virtual reality, which favors the coordination and integration of resources between companies and consumers and improves the perceptions of valuein-use of the latter (Boyd and Koles, 2019). Therefore, in the paradigm of marketing 4.0 and tools 4.0, co-creation remains a fundamental activity for generating value for both organizations and consumers (Gómez-Suárez et al., 2017). One of the fundamental metrics for quantifying the value that organizations obtain is their brand equity or the preference these obtain among consumers. Traditionally, research on co-creation has been attached to the service-dominant logic literature (hereinafter SDL) (Vargo and Lusch $(2004,2008)$, while brand equity has belonged to brand literature. This study combines both research trends, relating value co-creation and brand equity. Previous studies already indicate that consumers who are involved in co-creation processes 
have higher levels of loyalty, commitment, and recommendation toward organizations and brands (Casaló et al., 2010; Ariño et al., 2011; Fiol et al., 2012; Agag and El-Masry, 2016).

In the era of marketing 4.0, virtual communities will continue to be an ideal study environment, since they allow the analysis of large amounts of data and favor the co-creation process (Healy and McDonagh, 2013). This paper presents a review of the literature on value co-creation, fundamentally applied to digital environments.

\section{CONCEPTUAL BACKGROUND: CO-CREATION VALUE}

Co-creation value is a fundamental concept in the theory and practice of marketing since the apparition of SDL (Vargo and Lusch, 2016), whose meaning needs to be contrasted in specific digital contexts (Yi and Gong, 2013). Among the most widely accepted definitions of co-creation are as follows: (1) Value cocreation is the joint creation of value by the company and the customers, allowing the customers to co-construct the service experience to suit their context (Prahalad and Ramaswamy, 2004). Subsequently, given that the co-creation of value not only affects the bilateral relationship between the consumer and the company, the definition has been transformed to incorporate the multiple agents involved in the process: and (2) Value co-creation describes the way actors behave, interact, interpret, experience, use, and evaluate propositions based on the social construction of which they are a part (Ranjan and Read, 2016).

The first studies on co-creation assimilated this concept to that of co-production, defined as the participation of the consumer in some of the phases of the development of new products, mainly applied in leading brands (Hoyer et al., 2010; Tynan et al., 2010).

Likewise, the close relationship established between consumers and service providers during the service favors the collaboration between actors (Revilla-Camacho et al., 2015; Cossío-Silva et al., 2016), such that the study of co-creation in the services literature has also been frequent (Chen et al., 2012), mainly in the tourism sector (Mathis et al., 2016). An example of this is the involvement of the users in their experience, when they design, together with the service provider, the activities of a trip, the places to visit, etc. Value co-creation can also occur when users collaborate with organizations in the recovery of a service, since participation for the satisfactory resolution of a problem generates user satisfaction (Roggeveen et al., 2012).

There is currently consensus that co-creation is a multidimensional concept. Its dimensions are grouped around two categories: (1) the ability of the participants to co-create value and (2) their disposition to do so. According to Merz et al. (2018), the first of the categories comes from the literature on engagement and refers to the resources that the participating agents voluntarily offer so that co-creation can take place, such as their knowledge, skills, creativity, and network. This group of dimensions is what Ranjan and Read (2016) understand as co-production, which incorporates variables such as knowledge, equity, and interaction. The second category of dimensions, the favorable disposition toward co-creation, is based on the

relationship literature, referring to the motivation of the actors to participate in the co-creation process, and refers to variables such as passion, commitment, and trust. Ranjan and Read (2016) call this second category value-in-use with dimensions of experience, personalization, and relationship. According to Verleye (2015), the dimensions that define the co-creation experience are hedonic experience, cognitive experience, social/personal experience, and pragmatic/economic experience.

Closely linked to value co-creation, but not to be confused with it, are co-creation behaviors. The first authors who measured these behaviors were Yi and Gong (2013), distinguishing between customer participation behavior and customer citizenship behavior. The variables that define the former are information

TABLE 1 | Value co-creation definitions and measurement scalers.

\section{Co-creation definitions}

The process by which stakeholders and organizations jointly create value from products and brands (Prahalad and Ramaswamy, 2004; Merz et al., 2018).

Co-creation is defined as the enactment of interactional creation across interactive system environments (afforded by interactive platforms), entailing agency engagements and structuring organizations (Ramaswamy and Ozcan, 2018)

Co-creation is defined as a joint, collaborative, concurrent, peer-like process of producing new value, both materially and symbolically, through the voluntary contributions of multiple actors resulting in reciprocal well-being (Vargo and Lusch, 2016; Busser and Shulga, 2018)

Co-creation implies that the value exchange is not only defined by the supplier but also negotiated through the exchange of resources between providers, users, and other co-creators (Tommasetti et al., 2017)

Co-creation process describes the way actors behave, interact, interpret, experience, use, and evaluate propositions based on the social construction of which they are a part. Value can extend into future processes beyond the instant realm of exchange or without the "direct" intervention of another party (e.g., through use, social relation, and joint construction) (Ranjan and Read, 2016)

Co-creation describes the customer as an active participant and collaborative partner in relational exchanges, through involvement in the entire service value chain (Yi and Gong, 2013)

\section{Co-creation dimensions}

(1) Customer-owned resources: knowledge, persuasion/skills, creativity, and network/connectedness (2) Customer motivation: passion, commitment, and trust Not defined
(1) Meaningfulness
(2) Collaboration
(3) Contribution
(4) Recognition
(5) Affective response

(1) Cerebral activities

(2) Cooperation

(3) Information research and collation

(4) Combination of complementary

activities

(5) Changes in habits

(6) Co-production

(7) Co-learning

(8) Connection

(1) Co-production: knowledge, equity and interaction

(2) Value in use: experience,

personalization, and relationship

(1) Customer participation: information seeking, information sharing, responsible behavior, and personal interaction

(2) Customer citizenship: feedback, advocacy, helping, and tolerance 
seeking, information sharing, responsible behavior, and personal interaction, and those that determine the latter are feedback, advocacy, helping, and tolerance. According to Rubio et al. (2019), in subsequent studies, these behaviors have been modified depending on the application context (brand communities, digital platforms, and social networks) (Tonteri et al., 2011; Tsai and Pai, 2013; Vernette and Hamdi-Kidar, 2013; Chen et al., 2014; Xu and Li, 2015; Chou et al., 2016; Hu et al., 2016). For example, video watching, video commenting, video producing, and video sharing are co-creation behaviors specific to videosharing communities (i.e., Hu et al., 2016). Creating groups and/or events, participating in them, sending and answering invitations to friends, and visiting other users' profiles are behaviors characteristic of social networks (Chen et al., 2014). It should be noted that while there are authors who argue that the search for information is not a co-creation behavior (e.g., Tsai and Pai, 2013), there are other studies that support the opposite thesis (Yi and Gong, 2013; Hu et al., 2016).

Finally, co-innovation is another co-creation behavior stressed by studies of value co-creation in digital environments (Sánchez et al., 2013; Vernette and Hamdi-Kidar, 2013; Bugshan, 2015). Co-innovation as a co-creation behavior is related to users' participation in contributing ideas, such as for example new product/service modalities, ways to improve them, identification of new users, new moments of consumption, and trends.

Table 1 shows a review of value co-creation definitions and value co-creation scales.

In short, co-creation behaviors can be classified into different levels (Vernette and Hamdi-Kidar, 2013), starting from a more basic level determined by the search for information, a second level defined through interaction with other actors, creating content and generating feedback, and finally a high level of cocreation, in which participants carry out co-innovation activities. Regardless of the level, the different co-creation behaviors produce positive affective responses, among which should be noted the bond with the brand or the brand equity (Zhang et al., 2015; Busser and Shulga, 2018; González-Mansilla et al., 2019; Omar et al., 2020).

Following Correia Loureiro et al.'s (2019) methodology, 40 papers were reviewed. As a starting point, two seminal articles in the marketing field were analyzed to clarify the theoretical context on value co-creation: Prahalad and Ramaswamy (2004) and Vargo and Lusch (2004). These articles are selected based on their number of citations. This initial process helped us as a starting point when creating search strings for value cocreation (search string: value co-creat*). Two leading databases, Web of Science and Scopus, are employed to get access to the articles. Inside these databases, articles with titles and/or abstracts containing the term value co-creation are searched. The review is restricted to peer-reviewed articles and recent articles (from 2013 to 2019) based on SDL theory.

\section{CONCLUSION}

Value co-created between actors in the service system is a central premise of SDL (Busser and Shulga, 2018). While value co-creation has received great attention both conceptually and empirically in the marketing literature, it is still necessary to narrow down the meaning of certain concepts related to value co-creation. In this paper, the terms co-production, cocreation, and co-innovation have been delimited, as close to each other, but which present certain differences both in their conceptualization and in their measurement. The difficulty of addressing the meaning of value co-creation is that it is a complex construct, specific to the context and agent centric, and therefore, there are multiple interpretations and various approaches to its measurement (Busser and Shulga, 2018). Likewise, it has been noted that the value co-creation concept has been applied to different objects of study, for example, brand value co-creation (Tajvidi et al., 2017) and co-creation of experiences in the tourism sector (Frias-Jamilena et al., 2017). From a conceptual point of view, the value co-creation process occurs between multiple agents that belong to the same network and that participate directly and indirectly in activities for their mutual benefit and to improve the vitality of the network. As mentioned in the paper, this means that value co-creation can occur between organization and consumer (Yim et al., 2012), between consumers in a virtual community (Chou et al., 2016), between consumers and the virtual community (Rubio et al., 2019), between organization and employees (Dean et al., 2016), and between organizations (Hein et al., 2019). It should also be noted that although value co-creation has been studied as a process of value creation, value can also be destroyed through interactions between the different actors in the network, when they accidentally or intentionally misuse their own resources or those provided by other users, acting in an unexpected or inappropriate way (Harris et al., 2010).

In short, in the era of marketing 4.0, where the importance of big data is remarkable, the virtual communities are a fantastic context for the analysis of large amounts of data provided by their users during the co-creation process, since through these communities, stakeholders share knowledge, skills, competencies, etc. In addition, the virtual community literature suggests that members of communities share consumption experiences and favor attachment to brands, since they passionately show their opinions about them (Merz et al., 2018). This contributes to favoring the brand equity of both the products/services on which comments are made in the virtual community and the brand equity of the virtual community itself, because the more comments there are, and the more reliable and realistic they are and the greater the preference for said community expressed by users.

As limitations, this paper employs two databases of scientific articles. Thus, employing other databases, articles in other languages, and chapters or working papers would enrich our findings. In addition, future research on value co-creation should include other concepts such as open innovation and stakeholder engagement.

\section{AUTHOR CONTRIBUTIONS}

All authors listed have made a substantial, direct and intellectual contribution to the work, and approved it for publication. 


\section{REFERENCES}

Agag, G., and El-Masry, A. A. (2016). Understanding consumer intention to participate in online travel community and effects on consumer intention to purchase travel online and WOM: an integration of innovation diffusion theory and TAM with trust. Comput. Huma. Behav. 60, 97-111.

Ariño, L. V. C., Blanco, C. F., and Blasco, M. G. (2011). Observación y participación activa en comunidades virtuales comerciales: el caso del sector turismo. Rev. Española Invest. Mark. ESIC 15, 113-134.

Boyd, D. E., and Koles, B. (2019). Virtual reality and its impact on B2B marketing: a value-in-use perspective. J. Bus. Res. 100, 590-598.

Bugshan, H. (2015). Co-innovation: the role of online communities. J. Strat. Mark. 23, 175-186. doi: 10.1016/j.apergo.2017.04.013

Busser, J. A., and Shulga, L. V. (2018). Co-created value: multidimensional scale and nomological network. Tour. Manag. 65, 69-86.

Casaló, L. V., Flavián, C., and Guinalíu, M. (2010). Determinants of the intention to participate in firm-hosted online travel communities and effects on consumer behavioral intentions. Tour. Manag. 31, 898-911.

Chen, A., Lu, Y., Chau, P. Y., and Gupta, S. (2014). Classifying, measuring, and predicting users' overall active behavior on social networking sites. J. Manag. Inform. Syst. 31, 213-253.

Chen, T., Drennan, J., and Andrews, L. (2012). Experience sharing. J. Mark. Manag. 28, 1535-1552.

Chou, E. Y., Lin, C. Y., and Huang, H. C. (2016). Fairness and devotion go far: integrating online justice and value co-creation in virtual communities. Int. J. Inform. Manag. 36, 60-72.

Correia Loureiro, S. M., Romero, J., and Bilro, R. G. (2019). Stakeholder engagement in co-creation processes for innovation: a systematic literature review and case study. J. Bus. Res. (in press). doi: 10.1016/j.jbusres.2019.09.038

Cossío-Silva, F. J., Revilla-Camacho, M. Á, Vega-Vázquez, M., and PalaciosFlorencio, B. (2016). Value co-creation and customer loyalty. J. Bus. Res. 69, 1621-1625. doi: 10.3390/vetsci5040095

Dean, D., Arroyo-Gamez, R. E., Punjaisri, K., and Pich, C. (2016). Internal brand co-creation: the experiential brand meaning cycle in higher education. J. Bus. Res. 69, 3041-3048.

Fiol, L. J. C., García, J. S., Tena, M. A. M., and Coll, S. F. (2012). La importancia de las comunidades virtuales para el análisis del valor de marca: El caso de TripAdvisor en Hong Kong y París. Papers Tur. 52, 89-115.

Frias-Jamilena, D. M., Polo Pena, A. I., and Rodriguez Molina, M. A. (2017). The effect of value-creation on consumer-based destination brand equity. J. Travel Res. 56, 1011-1031.

Gómez-Suárez, M., Martínez-Ruiz, M. P., and Martínez-Caraballo, N. (2017). Consumer-brand relationships under the marketing 3.0 paradigm: a literature review. Front. Psychol. 8:252. doi: 10.3389/fpsyg.2017.00252

González-Mansilla, O., Berenguer-Contri, G., and Serra-Cantallops, A. (2019). The impact of value co-creation on hotel brand equity and customer satisfaction. Tour. Manag. 75, 51-65.

Harris, L., Russell-Bennett, R., Plé, L., and Cáceres, R. C. (2010). Not always cocreation: introducing interactional co-destruction of value in service-dominant logic. J. Serv. Mark. 24, 430-437.

Healy, J. C., and McDonagh, P. (2013). Consumer roles in brand culture and value co-creation in virtual communities. J. Bus. Res. 66, 1528-1540.

Hein, A., Weking, J., and Schreieck, M. (2019). Value co-creation practices in business-to-business platform ecosystems. Electr. Mark. 29, 503-518.

Hoyer, W. D., Chandy, R., Dorotic, M., Krafft, M., and Singh, S. S. (2010). Consumer cocreation in new product development. J. Serv. Res. 13, 283-296. doi: 10.1016/j.foodres.2016.07.010

$\mathrm{Hu}$, M., Zhang, M., and Luo, N. (2016). Understanding participation on video sharing communities: the role of self-construal and community interactivity. Comput. Hum. Behav. 62, 105-115.

Martínez-Cañas, R., Ruiz-Palomino, P., Linuesa-Langreo, J., and Blázquez-Resino, J. J. (2016). Consumer participation in co-creation: an enlightening model of causes and effects based on ethical values and transcendent motives. Front. Psychol. 7:793. doi: 10.3389/fpsyg.2016.00793

Mathis, E. F., Kim, H. L., Uysal, M., Sirgy, J. M., and Prebensen, N. K. (2016). The effect of co-creation experience on outcome variable. Ann. Tour. Res. 57, 62-75. doi: 10.1016/j.annals.2015.11.023

Merz, M. A., Zarantonello, L., and Grappi, S. (2018). How valuable are your customers in the brand value co-creation process? The development of a Customer Co-Creation Value (CCCV) scale. J. Bus. Res. 82, 79-89.

Omar, N. A., Kassim, A. S., Shah, N. U., Shah-Alam, S., and Che-Wel, C. A. (2020). The influence of customer value co-creation behavior on SME brand equity: an empirical analysis. Iran. J. Manag. Stud. 13, 165-196.

Prahalad, C. K., and Ramaswamy, V. (2004). Co-creation experiences: The next practice in value creation. J. Interact. Mark. 18, 5-14.

Ramaswamy, V., and Ozcan, K. (2018). What is co-creation? An interactional creation framework and its implications for value creation. J. Bus. Res. 84, 196-205.

Ranjan, K. R., and Read, S. (2016). Value co-creation: concept and measurement. J. Acad. Mark. Sci. 44, 290-315. doi: 10.1186/s12913-018-3389-y

Revilla-Camacho, M. Á, Vega-Vázquez, M., and Cossío-Silva, F. J. (2015). Customer participation and citizenship behavior effects on turnover intention. J. Bus. Res. 68, 1607-1611.

Roggeveen, A. L., Tsiros, M., and Grewal, D. (2012). Understanding the co-creation effect: when does collaborating with customers provide a lift to service recovery? J. Acad. Mark. Sci. 40, 771-790.

Rubio, N., Villaseñor, N., and Yague, M. J. (2019). Does use of different platforms influence the relationship between cocreation value-in-use and participants' cocreation behaviors? an application in third-party managed virtual communities. Complexity 1, 1-15. doi: 10.1155/2019/7562903

Sánchez, J. A. L., Mieres, C. G., and Vijande, M. L. S. (2013). Innovación de servicio y co-creación con los clientes de la empresa: efectos sobre los resultados. Rev. Española Invest. Mark. ESIC 17, 79-102.

Tajvidi, M., Wang, Y., Hajli, N., and Love, P. E. (2017). Brand value Co-creation in social commerce: the role of interactivity, social support, and relationship quality. Comput. Hum. Behav. 1:105238. doi: 10.1016/j.chb.2017.11.006

Tommasetti, A., Troisi, O., and Vesci, M. (2017). Measuring customer value co-creation behavior. J. Serv. Theory Pract. 27, 930-950.

Tonteri, L., Kosonen, M., Ellonen, H. K., and Tarkiainen, A. (2011). Antecedents of an experienced sense of virtual community. Comput. Hum. Behavi. 27, 2215-2223.

Tsai, H. T., and Pai, P. (2013). Explaining members' proactive participation in virtual communities. Int. J. Hum. Comput. Stud. 71, 475-491.

Tynan, C., McKechnie, S., and Chhuon, C. (2010). Co-creating value for luxury brands. J. Bus. Res. 63, 1156-1163.

Vargo, S. L., and Lusch, R. F. (2004). Evolving to a new dominant logic for marketing. J. Mark. 68, 1-17.

Vargo, S. L., and Lusch, R. F. (2008). Service-Dominant Logic of Marketing: continuing the evolution. J. Acad. Mark. Sci. 36, 1-10.

Vargo, S. L., and Lusch, R. F. (2016). Institutions and axioms: an extension and update of service-dominant logic. J. Acad. Mark. Sci. 44, 5-23.

Verleye, K. (2015). The co-creation experience from the customer perspective: its measurement and determinants. J. Serv. Manag. 26, 321-342.

Vernette, E., and Hamdi-Kidar, L. (2013). Co-creation with consumers: who has the competence and wants to cooperate. Int. J. Mark. Res. 55, 539-561.

$\mathrm{Xu}, \mathrm{B}$., and Li, D. (2015). An empirical study of the motivations for content contribution and community participation in Wikipedia. Inform. Manag. 52, 275-286.

Yi, Y., and Gong, T. (2013). Customer value co-creation behavior: scale development and validation. J. Bus. Res. 66, 1279-1284.

Yim, C. K., Chan, K. W., and Lam, S. S. (2012). Do customers and employees enjoy service participation? Synergistic effects of self-and other-efficacy. J. Mark. 76, 121-140.

Zhang, J., Jiang, Y., and Shabbir, R. (2015). Building industrial brand equity by leveraging firm capabilities and co-creating value with customers. Indus. Mark. Manag. 51, 47-58.

Conflict of Interest: The authors declare that the research was conducted in the absence of any commercial or financial relationships that could be construed as a potential conflict of interest.

Copyright (C) 2020 Rubio, Villaseñor and Yagüe. This is an open-access article distributed under the terms of the Creative Commons Attribution License (CC BY). The use, distribution or reproduction in other forums is permitted, provided the original author(s) and the copyright owner(s) are credited and that the original publication in this journal is cited, in accordance with accepted academic practice. No use, distribution or reproduction is permitted which does not comply with these terms. 
OPEN ACCESS

Edited by:

Monica Gomez-Suárez, Autonomous University of Madrid,

Spain

Reviewed by:

Nicholas J. Kelley, Northwestern University,

United States

Song Xue,

Nanjing Normal University, China

${ }^{*}$ Correspondence:

Jia Jin

jinjia@nbu.edu.cn

Specialty section:

This article was submitted to

Organizational Psychology,

a section of the journal

Frontiers in Psychology

Received: 20 January 2020

Accepted: 28 May 2020

Published: 03 July 2020

Citation:

Wang C, Fu W, Jin J, Shang Q,

Luo $X$ and Zhang X (2020) Differential

Effects of Monetary and Social

Rewards on Product Online Rating

Decisions in E-Commerce in China.

Front. Psychol. 11:1440.

doi: 10.3389/fpsyg.2020.01440

\section{Differential Effects of Monetary and Social Rewards on Product Online Rating Decisions in E-Commerce in China}

\author{
Cuicui Wang ${ }^{1,2,4}$, Weizhong Fu', ${ }^{1,2}$ Jia Jin' ${ }^{3,45 *}$, Qian Shang ${ }^{6}$, Xuan Luo ${ }^{1,2}$ and Xin Zhang ${ }^{1,2}$ \\ ${ }^{1}$ School of Management, Hefei University of Technology, Hefei, China, ${ }^{2}$ Key Laboratory of Process Optimization \\ and Intelligent Decision-Making, Ministry of Education, Hefei University of Technology, Hefei, China, ${ }^{3}$ School of Business and \\ Management, Shanghai International Studies University, Shanghai, China, ${ }^{4}$ Academy of Neuroeconomics \\ and Neuromanagement, Ningbo University, Ningbo, China, ${ }^{5}$ Center of Group Behavior and Social Psychological Service, \\ Ningbo University, Ningbo, China, ${ }^{6}$ School of Management, Hangzhou Dianzi University, Hangzhou, China
}

Humans can change their behaviors to obtain environmental rewards (e.g., money, food, and sex). However, our knowledge regarding how rewards affect human behaviors by priming and whether there are differences among types of rewards is limited. This study focused on whether monetary and social rewards have different priming effects on product rating decisions in e-commerce by using a behavioral experiment and event-related potentials (ERPs). Using cash/discount coupons as a monetary reward and greeting cards as a social reward, the behavioral data showed that unsatisfactory products with a monetary reward induced a less negative consumer attitude than those with a social reward or no reward; additionally, such products were associated with a longer reaction time while rating products than those with a social reward, reflecting that monetary rewards made it more difficult for the subjects to rate unsatisfactory products than social rewards. The P2, N2, and P3 components of the ERP data were evaluated. Unsatisfactory products caused negative emotion, which could be compensated more by the monetary reward than the social reward as reflected by a smaller P2 amplitude. Due to the compensation effect of the monetary reward, unsatisfactory products were associated with more decision conflict than the social reward as reflected by a more negative N2 amplitude, which is consistent with the behavioral results. However, in the subsequent controlled process, regardless of whether the products were satisfactory or unsatisfactory, the monetary reward caused more attention reallocation and was more motivating than the social reward as reflected by a larger P3 component. These findings have implications for the marketing strategy of online sellers and value of online reviews and suggest attaching importance to ethical issues induced by monetary rewards in rating behaviors.

Keywords: monetary reward, social reward, event-related potentials, product rating decision, compensation effect 


\section{INTRODUCTION}

Human behaviors can be affected by various types of environmental rewards, such as food, sex, money, or social affiliation (Ait Oumeziane et al., 2017; Wang et al., 2017). These rewards can meet individual needs and provide subjective pleasure. In e-commerce, online sellers often provide various types of rewards (i.e., cash/discount coupons, giveaways, and free sample). Thus, it is important for sellers to know the effects of different types of rewards on consumers' attitudes and behaviors. The role of monetary rewards as a powerful incentive measure is well known. Recently, researchers have started to explore the differences in neural mechanisms between monetary and social rewards, and most research has focused on the different incentive effects of monetary and social rewards occurring after subjects achieve a certain goal-directed behavior (Izuma et al., 2008; Kohls et al., 2009; Spreckelmeyer et al., 2009; Flores et al., 2015; Ait Oumeziane et al., 2017). However, in real life, we often provide rewards without any direct requirements. For example, customers may receive smiles or coupons from staff members at a supermarket, and such rewards are given directly with no other requirement that may affect individual behaviors. However, knowledge regarding the priming effects of monetary and social rewards is limited.

In e-commerce in China, online sellers often send coupons (monetary reward) or greeting cards (social reward) to customers with no direct requirements to influence customer satisfaction and behavioral intention. Consumers' behavioral intentions usually contain the following two aspects: willingness to recommend behavior and future purchasing behavior (Maulisa and Hijrah Hati, 2019). On the one hand, online sellers mail coupons or greeting cards with products purchased at online stores through an express company. Online sellers hope that the monetary or social rewards will increase customer satisfaction and lead to positive reviews of the purchase as customergenerated review ratings have a substantial impact on the success or failure of a product on internet commerce (Chevalier and Mayzlin, 2006; Lafky, 2014). On the other hand, in daily life, coupons and greeting cards are still repeatedly sent to customers by text or e-mail, which could serve as reminders to customers and affect purchase decisions in the future. Thus, monetary and social rewards are often used as primers in e-commerce platforms. However, few studies investigated whether monetary and social rewards have different priming effects on the decisions of customers to provide online review ratings in e-commerce, especially when customers have different degrees of customer satisfaction with the products purchased in online platforms.

\section{CONCEPTUAL FRAMEWORK}

\section{Product Rating Generation Process}

A product's star rating is a main online review element affecting product sales and consumers' purchase intention (Luca, 2011; Moe and Trusov, 2011). Thus, it is necessary to know the online product rating generation process. First, previous research found that consumer preferences affected their rating choice and social interactions had an effect on the review generation process (Lee et al., 2015), providing empirical evidence enhancing our understanding of how social imitation and learning affect consumer rating generation. Second, recent studies found evidence of fake reviews in many contexts (Lappas et al., 2016; Wang et al., 2018). For example, in the context of hotel reviews, manipulating online reviews had a significant effect on changing product visibility (Lappas et al., 2016). In the online shopping context in China, the strategy of returning cash coupons if consumers give a five-star rating is likely to increase false rating behaviors (Wang et al., 2018). Third, the previous literature studied reviewer motivation and found that intrinsic and extrinsic factors, such as the social network structure, social interaction, economic incentives, etc., motivated reviewers to comment (Goes et al., 2014; Warut et al., 2018). Warut et al. (2018) found that money, which is an extrinsic reward, could attract new reviewers to give more positive reviews but reduced the participation level of existing reviewers.

Considering that social interactions with friends or a crowd can affect the review generation process (Lee et al., 2015), we speculated that social interaction between consumers and online sellers could affect the product rating generation process. Social rewards (e.g., smiles and greeting cards) are important mediums that could have an effect on the product rating generation process. In addition, monetary rewards during the feedback stage can lead to false-positive rating behaviors (Wang et al., 2018). We speculated that monetary rewards during the priming stage might affect the product rating generation. Thus, we examine prior works investigating the impact of monetary and social incentives in related contexts and speculate regarding the possible psychological mechanism driving consumers to give ratings for online products with monetary or social rewards.

\section{Impact of Monetary and Social Rewards}

Monetary and social rewards are the two main reward types and are generally considered related to human motivation and behavior (Wang et al., 2017). Monetary rewards, such as discounts or coupons, tend to "serve as a means to an end" (Lea and Webley, 2006) and are valued for the economic advantages they offer to customers. Economic approaches to money are based on a model of rational behavior and are considered at the macroeconomic level of analysis. However, psychological approaches to money typically pay attention to human attitudes or related behaviors in special situations (Lea et al., 2009). Numerous studies indicate that money is not only instrumental but also symbolic and emotional in interpersonal and intrapersonal regulation (Zhang, 2009; Zhou et al., 2009). Social rewards, such as smiling faces, encouraging gestures, and verbal praise, are regarded as another essential and advanced reward process with a large impact on individuals' behavioral development. Previous studies show that social rewards are positive reinforcers that can increase the likelihood that a corresponding behavior will be executed in the future (Spreckelmeyer et al., 2009; Stavropoulos and Carver, 2013). Moreover, neuroscience approaches are used to investigate the neural basis of monetary and social reward processing. Focusing on the motivation for goal-directed behavior, Izuma et al. (2008) 
used functional magnetic resonance imaging (fMRI) experiments to investigate whether the acquisition of a social reward activated the same reward-related brain areas as a monetary reward (Izuma et al., 2008). Spreckelmeyer et al. (2009) further explored the differences between men and women in coding monetary and social rewards at the brain level and found that monetary rewards evoked a wider network of mesolimbic brain regains than social rewards in men but not in women (Spreckelmeyer et al., 2009). Based on electrophysiological evidence, Flores et al. (2015) and Ait Oumeziane et al. (2017) used monetary and social incentive delay (MID and SID) tasks to study the different neural responses to anticipation and evaluation of monetary and social rewards (Flores et al., 2015; Ait Oumeziane et al., 2017).

In most previous research, monetary and social rewards were given as outcomes after individuals made certain behavioral decisions, and reward processing focused on the behavioral influencing mechanism from the perspective of incentive theory. However, whether differences exist between social and monetary rewards as priming stimuli in e-commerce, especially the effect of different types of rewards on individuals' perception of dissatisfaction with products and subsequent review rating decision making, is unclear. The theory of planned behavior (TPB) developed by Ajzen aims to predict or understand actualized behaviors in specified circumstances and emphasizes the role of the following three concepts: attitudes toward a behavior, subjective norms, and perceived behavioral control (Ajzen, 1991). Based on this theory, a person who has a positive attitude receives great support from significant others and perceives that strong behavior control is more likely to perform a behavior. Bittner and Shipper (2014) used the improved model of the TPB to predict the purchase intention of gamified products. Amini et al. (2014) revealed that rewards serving as an intervention factor had important relationships with individuals' attitudes, subjective norms, and perceived behavioral control and affected motivations for particular behaviors. In fact, rewards also play a prominent role in online behavior, and we can use the TPB to speculate the possible effect of rewards on consumers' online behavior. In the current study, consumers have different emotions toward satisfactory and unsatisfactory products, which could affect their rating behavior. Unsatisfactory products could induce unpleasant feelings among consumers, which could be affected by different reward types. We speculate that monetary or social rewards given after customers experience dissatisfaction with products could compensate for the unpleasant feelings experienced by individuals, change their attitude, and further affect their review rating, which could represent a new perspective enhancing our understanding of reward processing.

The priming effect of money suggests that counting money beforehand can protect people from experiencing unpleasant feelings caused by physical pain or distress (Zhou et al., 2009). However, few studies have examined the priming effect of social rewards. In the present study, using the context of Business-toCustomer (B2C) e-retailing, we focus on the priming effect of monetary and social rewards on consumer-generated ratings of unsatisfactory and satisfactory products purchased by customers in e-commerce. In prior studies, monetary outcomes were reflected by wins or losses of money, and most social outcomes were reflected by individual face pictures/videos (i.e., a face with a slight smile) (Spreckelmeyer et al., 2009; Flores et al., 2015; Bottini, 2018). However, Yang et al. (2002) demonstrated that our brain is sensitive to facial stimuli, and thus, social reward processing may be conflated by face processing when using faces as social feedback. In research comparing the time courses of social and monetary reward processing, Ait Oumeziane et al. (2017) used a thumbs up or down to reflect social reward (Ait Oumeziane et al., 2017), which is perceptually not very similar to monetary reward because the material used as the social reward was a picture, while the monetary reward was in the form of several words. In e-commerce, cash/discount coupons and greeting cards are often shipped by merchants along with the products purchased from online stores ${ }^{1}$ (in China). Considering both the limitations of previous research concerning social rewards and the context of our study, we sought to use cash/discount coupons and greeting phrases as novel monetary and social rewards. To minimize the neural differences driven by the physical characteristics of both reward types (e.g., images of faces/thumbs vs. money), both reward types were displayed as Chinese characters and represented ecologically valid monetary and social stimuli, which could be effective for tapping into relevant real-world processes of e-commerce.

\section{ERP Method and ERP Components}

An event-related potential (ERP) is an electrophysiological brain signal associated with cognitive responses to an event (e.g., the presentation of a stimulus). Recently, the ERP approach has begun to be used to measure the complex cognitive processes of consumer behavior in marketing (Telpaz et al., 2015; Venkatraman et al., 2015; Barnett and Cerf, 2017; Lin et al., 2018; Fu et al., 2019). To explore the potential neural processes of how different reward types have a priming effect on rating decision making for unsatisfactory products purchased by customers in e-retailing, we attempted to apply ERPs with a behavioral method to examine the dynamic electrophysiological time course. Flores et al. (2015) and Ait Oumeziane et al. (2017) used MID and SID tasks and proposed temporal stage models to describe monetary and social reward processing. During the reward anticipation stage, the N1, P2, and P3 components were found to reflect the allocation of attentional and motivational resources (Flores et al., 2015; Ait Oumeziane et al., 2017). During the reward evaluation stage, the P2, feedback-related negativity (FRN) and P3 components, which reflected affective and cognitive processes, were modulated by the reward types (Flores et al., 2015). In addition to the anticipation and evaluation stages, Ait Oumeziane et al. (2017) further studied the processing stage of reward cues. In the current study, monetary and social rewards were given to individuals as primers without any requests; thus, there was no reward cue stage or reward anticipation stage. We focused on the neural processes of different reward types affecting rating behavior when customers felt that the products or services purchased via e-commerce were unsatisfactory. Thus, the evaluation and decision processes were emphasized. Considering that the rewards in the current study were not provided during

\footnotetext{
${ }^{1}$ Taobao.com
} 
the feedback stage, we speculated that the FRN component would not be evoked. Based on previous ERP studies (Flores et al., 2015; Ait Oumeziane et al., 2017), three components, namely, P2, N2, and P3, could be involved in the temporal course of consumer-generated ratings of unsatisfactory products with two types of reward primers.

\section{P2}

The P2 component is a positive potential over the frontal region that occurs approximately $200 \mathrm{~ms}$ after the stimulus onset. Prior studies have suggested that the P2 component is related to the emotional evaluation of prospective rewards (Doñamayor et al., 2012; Flores et al., 2015) and that the P2 amplitude is associated with reward sensitivity (Martin and Potts, 2004; Potts et al., 2006). In the study conducted by Flores et al. (2015), there was no significant main effect of reward type on P2, but the P2 difference between reward and non-reward under the monetary condition was larger than that under the social feedback condition (Flores et al., 2015). In the current study, unsatisfactory products or services induced unpleasant feelings that could be compensated by monetary or social rewards, which could affect the emotional evaluation processes of rewards. Therefore, we speculate that emotional evaluation processes of different reward types could be affected by unpleasant feelings evoked by unsatisfactory products, which could be reflected by the amplitude of the P2 component.

\section{N2}

The N2 component is a negative component with a wave peaking at approximately 200-350 ms after stimulus onset, and N2 over the frontal region elicited by visual stimuli can be related to the detection of mismatch and conflict-related monitoring (Donkers and Van Boxtel, 2004; Folstein and Van Petten, 2008; Larson et al., 2014; Deng et al., 2015). Research has demonstrated that the amplitude of $\mathrm{N} 2$ in conflict detection is more negative (i.e., larger) in incongruent trials than in congruent trials (Veen and Carter, 2002; Yeung et al., 2004). Wang et al. (2018) found that the N2 component could reflect the perceptual conflict detected by subjects asked to give a good comment for a defective product (Wang et al., 2018). Moreover, rewards can modulate the perceptiveness of and adaptations to conflict (Braem et al., 2012). In the current study, based on the TPB, individuals had a negative attitude while rating an unsatisfying product but a positive attitude while rating a satisfactory product. Thus, response conflict occurs when subjects decide to give a fivestar rating to an unsatisfying product, which evokes the N2 component. The different reward types could have a priming effect on the response tendency and moderate the amplitude of N2. Therefore, we speculate that conflict is detected when giving a good rating to an unsatisfactory product and that the reward type could moderate the conflict perception as reflected by the N2 component.

\section{P3}

The P3 component is maximal over parietal sites and is a positive ERP component with a wave peaking at approximately 300-500 ms following stimulus onset (Polich and Kok, 1995). Many previous studies suggested that the P3 amplitude is sensitive to reward valence (e.g., reward/non-reward) and magnitude (e.g., large reward/small reward), which is associated with attentional resource reallocation when evaluating the motivational significance of stimuli (Nieuwenhuis et al., 2005; Schevernels et al., 2014; Wu et al., 2016; Zhang et al., 2017). In addition, considering the differences between monetary and social rewards, Flores et al. (2015) found that monetary rewards might be more motivationally salient than social reward, which could be reflected by the P3 amplitude (Flores et al., 2015). In the current study, according to the TPB, there was a positive attitude toward satisfactory products and a negative attitude toward unsatisfactory products, which affected the motivational effects of the different reward types. Therefore, we speculated that the incentive effect of monetary and social rewards could be affected by the different attitudes caused by satisfactory or unsatisfactory products or services, which could be reflected by the amplitude of the P3 component.

The objective of this paper was to explore the neural processing of monetary and social rewards as primers in the decision to give review ratings for satisfactory or unsatisfactory products in e-commerce by using behavioral and ERP measures. We predicted that monetary and social rewards could have a significant effect on consumers' attitude and rating behavior and that the amplitudes of the P2, N2, and P3 components could be evoked to reflect the neural processes. As mentioned above, P2 was expected to reflect the early emotional evaluation processes of different reward types, N2 was expected to reflect response conflict detection when giving review ratings for satisfactory or unsatisfactory products with different rewards as primers, and P3 was expected to reflect the incentive effect of monetary and social rewards in giving review rating decisions. The findings of this study could extend the current understanding of the different effects of reward types on consumer rating behavior and introduce the ERP method to thoroughly explore the neural bases above. In addition, this research aims to provide recommendations for e-retailers regarding how to use rewards as primers to exert positive influences on rating behavior.

\section{STUDY 1: ERP EXPERIMENT}

\section{Materials and Methods Participants}

In the ERP experiment, ERP data from 21 native Chinese undergraduates (10 male) from Ningbo University aged between 20 and 26 years $(M=22.857$, S.D. $=1.236)$ were analyzed in the current study. All participants were right-handed and had normal or corrected-to-normal vision with no history of neurological or psychiatric disorders. All participants had experience with online shopping and were familiar with cash/discount coupons and greeting cards in e-commerce. This study was approved by the Internal Review Board of the Center for Management Decision and Neuroscience at Ningbo University. Before the experiment, each participant provided written informed consent. The EEG data of the 1st, 11th, and 21st participants were excluded due to excessive artifacts. In total, 18 (9 male) subjects had valid behavioral data and EEG data. 


\section{Stimulus Materials}

In the current ERP experiment, we used a priming-probe paradigm. In the priming set of stimuli (S1), each stimulus consisted of a product photo with a phrase below that described the perceived quality of the product by customers. Considering that experience products can be evaluated only during or after consumption while search products are evaluated prior to their purchase (Franke et al., 2004; Jiménez and Mendoza, 2013), experience products were more suitable as stimuli in the current experiment. Furthermore, the clothing category of experience products was chosen because youngsters attending a university generally have experience with buying clothing online and care about the impression made by clothing (Dhiman et al., 2018). Subsequently, to avoid differences in familiarity with the products between the men and women, a focus group discussion was conducted, and sweaters and shoes from the clothing category were chosen as the two products used in the current experiment. In addition, to control for physical features, such as color and style, we separately chose pictures of a sweater and a pair of shoes from the bestselling products of Taobao e-commerce ${ }^{1}$ as the stimuli for the two product pictures. According to the online comments of the two products, word frequency statistics were adopted to identify five phrases reflecting consumer satisfaction (e.g., works excellent) and five phrases reflecting consumer dissatisfaction (e.g., works rough). Therefore, S1 comprised 20 stimuli, i.e., 2 pictures (sweater or shoes) $\times 2$ categories of product customer satisfaction $\times 5$ phrases per category of product customer satisfaction.

The second set of stimuli (S2) comprised eight rewards (no more than seven Chinese characters) chosen from two categories, namely, monetary rewards and social rewards. The monetary rewards were reflected by four cash or discount coupons as follows: a $5 \mathrm{RMB}$ cash coupon, a $10 \mathrm{RMB}$ cash coupon, a $12 \%$ discount, and a $2 \%$ discount; these monetary rewards were frequently received by the customers in our pilot investigation. The social rewards were reflected by four greeting cards (e.g., enjoy your shopping). Therefore, the stimuli in the current experiment consisted of 160 pairs of product customer satisfaction (S1) and rewards (S2), i.e., 2 pictures (sweater or shoes $) \times 2$ categories of product customer satisfaction $\times 5$ phrases per category of product customer satisfaction $\times 2$ types of rewards $\times 4$ rewards per reward type. Each stimulus was digitized to 400 pixels $\times 300$ pixels, and the mean luminance level of the stimuli was $186.17 \mathrm{~cd} / \mathrm{m}^{2}$ (candela/square meter) with a standard deviation of $25.82 \mathrm{~cd} / \mathrm{m}^{2}$.

\section{Procedures}

The ERP experiment comprised four blocks, and each block included 40 pairs of product pictures with product customer satisfaction (S1) and rewards (S2). All pair sequences were randomized. The presentation of all stimuli was controlled by the E-prime 2.0 software package (Psychology Software Tools, Pittsburgh, PA, United States). Each stimulus was presented at the center of a computer screen placed $1 \mathrm{~m}$ away from the eyes of the participants. Thus, the horizontal and vertical visual angles were $2.58^{\circ}$ and $2.4^{\circ}$, respectively.

In each trial, a fixation cross "+" was presented against a gray background for 600-800 ms. Then, S1 was presented for $2000 \mathrm{~ms}$, followed by a blank screen for 600-800 ms; then, S2 appeared. After the participants made decisions, S2 disappeared, followed by a blank screen for 600-800 ms (as shown in Figure 1).

The participants were seated in a sound-attenuated and electrically shielded room and were required to fix their eyes on the fixation cross at the center of the screen. The participants were given the following introductions: "You received a parcel that included a sweater/a pair of shoes bought from Taobao.com, and the quality may or may not be to your satisfaction, which

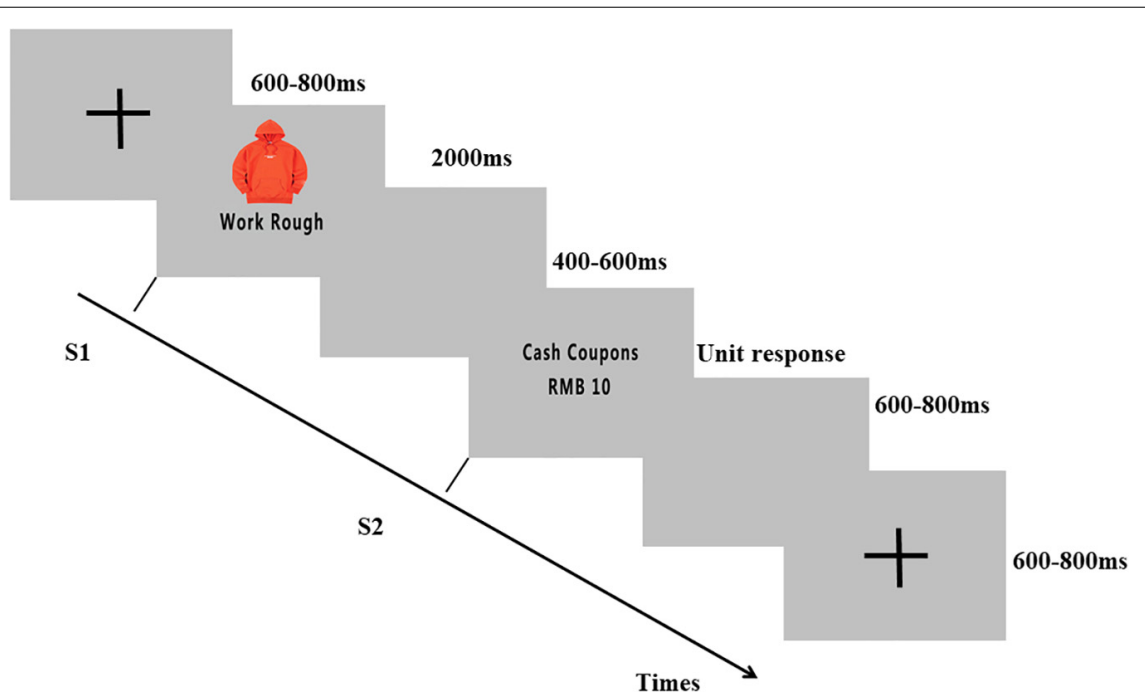

FIGURE 1 | Event-related potentials (ERP) paradigm. Participants were instructed to observe a product photo with a phrase below that described the perceived quality of the product by customers (S1) and then decide whether to give the product a five-star rating with the presentation of monetary or social rewards (S2). Subject EEGs were recorded throughout the experiment. 
is reflected by $\mathrm{S} 1$. In addition, a coupon or a card was mailed with the product, which is reflected by S2. According to the information of S1 and S2, please evaluate whether you would give the product a five-star rating or not." A compatible keyboard was used to allow the participants to make their behavioral decisions. Eleven subjects were asked to press 1 to indicate their choice to give a five-star rating and 3 to indicate their choice to not give a five-star rating. For the other 10 subjects, the keys were defined in reverse to counterbalance the difference between left and right hands. After the introduction, 10 training trials were performed by each participant as practice trials. The participants could rest for several minutes after each block. After the end of the experiment, the participants were paid 50 Chinese yuan (approximately US\$ 7) for their participation.

\section{Electroencephalography Recordings and Analysis}

Electroencephalography (EEG) was recorded using a NeuroScan SynAmps2 Amplifier (Curry 7, Neurosoft Labs, Inc., Sterling, VA, United States), which harbored $64 \mathrm{Ag} / \mathrm{AgCl}$ electrodes according to the extended international 10-20 system and had a sampling rate of $1,000 \mathrm{~Hz}$. The EEGs were referenced to the left mastoid with a cephalic (forehead) location as the ground. Electrooculogram (EOG) electrodes placed $10 \mathrm{~mm}$ from the lateral canthi of both eyes and above/below the left eye recorded blinks and vertical/horizontal eye movements, respectively. The experiment began when the electrode impedances were kept under $10 \mathrm{k} \Omega$.

The EEG recordings were processed offline using NeuroScan analysis software (Scan 4.5, Neurosoft Labs, Inc., Sterling, VA, United States). The EOG artifacts (eye blinks and movement) were corrected. The EEG signals were digitally filtered through a zero-phase shift (low pass at $20 \mathrm{~Hz}, 24 \mathrm{~dB} /$ Octave) and divided into epochs extending from $200 \mathrm{~ms}$ before the onset of S2 to $800 \mathrm{~ms}$ after S2 onset with a $200 \mathrm{~ms}$ period prior to S2 onset as baseline correction. The trials during which the peak voltages exceeded $\pm 100 \mu \mathrm{V}$ after correction were excluded before averaging. More than 30 sweeps in each condition remained, which was adequate for achieving stable and reliable measurements of P2, N2, and P3 (Luck, 2005). Thus, the EEG data of three participants (the 1st, 11th, and 21st participants) were excluded due to the attainment of less than 30 valid trials per condition. The EEG epochs of each subject were averaged across the four conditions (2 categories of product customer satisfaction $\times 2$ categories of reward type).

Consistent with the published guidelines mentioned in the Section "Introduction," three ERP components, namely, P2, N2, and P3, were analyzed in the current experiment. Based on a visual inspection of the grand-average data and previous research cited in the Section "Introduction," the following representative channels and time windows of P2, N2, and P3 were selected: (I) $\mathrm{P} 2$, channels F3, Fz, F4, FC3, FCz, and FC4 in the time window from $200 \mathrm{~ms}$ to $260 \mathrm{~ms}$; (II) N2, channels F3, Fz, F4, FC3, FCz, and FC4 in the time window from 270 to $370 \mathrm{~ms}$; and (III) P3, channels $\mathrm{P} 3, \mathrm{Pz}, \mathrm{P} 4, \mathrm{PO} 3, \mathrm{POz}$, and PO4 in the time window from 300 to $450 \mathrm{~ms}$. The mean amplitudes under each condition were extracted separately within the time windows of P2, N2, and
P3. A three-way repeated-measures ANOVA with three withinsubject factors (i.e., product customer satisfaction, reward type and electrode) was conducted for each component.

\section{Results \\ Behavioral Results}

In the ERP experiment, to analyze the possible differences in favorite ratings (FRs) and reaction times (RTs) between monetary and social rewards following the presentation of satisfactory products or unsatisfactory products, two-way 2 (satisfactory products vs. unsatisfactory products) $\times 2$ (monetary reward vs. social reward) repeated-measures ANOVAs were performed. Regarding the FRs, there were statistically significant differences between the satisfactory products and unsatisfactory products, $F(1,17)=1606, p<0.001, \eta^{2}=0.990$, and the satisfactory products $(M=0.945, S . E .=0.021)$ had higher FRs than the unsatisfactory products $(M=0.032, S . E .=0.011)$. There was no significant difference between the monetary and social rewards, and no significant interaction effect was observed between product customer satisfaction and the reward type.

Regarding the RTs in the ERP experiment, there was a significant effect of the reward type, $F(1,17)=4.932, p<0.05$, $\eta^{2}=0.225$, and the monetary reward $(M=673.583$, S.E. $=50.061)$ had a longer RT than the social reward $(M=630.426$, S.E. $=44.589)$. There was no significant effect of product customer satisfaction $(p>0.1)$, but the interaction effect between the reward type and product customer satisfaction was notable $\left[F(1,17)=8.219, p<0.05, \eta^{2}=0.326\right]$. Therefore, a simple effect analysis was conducted (as shown in Figure 2). Under the condition of satisfactory products, no significant effect was found between the monetary and social rewards $(p>0.1)$. However, under the condition of unsatisfactory products, the difference between the monetary and social rewards was significant $\left[F(1,17)=9.994, p<0.01, \eta^{2}=0.370\right]$, suggesting that consumers required a longer time to make a rating decision when presented with the monetary reward $(M=694.550$, S.E. $=57.285)$ than when presented with the social reward $(M=594.524$, S.E. $=41.158)$. In addition, a 2 (product customer satisfaction $) \times 2$ (reward type) repeated ANOVA with gender as the between-subjects factor was conducted to analyze the RTs. There was no significant main effect of gender, and no significant interaction effects were observed between gender and product customer satisfaction/reward type or among all three factors above.

\section{ERP Results}

The grand-average ERPs in response to the factors of reward type and product customer satisfaction are shown in Figure 3. Repeated-measures ANOVAs of P2, N2, and P3 were performed in three time windows.

A three-way 2 (product customer satisfaction: satisfactory vs. unsatisfactory products) $\times 2$ (reward type: monetary vs. social rewards) $\times 6$ (electrode: F3, Fz, F4, FC3, FCz, and FC4) ANOVA was performed to analyze the P2 component in the time window of 200 to $260 \mathrm{~ms}$. There was no significant main effect of the reward type $(p>0.1)$, product quality $(p>0.1)$, or electrode $(p>0.1)$. However, the interaction effect between 


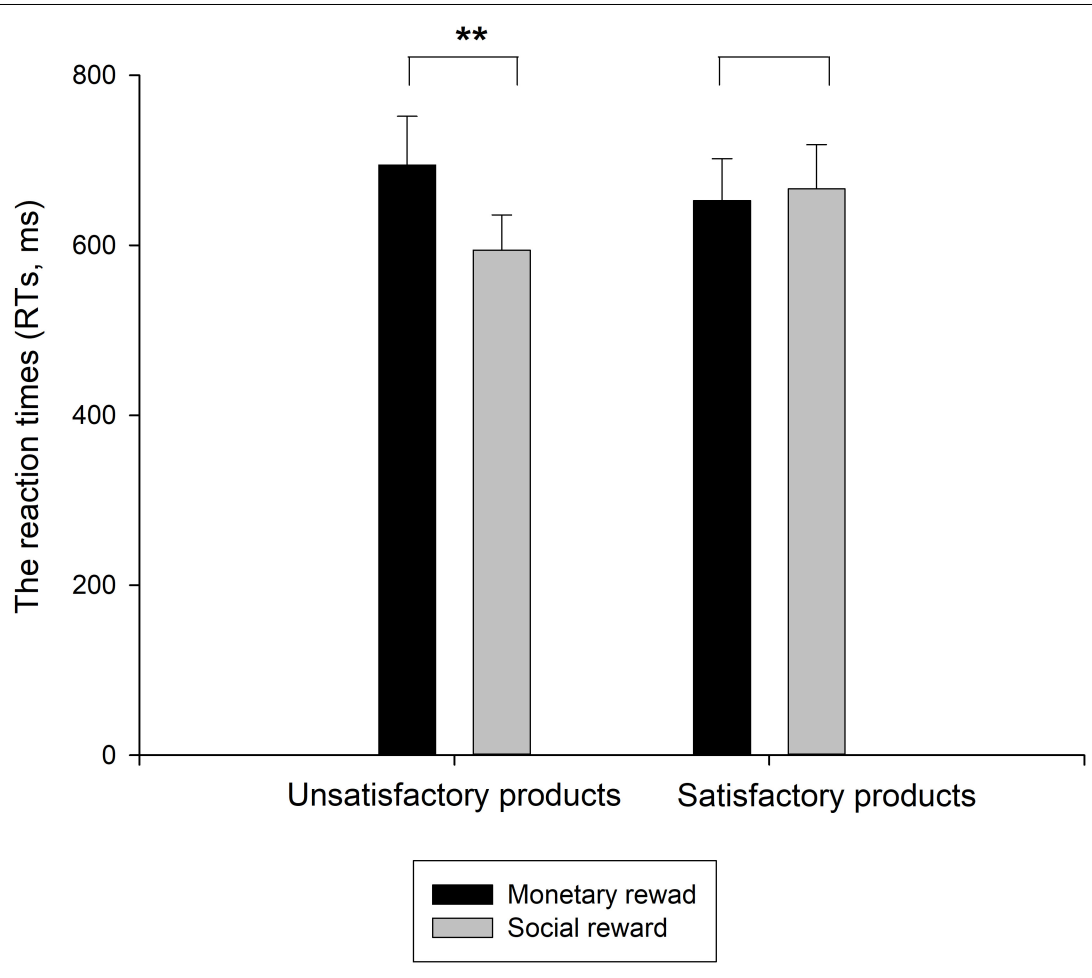

FIGURE 2 | Mean RTs to the monetary and social rewards sorted by product customer satisfaction as satisfactory products and unsatisfactory products. Error bars indicate the SE of the RT. ${ }^{\star *} p<0.01$.

the reward type and product quality was notable, $F(1,17)=5.386$, $p<0.05, \eta^{2}=0.241$. Thus, a simple effect analysis was conducted. Under the monetary reward condition, there were significant differences between the satisfactory and unsatisfactory products, $F(1,17)=4.641, p<0.05, \eta^{2}=0.214$, reflecting that the satisfactory products $(M=3.182$, S.E. $=0.782)$ evoked a larger P2 amplitude than the unsatisfactory products $(M=2.506$, S.E. $=0.773)$ in processing monetary rewards. However, under the social reward condition, no significant difference was found between the satisfactory and unsatisfactory products $(p>0.1)$.

A 2 (product customer satisfaction: satisfactory vs. unsatisfactory products) $\times 2$ (reward type: monetary vs. social rewards) $\times 6$ (electrode: F3, Fz, F4, FC3, FCz, and FC4) ANOVA was conducted to analyze the N2 component in the time window of 270 to $370 \mathrm{~ms}$. No significant main effect of product quality $(p>0.1)$ or reward type $(p>0.1)$ was found, but the interaction effect between product quality and reward type was significant $\left[F(1,17)=4.792, p<0.05, \eta^{2}=0.220\right]$. Therefore, a simple effect analysis was conducted. Under the condition of satisfactory products, there was no significant difference between the monetary and social rewards $(p>0.1)$. However, under the condition of unsatisfactory products, the difference between the reward types was significant $[F(1,17)=5.298, p<0.05$, $\left.\eta^{2}=0.238\right]$, suggesting that the monetary rewards $(M=-0.480$, S.E. $=0.821)$ elicited a more negative N2 amplitude than the social rewards $(M=0.538$, S.E. $=0.846)$.

A 2 (product quality: satisfactory vs. unsatisfactory products $) \times 2$ (reward type: monetary vs. social rewards) $\times 6$ (electrode: P3, PZ, P4, PO3, POz, and PO4) ANOVA was conducted to analyze the P3 component in the time window of 300 to $450 \mathrm{~ms}$. There was a significant effect of product quality $\left[F(1,17)=7.041, p<0.05, \eta^{2}=0.293\right]$, reward type $\left[F(1,17)=5.885, p<0.05, \eta^{2}=0.257\right]$, and electrode $\left[F(5,17)=9.890, p<0.05, \eta^{2}=0.128\right]$, but there was no significant interaction effect between product quality and reward type $(p<0.1)$. Regarding the product quality factor, the satisfactory products $(M=4.664, S . E .=0.466)$ evoked a larger P3 amplitude than the unsatisfactory products $(M=4.049$, S.E. $=0.361)$. Regarding the reward type, the monetary reward $(M=4.658$, S.E. $=0.422)$ evoked a larger P3 amplitude than the social reward $(M=4.055$, S.E. $=0.417)$.

In addition, 2 (product customer satisfaction) $\times 2$ (reward type) $\times 6$ (electrode) repeated-measures ANOVAs with gender as a between-subjects factor was conducted to analyze the P2, $\mathrm{N} 2$, and P3 components separately. The results showed that the main effect of gender on the P2, N2, and P3 amplitudes was not significant $(p>0.05)$, and none of the interaction effects between gender and product customer satisfaction/reward type or among all three factors above were significant $(p>0.05)$.

\section{Discussion}

The ERP method was used in Study 1 to examine the potential neural processing of monetary rewards (cash/discount coupons) and social rewards (greeting cards) when customers were satisfied or dissatisfied with the products purchased in e-retailing. The behavioral results showed that the satisfactory products had 


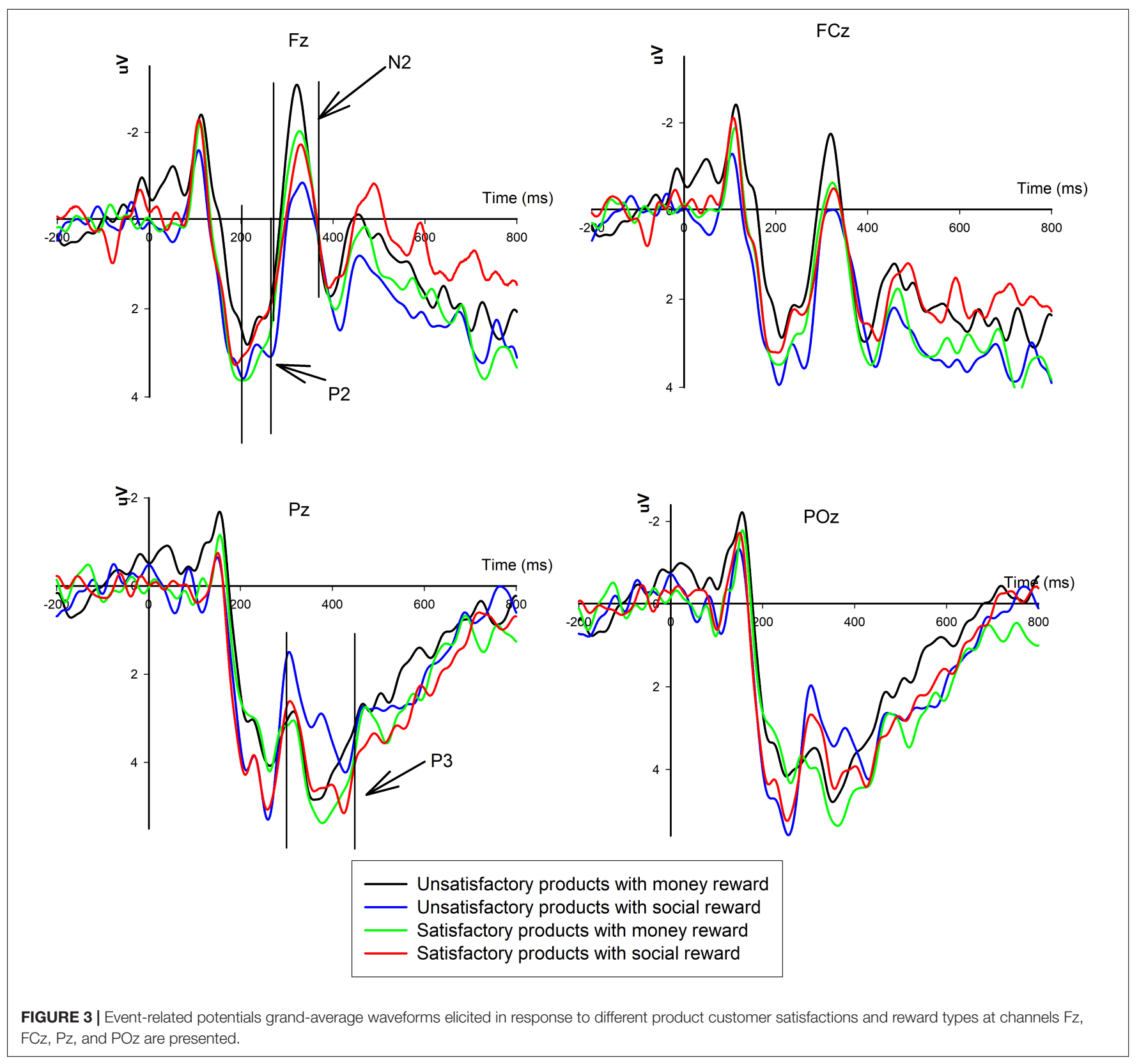

a higher favorite rating than the unsatisfactory products and that the monetary reward was associated with a longer time required by the consumers to make rating decisions regarding the unsatisfactory products than the social reward. However, there was no significant difference between the monetary and social rewards, and no significant interaction effect was observed between product customer satisfaction and the reward type on the favorite rating behavior. A possible reason could be that the binary state of the choice (give or not give a five-star rating) in Study 1 had a low sensitivity and could not properly reflect the consumers' real attitude. The participants may have positive/negative rating behaviors in response to both monetary and social rewards, but the degree of their attitude differed between the monetary and social rewards. In addition, the sample size could not adequately reflect the rating behaviors, and we would conduct Study 2 to further explore.

The ERP results demonstrated that monetary rewards for satisfactory products evoked a larger P2 amplitude than monetary rewards for unsatisfactory products, and no differences were observed in response to social rewards. However, monetary rewards for unsatisfactory products elicited a more negative N2 amplitude than social rewards. Regarding the P3 component, the amplitude evoked by satisfactory products and monetary rewards was larger than that evoked by unsatisfactory products and social rewards, and no interactive effects were observed between the products and reward factors.

Regarding the ERP results, we found that the P2 amplitude evoked by monetary rewards for satisfactory products was larger 
than that evoked by unsatisfactory products. As mentioned above, the P2 component is an early attention-related potential and is associated with the emotional evaluation of rewards (Ito and Urland, 2003, 2005; Potts et al., 2006; Doñamayor et al., 2012; Flores et al., 2015). In the current study, the unsatisfactory products induced negative feelings that could be offset by the subsequent monetary reward. Thus, under the condition of unsatisfactory products, the early emotional evaluation of the monetary reward was decreased, which was reflected by a lesspositive P2 component. However, in response to the social reward, no significant difference in the P2 component was found between the satisfactory and unsatisfactory products. A possible reason is that the early emotional evaluation of the social reward was not affected by the negative emotion induced by the unsatisfactory products. Thus, the social reward was not considered compensation for the unsatisfactory products.

As partially expected based on the result of the N2 component, the monetary reward elicited a more negative $\mathrm{N} 2$ potential than the social reward under the unsatisfactory products conditions without salient differences in response to the satisfactory products. As mentioned in the Section "Introduction," the anterior N2 component could reflect cognitive conflict monitoring in decision-making processes (Folstein and Van Petten, 2008; Larson et al., 2014; Deng et al., 2015; Shang et al., 2017). In addition, incorrect decision tendencies are overturned by overt correct decisions, resulting in high decision conflict, which could evoke the N2 component (Ridderinkhof et al., 2004). In the current study, the overt correct response to the unsatisfactory products was not giving a fivestar rating, whereas giving a five-star rating could be considered an incorrect response. The monetary reward could counteract the negative effects of the unpleasant feelings caused by the unsatisfactory products, while the social reward could not be considered compensation for the unsatisfactory products. Thus, more decision conflict was detected when the subjects made the choice to give a five-star rating to the unsatisfactory products when offered a monetary reward than when offered a social reward; thus, the N2 component evoked by the monetary reward was more negative than that evoked by the social reward under the unsatisfactory products condition. However, no significant difference in the N2 component was found between the monetary reward and social reward under the satisfactory products condition. Notably, the stimuli used to present the monetary reward were discount coupons or cash coupons that could be spent only at specified online retailers rather than currency. This factor could have contributed to the lack of significant difference in conflict detection between the monetary reward and social reward under the satisfactory products condition.

The P3 component was found following the N2 component in this study. Regarding the P3 component, we found that the monetary reward evoked a larger P3 amplitude than the social reward and that the $\mathrm{P} 3$ elicited by the satisfactory products was more positive than that elicited by the unsatisfactory products. Previous studies have demonstrated that P3 can index the reallocation of attention and that a more positive $\mathrm{P} 3$ amplitude suggests that more attentional resources are paid to the stimuli and enhance the activation of the motivational system (Polich and Kok, 1995; Yeung and Sanfey, 2004; Broyd et al., 2012; Doñamayor et al., 2012; Wang et al., 2018). In the current study, the monetary reward reallocated more attention during the later processing stage and had a greater incentive effect on the subjects to make decisions than the social reward. In addition, product customer satisfaction could affect the later controlled and elaborate processing of the reward stimuli. According to the TPB, when the subjects received unsatisfactory products, a negative attitude toward giving five-star ratings was induced, and the motivation to give such products a favorable rating was lower than that when receiving satisfactory products. Thus, the P3 component evoked by the monetary reward and satisfactory products was larger than that evoked by the social reward and unsatisfactory products separately in the current study. However, there was no interaction effect between the factors reward type and product customer satisfaction in the $\mathrm{P} 3$ component.

\section{STUDY 2: BEHAVIORAL EXPERIMENT}

In Study 2, we used a behavioral experiment and enlarge the sample size to probe the robustness of the effect observed in Study 1. First, to address the potential issue of the lack of a control, a control group receiving no reward type was tested in Study 2. Second, according to the theory of TPB, consumers' attitudes were closely associated with their rating behavior. Thus, we used a seven-item scale to measure the consumers' attitudes and their likelihood of giving five-star ratings across the conditions in Study 2 to further explain the behavioral results in the ERP experiment. Third, gender and online shopping experience were considered in Study 2. Therefore, Study 2 included some control variables and used a different method with a larger sample size to further explore the differential effects of monetary and social rewards on product online rating decisions in e-commerce.

\section{Materials and Methods Participants}

In the behavioral experiment, 365 native Chinese $(84.7 \%$ 1924 years old, $61.9 \%$ female) mainly from Hefei University of Technology and Ningbo University participated in this behavioral investigation research in exchange for monetary compensation, and none of these participants participated in the ERP experiment in Study 1. All participants had online shopping experience; $87.4 \%$ of the participants had more than 2 years of online shopping experience, and $95.1 \%$ of the participants engaged in online shopping at least once every 3 months. In total, 158 participants were subjected to the no-reward condition, 102 participants were subjected to the monetary reward condition, and 105 participants were subjected to the social reward condition.

\section{Stimulus Materials}

In the behavioral experiment, the materials selected were the same as those described in the ERP experiment. The behavioral experiment employed a 2 (product customer satisfaction: satisfactory or unsatisfactory) $\times 3$ (reward type: monetary reward, social reward or no reward) mixed design. Product 
customer satisfaction was a within-subject factor, and the reward type was a between-subject factor. The monetary reward type, social reward type, and no-reward type conditions included sweaters and shoes from the clothing category with phrases reflecting consumer satisfaction or dissatisfaction. The monetary rewards were reflected by cash or discount coupons, while the social rewards were reflected by greeting cards, which were the same as those described in the ERP experiment.

\section{Procedures}

In the behavioral experiment, the participants in each reward type condition (monetary reward, social reward, and no reward) were informed that the research purpose was to understand how consumers give ratings to the goods purchased in online shopping. After the introduction, the participants imagined that they received a sweater/a pair of shoes purchased from Taobao.com, and the quality was reflected by the following pictures with phrases, which were the same as the pictures used in the ERP experiment. Moreover, under the monetary and social reward conditions, the information "online sellers gave cash or discount coupons/greeting cards as show in the following pictures" was presented. After reviewing the product information, the participants reported their attitudes toward this online shopping experience or online seller $(1=$ not at all pleasant, 7 = very pleasant; $1=$ not at all satisfactory, $7=$ very satisfactory; $1=$ not at all reliable, $7=$ very reliable; $\alpha=0.95$ ) and how likely they would be to give five-star ratings to this purchase ( $1=$ not at all likely, $7=$ very likely). Considering the high internal consistency ( $\alpha=0.95$ ), we used the average to form a consumer attitude index.

\section{Results and Discussion Results}

For the behavioral experiment, two-way 2 (satisfactory products vs. unsatisfactory products) $\times 3$ (monetary reward vs. social reward vs. no reward) repeated-measures ANOVAs were performed to analyze the attitudes toward this online shopping experience and rating behaviors. Regarding consumer attitudes, there were significant differences between the satisfactory products and unsatisfactory products, $F(1,362)=737.73$, $p<0.001, \eta^{2}=0.671$, and consumers had more positive attitudes toward the satisfactory products $(M=5.443$, S.E. $=0.064)$ than the unsatisfactory products $(M=2.980, S . E .=0.071)$. The main effect of reward type was significant $[F(2,362)=16.223$, $\left.p<0.01, \eta^{2}=0.082\right]$, and the consumer attitudes under the no-reward condition were lower than those under the monetary reward $(p<0.01)$ and social reward $(p<0.01)$ conditions. Moreover, the interaction effect between the reward type and product customer satisfaction was notable $[F(2,362)=10.256$, $\left.p<0.01, \eta^{2}=0.054\right]$. Therefore, a simple effect analysis was conducted, and under the satisfactory products condition, no significant effect was found among the monetary, social, and no-reward types $(p>0.05)$. However, under the unsatisfactory products condition, the difference among the three reward types was significant $\left[F(2,362)=22.246, p<0.01, \eta^{2}=0.109\right]$. The consumer attitudes under the monetary reward type condition $(M=3.549$, S.E. $=0.133)$ were less negative than those under the social reward $(M=2.971, S . E .=0.131, p<0.01)$, and noreward $(M=2.421, S . E .=0.107, p<0.01)$ conditions, and the consumer attitudes under the social reward type condition were less negative than those under the no-reward type condition $(p<0.01)$. In addition, there were no significant main effects of gender or online shopping experience, and the interaction effects between gender/online shopping experience and product customer satisfaction or among the reward types on consumer attitude were statistically insignificant $(p>0.1)$.

Regarding the rating behaviors in the behavioral experiment, the satisfactory products $(M=5.439, S . E .=0.074)$ were more likely to receive five-star ratings than the unsatisfactory products $(M=2.818$, S.E. $=0.073, p<0.01)$. The factor of the reward type had a significant main effect $[F(2,362)=5.419, p<0.01$, $\left.\eta^{2}=0.029\right]$, and consumers were less likely to give five-star ratings under the no-reward condition $(M=3.894$, S.E. $=0.084)$ than the monetary reward $(M=4.314$, S.E. $=0.104, p<0.01)$ and social reward $(M=4.179$, S.E. $=0.103, p<0.1)$ conditions. More importantly, the interaction effect between the reward type and product customer satisfaction was marginally significant $\left[F(2,362)=2.950, p<0.1, \eta^{2}=0.016\right]$. Therefore, a simple effect analysis was conducted. Under the satisfactory products condition, no significant effect was found among the three reward types $(p>0.05)$. However, under the unsatisfactory products condition, the difference among the three reward types was significant $\left[F(2,362)=8.310, p<0.01, \eta^{2}=0.044\right]$, and the consumers were less likely to give five-star ratings under the no-reward condition $(M=2.456, S . E .=0.108)$ than under the monetary reward $(M=3.147, S . E .=0.135, p<0.01)$ and social reward $(M=2.852$, S.E. $=0.133, p<0.1)$ conditions. However, the rating behaviors did not significantly differ between the monetary reward and social reward types $(p>0.1)$. In addition, there were no significant effects of gender or online shopping experience, and no significant interaction effects were observed between gender/online shopping experience and product customer satisfaction or among the reward types on the rating behaviors $(p>0.1)$.

\section{Discussion}

The behavioral experiment in Study 2 was conducted to examine the emotional effect of monetary rewards (cash/discount coupons) and social rewards (greeting cards) on consumers' attitudes and rating behavior when the customers were satisfied or dissatisfied with the products purchased in e-retailing. According to the results of the main effect, the consumers had a more positive attitude toward and were more willing to give a five-star rating for satisfactory products than unsatisfactory products. Moreover, compared with the control group (noreward condition), the consumers under the monetary and social reward conditions had a more positive attitude and preferred to give five-star ratings, reflecting that either monetary or social rewards could improve consumer attitudes and promote positive rating behavior.

Regarding the results of the interaction effect, the three reward conditions had different significant effects on consumer attitudes and rating behaviors only when the consumers received an unsatisfactory product. Thus, under the satisfactory products 
condition, the effect of the three reward conditions on consumer attitudes and rating behaviors did not significantly differ. Specifically, the monetary reward induced a more positive attitude than the social reward under the unsatisfactory products condition, indicating that monetary rewards can decrease the more negative feeling evoked by unsatisfactory products than social rewards. Moreover, the consumers under the no-reward condition were less likely to give five-star ratings than those under the monetary and social rewards conditions under the unsatisfactory products condition. The rating behaviors did not significantly differ between the monetary and social rewards under the satisfactory products condition $(p=0.120)$, but the average likelihood of giving a five-star rating under the monetary reward condition was larger than that under the social monetary reward condition. This finding may indicate that different effects of monetary and social rewards on rating behavior exist to some extent, and combining the reaction time results presented in Study 1 is needed to further explain this finding.

\section{GENERAL DISCUSSION}

\section{Research Finding}

In the current study, we used behavioral and ERP experiments to examine the emotional effect and potential neural processing of monetary rewards (cash/discount coupons) and social rewards (greeting cards) when customers are satisfied or dissatisfied with products purchased in e-retailing.

The behavioral results of both Study 1 and Study 2 reflected that customers were more willing to give a five-star rating for satisfactory products than unsatisfactory products. According to the results of Study 1, customers had a more positive attitude toward satisfactory products than unsatisfactory products, and thus, the former had a higher rating than the latter, supporting the TPB. Regarding unsatisfactory products, monetary rewards induced more positive attitudes than social rewards and no rewards, while social rewards induced more positive attitudes than no rewards, indicating that monetary and social rewards can decrease negative feelings evoked by unsatisfactory products and that the compensation effect of monetary rewards could be better than that of social rewards. Moreover, according to the RT results in Study 1, the customers under the monetary reward condition took a longer time to make a decision than those under the social reward condition. Previous research has demonstrated that a longer reaction time is associated with a higher cognitive load and greater task difficulty (Sweller, 1988; Wang et al., 2016; Jin et al., 2017). In this study, unsatisfactory products and monetary rewards guided the decision to give a five-star rating in two opposite directions. The unsatisfactory products were related to negative attitudes and negative review ratings, while monetary rewards were related to positive attitudes and positive review ratings, thus increasing the decision difficulty. Thus, the participants needed to exert more cognitive effort to make the decision to give the product five stars when a monetary reward was offered for unsatisfactory products, whereas it was relatively easier to make a decision when a social reward was offered for unsatisfactory products. Thus, monetary rewards affect the decision process more than social rewards when customers are dissatisfied with the quality of a product.

In addition, the behavioral results of the ERP experiment in Study 1 were not exactly consistent with the results of the behavioral experiment in Study 2, which was reflected by the lack of an interaction effect on the rating behavior between the reward type and product quality. There are two possible reasons for the notable interaction effects. First, a no-reward condition as a control group was included in Study 2, which could have led to the differences in the interaction effects between the two experiments. Second, the binary state of the choice (giving or not giving a five-star rating) in Study 1 had a low sensitivity and could not reflect the consumers' real rating attitude; in contrast, a sevenitem scale was used to measure the likelihood of giving five-star ratings in Study 2. Moreover, the reaction time data recorded in Study 1 could further support the conclusions of Study 2.

Three ERP components were found to reflect the neural processing of the monetary and social rewards as primers in the decision to give review ratings for satisfactory or unsatisfactory products in e-commerce. Monetary rewards for satisfactory products elicited a more positive P2 amplitude than monetary rewards for unsatisfactory products, but no differences were observed in response to social rewards. However, monetary rewards for unsatisfactory products evoked a more negative N2 amplitude than social rewards. Regarding the P3 component, the amplitude evoked by the satisfactory products and monetary reward was larger than that evoked by the unsatisfactory products and social reward, and no interactive effects between the products and reward factors were observed. The significant interaction effects on the P2 and N2 components may suggest that unsatisfactory products affect the early reward processing stage, without any notable effect on the later elaborate process. Thus, the unsatisfactory products caused a negative emotion that could be compensated by a monetary reward (but not a social reward) as reflected by the $\mathrm{P} 2$ component. Thus, the unsatisfactory products with monetary rewards were observed to have greater decision conflict regarding whether to give a fivestar rating than the products with social rewards as reflected by the $\mathrm{N} 2$ component. In the later controlled process, regardless of whether the products were satisfactory or unsatisfactory, the monetary rewards caused more attention reallocation and were more motivating as reflected by the P3 component. In addition, different rewards as primers influenced P2, N2, and P3, which may provide deep insight into these three components. It can be speculated that the P2, N2, and P3 components were not only sensitive to the rewards during the feedback stage but also evoked by the rewards during the priming stage.

Furthermore, the results show that there was no significant gender effect in the two experiments. In a study conducted by Spreckelmeyer et al. (2009) involving social and monetary rewards as feedback, a gender effect was found in the behavioral and brain data, demonstrating that males, but not females, are more sensitive to monetary rewards than social rewards. A possible explanation for the lack of a significant gender effect is that the paradigm in the current study used monetary and social rewards as primers, and the task was rating behavior in e-commerce. Therefore, males and females may have similar 
psychological and cognitive processing when facing different reward types in giving rating decisions. In addition, the current study did not find a significant difference in the online shopping experience factor in the behavioral experiment. A possible reason is that most participants had relatively rich experience with online shopping. In total, $76.7 \%$ of the participants in the current study reported that they engage in at least one online purchase per month, and $95.1 \%$ of the participants reported engaging in online purchasing at least once every 3 months.

\section{Theoretical Contributions and Practical Implications}

A major deficiency of previous studies concerning monetary and social rewards is that the role of rewards as primers remains relatively unexamined. The current study used behavioral and ERP measures to examine reward processing across monetary and social reward types as primers, which had large differences from previous studies investigating social and monetary rewards (Izuma et al., 2008; Spreckelmeyer et al., 2009; Flores et al., 2015; Ait Oumeziane et al., 2017). Recent studies adapted MID and SID tasks in ERP studies to enable a comparison of social and reward processing in several stages (e.g., reward cue phrase, outcome anticipation phrase, and outcome evaluation/delivery phase) (Flores et al., 2015; Ait Oumeziane et al., 2017). The rewards in the MID or SID paradigms were given as feedback after the subjects made a choice. However, in the current study, the monetary or social rewards were offered before the participants made decisions. Thus, the participants could always gain the rewards regardless of their decisions. Therefore, the current study is the first to use reward for priming to study the difference between monetary and social rewards. Moreover, the paradigm of the rewards as primers was more consistent with reality as this paradigm represents an unethical manipulation offering consumers monetary rewards after they give a good rating on e-commerce platforms ${ }^{1}$ in China.

In addition, the aim of this paper was to open the black box of consumers' brain in the decision-making process and introduce the ERP method to thoroughly explore the neurocognitive processes underlying monetary and social rewards as primers in making rating decisions in e-retailing. We found that the dynamic electrophysiological time course of consumers' giving rating process could be divided into three main stages, with P2 reflecting early emotional evaluation, N2 reflecting conflict detection, and $\mathrm{P} 3$ reflecting the incentive effect. The ERP findings of P2, N2, and P3 could indicate that monetary rewards (such as discount coupons or cash coupons) as primers could compensate for the negative emotion caused by unsatisfactory products and had a greater motivation effect, while social rewards as primers may have no compensation effect for unsatisfactory products with a low incentive effect on consumers' rating behavior in e-commerce.

The findings of the current study could be of great interest to online sellers. With the popularization of e-commerce, it is very possible to receive unsatisfactory goods due to the risk of uncertainty in online shopping. On the one hand, consumers grade products or service after their purchase, while on the other hand, they refer to online reviews before purchasing. Thus, it is necessary and important to understand the potential neural processes of how different reward types influence consumer cognition and emotion in making rating decisions, especially when consumers receive unsatisfactory products. A previous study indicated that enterprises should focus more on incorporating reward elements, such as monetary rewards with points and virtual goods and social rewards with badges and status, into mobile electronic commerce (Li, 2018). The results of this research illustrate the importance of giving cash/discount coupons to consumers in rating decision making. Online retailers should take advantage of monetary rewards to exert a positive influence on consumer rating behavior. However, notably, some marketing strategies involving monetary rewards are illegal, such as the strategy of returning cash/discount coupons if a consumer gives a five-star rating. Although previous research found that a strategy involving a monetary reward with related goals (illegal strategy) had a stronger effect on consumer rating behavior than monetary reward with no additional requirements (Wang et al., 2018), we suspect that there is a great negative effect on online sellers when the illegal marketing strategy is disclosed. Thus, e-retailers should be cautious when using monetary rewards in online marketing because it is conditional. Moreover, even if a marketing strategy involving a monetary reward as a primer is not illegal, its accompanying ethical issue should receive more attention. Monetary rewards could compensate more for consumer dissatisfaction derived from poor-quality products, further influencing consumer rating behavior. Therefore, monetary rewards make consumers disregard the real facts and induce an increase in online fake comments, which has a negative effect on the overall network environment.

In addition, the present results show that online reviews could be influenced by rewards, especially monetary rewards. Thus, online reviews can be manipulated to some extent, inducing an increase in fake comments. Consumers should be aware that it is very risky to depend only on comments when making decisions in online shopping. It is necessary for consumers to comprehensively consider various types of information, such as product sales, online reviews, and product descriptions, in purchase decisions.

\section{Limitations and Future Research}

Several limitations in the current study need to be considered. First, considering that brain activities are sensitive and intricate, it is necessary for ERP experiments to follow strict environmental and equipment requirements. Therefore, the online purchase scenario in the current experiment was highly abstract. Although the discount coupons or cash coupons used as monetary reward stimuli were based on real-world scenarios, there were some differences from the actual online purchasing scenario. Second, the monetary rewards were reflected by cash/discount coupons, while the social rewards were reflected by greeting cards. To generalize the present findings, a wider range of monetary and social rewards with different intensities (e.g., badges or points on membership account) could be used as stimuli in future 
research. Third, the current ERP study compared monetary and social rewards at a brain level without considering the no-reward condition in the experimental design. Future research is needed to improve the paradigm and replicate the ERP findings with other behaviors, such as purchasing behavior or recommending behavior, and a greater sample size may increase the robustness of the current results. Moreover, most recruited participants were college students. Participants with more diverse backgrounds should be recruited to form a more comprehensive view of general brain activities during consumers' rating decisions with rewards as primers.

\section{CONCLUSION}

This research aimed to use behavioral and ERP measures to explore the priming effects of monetary and social rewards on rating decision making when consumers receive satisfactory or unsatisfactory products in e-retail. Using cash/discount coupons as a monetary reward and greeting cards as a social reward, the behavioral results showed that monetary rewards as primers for unsatisfactory products induced a more positive attitude and a longer reaction time than social rewards as primers, indicating that monetary rewards made it more difficult for the subjects to rate the unsatisfactory products than social rewards. The ERP results indicated that monetary rewards could compensate for unsatisfactory products during the early processing stage. The unsatisfactory products caused negative emotions that could be compensated by monetary rewards (but not social rewards) as reflected by the P2 component. Then, unsatisfactory products with monetary rewards were found to induce more decision conflict than those with social rewards as reflected by the $\mathrm{N} 2$ component. In the later controlled process, regardless of whether the products were satisfactory or unsatisfactory, monetary rewards caused more attention reallocation and were more motivating as reflected by the P3 component. To the best of our knowledge, the current study is among the first to use a reward as a primer to explore the differences between monetary and social reward types. Studying

\section{REFERENCES}

Ait Oumeziane, B., Schryer-Praga, J., and Foti, D. (2017). “Why don't they 'like’ me more?": comparing the time courses of social and monetary reward processing. Neuropsychologia 107, 48-59. doi: 10.1016/j.neuropsychologia.2017. 11.001

Ajzen, I. (1991). The theory of planned behavior. Organ. Behav. Hum. Decis. Process. 50, 179-211. doi: 10.1016/0749-5978(91)90020-T

Amini, F., Ahmad, J., and Ambali, A. R. (2014). The influence of reward and penalty on households' recycling intention. APCBEE Proc. 10, 187-192. doi: 10.1016/j.apcbee.2014.10.036

Barnett, S. B., and Cerf, M. (2017). A ticket for your thoughts: method for predicting movie trailer recall and future ticket sales using neural similarity among moviegoers. J. Consum. Res. 49, 160-181. doi: 10.1093/jcr/ ucw083

Bittner, V. J., and Shipper, J. (2014). Motivational effects and age differences of gamification in product advertising. J. Consum. Mark. 31, 391-400. doi: 10. 1108/JCM-04-2014-0945 the different effects of monetary and social reward types on unsatisfactory products could help e-retailers understand the role of the two reward types in e-retail, especially when it is ineluctable that products or services are not completely satisfactory to consumers.

\section{DATA AVAILABILITY STATEMENT}

The datasets generated for this study are available on request to the corresponding author.

\section{ETHICS STATEMENT}

The studies involving human participants were reviewed and approved by Internal Review Board of the Center for Management Decision and Neuroscience at Ningbo University. The patients/participants provided their written informed consent to participate in this study.

\section{AUTHOR CONTRIBUTIONS}

CW, WF, and JJ conceived and designed the experiments. CW, QS, and JJ performed the experiments. CW, WF, and XL analyzed the data. CW, QS, and XZ wrote and refined the article. All authors contributed to the article and approved the submitted version.

\section{FUNDING}

This work was supported by the National Natural Science Foundation of China (Nos. 71502047, 71603139, and 71602044), Humanities and Social Sciences Foundation of the Ministry of Education of China (No. 20YJAZH098), Philosophy and Social Sciences Foundation of Hefei University of Technology (No. JS2020HGXJ0032), and open projects from the Academy of Neuroeconomics and Neuromanagement at Ningbo University.

Bottini, S. (2018). Social reward processing in individuals with autism spectrum disorder: a systematic review of the social motivation hypothesis. Res. Autism Spectr. Disord. 45, 9-26. doi: 10.1016/j.rasd.2017.10.001

Braem, S., Verguts, T., Roggeman, C., and Notebaert, W. (2012). Reward modulates adaptations to conflict. Cognition 125, 324-332. doi: 10.1016/j.cognition.2012. 07.015

Broyd, S. J., Richards, H. J., Helps, S. K., Chronaki, G., Bamford, S., and SonugaBarke, E. J. (2012). An electrophysiological monetary incentive delay (e-MID) task: a way to decompose the different components of neural response to positive and negative monetary reinforcement. J. Neurosci. Methods 209, 40-49. doi: 10.1016/j.jneumeth.2012.05.015

Chevalier, J. A., and Mayzlin, D. (2006). The effect of word of mouth on sales: online book reviews. J. Mark. Res. 43, 345-354. doi: 10.1509/jmkr.43. 3.345

Deng, Y., Wang, Y., Ding, X., and Tang, Y.-Y. (2015). Conflict monitoring and adjustment in the task-switching paradigm under different memory load conditions: an ERP/sLORETA analysis. NeuroReport 26, 124-130. doi: 10.1097/ WNR.0000000000000310 
Dhiman, R., Chand, P. K., and Gupta, S. (2018). Behavioural aspects influencing decision to purchase apparels amongst young Indian consumers. FIIB Bus. Rev. 7, 188-200. doi: 10.1177/2319714518790308

Doñamayor, N., Schoenfeld, M. A., and Münte, T. F. (2012). Magnetoand electroencephalographic manifestations of reward anticipation and delivery. Neuroimage 62, 17-29. doi: 10.1016/j.neuroimage.2012. 04.038

Donkers, F. C., and Van Boxtel, G. J. (2004). The N2 in go/no-go tasks reflects conflict monitoring not response inhibition. Brain Cogn. 56, 165-176. doi: 10.1016/j.bandc.2004.04.005

Flores, A., Münte, T. F., and Doñamayor, N. (2015). Event-related EEG responses to anticipation and delivery of monetary and social reward. Biol. Psychol. 109, 10-19. doi: 10.1016/j.biopsycho.2015.04.005

Folstein, J. R., and Van Petten, C. (2008). Influence of cognitive control and mismatch on the N2 component of the ERP: a review. Psychophysiology 45, 152-170. doi: 10.1111/j.1469-8986.2007.00602.x

Franke, G. R., Huhmann, B. A., and Mothersbaugh, D. L. (2004). Information content and consumer readership of print ads: a comparison of search and experience products. J. Acad. Mark. Sci. 32, 20-31. doi: 10.1177/ 0092070303257856

Fu, H., Ma, H., Bian, J., Wang, C., Zhou, J., Ma, Q., et al. (2019). Don't trick me: an event-related potentials investigation of how price deception decreases consumer purchase intention. Neurosci. Lett. 713:134522. doi: 10.1016/j.neulet. 2019.134522

Goes, P. B., Lin, M. F., and Au Yeung, C.-M. (2014). Popularity effect in usergenerated content: evidence from online product reviews. Inform. Syst. Res. 25, 222-238. doi: 10.1287/isre.2013.0512

Ito, T. A., and Urland, G. R. (2003). Race and gender on the brain: electrocortical measures of attention to the race and gender of multiply categorizable individuals. J. Pers. Soc. Psychol. 85, 616-626. doi: 10.1037/0022-3514.85. 4.616

Ito, T. A., and Urland, G. R. (2005). The influence of processing objectives on the perception of faces: an ERP study of race and gender perception. Cogn. Affect. Behav. Neurosci. 5, 21-36. doi: 10.3758/cabn.5.1.21

Izuma, K., Saito, D. N., and Sadato, N. (2008). Processing of social and monetary rewards in the human striatum. Neuron 58, 284-294. doi: 10.1016/j.neuron. 2008.03.020

Jiménez, F. R., and Mendoza, N. A. (2013). Too popular to ignore: the influence of online reviews on purchase intentions of search and experience products. J. Interact. Mark. 27, 226-235. doi: 10.1016/j.intmar.2013. 04.004

Jin, J., Zhang, W., and Chen, M. (2017). How consumers are affected by product descriptions in online shopping: event-related potentials evidence of the attribute framing effect. Neurosci. Res. 125, 21-28. doi: 10.1016/j.neures.2017. 07.006

Kohls, G., Peltzer, J., Herpertz-Dahlmann, B., and Konrad, K. (2009). Differential effects of social and non-social reward on response inhibition in children and adolescents. Dev. Sci. 12, 614-625. doi: 10.1111/j.1467-7687.2009.00816.x

Lafky, J. (2014). Why do people rate? Theory and evidence on online ratings. Games Econ. Behav. 87, 554-570. doi: 10.1016/j.geb.2014.02.008

Lappas, T., Sabnis, G., and Valkanas, G. (2016). The impact of fake reviews on online visibility: a vulnerability assessment of the hotel industry. Inform. Syst. Res. 27, 940-961. doi: 10.1287/isre.2016.0674

Larson, M. J., Clayson, P. E., and Clawson, A. (2014). Making sense of all the conflict: a theoretical review and critique of conflict-related ERPs. Int. J. Psychophysiol. 93, 283-297. doi: 10.1016/j.ijpsycho.2014.06.007

Lea, S. E., Tarpy, R. M., and Webley, P. (2009). The Individual in Economy. A Survey of Economic Psychology. Cambridge: Cambridge University Press.

Lea, S. E., and Webley, P. (2006). Money as tool, money as drug: the biological psychology of a strong incentive. Behav. Brain Sci. 29, 161-209. doi: 10.1017/ S0140525X06009046

Lee, Y.-J., Hosanagar, K., and Tan, Y. (2015). Do I follow my friends or the crowd? Information cascades in online movie ratings. Manag. Sci. 61, 2241-2258. doi: $10.1287 / \mathrm{mnsc} .2014 .2082$

Li, C. (2018). Consumer behavior in switching between membership cards and mobile applications: the case of starbucks. Comput. Hum. Behav. 84, 171-184. doi: $10.1016 /$ j.chb.2017.12.042
Lin, M. H., Cross, S. N. N., Jones, W. J., and Childers, T. L. (2018). Applying eeg in consumer neuroscience. Eur. J. Mark. 52, 66-91. doi: 10.1108/EJM-12-20160805

Luca, M. (2011). Reviews, Reputation, and Revenue: The Case of Yelp.Com. Boston, MA: Harvard Business School.

Luck, S. J. (2005). “Ten simple rules for designing ERP experiments," in Event Related Potentials: A Methods Handbook, ed. T. C. Handy (Cambridge, MA: MIT Press), 17-32.

Martin, L. E., and Potts, G. F. (2004). Reward sensitivity in impulsivity. Neuroreport 15, 1519-1522. doi: 10.1097/01.wnr.0000132920.12990.b9

Maulisa, A. R., and Hijrah Hati, S. R. (2019). The anomaly of airline passenger behavioral intention: a comparison between low-cost and full-service airlines. ASEAN Mark. J. 2, 75-90. doi: 10.21002/amj.v10i2.10621

Moe, W. W., and Trusov, M. (2011). The value of social dynamics in online product ratings forums. J. Mark. Res. 48, 444-456. doi: 10.1509/jmkr.48. 3.444

Nieuwenhuis, S., Aston-Jones, G., and Cohen, J. D. (2005). Decision making, the p3, and the locus coeruleus-norepinephrine system. Psychol. Bull. 131, 510-532. doi: 10.1037/0033-2909.131.4.510

Polich, J., and Kok, A. (1995). Cognitive and biological determinants of P300: an integrative review. Biol. Psychol. 41, 103-146. doi: 10.1016/0301-0511(95) 05130-9

Potts, G. F., Martin, L. E., Burton, P., and Montague, P. R. (2006). When things are better or worse than expected: the medial frontal cortex and the allocation of processing resources. J. Cogn. Neurosci. 18, 1112-1119. doi: 10.1162/jocn.2006. 18.7.1112

Ridderinkhof, K. R., Ullsperger, M., Crone, E. A., and Nieuwenhuis, S. (2004). The role of the medial frontal cortex in cognitive control. Science 306, 443-447. doi: 10.1126/science.1100301

Schevernels, H., Krebs, R. M., Santens, P., Woldorff, M. G., and Boehler, C. N. (2014). Task preparation processes related to reward prediction precede those related to task-difficulty expectation. NeuroImage 84, 639-647. doi: 10.1016/j. neuroimage.2013.09.039

Shang, Q., Pei, G., and Jin, J. (2017). My friends have a word for it: event-related potentials evidence of how social risk inhibits purchase intention. Neurosci. Lett. 643, 70-75. doi: 10.1016/j.neulet.2017.02.023

Spreckelmeyer, K. N., Krach, S., Kohls, G., Rademacher, L., Irmak, A., Konrad, K., et al. (2009). Anticipation of monetary and social reward differently activates mesolimbic brain structures in men and women. Soc. Cogn. Affect. Neurosci. 4, 158-165. doi: 10.1093/scan/nsn051

Stavropoulos, K. K. M., and Carver, L. J. (2013). Reward sensitivity to faces versus objects in children: an ERP study. Soc. Cogn. Affect. Neurosci. 9, 1569-1575. doi: $10.1093 /$ scan/nst149

Sweller, J. (1988). Cognitive load during problem solving: effects on learning. Cogn. Sci. 12, 257-285. doi: 10.1016/0364-0213(88)90023-7

Telpaz, A., Webb, R., and Levy, D. J. (2015). Using eeg to predict consumers' future choices. J. Mark. Res. 52, 511-529. doi: 10.1509/jmr.13.0564

Veen, V. V., and Carter, C. S. (2002). The timing of action-monitoring processes in the anterior cingulate cortex. J. Cogn. Neurosci. 14, 593-602. doi: 10.1162/ 08989290260045837

Venkatraman, V., Dimoka, A., Pavlou, P. A., Vo, K., Hampton, W., Bollinger, B., et al. (2015). Predicting advertising success beyond traditional measures: new insights from neurophysiological methods and market response modeling. J. Mark. Res. 52, 436-452. doi: 10.1509/jmr.13.0593

Wang, C. C., Li, Y., Luo, X., Ma, Q. G., Fu, W. Z., and Fu, H. J. (2018). The effects of money on fake rating behavior in e-commerce: electrophysiological time course evidence from consumers. Front. Neurosci. 12:156. doi: 10.3389/fnins. 2018.00156

Wang, D., Liu, T., and Shi, J. (2017). Development of monetary and social reward processes. Sci. Rep. 7:11128. doi: 10.1038/s41598-017-11558-6

Wang, Q., Meng, L., Liu, M., Wang, Q., and Ma, Q. (2016). How do socialbased cues influence consumers' online purchase decisions? An event-related potential study. Electron. Commerce Res. 16, 1-26. doi: 10.1007/s10660-0159209-0

Warut, K., Karthik, K., and Hossein, G. (2018). Extrinsic versus intrinsic rewards for contributing reviews in an online platform. Inform. Syst. Res. 29, 871-892. doi: $10.1287 /$ isre.2017.0750 
Wu, H., Gui, D., Lin, W., Gu, R., Zhu, X., and Liu, X. (2016). The procrastinators want it now: behavioral and event-related potential evidence of the procrastination of intertemporal choices. Brain Cogn. 107, 16-23. doi: 10.1016/j.bandc.2016.06.005

Yang, T. T., Menon, V., Eliez, S., Blasey, C., White, C. D., Reid, A. J., et al. (2002). Amygdalar activation associated with positive and negative facial expressions. Neuroreport 13, 1737-1741. doi: 10.1097/00001756-20021007000009

Yeung, N., Botvinick, M. M., and Cohen, J. D. (2004). The neural basis of error detection: conflict monitoring and the error-related negativity. Psychol. Rev. 111, 931-959. doi: 10.1037/0033-295x.111.4.931

Yeung, N., and Sanfey, A. G. (2004). Independent coding of reward magnitude and valence in the human brain. J. Neurosci. 24, 6258-6264. doi: 10.1523/jneurosci. 4537-03.2004

Zhang, L. (2009). An exchange theory of money and self-esteem in decision making. Rev. Gen. Psychol. 13, 66-76. doi: 10.1037/a001 4225
Zhang, Y., Li, Q., Wang, Z., Liu, X., and Zheng, Y. (2017). Temporal dynamics of reward anticipation in the human brain. Biol. Psychol. 128, 89-97. doi: 10.1016/ j.biopsycho.2017.07.011

Zhou, X., Vohs, K. D., and Baumeister, R. F. (2009). The symbolic power of money: reminders of money alter social distress and physical pain. Psychol. Sci. 20, 700-706. doi: 10.1111/j.1467-9280.2009.02353.x

Conflict of Interest: The authors declare that the research was conducted in the absence of any commercial or financial relationships that could be construed as a potential conflict of interest.

Copyright (c) 2020 Wang, Fu, Jin, Shang, Luo and Zhang. This is an open-access article distributed under the terms of the Creative Commons Attribution License (CC BY). The use, distribution or reproduction in other forums is permitted, provided the original author(s) and the copyright owner(s) are credited and that the original publication in this journal is cited, in accordance with accepted academic practice. No use, distribution or reproduction is permitted which does not comply with these terms. 


\section{OPEN ACCESS}

Edited by:

Maria Pilar Martinez-Ruiz, University of Castilla-La Mancha,

Spain

Reviewed by:

Francisco Liebana-Cabanillas, University of Granada, Spain

Eleni Papaoikonomou,

University of Rovira i Virgili, Spain

*Correspondence:

Inma Rodríguez-Ardura

irodriguez@uoc.edu

Specialty section:

This article was submitted to

Organizational Psychology, a section of the journa

Frontiers in Psychology

Received: 25 March 2020

Accepted: 07 July 2020

Published: 07 August 2020

Citation:

Rodríguez-Ardura I and Meseguer-Artola A (2020) A

PLS-Neural Network Analysis of Motivational Orientations Leading

to Facebook Engagement and the Moderating Roles of Flow and Age. Front. Psychol. 11:1869.

doi: 10.3389/fpsyg.2020.01869

\section{A PLS-Neural Network Analysis of Motivational Orientations Leading to Facebook Engagement and the Moderating Roles of Flow and Age}

\author{
Inma Rodríguez-Ardura* and Antoni Meseguer-Artola \\ Department of Economics and Business, Open University of Catalonia, Barcelona, Spain
}

Despite engagement being a criterion for the success of initiatives on Facebook, there is a lack of conclusive evidence about its connections with the psychological and motivational orientations that lead one to use Facebook. Built upon the uses and gratifications theory, we develop an integrative and context-specific model that links engagement with enjoyment, self-presentation, and community belonging-identified as motivational orientations underlying Facebookers' behaviors. We also draw on current flow accounts and socioemotional selectivity theory to examine the potential moderating roles of both flow experiences and age differences. We validate the survey instrument and test the model on a sample of active Facebook users. Model testing and sensitive analysis is performed with a two-stage method that combines partial least squares (PLS) and artificial neural network analysis. The results provide strong support for the validity of the hypothesized causal, mediating and moderating relationships embodied in the model. The research also provides insights into practitioners seeking to enhance Facebookers' engagements and promote continued use of Facebook.

Keywords: engagement, Facebook, enjoyment, self-presentation, community belonging, flow, age

\section{INTRODUCTION}

Facebook is the world's biggest social networking service (SNS), both in terms of active users per month and geographical reach. Although there is the systemic and ongoing issue of misinformation, Facebook continues to reach high diffusion rates in the United States and European Union markets (Isaac, 2018), with skyrocketing growth in other regions around the world. As of March 31, 2020, Facebook had 2.6 billion monthly active users worldwide, which represents an increase of 105 million users from the previous quarter (Facebook, 2020).

For organizations and brands, engaging a large number of users through a brand's content and services on Facebook is considered to be one of their integrated marketing communication programs' most critical success factors (Boyd and Forbes Agency Council, 2018). Engagement manifests itself as positive affective feelings and motivationally directed behaviors (Hollebeek et al., 2016) through which an individual volitionally connects and contributes, directly or indirectly, to a community, brand, or organization (Pansari and Kumar, 2017). On Facebook, a user's engagement behaviors go beyond commercial exchanges and might consist of practices such as: providing creative feedback and assistance to other users in their personal social network; 
producing imaginative stories or content about a common interest, an event or a brand with whom the user identifies; fostering communication and interaction amongst fellow Facebookers; and willingly replying to calls, stories, or posts by other users.

From both a practical and theoretical point of view, understanding the motivational orientations that lead people to engage in Facebook is of great importance (Verhagen et al., 2015). Users' motivations give them reason and purpose to interact on Facebook. Many studies have primarily connected users' social participation on Facebook to two psychological motivational drivers: people's need for self-presentation and their need to belong (Seidman, 2013; van Dijck, 2013). Recent studies have highlighted a third pervasive motivational element that makes Facebook an appealing SNS for its users: the need for entertainment and intrinsic enjoyment (Rodríguez-Ardura and Meseguer-Artola, 2018).

However, very little is known about how these central motivational drivers contribute to engagement formation (Verhagen et al., 2015). Even though the concept of engagement has increasingly drawn scholarly attention in recent years (Pansari and Kumar, 2017), previous research's focus has been on the conceptual delimitation and measurement of engagement (Hollebeek et al., 2014; Baldus et al., 2015), taxonomies of engagement practices (Hollebeek et al., 2017; Eigenraam et al., 2018), the fit of the engagement concept with service-dominant logic and value co-creation frameworks (Jaakkola and Alexander, 2014; Hollebeek et al., 2016), and the contribution of engagement to business performance (Harmeling et al., 2017; Huang and Chen, 2018). Moreover, the handful of previous studies aimed at connecting the dots between motivation and engagement focus on a particular engagement object, such as a brand or a social venture (Hall-Phillips et al., 2016), as well as a specific context: brands' Facebook pages (Zheng et al., 2015; Huang and Chen, 2018). Overall, this highlights the importance of examining the motivational drivers of Facebook engagement for both commercial and non-commercial content, and of doing so by adopting an integrated approach, which will be robust to small changes within, and additions to, the Facebook landscape-such as the emergence of new features, brand page functionalities, or embedded games. In this paper, we adopt this perspective, and, through the uses and gratifications theory, our first goal is to examine the interplay of motivational pillars (i.e., enjoyment, self-presentation, and community belonging) with Facebook engagement.

A couple of previous studies have focused on flow experiences' contribution to engagement (Shin, 2018; Rodríguez-Ardura and Meseguer-Artola, 2019) but without adding motivations to the equation. Similarly, no previous study appears to have explained age's moderating effect on the multidimensional facets of engagement that lead one to patronize Facebook; and empirical tests in media usage have offered little and sometimes contradictory evidence about the way younger and older individuals create and process SNS content (e.g., Hayes et al., 2015; Manzi et al., 2018). However, on the basis of flow accounts and socioemotional selectivity theory, it is plausible to expect that some key psychological factors' contribution to enduring Facebook usage interacts with flow experiences and age differences. Accordingly, the second goal of this study is to determine the moderating effects of flow experiences and age.

In the present study, we develop an integrative model, new in the literature, about the dynamics of Facebook engagement. The originality of the model is threefold. First, it considers the cognitive, affective, and behavioral dimensions of engagement, and it shows, for the first time, how enjoyment, self-presentation, and community-belonging motivations trigger engagement. Second, it illustrates that flow moderates the effect of the enjoyment motivation on engagement and that age differences intensify the effect of engagement on the level of stickiness Facebook offers the individual. Third, we use a combined two-step partial least square (PLS)-neural network method to empirically test the model. This has allowed us not only to provide evidence about the causal, moderating, and mediating linear relationships triggering Facebook engagement and continuance, but also to test complex and non-linear relationships in the model.

\section{THEORETICAL BACKGROUND}

\section{User Engagement}

The emergence of service-dominant logic (Vargo and Lusch, 2016), which suggests that consumers interact with media, organizations, and brands to co-create value, has come accompanied by an integrated perspective of online media consumption. This perspective conceives engagement as central to the interplay between the individuals and the medium's, organization's or brand's value proposition online (Hollebeek et al., 2016). The concept of engagement is fundamental to the notion that SNS users are active participants and, sometimes, creative producers of mediated content (Lüders, 2008). This breaks with the traditional view of users as exogenous to the media, as passive recipients of mediated content and services (Bijmolt et al., 2010).

In the literature, a myriad of definitions and conceptualizations of engagement has been put forward, which overall presents engagement as a complex, multifaceted phenomenon. Some conceptualizations focus primarily on the individual's behavior, suggesting that engagement is a conative manifestation of the individual's satisfaction and his or her emotional closeness with a value proposition online (e.g., Junco, 2012; Jaakkola and Alexander, 2014). Under this view, engagement goes beyond a mere utilization decision and passive consumption (Harmeling et al., 2017) and translates into the individual's contribution to the medium's, organization's or brand's value proposition (Vivek et al., 2012). In contrast to this, there is a perspective that defends the notion of engagement as an internal drive that underlies an individual's communications and collaboration activities (Baldus et al., 2015; Rodríguez-Ardura and Meseguer-Artola, 2019). This inner drive is triggered by the time and effort that the user invests in interacting with the value proposition, and it might be so exciting that it can compel him or her to display affective and behavioral reactions (Brodie et al., 2013; Zheng et al., 2015). 
Added to this, a more integrated view has expanded the conceptualization of engagement and depicts it as a multidimensional, psychological mechanism (Brodie et al., 2011) that is built upon the user's interactive experiences and which embodies cognitive, affective, and behavioral facets (Harrigan et al., 2018; Ferreira et al., 2020). Since in this paper we aim to offer a more comprehensive understanding of engagement, we adopt this latter perspective and conceive engagement as a multidimensional construct, with cognitive (i.e., knowledge-related involvement), emotional (i.e., positive affective feelings), and conative (e.g., participation, socialization) core components that result from the interaction between the individual and a value proposition online. Furthermore, we regard engagement as a volitional, desired construct (Bowden et al., 2017)-insofar as individuals voluntarily choose to devote internal resources to interact with the value proposition-and as being conceptually connected to, but distinct from, other key psychological mechanisms online (Hollebeek et al., 2016; Rodríguez-Ardura and Meseguer-Artola, 2019), such as the immersive experience of flow.

Because engagement is brought about by the user's interactive experience with the value proposition, some confusion may arise between the concept of engagement and that of user experience. However, the experiences that users might have consist of subjective, highly immersive episodes that are not necessarily triggered by a motivational state or a particular interest (Brakus et al., 2015); instead, they help to process, give meaning to, and raise inner responses to the interplay between the user and the online value proposition (RodríguezArdura and Meseguer-Artola, 2019). By contrast, engagement is motivationally based (Eigenraam et al., 2018): users choose to form thoughts, express affective feelings, and adopt behaviors due to their "intrinsic worth" (Searle et al., 2014, 381). Moreover, unlike user experiences, engagement has a behavioral basis (van Doorn et al., 2010).

Consistent with our view of engagement as a subjective episode, engagement is increasingly considered as a mediating theoretical entity rather than a final outcome (Harrigan et al., 2017; Rodríguez-Ardura and Meseguer-Artola, 2019). From this perspective, engagement reflects a user's motivations and manifests in cognitive elaborations, positive affective feelings, and participation behaviors, which ultimately might conclude in iterative, continued usage (Eigenraam et al., 2018). So the transitional path, starting with a user's motivational forces and finishing with continued use, might comprise cognitive, affective, and behavioral engagement (Brodie et al., 2013). A number of researchers have considered the consequences of engagement, which include the criterion variables of positive behaviors such as a higher intention to engage in continued use (So et al., 2016; Harrigan et al., 2017; Huang and Chen, 2018).

\section{Uses and Gratifications Theory}

According to our integrated notion of engagement, engaged individuals are motivationally driven; they voluntarily invest personal resources in interactions with a value proposition (Hollebeek et al., 2016). It is precisely the uses and gratifications theory, a communication approach that examines consumer decisions in media consumption, that has the potential to explain why people deliberately perform certain behaviors in terms of their individual psychological motives.

The uses and gratifications theory presumes that people are active users of specific media channels who know their psychological needs and purposively utilize these media channels to their benefit (Katz et al., 1973; McQuail, 2012). Through the lens of this perspective, people's actions regarding a medium or content are explained on the basis of the benefits sought (Luo and Remus, 2014), so that the mechanisms that direct people's behavior relate to the potential benefits of using such a medium or content. This reasoning is further consistent with goal-related theoretical frameworks like the goal-setting theory (Locke and Latham, 2002), which posits that an individual's conscious goals impel his or her subsequent actions. Similarly, Malthouse et al. (2016) built a goal-based model of user-generated online content that suggested that potential benefits operate as personal goals, the influence of which is contingent upon the active thinking they prompt. Hence, we propose that personal motivations related to Facebook usage influence engagement with Facebook.

To provide a better understanding of the diversity of psychological motivations underlying media usage, the uses and gratifications theory has summarized them in four broad categories (McQuail, 1994): entertainment-related motivations, which hedonically direct people to get intrinsic pleasure or enjoyment (Luo and Remus, 2014; Li et al., 2015); identityrelated motivations, which help to express personal values and strengthen one's self-concept (Mehdizadeh, 2010; Manzi et al., 2018); social-related motivations, which facilitate interpersonal interactions, companionship, and a sense of belonging ( $\mathrm{Wu}$ et al., 2010; Sheldon and Bryant, 2016); and learning-related motivations, which drive individuals to discover, elaborate, and build new knowledge (Malthouse et al., 2016).

The interest drawn by SNSs and other social media (Meng et al., 2017) has allowed the uses and gratifications paradigm to continue to flourish (Quan-Haase and Young, 2014; Verhagen et al., 2015). A few studies into Facebook have shown the appropriateness of this theoretical framework and its classification of motivational drivers, except in regard to learning-related motivations (Smock et al., 2011; Li et al., 2015). As suggested by Sin (2016), SNSs like Facebook are not primarily used for knowledge acquisition purposes, but the rest of the motivational forces proposed by the uses and gratifications paradigm might come into play.

This is in sync with many studies on Facebook that have mainly related the nature of a user's participation to the need for self-presentation and the need to belong to a community (e.g., Seidman, 2013; van Dijck, 2013; Casale and Fioravanti, 2018), as well as recent studies that have highlighted a third pervasive motivational element: the need for entertainment or intrinsic enjoyment (Hung et al., 2016; Rodríguez-Ardura and Meseguer-Artola, 2018). The motivation toward self-presentation is conceived as an inner factor that leads the user to enhance their self-concept and make a good impression on others (Krasnova et al., 2010), while the motivation toward community belonging leads the user to feel attached to other people who are important to him or her and form interpersonal 
bonds (Baumeister and Leary, 1995). Through storytelling and narrative self-presentations, Facebookers compound and manage standardized persona displays (van Dijck, 2013); via affordances that facilitate connectedness (e.g., groups, friending, liking, following, messaging), they foster interpersonal relationships and social acceptance amongst fellow users (Nabi et al., 2013). In addition, Facebookers entertain and have fun, not only with the pure-game resources included in the platform (Lai and Yang, 2016) but also with the use of self-presentation and social interaction functionalities in a humorous, amusing, and waggish fashion (Lewin-Jones, 2015), with memes, gags, and funny or ironic videos of celebrities and politicians shared in the news feed and with bouncy dialogs and jokes about the content at hand (Lambert, 2013).

We included these three motivational pillars (need for enjoyment, need for self-presentation, and need for community belonging) in our model based on two considerations. First, the selected potential motivations correspond to the generic categories identified in uses, and gratifications studies are supported by literature on Facebookers' behavior and have been empirically tested. This will facilitate the soundness of the motivational forces under study and give our results a broader perspective. Second, we limited the selection of motivational elements to those discussed and validated as core motivational drivers in the literature. This will allow us to ensure that the structure of our model is both comprehensive and manageable.

\section{Flow Under Study}

Of the diverse theoretical entities that put interactivity between the user and the value proposition at the core, flow seems to be the closest psychological mechanism to what is believed to be the "quintessence" of a user's immersive experience (Rodríguez-Ardura and Meseguer-Artola, 2016, 508). From a user standpoint, flow episodes are exceptionally enjoyable and have intrinsic hedonic motivational drivers (Csikszentmihalyi, 1975a). This is because, for a user to experience a flow episode, he or she must be deeply engrossed in the activity being performed, and the level of satisfaction generated by such an activity is so high that it turns out to be an end in and of itself (Csikszentmihalyi, 2008). Moreover, when users go through immersive episodes of flow, they are so absorbed by the activity at hand that they lose sight of their immediate physical surroundings and track of time (Fang et al., 2013; Pelet et al., 2017).

Our decision to include flow in our model is founded on the notion that flow is particularly applicable to the realm of Facebook experiences (Kaur et al., 2016; Rodríguez-Ardura and Meseguer-Artola, 2019) and on the consensus that flow leads to satisfy the need for enjoyment (Sherry, 2004; Fang et al., 2013)-so it is a relevant component of the nomological network of engagement (Pagani and Mirabello, 2011; Shin, 2018). Flow theory offers an explanation of how and why users subjectively experience a sense of intrinsically motivating enjoyment when they involve themselves in immersive online activities and spend a long time with entertaining new media content (Weber et al., 2009). We therefore maintain that flow episodes are particularly relevant for SNSs like Facebook due to its users' interest in fulfilling intrinsic hedonic motivations (Hung et al., 2016; Rodríguez-Ardura and Meseguer-Artola, 2018), giving room to gratifications that might be described as enjoyment (Lin and Lu, 2011; Reinecke et al., 2014).

\section{The Role of Age in Continuance Intention}

Previous studies have observed age-related differences in the effects of emotionally valenced experiential stimuli when making decisions about time use and activities to be involved in (for a meta-analysis see Reed et al., 2014). This age-by-valence interaction translates into a disproportionate preference among older adults to take into consideration and process positive over negative experiential information.

Socioemotional selectivity theory (Carstensen, 2006, 2018), a lifespan theory of behavioral intentions, offers an explanation of this positivity effect among older adults. The theory posits that, with age, people are increasingly aware of the finitude of their lives, so as they grow older they adopt emotionregulation strategies that guide them to prioritize emotionally gratifying activities and relationships (Mather and Carstensen, 2005; Martins et al., 2018), including online (Chang et al., 2015). By contrast, youngsters perceive longer and more nebulous time horizons, so they do not feel compelled to set aside activities, regardless of their valence, if they might provide valuable resources in the future (Chang et al., 2015).

Because we understand engagement as a positively valenced multidimensional mechanism (Hollebeek et al., 2014, 2016), we apply tenets from socioemotional selectivity theory to explain the part age-related differences play in users' decisions to continue spending time and cognitive efforts on Facebook.

\section{RESEARCH MODEL AND HYPOTHESES}

Figure 1 displays our conceptual model. In line with our first research goal and according to the uses and gratifications theory and existing literature on Facebook, three selected motivational forces (i.e., enjoyment, self-presentation, and community belonging) are modeled as predictors of Facebook engagement. In turn, engagement is conceived as a mediating psychological mechanism that facilitates continued use. In sync with our second research goal, and supported by accounts on flow, flow is expected to have a moderating role in engagement formation. Also, through socioemotional selectivity theory, age is considered to be a moderating variable of the engagementcontinued use pathway. In the remainder of this section, we delineate the constructs in the model and justify the hypothesized relationships between them.

\section{Motivational Drivers Leading to Engagement}

Consistent with the uses and gratifications theory (see QuanHaase and Young, 2014), people who use Facebook on an ongoing basis are motivated-at least to some degree-by the enjoyment associated with the interactions within this SNS (Błachnio et al., 2016; Rodríguez-Ardura and Meseguer-Artola, 2018). In the case of Facebookers, enjoyment motivation refers to their drive for 


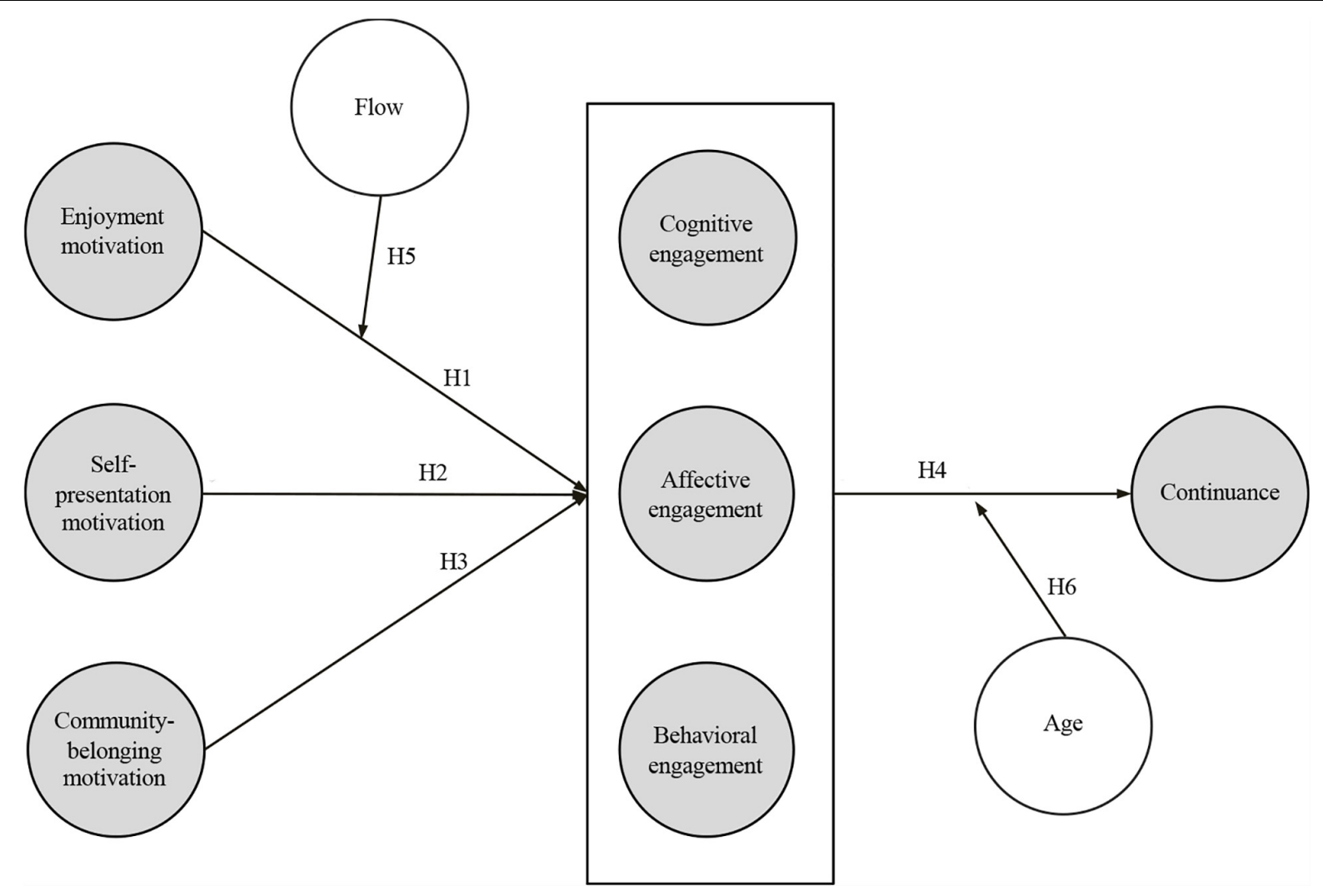

FIGURE 1 | Theoretical backbone of engagement.

the playfulness, pleasure, or intrinsic fun derived from interacting online with people, games, or entertaining content (Malik et al., 2015; Hung et al., 2016).

Overall, Facebook cannot merely be characterized as a platform for social networking because it offers a wealth of entertainment (Yang and Lin, 2014), which means it has a strong potential to provide immediate enjoyment gratification (Reinecke et al., 2014; Luqman et al., 2017). These enjoyment rewards are even more likely to arise when content is produced by peer Facebookers, encourages the user's mental imagery or sensory experiences, and appeals to user interactions (Sashittal et al., 2012; Yang and Lin, 2014), as well as when the Facebooker engrosses him- or herself in embedded games (Yang and Lin, 2014) or makes use of the co-creation or personalization functionalities at hand (Hung et al., 2016). The characteristics of the enjoyment benefits and the recreational behaviors relate to the features of engagement (Pöyry et al., 2013). Indeed, there is evidence about the contribution of perceived enjoyment to triggering engagement-either operationalized as mental involvement (Rodríguez-Ardura and Meseguer-Artola, 2018), as browsing and participation behavioral practices (Pöyry et al., 2013), or as knowledge sharing (Moghavvemi et al., 2017)-on Facebook. In light of these arguments, we propose the following hypotheses:

H1: Enjoyment motivation has a positive effect on engagement.
Self-presentation motivation-fundamental to the individual's interpersonal, creative expression of thoughts, emotions, and experiences and the development of a sense of self (Chaudoir and Fisher, 2011)-is regarded as a major motivation for hosting a personal page on Facebook (Seidman, 2013; Błachnio et al., 2016). Self-presentation motivation has been related to the Facebookers' interests in drawing attention and gaining a certain reputation within their personal social networks (Seidman, 2014). On Facebook, self-presentation translates into the construction of one's own tangible identity as well as a strategic endeavor to prompt desired impressions of oneself among an intended Facebooker audience (Mimoun and Ammar, 2013; Błachnio et al., 2016).

Facebookers who aim to fulfill their needs for self-presentation are likely to convey important aspects of their selves within their digital portraits and make themselves noticeable through their Facebook contributions (van Dijck, 2013; Seidman, 2014). There is evidence suggesting that, thanks to Facebook functionalities for self-expression and self-promotion (like personal profiles crafted as narrative biographies, and status updates and posts involving cultural events, brands, causes, and trends with semiotic potential), users shape their persona portraits and establish associations with external elements that are consistent with their own self-identity (Seidman, 2013; Manzi et al., 2018). On the basis of the uses and gratifications theory, we thus argue that Facebookers who seek to have their 
self-presentation needs satisfied will utilize this SNS to the extent that they become engaged.

H2: Self-presentation motivation has a positive
effect on engagement.

There is a consensus among many researchers, which states that the intrinsic motivation of community belonging is a core driver of Facebook use (e.g., Ha et al., 2015; Casale and Fioravanti, 2018). Sense of community belonging is driven by the human need for interpersonal attachment (Baumeister and Leary, 1995); it helps to explain relatedness functioning (Zhao et al., 2012) and might be fostered in online environments (Zhao et al., 2012; Hoffman et al., 2017). On SNSs such as Facebook, a sense of community belonging refers to the feeling of attachment, affiliation, or identification with the other members of a personal social network or group.

When Facebookers feel a certain sense of community belonging, they might be more willing to care about other people in their social network (Burke and Kraut, 2016) and interact with them (Zhao et al., 2012)-either by creating content (or communicating) about topics that matter to them, being a reliable interlocutor, or giving (or taking) emotional support (Seo et al., 2016; Liu et al., 2018). This interpersonal connectivity encourages bonding with members of the personal social network (Oh et al., 2014; Yang and Lin, 2014) and, therefore, it enhances the social and affectual reward that Facebookers perceive (Marbach et al., 2016), which in turn boosts their psychological engagement (Lee et al., 2011; Marbach et al., 2016). Accordingly, the motivational mechanism that leads one to feel emotionally close and connected to others is expected to produce relatedness gratifications and thus activate engagement.

\section{H3: Community-belonging motivation has a positive effect on engagement.}

Because we adopt an integrated approach, we conceptualize engagement as a motivated (Eigenraam et al., 2018) and positively valenced (Schamari and Schaefers, 2015; Hollebeek et al., 2016) psychological state resulting from users' interactions (Hollebeek et al., 2016; Eigenraam et al., 2018) -often social in nature (Hollebeek et al., 2016; Eigenraam et al., 2018). However, we also give credit to the multidimensional quality of engagement, which reflects the cognitive, affective, and behavioral nature of the efforts Facebookers invest in their interactions within this SNS (Bowden et al., 2017; Harrigan et al., 2018). This multidimensional understanding of engagement gives relevance to Mollen and Wilson's (2010), Brodie et al.'s (2013) views, looking beyond engagement as a mere state of mental involvement-or interest that facilitates the use of cognitive capabilities-and an emotional attachment to see it as encompassing actual behavioral connections within, or related to, an SNS like Facebook (Dessart et al., 2016; Harrigan et al., 2018). Accordingly, our subsequent operationalization of engagement will portray it as a superordinate construct that subsumes users' cognitive, affective, and conative ways of becoming mentally active on, energized by, or connected with Facebook.

\section{Engagement Leading to Continuance}

As indicated above, engagement is a psychological entity that may mediate the effects of an individual's motivational drivers to use Facebook on his or her willingness to use this SNS longterm (Huang and Chen, 2018). In fact, loyalty to Facebook has been seen as a higher-level outcome of users' engagement with Facebook (Huang and Chen, 2018; Rodríguez-Ardura and Meseguer-Artola, 2019).

One rationale that helps to explain the impact of engagement on continued Facebook use is social exchange theory (Homans, 1958; Blau, 2009), which holds that people become involved in social exchanges based on their perceptions of such exchanges' worth (Homans, 1974). In line with this theoretical framework, and because engagement has a positive value for the Facebooker (Verleye et al., 2014), engagement potentially drives the individual's decision to maximize his or her reward and repeat the interactive dynamics that created such a positive outcome (Homans, 1974), leading them, therefore, to continue their previous interactive use of Facebook. Put differently, engagement on Facebook relates to how Facebook's value proposition is relevant for the user and thus becomes an underlying core pathway to the creation of lasting bonds with this SNS (Rodríguez-Ardura and Meseguer-Artola, 2019; Kaur et al., 2020). Based on all of the above, the position is that higher levels of engagement with Facebook will increase a Facebooker's likelihood of continuing to use Facebook.

H4: Engagement has a positive effect on willingness to continue.

\section{Flow}

The sense that consuming novel content, which challenges the user's imagination, is an enjoyable and intrinsically rewarding activity is central to flow (Sherry, 2004; Baumann et al., 2016). Flow is understood to be an intrinsically enjoyable peak experience that is plunged into by users who are so deeply immersed in some particular activity online that they lose their sense of time (Csikszentmihalyi et al., 2005; Hoffman and Novak, 2009). Enjoyment, as accomplished in flow, is an "autotelic" and intrinsically rewarding experience (Asakawa, 2010), characterized by the loss of self-consciousness and a distortion of temporal orientation (Hardie-Bick and Bonner, 2016; Pelet et al., 2017). It is not surprising that an SNS like Facebook is a particularly strong enabler of the conditions that elicit flow episodes (Weber et al., 2009): a profound absorption in the events and actions happening online (Lai and Yang, 2016) and a distortion of the passage of time (Kwak et al., 2014).

Subjective experiences of flow might influence the levels of thoughts, attitudes, and conative elements related to engagement. Flow has been found to have a relevant effect on enduring involvement (McGinnis et al., 2008), participatory behavior (Pöyry et al., 2013; Chang, 2015), and further action (Kim et al., 2013; Rodríguez-Ardura and Meseguer-Artola, 2017). Seminal descriptions of flow episodes (Csikszentmihalyi, 1975b; Hoffman and Novak, 1996) show how flow is accompanied by feelings that we can relate to engagement. This is because the characteristic state of mind of a user in flow is that of an 
intense involvement and deep concentration on the activity they are performing online at the present moment. The activities capable of raising flow are challenging or intrinsically interesting (Rodríguez-Sánchez et al., 2011), so they require from the user a deep and focused concentration on relevant stimuli, and do not allow the individual to devote psychic energy to distractions (Rodríguez-Sánchez et al., 2011; Hamari et al., 2016). Hence, from a flow theory perspective, flow is a source for mental activation, meaningful accomplishment, and related emotions by means of stimulating activities that require high attention and engage - not only cognitively but also affectively and behaviorally (Hamari et al., 2016).

Ranaweera et al. (2005), Chang et al. (2014), Alcantara-Pilar et al. (2015) observed that, when users become wrapped up in their enjoyment of their online immersive experiences, these experiences moderate the path toward behavioral commitment. Similarly, engagement in a serious game has been reported to be moderated by the user's experience in and of itself (DeaterDeckard et al., 2014). This is because external stimuli might alter the impact of an individual's expectations (Chang et al., 2014). So, in the focal context of Facebook, the effect of the hedonic expectation of enjoyment might be reinforced with the actual occurrence of flow episodes. Accordingly, an intense flow experience might encourage the Facebooker to express his or her need for enjoyment as a high degree of willingness to engage. Conversely, for the user who seeks enjoyment yet finds that Facebook does not elicit flow, flow might interact negatively with this need for enjoyment.

H5: The positive effect of need for enjoyment and engagement is moderated by flow.

\section{Age Differences}

Although psychological motivations to use Facebook do not seem to vary significantly across generations (Manzi et al., 2018), it has been found that, compared to younger Facebookers, older cohorts have less friends on Facebook (McAndrew and Jeong, 2012; Chang et al., 2015), are involved in a narrower range of Facebook activities (Mo et al., 2018) and experience less negative emotions than do younger Facebookers (Hayes et al., 2015; Settanni and Marengo, 2015). Older Facebookers are also less emotionally impacted by this SNS than their younger counterparts (Hayes et al., 2015), so they show a higher degree of emotional stability than younger Facebookers (Mo et al., 2018). Parallel to this, it has been suggested that age differences have a moderating role in a user's decision to continue using online games (Li et al., 2015; Jang et al., 2018).

However, to the best of the authors' knowledge, no previous study has explored whether age-related differences are a relevant element in explaining a positive association between engagement and people's intention to continue using an SNS such as Facebook. Based on the tenets of socioemotional selectivity theory (Reed et al., 2014; Chang et al., 2015), this potential moderating role implies that, unlike younger Facebookers, older users see their life span as being shorter, so they are more inclined to choose to be involved in online activities and relationships that generate positive feelings. In other words, they might emphasize emotional well-being in the present moment and center their Facebook interactions on pleasant content, activities, and social connections that offer meaningful and immediate emotional satisfaction (Sinclair and Grieve, 2017).

This preference for positive over negative external stimuli manifests at the behavioral level (Swirsky and Spaniol, 2019)-so older Facebookers might tend to avoid negative information and look for, and choose to be exposed to, content and activities that help them to keep a positive mood. Accordingly, they will attempt to optimize engagement's positive-valence mechanisms by implementing continuance decisions that enhance the possibility of experiencing engagement again. Therefore, we hypothesize that age strengthens the causation between engagement and continuance intention.

H6: Age has a reinforcing effect on the relationship between engagement and continuance.

\section{RESEARCH METHODOLOGY}

\section{Participants}

To collect the empirical data, an online survey was conducted on Facebook in Spain. Participant Facebookers were recruited via snowball sampling, which is a relatively high-quality method of recruitment when no list of members of the sample frame exists, and therefore it is not possible to use a probability sampling (Kosinski et al., 2015). Also, an SNS like Facebook is suited to the study of people's experiences in this same setting (Reis and Gosling, 2010), especially when they might be related to the communication dynamics in social networks themselves (Landers and Behrend, 2015).

Participation in, and referrals to, the survey were not financially rewarded, so respondents participated out of interest and invited Facebookers with who they shared social connections. This has been related to a higher willingness to join the survey, more honest responses and yielding data of higher quality (Baltar and Brunet, 2012; Kosinski et al., 2015). In a first wave, the online questionnaires were only distributed among members of an ad hoc sample. However, in the following waves, participants used chain referral to promote the survey and recruit new respondents. Therefore, the sampling developed through "semi-random" recruitment (Baltar and Brunet, 2012, 70). To boost the likelihood that the subsequent waves in the snowballing process would reach diverse segments within the same sample frame (Johnston and Sabin, 2010; Morgan, 2012), the starting pool of participants was diverse.

A total of 1,285 people participated in the survey, of which 878 were removed after screening and checking for response uniqueness, questionnaire completeness, and elegibility criteria (i.e., being a monthly active Facebook user with a minimum age of 18), and also by examining the existence of insufficient effort in responding and careless response patterns (Desimone et al., 2015; Godinho et al., 2016). The size of the final sample (407) was valid for the subsequent PLS analysis since it considerably exceeded 
the product of 10 times the largest number of paths pointing to a particular endogenous construct in the model (Barclay et al., 1995) - which was $50(10 \times 5)$.

To discard non-coverage and non-response biases and verify the representativeness of the final sample, we confirmed that the differences between the demographic features of the sample and those reported for the Spanish target population were minor and non-significant. As seen in Table 1, the female/male ratio and the age structure in the sample were similar to those of the population. Furthermore, the $t$-test (in the case of gender, $p$-Value $=0.19$ ) and the chi-squared test (in the case of the age structure, $p$-Value $=0.11$ ) did not reveal any statistically significant differences. In addition to this, we used the multigroup comparison technique (Sarstedt et al., 2011) to check that gender did not have an interaction effect in the main model.

\section{Measures}

Since Facebookers' motivations, engagement, and flow episodes reflect phenomenal experiences or psychological mechanisms that are not observable, we assessed these constructs with self-report scales (Sigerson and Cheng, 2018)-all validated by previous studies (see Table 2). To measure enjoyment motivation, we used Ghani and Deshpande's (1994) scale. We adapted Schouten et al.'s (2007) online self-disclosure scale, partially based on Miller et al.'s (1983), to capture selfpresentation motivation. A scale employed by Sánchez-Franco et al. (2015) to operationalize identification with the Facebook community was used to depict users' community-belonging motivation. In line with Hollebeek et al. (2014), engagement was a second-order construct, and its three components were first-order factors measured by their respective indicators: the cognitive importance subscale; the affection subscale; and the community activation subscale, as developed by McQuarrie and Munson (1992); the affection subscale of the engagement scale built by Hollebeek et al. (2014); and the community Koh and Kim's (2004) activation scale. The three items we used to measure continuance intention were originally operationalized by Moon and Kim (2001); and the other three that captured flow episodes were adapted from Novak et al. (2000). The variables were all reflective in nature and were measured with multiitem scales-using a seven-point rating scale for each item. Self-presentation motivation was measured on a scale anchored between "I do not say anything about this" and "I say everything about this"; and an item of flow (F3) was measured on a scale ranging from "never" to "always." All remaining items

TABLE 1 | Descriptive statistics of the sample.

\begin{tabular}{llcc}
\hline Variables & & Population (\%) & Sample (\%) \\
\hline Gender & Female & 53.0 & 56.3 \\
& Male & 47.0 & 43.7 \\
Age & $18-39$ & 52.0 & 50.3 \\
& $40-64$ & 42.0 & 44.8 \\
& $\geq 65$ & 6.0 & 4.9
\end{tabular}

*Source: The Social Media Family (2018). were measured with a Likert-type scale ranging from "strongly disagree" to "strongly agree."

The instrument measurement was made available in the three languages most used on Facebook Spain (Owloo, 2015). The original scale items were translated through a back-translation procedure (Brislin, 1986), and pre-tested for content validity (Haynes et al., 1995). Ten scholars, all familiar with the research issue and the goals of the measurement instrument, participated in the pre-test. In addition, a pilot test was conducted with 60 university students to detect translation biases. Results of a multivariate analysis of variance showed that there were no significant differences between the constructs in the model due to the language used by the pilot participants.

\section{Prevention and Assessment of Common Method Variance}

Validity of the survey instrument might be compromised by potential systematic method variance, which might affect item validities, reliabilities, and covariations between observed variables (MacKenzie and Podsakoff, 2012; Rodríguez-Ardura and Meseguer-Artola, 2020). This potential issue is stronger when all the constructs have been measured with self-report scales and data has been gathered from the same sample and at the same time-which is our case.

To prevent the appearance of common method bias, in the design of the measurement instrument we adopted the procedural measures suggested by Podsakoff et al. (2003). For example, we adapted the items' wording to the focal context of Facebook (Table 2) and ensured the respondents' anonymities and the confidentiality of their answers.

Furthermore, we applied two post hoc statistical techniques to discard any problematic common method variance interfering in data analysis: Harman's single-factor test and the correlation matrix procedure. First, in the unrotated factor analysis, there is no single factor that accounts for the majority of the covariance among the measures (a minimum of three factors explains more than the $50 \%$ of the variance). Second, all the pairwise correlations between constructs are clearly below the recommended maximum value of 0.90 (Table 6).

\section{PLS-Neural Network Method}

We assessed the predictive power of the conceptual model, along with the hypothesized relationships between constructs, using a multianalytical method. This approach integrates neural network analysis into the methodological framework of the variancebased structural equation modeling (SEM) method, known as PLS modeling (see Qin and McAvoy, 1992).

PLS is considered to be an effective, powerful technique for estimating both the relationships among the (latent) constructs in a proposed model and the connections between the constructs and the measurement scale items. Unlike the covariance-based SEM (CB-SEM) techniques, PLS neither requires big sample sizes nor that the data has a multivariate normal distribution (Reinartz et al., 2009). Furthermore, it is particularly well suited to testing complex models (Hair et al., 2017a), with higher-order latent structures and many scale items, and, combined with the product indicator approach, it is highly accurate in assessing interaction 
TABLE 2 | Measurement scales.

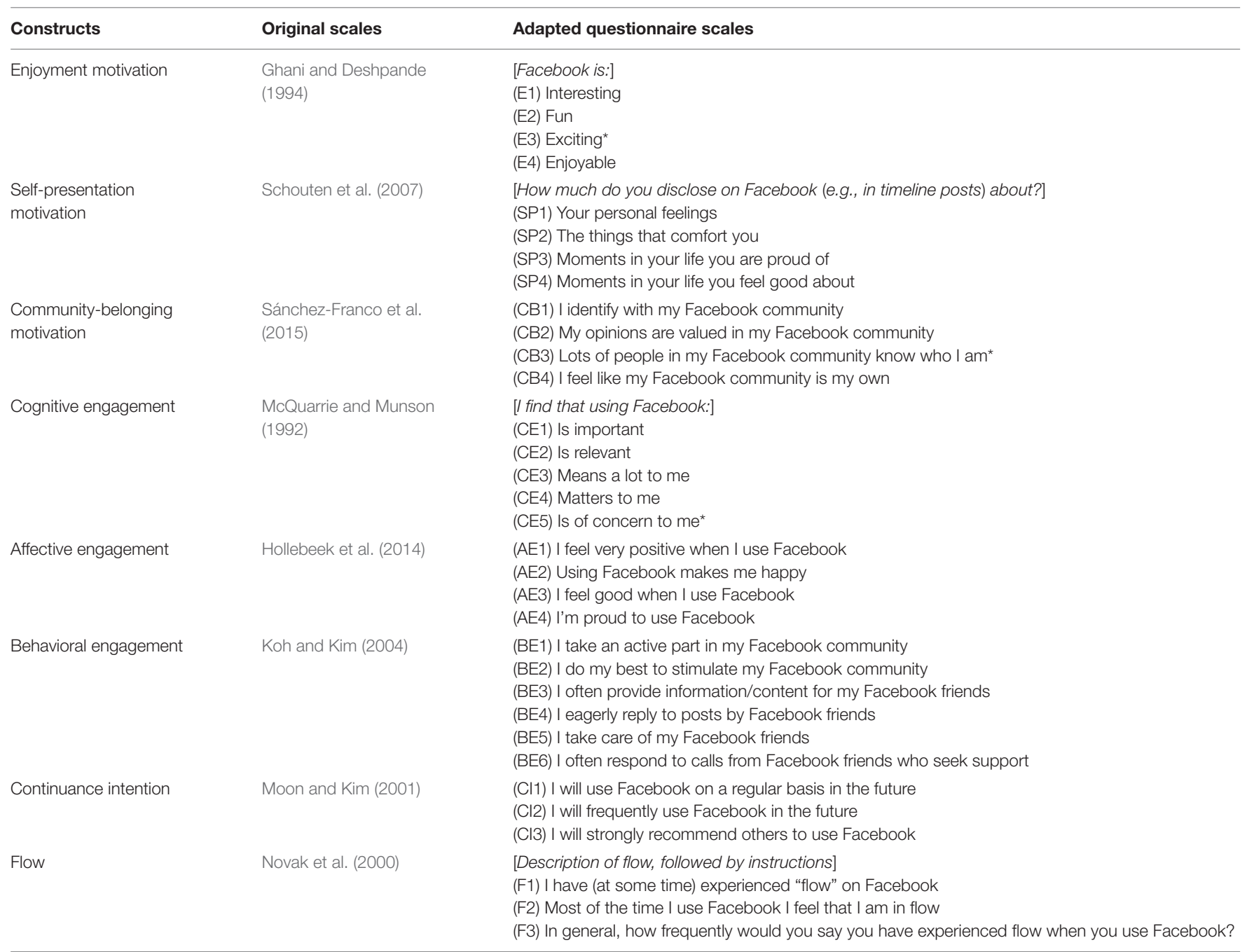

${ }^{*}$ Removed after reliability analysis.

effects (Henseler and Chin, 2010). However, all SEM techniques, PLS included, presume the linearity of all causal paths (Qin and McAvoy, 1992), which might oversimplify the analysis of users' behaviors (Leong et al., 2015).

On the other hand, the artificial intelligence method of neural network analysis is suitable for examining both linear and non-linear relationships between variables with high predictive precision (Leong et al., 2013) and does not require the data to meet key underlying assumptions of normality, homoscedasticity, linearity, and non-multicollinearity (Tan et al., 2014). Nevertheless, neural network analysis is affected by overfitting problems-that is, the network correctly recognizes existing patterns but has low accuracy with new data sets (Chong, 2013; Ahani et al., 2017)-and it does not allow causal paths between variables to be statistically assessed (Chan and Chong, 2012; Chong, 2013).

Because of the complementary advantages of PLS and neural network analysis, we combined both methods in a two-step process. First, we used the PLS framework to assess the measurement model and the statistical significance of the hypothesized (causal and moderating) relationships within the proposed structural model. Second, we extended the PLS modeling to a non-linear setting and used a neural network analysis to determine the predictive capacity of the input factors and their relative importance.

\section{RESULTS}

\section{Measurement Model}

To assess the measurement model, we considered internal consistency reliability, individual item reliability, the convergent validity, and the discriminant validity. Internal consistency reliability is satisfactory (see Table 3) given that all Cronbach's $\alpha$ values and Dillon-Goldstein's $\rho$ values are above the minimum threshold of 0.70 , the first eigenvalues are all greater than 1 , and all second eigenvalues are below 1.

In the initial exploratory analysis, the two items that did not meet individual item reliability criteria (E3, CE5) were removed. The loadings of the remaining items on their corresponding 
TABLE 3 | Internal consistency reliability.

\begin{tabular}{|c|c|c|c|c|c|}
\hline & Num. of items & Cronbach's $\alpha$ & Dillon-Goldstein's $\rho$ & First eigenvalue & Second eigenvalue \\
\hline Enjoyment motivation & 3 & 0.855 & 0.912 & 2.330 & 0.397 \\
\hline Self-presentation motivation & 4 & 0.852 & 0.901 & 2.780 & 0.611 \\
\hline Community-belonging motivation & 3 & 0.824 & 0.895 & 2.220 & 0.503 \\
\hline Cognitive engagement & 4 & 0.887 & 0.922 & 2.990 & 0.472 \\
\hline Affective engagement & 4 & 0.907 & 0.935 & 3.140 & 0.461 \\
\hline Behavioral engagement & 6 & 0.891 & 0.917 & 3.900 & 0.884 \\
\hline Continuance intention & 3 & 0.859 & 0.915 & 2.350 & 0.465 \\
\hline Flow & 3 & 0.895 & 0.935 & 2.480 & 0.289 \\
\hline
\end{tabular}

TABLE 4 | Individual item reliability and convergent validity.

\begin{tabular}{|c|c|c|c|c|}
\hline & AVE & Weight & Loading & Communality \\
\hline Enjoyment motivation & 0.775 & & & \\
\hline E1 & & 0.371 & 0.867 & 0.751 \\
\hline E2 & & 0.397 & 0.908 & 0.824 \\
\hline E4 & & 0.367 & 0.867 & 0.751 \\
\hline $\begin{array}{l}\text { Self-presentation } \\
\text { motivation }\end{array}$ & 0.694 & & & \\
\hline SP1 & & 0.302 & 0.789 & 0.622 \\
\hline SP2 & & 0.307 & 0.809 & 0.655 \\
\hline SP3 & & 0.310 & 0.881 & 0.776 \\
\hline SP4 & & 0.282 & 0.851 & 0.724 \\
\hline $\begin{array}{l}\text { Community-belonging } \\
\text { motivation }\end{array}$ & 0.741 & & & \\
\hline CB1 & & 0.405 & 0.896 & 0.803 \\
\hline CB2 & & 0.405 & 0.885 & 0.784 \\
\hline CB4 & & 0.350 & 0.797 & 0.635 \\
\hline Cognitive engagement & 0.746 & & & \\
\hline CE1 & & 0.271 & 0.851 & 0.725 \\
\hline CE2 & & 0.271 & 0.837 & 0.700 \\
\hline CE3 & & 0.307 & 0.884 & 0.782 \\
\hline CE4 & & 0.307 & 0.883 & 0.779 \\
\hline Affective engagement & 0.784 & & & \\
\hline AE1 & & 0.275 & 0.889 & 0.790 \\
\hline AE2 & & 0.301 & 0.928 & 0.861 \\
\hline AE3 & & 0.304 & 0.922 & 0.850 \\
\hline AE4 & & 0.247 & 0.796 & 0.634 \\
\hline Behavioral engagement & 0.650 & & & \\
\hline BE1 & & 0.223 & 0.843 & 0.710 \\
\hline BE2 & & 0.202 & 0.799 & 0.638 \\
\hline BE3 & & 0.197 & 0.807 & 0.651 \\
\hline BE4 & & 0.208 & 0.842 & 0.708 \\
\hline BE5 & & 0.217 & 0.820 & 0.672 \\
\hline BE6 & & 0.193 & 0.721 & 0.519 \\
\hline Continuance intention & 0.782 & & & \\
\hline $\mathrm{Cl} 1$ & & 0.382 & 0.916 & 0.839 \\
\hline $\mathrm{Cl} 2$ & & 0.370 & 0.902 & 0.813 \\
\hline $\mathrm{Cl} 3$ & & 0.380 & 0.832 & 0.693 \\
\hline Flow & 0.826 & & & \\
\hline $\mathrm{F} 1$ & & 0.328 & 0.888 & 0.788 \\
\hline $\mathrm{F} 2$ & & 0.376 & 0.914 & 0.836 \\
\hline F3 & & 0.395 & 0.924 & 0.854 \\
\hline
\end{tabular}

constructs are all higher than 0.70 (Table 4), so all communalities are greater than 0.50 . In most cases, the constructs retain more than $70 \%$ of the item's variability. In addition, the convergent validity of the measures is satisfactory since the average variance extracted (AVE) of each construct is clearly above the minimum recommended 0.50 cut-off.

To assess the discriminant validity of the measurement model, we used the cross loadings of the items and Fornell and Larcker's (1981) criterion. First, all item loadings on their respective constructs are higher than their loadings on the rest of the constructs (Table 5). Second, the AVE square root value of each latent construct is greater than its correlations with other constructs (Table 6). Third, we evaluated the discriminant validity with the heterotrait-monotrait ratio (HTMT). As seen in Table 6, all values are clearly below the conservative threshold of 0.85 (Kline, 2011). Based on these results, we deemed that the measurement model satisfies the discriminant validity.

\section{Structural Model}

To measure the second-order molar construct of engagement we adopted the repeated indicators approach. The construct was reflectively associated with its three dimensions (i.e., cognitive engagement, affective engagement, behavioral engagement) by using all their items and, following Becker et al.'s (2012) recommendation, we used mode A to measure the higher-order indicator. We applied a centroid inner weighting scheme in the PLS algorithm.

We employed the product indicator approach to examine the hypothesized moderating relationships in the structural model (H5, H6). Accordingly, the interaction constructs were defined as the product between the items of the corresponding predictor and the associated moderator variable. To measure the moderation influence without possible undesired inflation effects (Hair et al., 2017b) we included in the model the moderator variables' direct effect on the related endogenous construct (flow $\rightarrow$ engagement, age $\rightarrow$ continuance).

We validated the structural model by analyzing the coefficient of determination $\left(R^{2}\right)$ of the two regressions in the model, the effect size of the exogenous constructs on the endogenous constructs $\left(f^{2}\right)$, the standardized root 
TABLE 5 | Cross loadings of items.

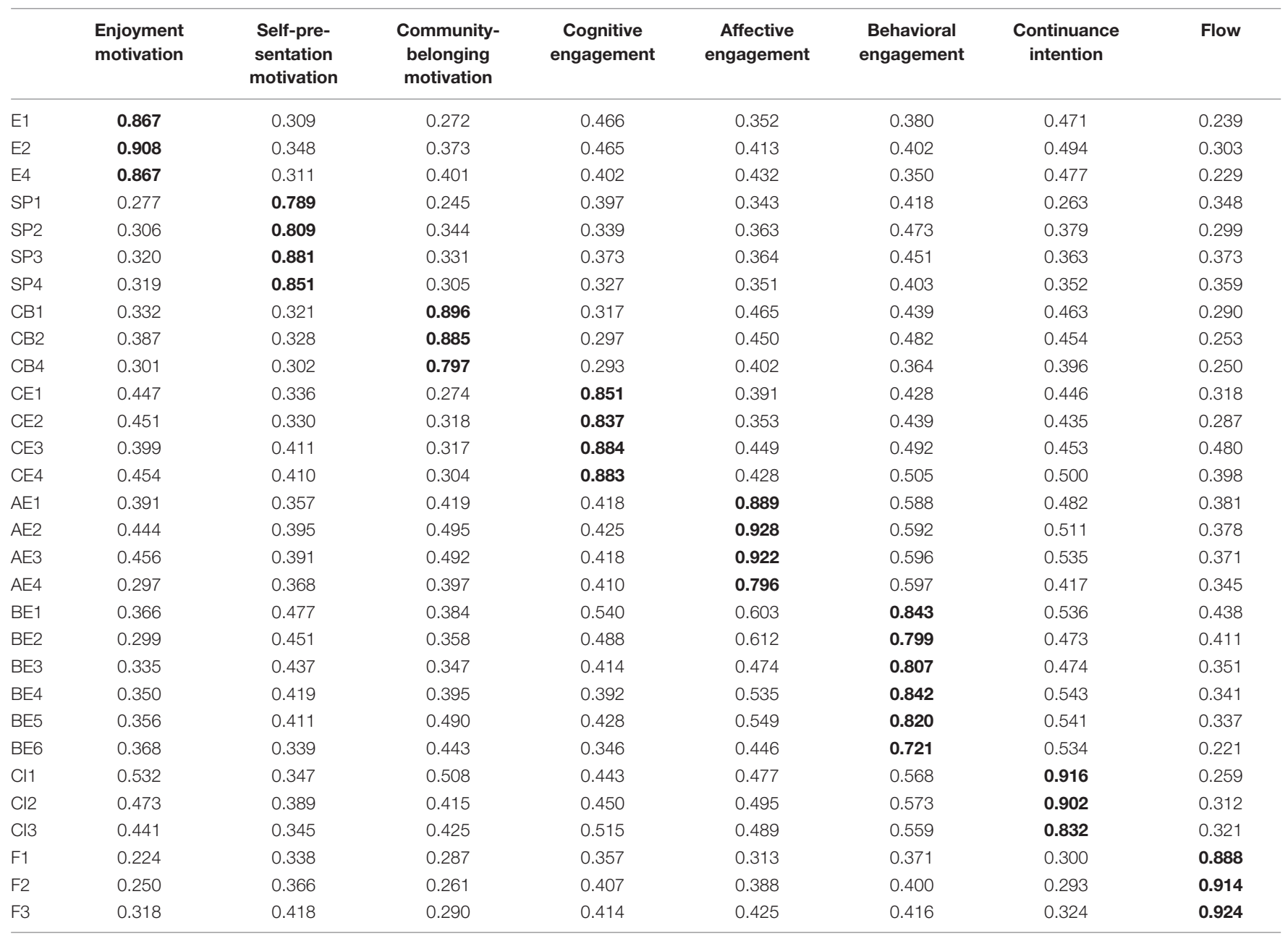

TABLE 6 | Discriminant validity analysis*.

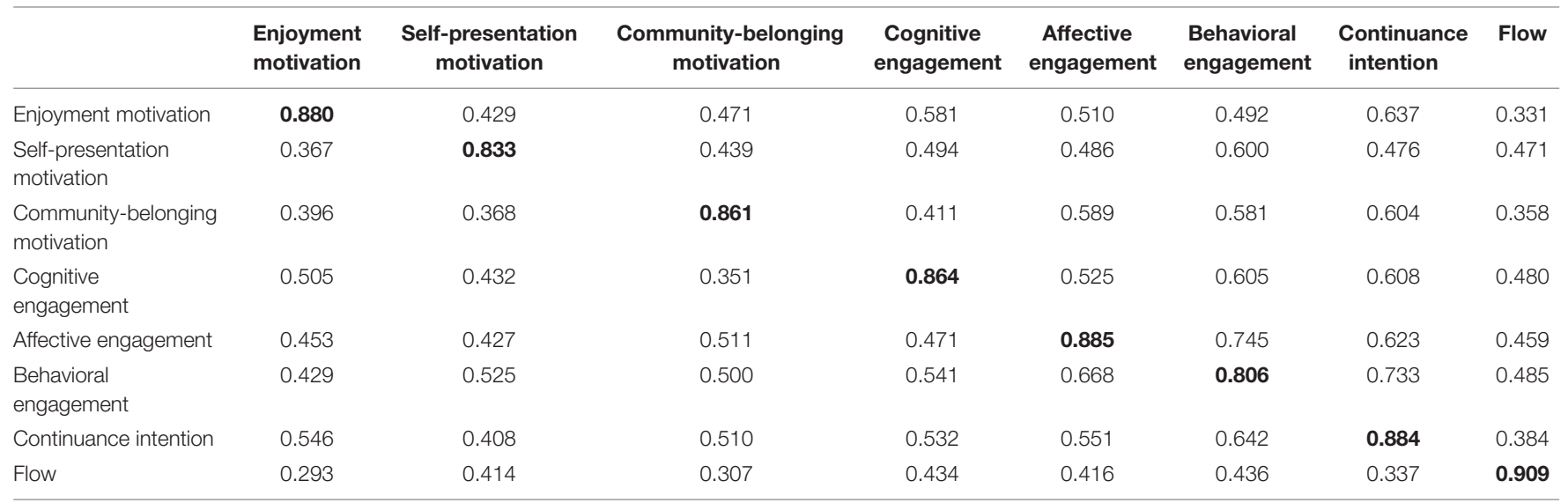

*HTMT above the diagonal, square root of the AVE on the diagonal (bold), and correlations between the dimensions under the diagonal.

mean residual (SRMR), the blindfolding-based crossvalidated redundancy measure $Q^{2}$ and the statistical significance of the path coefficients. The value of each coefficient of determination is between 0.25 and 0.75
(Table 7), which shows an acceptable or moderate level of predictive accuracy. In addition, the higher-order construct engagement is perfectly explained through its three dimensions $\left(R^{2}=1\right)$. 
TABLE 7 | Regressions with causal path coefficients.

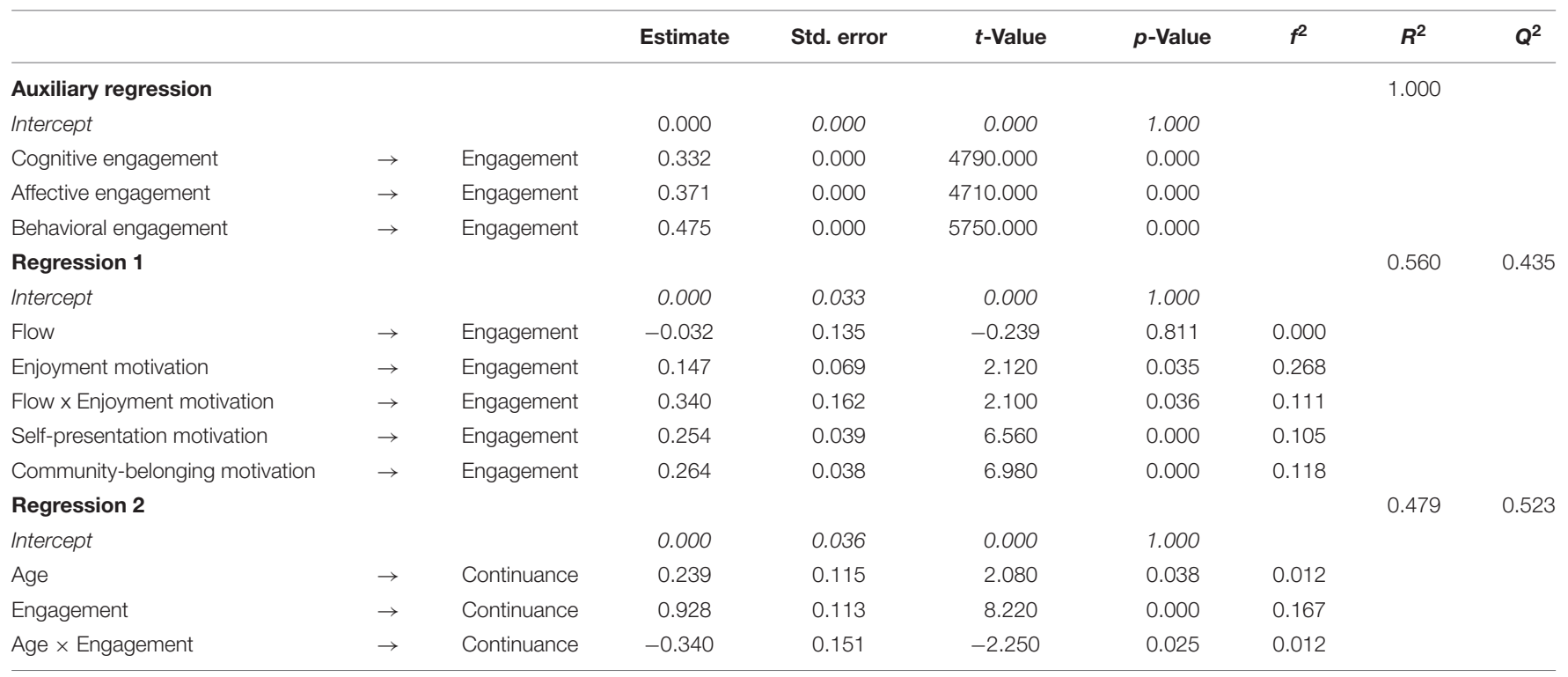

TABLE 8 | Results from bootstrap resampling procedure.

\begin{tabular}{|c|c|c|c|c|c|c|c|}
\hline & & & $\begin{array}{l}\text { Path coefficients } \\
\quad \text { (original) } \beta\end{array}$ & $\begin{array}{l}\text { Path coefficients } \\
\text { (boot-strapping) }\end{array}$ & Std. error & $p$-Value & $\alpha$ correction \\
\hline Flow & $\rightarrow$ & Engagement & -0.032 & -0.031 & 0.131 & 0.388 & 0.050 \\
\hline Flow $\times$ Enjoyment motivation & $\rightarrow$ & Engagement & 0.340 & 0.338 & 0.141 & 0.023 & 0.025 \\
\hline Self-presentation motivation & $\rightarrow$ & Engagement & 0.254 & 0.254 & 0.041 & 0.000 & 0.019 \\
\hline Community-belonging motivation & $\rightarrow$ & Engagement & 0.264 & 0.263 & 0.038 & 0.000 & 0.013 \\
\hline Engagement & $\rightarrow$ & Continuance & 0.928 & 0.914 & 0.119 & 0.000 & 0.006 \\
\hline Age $\times$ Engagement & $\rightarrow$ & Continuance & -0.340 & -0.320 & 0.146 & 0.036 & 0.038 \\
\hline
\end{tabular}

We examined the impact of the predictor variables on their associated endogenous constructs through their $f^{2}$ effect sizes, which show that enjoyment motivation has the most relevant effect on engagement and that engagement is the most important predictor of continuance. In addition, taking Cohen's cut-off values (1988) into consideration, we observe that enjoyment motivation has a medium effect on engagement while the rest of constructs have a low or very small effect. Similarly, engagement's impact on continuance is medium whereas the other two predictors have a very small effect.

The Stone-Geiser's $Q^{2}$ s values indicate that the predictive relevance of the path model for the endogenous latent variable is moderate (0.44) for engagement and high (0.52) for continuance (Hair et al., 2019). The structural model's SRMR is 0.09, which is below the recommended upper limit of 0.10 (Williams et al., 2009). Although this threshold is provisional and requires further analysis (Benitez et al., 2020), the SRMR's value is small and indicative of the structural model's validity.

Since data does not follow a multivariate normal distribution, we used the bootstrap resampling procedure (with 500 resamples) to test the statistical significance of the path coefficients (Table 8). All $p$-Values are below 0.05 and the corresponding Benjamini-Hochberg alpha correction, except for the $p$-Values associated with the moderator variables' direct effects on the endogenous construct. Accordingly, we can deem that all hypothesized causal and moderating links are supported (Figure 2).

Enjoyment motivation, self-representation motivation, and community-belonging motivation all have a significant, positive effect on engagement $(\beta=0.15, \beta=0.25$, and $\beta=0.26$, respectively)-while the former causal relationship is indeed moderated by flow $(\beta=0.34)$. The higher-order construct engagement (measured as a compound perception of cognitive engagement, affective engagement, and behavioral engagement) has a direct and significant impact on continuance $(\beta=0.91)$, which in turn is moderated by age $(\beta=-0.32)$.

All the indirect effects included in the proposed model are also significant (see bootstrapping results in Table 9). The three psychological motivations (enjoyment motivation, self-representation motivation, and community-belonging motivation) have an indirect effect on continuance. The indirect influence of enjoyment motivation is again moderated by flow. 


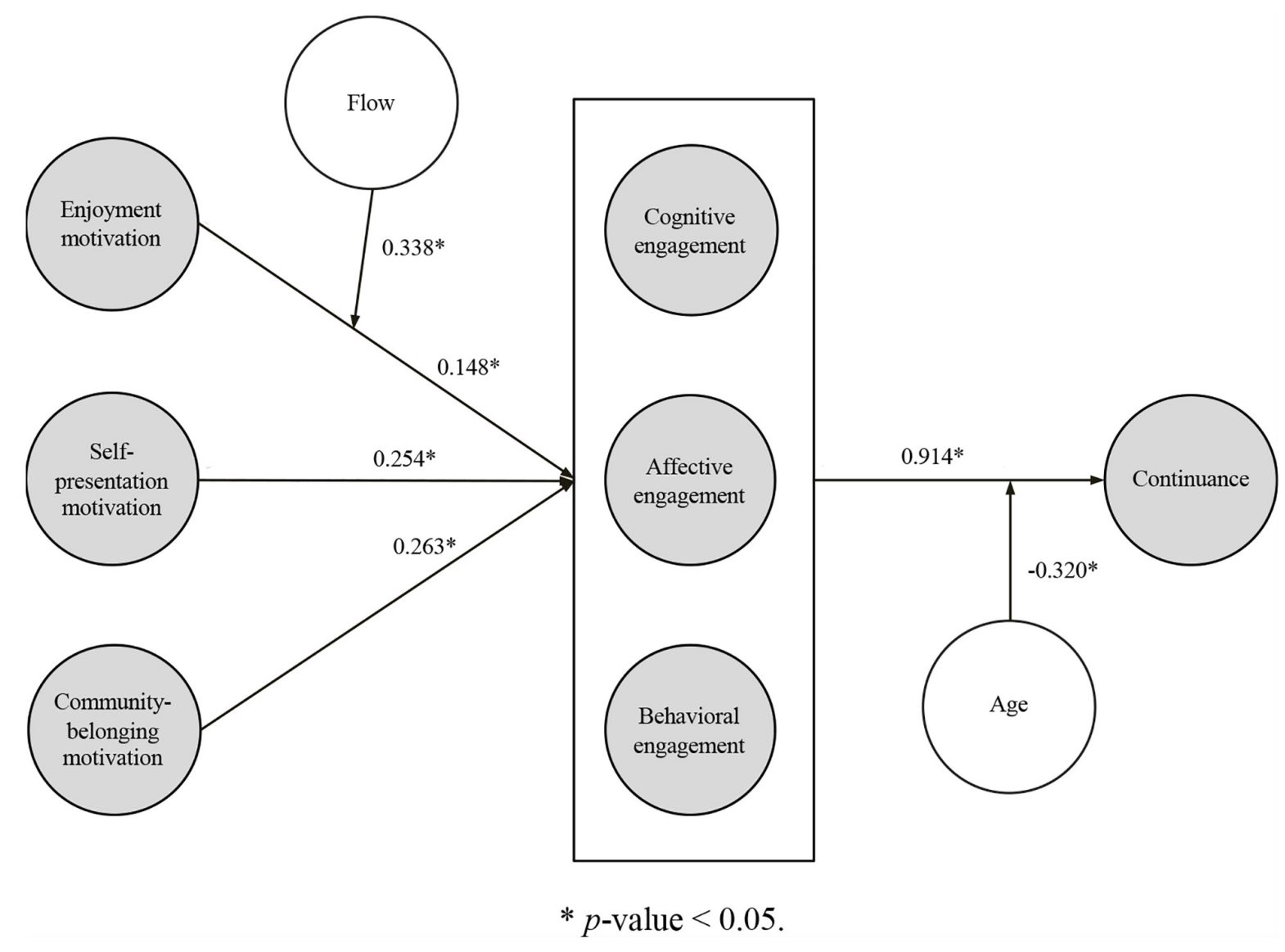

FIGURE 2 | PLS model with path coefficients.

TABLE 9 | Indirect impacts between constructs.

\begin{tabular}{llll}
\hline Relationships & & & Indirect effects \\
\hline Enjoyment motivation & $\rightarrow$ & Continuance & 0.136 \\
Flow $\times$ Enjoyment motivation & $\rightarrow$ & Continuance & 0.315 \\
Self-presentation motivation & $\rightarrow$ & Continuance & 0.236 \\
Community-belonging motivation & $\rightarrow$ & Continuance & 0.245
\end{tabular}

\section{Neural Network Analysis}

After using PLS to statistically test the causal and moderating relationships in the structural model, we integrated the neural network analysis with the PLS framework (Qin and McAvoy, 1992) so as to detect possible non-linear relationships and determine the importance of each factor (Ahani et al., 2017). Accordingly, we introduced the factors resulting from PLS analysis as significant and reliable inputs in the neural network; to boost performance (Negnevitsky, 2017), we adopted the min-max scale method to scale all data factors between 0 and 1 .

Since the general structural model has two endogenous constructs (i.e., engagement and continuance), we divided it into two subneural network models: model $\mathrm{A}$ and model $\mathrm{B}$ (Figure 3). In model A, the output variable was the endogenous construct engagement and the input variables were: the three constructs of the general model with significant influence on engagement (i.e., enjoyment motivation, self-representation motivation and community-belonging motivation); and the latent variable that captures the moderating effect of flow on the path from enjoyment motivation to engagement. The output variable of model $\mathrm{B}$ was continuance, and its input variables were engagement and the latent variable that represented the moderating role of age in the relationship between engagement and continuance.

To each submodel, we applied a neural network multilayer perceptron training algorithm, which had a single hidden layer to represent the continuous functions of the input nodes (Hornik et al., 1989; Negnevitsky, 2017). We used the traditional backpropagation algorithm with the logistic activation function provided in $R$ by the neuralnet package (Günther and Fritsch, 2012), and the sum of squared errors as the differentiable error function to minimize.

We established the number of nodes in the hidden layer of each submodel based on two key restrictions (Negnevitsky, 2017; Liébana-Cabanillas et al., 2018): (1) a limited number of hidden nodes does not allow complex patterns to be detected; and (2) a high number of hidden nodes can trigger overfitting issues. To satisfy both restraints, we selected the smallest number of hidden neurons possible to ensure a suitable generalization of the 


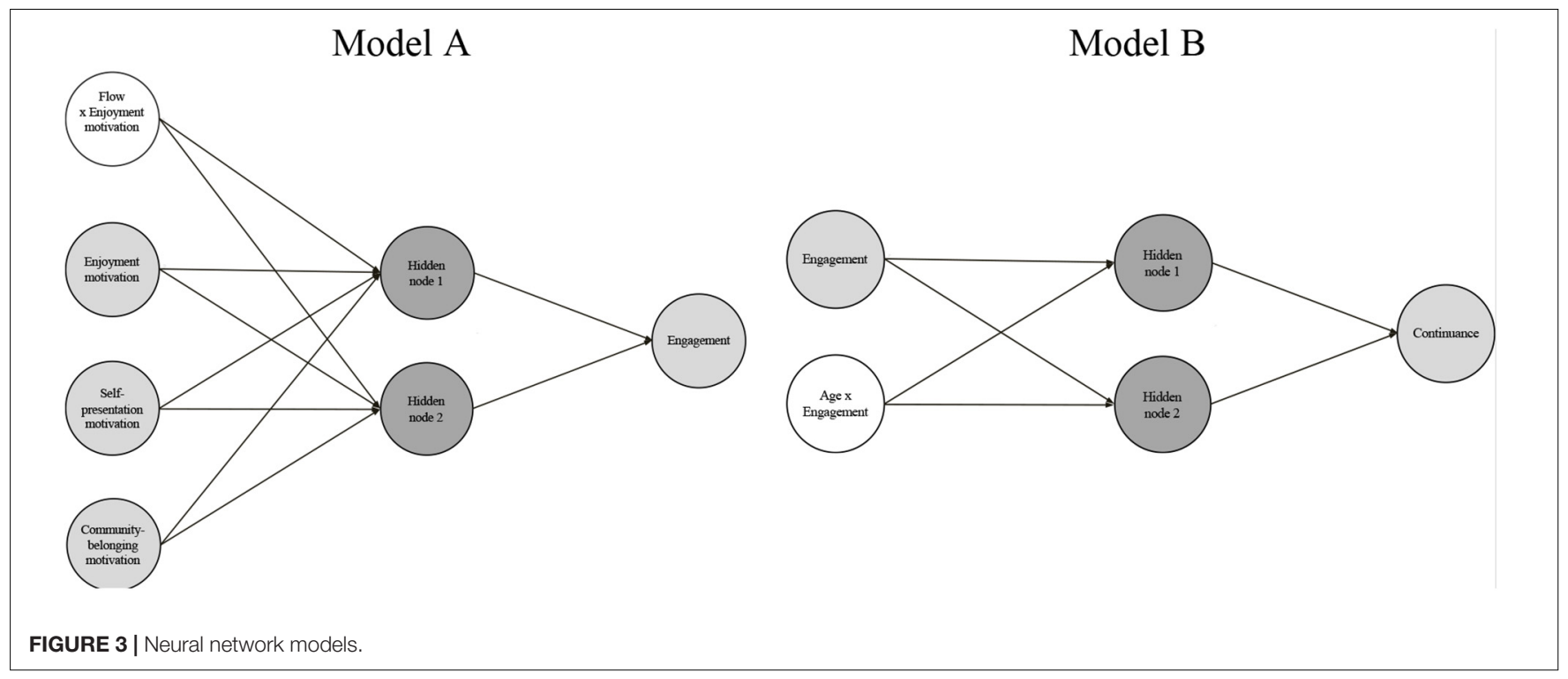

TABLE 10 | Neural network prediction accuracy.

\begin{tabular}{lccccc}
\hline \multirow{2}{*}{ Network } & \multicolumn{2}{c}{ Model A } & & \multicolumn{2}{c}{ Model B } \\
\cline { 2 - 3 } \cline { 5 - 6 } & Training & Testing & & Training & Testing \\
\hline 1 & 0.122 & 0.129 & & 0.162 & 0.169 \\
2 & 0.120 & 0.143 & & 0.164 & 0.187 \\
3 & 0.122 & 0.129 & & 0.166 & 0.137 \\
4 & 0.127 & 0.123 & & 0.167 & 0.159 \\
5 & 0.128 & 0.122 & & 0.164 & 0.157 \\
6 & 0.125 & 0.104 & & 0.169 & 0.143 \\
7 & 0.124 & 0.106 & & 0.164 & 0.149 \\
8 & 0.124 & 0.108 & & 0.163 & 0.160 \\
9 & 0.122 & 0.140 & & 0.165 & 0.149 \\
10 & 0.126 & 0.118 & & 0.165 & 0.148 \\
Mean & 0.124 & 0.122 & & 0.165 & 0.156 \\
s.d. & 0.003 & 0.014 & 0.002 & 0.015 \\
\hline
\end{tabular}

reliable; and all input factors are appropriate for predicting the endogenous variables.

We assessed the importance of each input factor on output variability by considering the average relative importance and the normalized importance and performed this sensitivity analysis with Garson's (1991) algorithm. To obtain the importance average, we used the results for each of the 10 networks; we calculated the normalized importance of each factor as the proportion of its relative importance with respect to the factors' maximum relative importance (Leong et al., 2013; Sharma et al., 2015). Table 11 shows that the most important factor in predicting engagement is community-belonging motivation, followed by the moderating effect flow $x$ enjoyment motivation, and also that the most important factor in predicting continuance is engagement.

complex model. Accordingly, we first considered Blum's (1992) proposition that the optimal number of nodes in the hidden layer is a value between the number of inputs and the number of outputs. Next, we followed a trial-and-error procedure (Chong and Bai, 2014; Sharma et al., 2015), which determined that, in both submodels, the best (prediction) results were obtained with two hidden nodes.

To prevent any potential bias caused by the tendency of neural network models to overfit (Geman et al., 1992; Prechelt, 1998), we performed a 10 -fold cross-validation for each submodel, with a data set ratio of 90:10 for training and testing (Chan and Chong, 2012; Liébana-Cabanillas et al., 2017). We used the root-mean-square error (RMSE)-obtained from the 10 optimizations-to analyze each submodel's accuracy. As seen in Table 10, the RMSE values for both the training data and testing data are acceptable in the two submodels. Therefore, we can safely establish that: the submodels are efficient and give high-precision predictions; the parameter estimations are

\section{DISCUSSION AND CONCLUSION}

The main purpose of this paper has been to predict Facebook engagement formation and explain the mediating effect of engagement on continuance use. On the grounds of the uses and gratifications theory, engagement literature, and social exchange theory, we hypothesized a causal path from enjoyment motivation, self-presentation motivation, and community-belonging motivation to continued Facebook use that is mediated by engagement-operationalized as a multidimensional construct. Furthermore, based on flow theory and socioemotional selectivity theory, we respectively projected that flow would interact with enjoyment motivation to trigger engagement, and age would moderate the influence of engagement on continued use. Our empirical research combined two techniques: a PLS approach that allowed us to validate the survey instrument and confirmed all the linear (direct, mediating, and moderating) hypothesized relationships; and a neural network analysis, which quantified engagement's and 
TABLE 11 | Neural network sensitivity analysis.

\begin{tabular}{|c|c|c|c|c|c|c|}
\hline Network & \multicolumn{4}{|c|}{ Model A } & \multicolumn{2}{|c|}{ Model B } \\
\hline 1 & 0.172 & 0.252 & 0.187 & 0.389 & 0.712 & 0.288 \\
\hline 2 & 0.197 & 0.237 & 0.184 & 0.383 & 0.882 & 0.118 \\
\hline 3 & 0.148 & 0.288 & 0.208 & 0.356 & 0.710 & 0.290 \\
\hline 6 & 0.182 & 0.257 & 0.189 & 0.373 & 0.959 & 0.041 \\
\hline 7 & 0.192 & 0.259 & 0.179 & 0.370 & 0.724 & 0.276 \\
\hline 8 & 0.200 & 0.217 & 0.215 & 0.368 & 0.716 & 0.284 \\
\hline 9 & 0.112 & 0.196 & 0.206 & 0.486 & 0.734 & 0.266 \\
\hline 10 & 0.101 & 0.204 & 0.145 & 0.550 & 0.719 & 0.281 \\
\hline
\end{tabular}

continuance behavior's sensitivity to each input factor and determined that the predictive model is highly accurate.

\section{Theoretical Contributions}

This research makes its main contributions in four areas. First, it theoretically integrates the research stream of engagement with the uses and gratifications paradigm and tests the suitability of this combined approach in terms of its explanatory power. In recent years, researchers have applied the uses and gratifications approach to SNSs like Facebook to examine motivations' effect on either usage or continued usage-usually measured in terms of time spent on Facebook. This previous research does not detail how the expected gratifications of using Facebook contribute to the psychological phenomena of engagement. The very few studies attempting to explain engagement, such as Verhagen et al. (2015), did not consider the cognitive, attitudinal, and behavioral nature of the construct and its mediating role in use decisions.

Our resulting research framework (motivation-engagementcontinued use) extends the uses and gratifications paradigm model, not only by conceiving engagement as a multidimensional psychological phenomenon-influenced by motivational drivers-but also by offering evidence about engagement's role as a mediating psychological mechanism in continued-use decisions. Furthermore, by conjointly assessing the various forms of engagement that Facebookers experience and why they engage, we have been able to offer a more comprehensive understanding of the psychological context of Facebookers' interactions.

A second contribution of this paper concerns the role attributed to immersive flow experiences in the nomological network of engagement. While previous research on flow has been mainly devoted to examining antecedents and consequences of flow, the two only empirical studies about flow's potential connection with engagement simply considered a causal path (Shin, 2018; Rodríguez-Ardura and MeseguerArtola, 2019), and do so with engagement operationalizations restricted to measures of cognitive involvement. These prior findings were consistent with flow's conceptual connection with the cognitive dimension of engagement (Hollebeek, 2011;
Medhurst and Albrecht, 2016) and gave proof that flow and engagement are distinct phenomena. However, they did not provide evidence of how a transient psychological mechanism like flow might intensify the more enduring emotional and behavioral facets of engagement. Our findings complement this view and show that, beyond it being characterized as a temporary yet highly immersive episode, flow also acts as a psychological amplifier that facilitates engagement's cognitive as well as affective and behavioral dimensions. Since flow experiences are enjoyable and therefore positive, they have an indirect and positive impact on the individual's emotional engagement. In addition, because flow is characterized by a high concentration on the online activities at hand, it becomes a highly functional episode that strengthens the subjective mechanisms leading toward behavioral engagement. As a consequence, the Facebookers whose enjoyment needs are met via flow tend to retain greater motivation-affectbehavior consistency.

Third, this study offers a novel line of evidence regarding age-related differences across Facebookers and shows, for the first time in the literature, their moderating role in engagement's relationship with users' continuance decisions. This indeed indicates the applicability of socioemotional selectivity theory in SNS contexts and extends this theory's reach to account for individual's decisions regarding continued use. Thus, socioemotional selectivity theory complements the perspective offered by the research stream on engagement to theoretically predict age-related changes in the effects of users' engagement.

Lastly, this is one of the few papers using a hybrid, twostage technique that integrates PLS and neural network analysis. In contrast to CB-SEM, PLS works well under multivariate non-normal conditions and is better-suited to modeling higherorder latent structures and assessing both direct (and mediating) paths and moderating effects. However, neither PLS nor CBSEM can detect non-linear relationships and achieve the high predictive performance levels offered by neural networks. In turn, neural networks by themselves cannot test causal relationships. The hybrid technique we used allowed us to overcome these 
disadvantages by embedding neural networks in the PLS framework, thus offering a highly accurate assessment of the relative (linear and non-linear) effects of each construct. Future research might employ this approach as a refined, powerful tool to assess complex structural models in online consumer behavior.

\section{Managerial Implications}

IT practitioners and digital marketers can benefit from this research in three main ways. First, our empirical examination-adaptable to any type of content or moderated changes in the Facebook environment-highlights that, while people interact long-term on Facebook as a means of presenting themselves and connecting with others, they also use Facebook for the sake of the enjoyment derived from the interaction experiences. As a result, continued Facebook use involves a contrast that encompasses expressing and communicating with other Facebookers while interacting with the content in and of itself. Therefore, for managers and specialists building content marketing strategies, a dual focus on social and entertainment values is recommended.

Second, our results enable managers and practitioners to be aware of the importance, for the brand and the firm, of Facebookers' engaging experiences, allowing them to make more informed decisions when implementing strategies to boost Facebookers' engagement. Our findings hold relevance for practitioners looking to promote engagement not only as a means by which people can achieve perceived benefits-gained from interaction experiences on Facebook-but also as a precursor to continued usage. In the professional literature, engagement has typically been depicted as either a user's repertory of digital practices (e.g., contributing activities, linking Facebook brand pages, etc.) or a user's involving mechanism or willingness to relate. The validated integrative measurement scale used in this study provides practitioners with a tool to enhance their understanding of the multidimensional nature of Facebook engagement and indicates that there are three major ways in which people engage in Facebook (i.e., by virtue of cognitive activation, emotional activation, and activities).

Third, managers and practitioners need to be aware that Facebook engagement fits different types of users. Our study highlights this fact through the example of flow episodes and age, although brands might use their own psychographic and behavioral segmentation criteria to detect what leads each segment to achieve engagement and what facets of engagement are most relevant for them. For example, a brand targeting both older and younger users will have to be aware that their engagement strategies will more strongly affect their older users. Additionally, by running the scale of engagement used here amongst the relevant segments of a brand's users, practitioners will be able to detect what motivational forces and engagement facets are most relevant for them. Ultimately, this will help them tailor digital marketing strategies to match each segment.

\section{Limitations and Future Research}

Although we endeavored to maximize the quality of our work with appropriate testing procedures and validation techniques, and the unlikely prospect that spurious correlations could occur due to common method bias, our results must be interpreted taking certain research limitations into account. For example, due to time and financial constraints, our research design was cross-sectional in nature, participants were recruited with a snowball sampling strategy, and the sampling frame was constricted to a single-country-which has a particular degree of individualism/collectivism, values conventionally linked to feminine roles, and specific individual and organizational cultural dynamics (Hofstede, 1983; Spector et al., 2001). All of this limited the predictive generalization of our findings. Because the engagement ecosystem in SNSs facilitates the detailed recording of engagement activities, future empirical enquiries could seize the opportunities offered by a mixed approach that supplements survey data with big data sources. Furthermore, future research could expand on this study by considering whether new phenomena, or extensive and profound transformations in the Facebook landscape, shape users' engagement mechanisms in the long term. Further insight could be gained by empirically testing if cultures (e.g., national cultures, consumption cultures) play a part in engagement formation. Previous cross-cultural studies have shown that, while motivational drivers to use an SNS like Facebook might be relatively similar across cultural contexts (Kim et al., 2011; Manzi et al., 2018), the way in which SNSs are used might significantly vary among cultural milieus. However, the simultaneous interplay between multiple cultural differences, psychological motivations, and behavior on Facebook remains unclear.

\section{DATA AVAILABILITY STATEMENT}

The datasets presented in this article are not readily available because participants did not give explicit consent for data sharing. Requests to access the datasets should be directed to irodriguez@uoc.edu.

\section{ETHICS STATEMENT}

The studies involving human participants were reviewed and approved by the Universitat Oberta de Catalunya's Research Ethics Board. The participants provided their informed consent to participate in this study.

\section{AUTHOR CONTRIBUTIONS}

IR-A contributed to the conception and design of the study, and wrote the (sub-)sections "Introduction," "Theoretical Background," "Research Model and Hypotheses," "Participants," "Measures," "Prevention and Assessment of Common Method Variance," and "Discussion and Conclusion" of the manuscript. AM-A organized the database, performed the statistical analysis, and wrote the sections "Participants," "Prevention and Assessment of Common Method Variance," "PLS-Neural Network Method," and "Results" of the manuscript. Both authors contributed to manuscript revision, read, and approved the submitted version. 


\section{REFERENCES}

Ahani, A., Rahim, N. Z. A., and Nilashi, M. (2017). Forecasting social CRM adoption in SMEs: a combined SEM-neural network method. Comput. Human Behav. 75, 560-578. doi: 10.1016/j.chb.2017.05.032

Alcantara-Pilar, J. M., Barrio-Garcia, S., del Porcu, L., and Crespo-Almendros, E. (2015). Motivational duality in online consumer behaviour: website usability and flow state as moderating factors. Int. J. Bus. Econ. 14, 79-104. doi: 10.1016/ j.jdmm.2017.09.005

Asakawa, K. (2010). Flow experience, culture, and well-being: how do autotelic Japanese college students feel, behave, and think in their daily lives? J. Happiness Stud. 11, 205-223. doi: 10.1007/s10902-008-9132-3

Baldus, B. J., Voorhees, C., and Calantone, R. (2015). Online brand community engagement: scale development and validation. J. Bus. Res. 68, 978-985. doi: 10.1016/j.jbusres.2014.09.035

Baltar, F., and Brunet, I. (2012). Social research 2.0: virtual snowball sampling method using Facebook. Internet Res. 22, 57-74. doi: 10.1108/ 10662241211199960

Barclay, D., Higgins, C., and Thompson, R. (1995). The partial least squares (PLS) approach to causal modeling: personal computer adoption and use as an illustration. Technol. Stud. 2, 285-309.

Baumann, N., Lürig, C., and Engeser, S. (2016). Flow and enjoyment beyond skilldemand balance: the role of game pacing curves and personality. Motiv. Emot. 40, 507-519. doi: 10.1007/s11031-016-9549-7

Baumeister, R. F., and Leary, M. R. (1995). The need to belong: desire for interpersonal attachments as a fundamental human motivation. Psychol. Bull. 117, 497-529. doi: 10.1037/0033-2909.117.3.497

Becker, J. M., Klein, K., and Wetzels, M. (2012). Hierarchical latent variable models in PLS-SEM: guidelines for using reflective-formative type models. Long Range Plann. 45, 359-394. doi: 10.1016/j.lrp.2012.10.001

Benitez, J., Henseler, J., Castillo, A., and Schuberth, F. (2020). How to perform and report an impactful analysis using partial least squares: guidelines for confirmatory and explanatory IS research. Inf. Manag. 57:103168. doi: 10.1016/ j.im.2019.05.003

Bijmolt, T. H. A., Leeflang, P. S. H., Block, F., Eisenbeiss, M., Hardie, B. G. S., Lemmens, A., et al. (2010). Analytics for customer engagement. J. Serv. Res. 13, 341-356. doi: 10.1111/bjc. 12044

Błachnio, A., Przepiorka, A., Boruch, W., and Bałakier, E. (2016). Self-presentation styles, privacy, and loneliness as predictors of Facebook use in young people. Pers. Individ. Diff. 94, 26-31. doi: 10.1016/j.paid.2015.12.051

Blau, P. M. (2009). Exchange and Power in Social Life, 2nd Edn. New Brunswick, NJ: Transaction Publishers, doi: 10.4324/9780203792643

Blum, A. (1992). Neural Networks in C++: an Object-Oriented Framework for Building Connectionist Systems. New York, NY: John Wiley \& Sons.

Bowden, J. L.-H., Conduit, J., Hollebeek, L. D., Luoma-aho, V., and Solem, B. A. (2017). Engagement valence duality and spillover effects in online brand communities. J. Serv. Theory Pract. 27, 877-897. doi: 10.1108/JSTP-04-20160072

Boyd, P., and Forbes Agency Council (2018). Six Content Marketing Trends for 2019. Forbes. Available online at: https://www.forbes.com/sites/ forbesagencycouncil/2018/11/14/six-content-marketing-trends-for-2019/ \#1c07f4ee5047 (accessed November 16, 2018).

Brakus, J. J., Schmitt, B. H., and Zarantonello, L. (2015). Brand experience: what is it? How is it measured? Does it affect loyalty? J. Mark. 73, 52-68. doi: 10.1509/ jmkg.73.3.52

Brislin, R. W. (1986). "The wording and translation of research instruments," in Field Methods in Cross-Cultural Research, eds W. J. Lonner and J. W. Berry (Thousand Oaks, CA: Sage), 137-164.

Brodie, R. J., Hollebeek, L. D., Juric, B., and Ilic, A. (2011). Customer engagement: conceptual domain, fundamental propositions, and implications for research. J. Serv. Res. 14, 252-271. doi: 10.1177/1094670511411703

Brodie, R. J., Ilic, A., Juric, B., and Hollebeek, L. D. (2013). Consumer engagement in a virtual brand community: an exploratory analysis. J. Bus. Res. 66, 105-114. doi: 10.1016/j.jbusres.2011.07.029

Burke, M., and Kraut, R. E. (2016). The relationship between Facebook use and well-being depends on communication type and tie strength. J. Comput. Commun. 21, 265-281. doi: 10.1111/jcc4.12162
Carstensen, L. L. (2006). The influence of a sense of time on human development. Science 312, 1913-1915. doi: 10.1126/science.1127488

Carstensen, L. L. (2018). Integrating cognitive and emotion paradigms to address the paradox of aging. Cogn. Emot. 33, 119-125. doi: 10.1080/02699931.2018. 1543181

Casale, S., and Fioravanti, G. (2018). Why narcissists are at risk for developing Facebook addiction: the need to be admired and the need to belong. Addict. Behav. 76, 312-318. doi: 10.1016/j.addbeh.2017.08.038

Chan, F. T. S., and Chong, A. Y. L. (2012). A SEM-neural network approach for understanding determinants of interorganizational system standard adoption and performances. Decis. Support Syst. 54, 621-630. doi: 10.1016/j.dss.2012.08. 009

Chang, I.-C., Liu, C.-C., and Chen, K. (2014). The effects of hedonic/utilitarian expectations and social influence on continuance intention to play online games. Internet Res. 24, 21-45. doi: 10.1108/IntR-02-2012-0025

Chang, K.-C. (2015). How travel agency reputation creates recommendation behavior. Ind. Manag. Data Syst. 115, 332-352. doi: 10.1108/IMDS-09-20140265

Chang, P. F., Choi, Y. H., Bazarova, N. N., and Löckenhoff, C. E. (2015). Age differences in online social networking: extending socioemotional selectivity theory to social network sites. J. Broadcast. Electron. Media 59, 221-239. doi: 10.1080/08838151.2015.1029126

Chaudoir, S. R., and Fisher, J. D. (2011). The disclosure processes model: understanding disclosure decision-making and post-disclosure outcomes among people living with a concealable stigmatized identity. Psychol. Bull. 136, 236-256. doi: 10.1037/a0018193.The

Chong, A. Y. L. (2013). A two-staged SEM-neural network approach for understanding and predicting the determinants of m-commerce adoption. Expert Syst. Appl. 40, 1240-1247. doi: 10.1016/j.eswa.2012.08.067

Chong, A. Y. L., and Bai, R. (2014). Predicting open IOS adoption in SMEs: an integrated SEM-neural network approach. Expert Syst. Appl. 41, 221-229. doi: 10.1016/j.eswa.2013.07.023

Cohen, J. (1988). Statistical Power Analysis for the Behavioral Sciences, 2nd Edn. Lawrence: Erlbaum Associates.

Csikszentmihalyi, M. (1975a). Beyond Boredom and Anxiety. San Francisco, CA: Jossey-Bass.

Csikszentmihalyi, M. (1975b). Play and intrinsic rewards. J. Humanist. Psychol. 15, 41-63. doi: 10.1177/002216787501500306

Csikszentmihalyi, M. (2008). Flow: the Psychology of Optimal Experience. New York, NY: Harper and Row.

Csikszentmihalyi, M., Abuhamdeh, S., and Nakamura, J. (2005). "Flow," in Handbook of Competence and Motivation, eds A. J. Elliot and C. S. Dweck (New York, NY: Guilford Press), 598-608.

Deater-Deckard, K., El Mallah, S., Chang, M., Evans, M. A., and Norton, A. (2014). Student behavioral engagement during mathematics educational video game instruction with 11-14 year olds. Int. J. Child-Computer Interact. 2, 101-108. doi: 10.1016/j.ijcci.2014.08.001

Desimone, J. A., Harms, P. D., and Desimone, A. J. (2015). Best practice recommendations for data screening. J. Organ. Behav. 36, 171-181. doi: 10. 1002/job.1962

Dessart, L., Veloutsou, C., and Morgan-Thomas, A. (2016). Capturing consumer engagement: duality, dimensionality and measurement. J. Mark. Manag. 32, 399-426. doi: 10.1080/0267257X.2015.1130738

Eigenraam, A. W., Eelen, J., van Lin, A., and Verlegh, P. W. J. (2018). A consumerbased taxonomy of digital customer engagement practices. J. Interact. Mark. 44, 102-121. doi: 10.1016/j.intmar.2018.07.002

Facebook (2020). Facebook Q1 2020. Available online at: https://investor.fb.com (accessed June 15, 2020).

Fang, X., Zhang, J., and Chan, S. S. (2013). Development of an instrument for studying flow in computer game play. Int. J. Hum. Comput. Interact. 29, 456-470. doi: 10.1080/10447318.2012.715991

Ferreira, M., Zambaldi, F., Guerra, D., and de, S. (2020). Consumer engagement in social media: scale comparison analysis. J. Prod. Brand Manag. 29, 491-503. doi: 10.1108/JPBM-10-2018-2095

Fornell, C., and Larcker, D. F. (1981). Evaluating structural equation models with unobservable variables and measurement error. J. Mark. Res. 18, 39-50. doi: 10.1177/002224378101800104 
Garson, G. D. (1991). Interpreting neural-network connection weights. AI Expert $6,47-51$.

Geman, S., Bienenstock, E., and Doursat, R. (1992). Neural networks and the bias/variance dilemma. Neural Comput. 4, 1-58. doi: 10.1162/neco.1992.4.1.1

Ghani, J. A., and Deshpande, S. P. (1994). Task characteristics and the experience of optimal flow in human-computer interaction. J. Psychol. 128, 381-391. doi: $10.1080 / 00223980.1994 .9712742$

Godinho, A., Kushnir, V., and Cunningham, J. A. (2016). Unfaithful findings: identifying careless responding in addictions research. Addiction 111, 955-956. doi: 10.1111/add.13221

Günther, F., and Fritsch, S. (2012). neuralnet: training of neural networks. $R$ J. 2, 30-38. doi: 10.1016/s1874-5938(00)80006-7

Ha, Y. W., Kim, J., Libaque-Saenz, C. F., Chang, Y., and Park, M.-C. (2015). Use and gratifications of mobile SNSs: Facebook and KakaoTalk in Korea. Telemat. Informatics 32, 425-438. doi: 10.1016/j.tele.2014.10.006

Hair, J. F. Jr., Hollingsworth, C. L., Randolph, A. B., and Chong, A. Y. L. (2017a). An updated and expanded assessment of PLS-SEM in information systems research. Ind. Manag. Data Syst. 117, 442-458. doi: 10.1108/IMDS-04-20160130

Hair, J. F. Jr., Hult, G. T. M., Ringle, C., and Sarstedt, M. (2017b). A Primer on Partial Least Squares Structural Equation Modeling (PLS-SEM), 2nd Edn. Thousand Oaks, CA: Sage.

Hair, J. F., Risher, J. J., Sarstedt, M., and Ringle, C. M. (2019). When to use and how to report the results of PLS-SEM. Eur. Bus. Rev. 31, 2-24. doi: 10.1108/EBR-112018-0203

Hall-Phillips, A., Park, J., Chung, T. L., Anaza, N. A., and Rathod, S. R. (2016). I (heart) social ventures: identification and social media engagement. J. Bus. Res. 69, 484-491. doi: 10.1016/j.jbusres.2015.05.005

Hamari, J., Shernoff, D. J., Rowe, E., Coller, B., Asbell-Clarke, J., and Edwards, T. (2016). Challenging games help students learn: an empirical study on engagement, flow and immersion in game-based learning. Comput. Human Behav. 54, 170-179. doi: 10.1016/j.chb.2015.07.045

Hardie-Bick, J., and Bonner, P. (2016). Experiencing flow, enjoyment and risk in skydiving and climbing. Ethnography 17, 369-387. doi: 10.1177/ 1466138115609377

Harmeling, C. M., Moffett, J. W., Arnold, M. J., and Carlson, B. D. (2017). Toward a theory of customer engagement marketing. J. Acad. Mark. Sci. 45, 312-335. doi: 10.1007/s11747-016-0509-2

Harrigan, P., Evers, U., Miles, M., and Daly, T. (2017). Customer engagement with tourism social media brands. Tour. Manag. 59, 597-609. doi: 10.1177/ 1096348012451456

Harrigan, P., Evers, U., Miles, M. P., and Daly, T. (2018). Customer engagement and the relationship between involvement, engagement, self-brand connection and brand usage intent. J. Bus. Res. 88, 388-396. doi: 10.1016/j.jbusres.2017.11. 046

Hayes, M., Van Stolk-Cooke, K., and Muench, F. (2015). Understanding Facebook use and the psychological affects of use across generations. Comput. Human Behav. 49, 507-511. doi: 10.1016/j.chb.2015.03.040

Haynes, S. N., Richard, D. C. S., and Kubany, E. S. (1995). Content validity in psychological assessment: a functional approach to concepts and methods. Psychol. Assess. 7, 238-247. doi: 10.1037/1040-3590.7.3.238

Henseler, J., and Chin, W. W. (2010). A comparison of approaches for the analysis of interaction effects between latent variables using partial least squares path modeling. Struct. Equ. Model. 17, 82-109. doi: 10.1080/10705510903 439003

Hoffman, D. L., and Novak, T. P. (1996). Marketing in hypermedia computermediated environments: conceptual foundations. J. Mark. 60, 50-68. doi: 10. $1177 / 002224299606000304$

Hoffman, D. L., and Novak, T. P. (2009). Flow online: lessons learned and future prospects. J. Interact. Mark. 23, 23-34. doi: 10.1016/j.intmar.2008.10.003

Hoffman, D. L., Novak, T. P., and Kang, H. (2017). Let's get closer: feelings of connectedness from using social media, with implications for brand outcomes. J. Assoc. Consum. Res. 2, 216-228. doi: 10.1086/690938

Hofstede, G. (1983). The cultural relativity of organizational practices and theories. J. Int. Bus. Stud. 14, 75-89. doi: 10.1057/palgrave.jibs. 8490867

Hollebeek, L. D. (2011). Demystifying customer brand engagement: exploring the loyalty nexus. J. Mark. Manag. 27, 785-807. doi: 10.1080/0267257X.2010. 500132
Hollebeek, L. D., Glynn, M. S., and Brodie, R. J. (2014). Consumer brand engagement in social media: conceptualization, scale development and validation. J. Interact. Mark. 28, 149-165. doi: 10.1016/j.intmar.2013.12.002

Hollebeek, L. D., Juric, B., and Tang, W. (2017). Virtual brand community engagement practices: a refined typology and model. J. Serv. Mark. 31, 204-217. doi: 10.1108/JSM-01-2016-0006

Hollebeek, L. D., Srivastava, R. K., and Chen, T. (2016). S-D logicinformed customer engagement: integrative framework, revised fundamental propositions, and application to CRM. J. Acad. Mark. Sci. 47, 161-185. doi: 10.1007/s11747-016-0494-5

Homans, G. C. (1958). Social behavior as exchange. Am. J. Sociol. 63, 597-606.

Homans, G. C. (1974). Social Behavior: Its Elementary Forms. New York, NY: Harcourt Brace Jovanovich.

Hornik, K., Stinchcombe, M., and Halbert, W. (1989). Multilayer feedforward networks are universal approximators. Neural Netw. 2, 359-366. doi: 10.1016/ 0893-6080(89)90020-8

Huang, S.-L., and Chen, C.-T. (2018). How consumers become loyal fans on Facebook. Comput. Human Behav. 82, 124-135. doi: 10.1016/j.chb.2018.01.006

Hung, S. Y., Tsai, J. C. A., and Chou, S. T. (2016). Decomposing perceived playfulness: a contextual examination of two social networking sites. Inf. Manag. 53, 698-716. doi: 10.1016/j.im.2016.02.005

Isaac, M. (2018). Facebook's Vision for the Future: Less News Feed, More Stories. New York, NY: New York Times.

Jaakkola, E., and Alexander, M. (2014). The role of customer engagement behavior in value co-creation: a service system perspective. J. Serv. Res. 17, 247-261. doi: $10.1177 / 1094670514529187$

Jang, S., Kitchen, P. J., and Kim, J. (2018). The effects of gamified customer benefits and characteristics on behavioral engagement and purchase: evidence from mobile exercise application uses. J. Bus. Res. 92, 250-259. doi: 10.1016/j.jbusres. 2018.07.056

Johnston, L. G., and Sabin, K. (2010). Sampling hard-to-reach populations with respondent driven sampling. Methodol. Innov. Online 5, 38-48. doi: 10.4256/ mio.2010.0017

Junco, R. (2012). The relationship between frequency of Facebook use, participation in Facebook activities, and student engagement. Comput. Educ. 58, 162-171. doi: 10.1016/j.compedu.2011.08.004

Katz, E., Blumler, J. G., and Gurevitch, M. (1973). Uses and gratifications research. Public Opin. Q. 37, 509-523.

Kaur, H., Paruthi, M., Islam, J. U., and Hollebeek, L. D. (2020). The role of brand community identification and reward on consumer brand engagement and brand loyalty in virtual brand communities. Telemat. Informatics 46:101321. doi: 10.1016/j.tele.2019.101321

Kaur, P., Dhir, A., Chen, S., and Rajala, R. (2016). Flow in context: development and validation of the flow experience instrument for social networking. Comput. Human Behav. 59, 358-367. doi: 10.1016/j.chb.2016.02.039

Kim, H., Suh, K.-S., and Lee, U.-K. (2013). Effects of collaborative online shopping on shopping experience through social and relational perspectives. Inf. Manag. 50, 169-180. doi: 10.1016/j.im.2013.02.003

Kim, Y., Sohn, D., and Choi, S. M. (2011). Cultural difference in motivations for using social network sites: a comparative study of American and Korean college students. Comput. Human Behav. 27, 365-372. doi: 10.1016/j.chb.2010.08.015

Kline, R. B. (2011). Principles and Practice of Structural Equation Modeling, 3rd Edn. New York, NY: Guilford Press.

Koh, J., and Kim, Y.-G. (2004). Knowledge sharing in virtual communities: an e-business perspective. Expert Syst. Appl. 26, 155-166. doi: 10.1016/S09574174(03)00116-7

Kosinski, M., Matz, S. C., Gosling, S. D., Popov, V., and Stillwell, D. (2015). Facebook as a research tool in the social and computer sciences. Am. Psychol. 70, 543-556. doi: 10.1037/a0039210

Krasnova, H., Spiekermann, S., Koroleva, K., and Hildebrand, T. (2010). Online social networks: why we disclose. J. Inf. Technol. 25, 109-125. doi: 10.1057/jit. 2010.6

Kwak, K. T., Choi, S. K., and Lee, B. G. (2014). SNS flow, SNS selfdisclosure and post hoc interpersonal relations change: focused on Korean Facebook user. Comput. Human Behav. 31, 294-304. doi: 10.1016/j.chb.2013. 10.046

Lai, C.-Y., and Yang, H.-L. (2016). Determinants and consequences of Facebook feature use. New Media Soc. 18, 1310-1330. doi: 10.1177/1461444814555959 
Lambert, A. (2013). Intimacy and Friendship on Facebook. Basingstoke: Palgrave Macmillan.

Landers, R. N., and Behrend, T. S. (2015). An inconvenient truth: arbitrary distinctions between organizational, mechanical turk, and other convenience samples. Ind. Organ. Psychol. 8, 142-164. doi: 10.1017/iop.2015.13

Lee, D., Kim, H. S., and Kim, J. K. (2011). The impact of online brand community type on consumer's community engagement behaviors: consumer-created vs. marketer-created online brand community in online social-networking web sites. Cyberpsychol. Behav. Soc. Netw. 14, 59-63. doi: 10.1089/cyber.2009.0397

Leong, L. Y., Hew, T. S., Lee, V. H., and Ooi, K. B. (2015). An SEM-artificialneural-network analysis of the relationships between SERVPERF, customer satisfaction and loyalty among low-cost and full-service airline. Expert Syst. Appl. 42, 6620-6634. doi: 10.1016/j.eswa.2015.04.043

Leong, L. Y., Hew, T. S., Tan, G. W. H., and Ooi, K. B. (2013). Predicting the determinants of the NFC-enabled mobile credit card acceptance: a neural networks approach. Expert Syst. Appl. 40, 5604-5620. doi: 10.1016/j.eswa.2013. 04.018

Lewin-Jones, J. (2015). Humour with a purpose: creativity with language in Facebook status updates. Linguist. Online 72, 69-87. doi: 10.13092/lo.72.1973

Li, H., Liu, Y., Xu, X., Heikkilä, J., and van der Heijden, H. (2015). Modeling hedonic is continuance through the uses and gratifications theory: an empirical study in online games. Comput. Human Behav. 48, 261-272. doi: 10.1016/j.chb. 2015.01.053

Liébana-Cabanillas, F., Marinković, V., and Kalinić, Z. (2017). A SEM-neural network approach for predicting antecedents of $\mathrm{m}$-commerce acceptance. Int. J. Inf. Manage. 37, 14-24. doi: 10.1016/j.ijinfomgt.2016.10.008

Liébana-Cabanillas, F., Marinkovic, V., Ramos de Luna, I., and Kalinic, Z. (2018). Predicting the determinants of mobile payment acceptance: a hybrid SEMneural network approach. Technol. Forecast. Soc. Change 129, 117-130. doi: 10.1016/j.techfore.2017.12.015

Lin, K.-Y., and Lu, H.-P. (2011). Why people use social networking sites: an empirical study integrating network externalities and motivation theory. Comput. Human Behav. 27, 1152-1161. doi: 10.1016/j.chb.2010.12.009

Liu, D., Wright, K. B., and Hu, B. (2018). A meta-analysis of social network site use and social support. Comput. Educ. 127, 201-213. doi: 10.1016/j.compedu.2018. 08.024

Locke, E. A., and Latham, G. P. (2002). Building a practically useful theory of goal setting and task motivation: a 35-year odyssey. Am. Psychol. 57, 705-717. doi: $10.1037 / 0003-066 X$ X.57.9.705

Lüders, M. (2008). Conceptualizing personal media. New Media Soc. 10, 683-702. doi: $10.1177 / 1461444808094352$

Luo, M. M., and Remus, W. (2014). Uses and gratifications and acceptance of webbased information services: an integrated model. Comput. Human Behav. 38, 281-295. doi: 10.1016/j.chb.2014.05.042

Luqman, A., Cao, X., Ali, A., Masood, A., and Yu, L. (2017). Empirical investigation of Facebook discontinues usage intentions based on SOR paradigm. Comput. Human Behav. 70, 544-555. doi: 10.1016/j.chb.2017.01.020

MacKenzie, S. B., and Podsakoff, P. M. (2012). Common method bias in marketing: causes, mechanisms, and procedural remedies. J. Retail. 88, 542-555. doi: 10. 1016/j.jretai.2012.08.001

Malik, A., Dhir, A., and Nieminen, M. (2015). Uses and gratifications of digital photo sharing on Facebook. Telemat. Informatics 33, 129-138. doi: 10.1016/j. tele.2015.06.009

Malthouse, E. C., Calder, B. J., Kim, S. J., and Vandenbosch, M. (2016). Evidence that user-generated content that produces engagement increases purchase behaviours. J. Mark. Manag. 32, 427-444. doi: 10.1080/0267257X.2016.1148066

Manzi, C., Coen, S., Regalia, C., Yévenes, A. M., Giuliani, C., and Vignoles, V. L. (2018). Being in the social: a cross-cultural and cross-generational study on identity processes related to Facebook use. Comput. Human Behav. 80, 81-87. doi: $10.1016 /$ j.chb.2017.10.046

Marbach, J., Lages, C. R., and Nunan, D. (2016). Who are you and what do you value? Investigating the role of personality traits and customer-perceived value in online customer engagement. J. Mark. Manag. 32, 502-525. doi: 10.1080/ 0267257X.2015.1128472

Martins, B., Sheppes, G., Gross, J. J., and Mather, M. (2018). Age differences in emotion regulation choice: older adults use distraction less than younger adults in high-Intensity positive contexts. J. Gerontol. Ser. B Psychol. Sci. Soc. Sci. 73, 603-611. doi: 10.1093/geronb/gbw028
Mather, M., and Carstensen, L. L. (2005). Aging and motivated cognition: the positivity effect in attention and memory. Trends Cogn. Sci. 9, 496-502. doi: 10.1016/j.tics.2005.08.005

McAndrew, F. T., and Jeong, H. S. (2012). Who does what on Facebook? Age, sex, and relationship status as predictors of Facebook use. Comput. Human Behav. 28, 2359-2365. doi: 10.1016/j.chb.2012.07.007

McGinnis, L. P., Gentry, J. W., and Gao, T. (2008). The impact of flow and communitas on service encounters. J. Serv. Res. 11, 74-90. doi: 10.1177/ 1094670508319046

McQuail, D. (1994). Mass Communication Theory: an Introduction. London: Sage Publications.

McQuail, D. (2012). McQuail's Mass Communication Theory, 6th Edn. London: Sage Publications.

McQuarrie, E. F., and Munson, J. M. (1992). A revised product involvement inventory: improved usability and validity. Adv. Consum. Res. 19, 108-115.

Medhurst, A. R., and Albrecht, S. L. (2016). Salesperson work engagement and flow: a qualitative exploration of their antecedents and relationship. Qual. Res. Organ. Manag. An Int. J. 11, 22-45. doi: 10.1108/qrom-04-2015-1281

Mehdizadeh, S. (2010). Self-presentation 2.0: narcissim and self-esteem on Facebook. Cyberpsychology. Behav. Soc. Netw. 13, 357-364. doi: 10.1089/cyber. 2009.0257

Meng, J., Martinez, L., Holmstrom, A., Chung, M., and Cox, J. (2017). Research on social networking sites and social support from 2004 to 2015: a narrative review and directions for future research. Cyberpsycho. Behav. Soc. Netw. 20, 44-51. doi: $10.1089 /$ cyber.2016.0325

Miller, L. C., Berg, J. H., and Archer, R. L. (1983). Openers: individuals who elicit intimate self-disclosure. J. Pers. Soc. Psychol. 44, 1234-1244. doi: 10.1037/00223514.44.6.1234

Mimoun, M. S. B., and Ammar, O. (2013). "Brands and strategies of selfpresentation on Facebook," in European Advances in Consumer Research, eds G. Cornelissen, E. Reutskaja, and A. Valenzuela (Duluth, MN: Association for Consumer Research), 95-97.

Mo, F., Zhou, J., Kosinski, M., and Stillwell, D. (2018). Usage patterns and social circles on Facebook among elderly people with diverse personality traits. Educ. Gerontol. 44, 265-275. doi: 10.1080/03601277.2018.1459088

Moghavvemi, S., Sharabati, M., Paramanathan, T., and Rahin, N. M. (2017). The impact of perceived enjoyment, perceived reciprocal benefits and knowledge power on students' knowledge sharing through Facebook. Int. J. Manag. Educ. 15, 1-12. doi: 10.1016/j.ijme.2016.11.002

Mollen, A., and Wilson, H. (2010). Engagement, telepresence and interactivity in online consumer experience: reconciling scholastic and managerial perspectives. J. Bus. Res. 63, 919-925. doi: 10.1016/j.jbusres.2009. 05.014

Moon, J.-W., and Kim, Y.-G. (2001). Extending the TAM for a world-wide-web context. Inf. Manag. 38, 217-230. doi: 10.1016/s0378-7206(00)00061-6

Morgan, D. L. (2012). "Snowball Sampling", in The SAGE Encyclopedia of Qualitative Research Methods, ed. M. Lisa (Thousand Oaks, CA :SAGE Publications). doi: 10.4135/9781412963909

Nabi, R. L., Prestin, A., and So, J. (2013). Facebook friends with (health) benefits? Exploring social network site use and perceptions of social support, stress, and well-being. Cyberpsychology, Behav. Soc. Netw. 16, 721-727. doi: 10.1089/cyber. 2012.0521

Negnevitsky, M. (2017). Artificial Intelligence: A Guide to Intelligent Systems. Harlow: Addison-Wesley.

Novak, T. P., Hoffman, D. L., and Yung, Y.-F. (2000). Measuring the customer experience in online environments: a structural modeling approach. Mark. Sci. 19, 22-42. doi: $10.1287 / \mathrm{mksc} .19 .1 .22 .15184$

Oh, H. J., Ozkaya, E., and Larose, R. (2014). How does online social networking enhance life satisfaction? The relationships among online supportive interaction, affect, perceived social support, sense of community, and life satisfaction. Comput. Human Behav. 30, 69-78. doi: 10.1016/j.chb.2013. 07.053

Owloo (2015). Análisis de España en Facebook. Available online at: https://www. owloo.com/facebook-stats/countries/spain\#_ = $($ accessed November 26, 2015).

Pagani, M., and Mirabello, A. (2011). The influence of personal and social-interactive engagement in social $\mathrm{TV}$ web sites. Int. J. Electron. Commer. 16, 41-67. doi: 10.2753/JEC1086-44151 60203 
Pansari, A., and Kumar, V. (2017). Customer engagement: the construct, antecedents, and consequences. J. Acad. Mark. Sci. 45, 294-311. doi: 10.1007/ s11747-016-0485-6

Pelet, J. -É, Ettis, S., and Cowart, K. (2017). Optimal experience of flow enhanced by telepresence: evidence from social media use. Inf. Manag. 54, 115-128. doi: 10.1016/j.im.2016.05.001

Podsakoff, P. M., MacKenzie, S. B., Lee, J.-Y., and Podsakoff, N. P. (2003). Common method biases in behavioral research: a critical review of the literature and recommended remedies. J. Appl. Psychol. 88, 879-903. doi: 10.1037/0021-9010. 88.5.879

Pöyry, E., Parvinen, P., and Malmivaara, T. (2013). Can we get from liking to buying? Behavioral differences in hedonic and utilitarian Facebook usage. Electron. Commer. Res. Appl. 12, 224-235. doi: 10.1016/j.elerap.2013.01.003

Prechelt, L. (1998). Automatic early stopping using cross validation: quantifying the criteria. Neural Netw. 11, 761-767. doi: 10.1016/S0893-6080(98)00010-0

Qin, S. J., and McAvoy, T. J. (1992). Nonlinear PLS modeling using neural networks. Comput. Chem. Eng. 16, 379-391. doi: 10.1016/0098-1354(92) 80055-E

Quan-Haase, A., and Young, A. L. (2014). "The uses and gratifications (U\&G) approach as a lens for studying social media practice," in The Handbook of Media and Mass Communication Theory, (New York, NY: John Wiley \& Sons), 269-286. doi: 10.1002/9781118591178.ch15

Ranaweera, C., McDougall, G., and Bansal, H. (2005). A model of online customer behavior during the initial transaction: moderating effects of customer characteristics. Mark. Theory 5, 51-74. doi: 10.1177/1470593105049601

Reed, A. E., Chan, L., and Mikels, J. A. (2014). Meta-analysis of the age-related positivity effect: age differences in preferences for positive over negative information. Psychol. Aging 29, 1-15. doi: 10.1037/a0035194

Reinartz, W., Haenlein, M., and Henseler, J. (2009). An empirical comparison of the efficacy of covariance-based and variance-based SEM. Int. J. Res. Mark. 26, 332-344. doi: 10.1016/j.ijresmar.2009.08.001

Reinecke, L., Vorderer, P., and Knop, K. (2014). Entertainment 2.0? The role of intrinsic and extrinsic need satisfaction for the enjoyment of Facebook use. J. Commun. 64, 417-438. doi: 10.1111/jcom.12099

Reis, H. T., and Gosling, S. D. (2010). "Social psychological methods outside the laboratory," in Handbook of Social Psychology, eds S. T. Fiske, D. T. Gilbert, and G. Lindzey (New York, NY: John Wiley \& Sons), 82-114. doi: 10.1002/ 9780470561119.soy001003

Rodríguez-Ardura, I., and Meseguer-Artola, A. (2016). E-learning continuance: the impact of interactivity and the mediating role of imagery, presence and flow. Inf. Manag. 53, 504-516. doi: 10.1016/j.im.2015.11.005

Rodríguez-Ardura, I., and Meseguer-Artola, A. (2017). Flow in e-learning: what drives it and why it matters. Br. J. Educ. Technol. 48, 899-915. doi: 10.1111/bjet. 12480

Rodríguez-Ardura, I., and Meseguer-Artola, A. (2018). The playfulness of Facebook - Shaped by underlying psychological drivers and gender differences. Telemat. Informatics 35, 2254-2269. doi: 10.1016/j.tele.2018.09.004

Rodríguez-Ardura, I., and Meseguer-Artola, A. (2019). Imagine, feel "there", and flow! Immersive experiences on m-Facebook, and their affective and behavioural effects. Inf. Technol. People 32, 921-947. doi: 10.1108/ITP- 10-20170358

Rodríguez-Ardura, I., and Meseguer-Artola, A. (2020). How to prevent, detect and control common method variance in electronic commerce research. J. Theor. Appl. Electron. Commer. Res. 15, 1-5. doi: 10.4067/S0718-18762020000200101

Rodríguez-Sánchez, A. M., Schaufelib, W., Salanovaa, M., Cifrea, E., and Sonnenschein, M. (2011). Enjoyment and absorption: an electronic diary study on daily flow patterns. Work Stress 25, 75-92. doi: 10.1080/02678373.2011. 565619

Sánchez-Franco, M. J., Buitrago-Esquinas, E. M., and Yñiguez-Ovando, R. (2015). What drives social integration in the domain of social network sites? Online Inf. Rev. 39, 5-25. doi: 10.1108/OIR-03-2014-0059

Sarstedt, M., Henseler, J., and Ringle, C. M. (2011). "Multigroup analysis in partial least squares (PLS) path modeling: alternative methods and empirical results," in Measurement and Research Methods in International Marketing, eds M. Sarstedt, M. Schwaiger, and C. R. Taylor (Bingley: Emerald), 195-218. doi: 10.1108/S1474-797920110000022012

Sashittal, H. C., Sriramachandramurthy, R., and Hodis, M. (2012). Targeting college students on Facebook? How to stop wasting your money. Bus. Horiz. 55, 495-507. doi: 10.1016/j.bushor.2012.05.006
Schamari, J., and Schaefers, T. (2015). Leaving the home turf: how brands can use webcare on consumer-generated platforms to increase positive consumer engagement. J. Interact. Mark. 30, 20-33. doi: 10.1016/j.intmar.2014.12.001

Schouten, A. P., Valkenburg, P. M., and Peter, J. (2007). Precursors and underlying processes of adolescents' online self-disclosure: developing and testing an "Internet-attribute-perception" model. Media Psychol. 10, 292-315. doi: 10. 1080/15213260701375686

Searle, A. K., Saywer, M. G., Miller-Lewis, L. R., and Baghurst, P. A. (2014). Prospective associations between children's preschool emotional and behavioural problems and kindergarten classroom engagement, and the role of gender. Elem. Sch. J. 114, 380-405. doi: 10.1086/674421

Seidman, G. (2013). Self-presentation and belonging on Facebook: how personality influences social media use and motivations. Pers. Individ. Diff. 54, 402-407. doi: 10.1016/j.paid.2012.10.009

Seidman, G. (2014). Expressing the "true self" on Facebook. Comput. Human Behav. 31, 367-372. doi: 10.1016/j.chb.2013.10.052

Seo, M., Kim, J., and Yang, H. (2016). Frequent interaction and fast feedback predict perceived social support: using crawled and self-reported data of Facebook users. J. Comput. Commun. 21, 282-297. doi: 10.1111/jcc4.12160

Settanni, M., and Marengo, D. (2015). Sharing feelings online: studying emotional well-being via automated text analysis of Facebook posts. Front. Psychol. 6:1045. doi: 10.3389/fpsyg.2015.01045

Sharma, S. K., Govindaluri, S. M., and Al Balushi, S. M. (2015). Predicting determinants of Internet banking adoption: a two-staged regression-neural network approach. Manag. Res. Rev. 38, 750-766. doi: 10.1108/mrr-06-20140139

Sheldon, P., and Bryant, K. (2016). Instagram: motives for its use and relationship to narcissism and contextual age. Comput. Human Behav. 58, 89-97. doi: 10. 1016/j.chb.2015.12.059

Sherry, J. L. (2004). Flow and media enjoyment. Commun. Theory 14, 328-347. doi: $10.1111 /$ j.1468-2885.2004.tb00318.x

Shin, D. (2018). Empathy and embodied experience in virtual environment: to what extent can virtual reality stimulate empathy and embodied experience? Comput. Human Behav. 78, 64-73. doi: 10.1016/j.chb.2017.09.012

Sigerson, L., and Cheng, C. (2018). Scales for measuring user engagement with social network sites: a systematic review of psychometric properties. Comput. Human Behav. 83, 87-105. doi: 10.1016/j.chb.2018.01.023

Sin, S.-C. J. (2016). Social media and problematic everyday life information-seeking outcomes: differences across use frequency, gender, and problem-solving styles. J. Assoc. Inf. Sci. Technol. 67, 1793-1807. doi: 10.1002/asi

Sinclair, T. J., and Grieve, R. (2017). Facebook as a source of social connectedness in older adults. Comput. Human Behav. 66, 363-369. doi: 10.1016/j.chb.2016. 10.003

Smock, A. D., Ellison, N. B., Lampe, C., and Wohn, D. Y. (2011). Facebook as a toolkit: a uses and gratification approach to unbundling feature use. Comput. Human Behav. 27, 2322-2329. doi: 10.1016/j.chb.2011.07.011

So, K. K. F., King, C., Sparks, B. A., and Wang, Y. (2016). The role of customer engagement in building consumer loyalty to tourism brands. J. Travel Res. 55, 64-78. doi: 10.1177/0047287514541008

Spector, P. E., Cooper, C. L., and Sparks, K. (2001). An international study of the psychometric properties of the Hofstede values survey module 1994: a comparison of individual and country/province level results. Appl. Psychol. 50, 269-281. doi: 10.1111/1464-0597.00058

Swirsky, L. T., and Spaniol, J. (2019). Cognitive and motivational selectivity in healthy aging. Wiley Interdiscip. Rev. Cogn. Sci. 10, 1-12. doi: 10.1002/wcs.1512

Tan, G. W. H., Ooi, K. B., Leong, L. Y., and Lin, B. (2014). Predicting the drivers of behavioral intention to use mobile learning: a hybrid SEM-Neural Networks approach. Comput. Human Behav. 36, 198-213. doi: 10.1016/j.chb.2014.03.052

The Social Media Family (2018). IV Estudio Sobre los Usuarios de Facebook, Twitter e Instagram en España. Madrid: The Social Media Family.

van Dijck, J. (2013). 'You have one identity': performing the self on Facebook and LinkedIn. Media, Cult. Soc. 35, 199-215. doi: 10.1177/0163443712 468605

van Doorn, J., Lemon, K. N., Mittal, V., Nass, S., Pick, D., Pirner, P., et al. (2010). Customer engagement behavior: theoretical foundations and research directions. J. Serv. Res. 13, 253-266. doi: 10.1177/1094670510375599

Vargo, S. L., and Lusch, R. F. (2016). Institutions and axioms: an extension and update of service-dominant logic. J. Acad. Mark. Sci. 44, 5-23. doi: 10.1007/ s11747-015-0456-3 
Verhagen, T., Swen, E., Feldberg, F., and Merikivi, J. (2015). Benefitting from virtual customer environments: an empirical study of customer engagement. Comput. Human Behav. 48, 340-357. doi: 10.1016/j.chb.2015. 01.061

Verleye, K., Gemmel, P., and Rangarajan, D. (2014). Managing engagement behaviors in a network of customers and stakeholders: evidence from the nursing home sector. J. Serv. Res. 17, 68-84. doi: 10.1177/1094670513494015

Vivek, S. D., Beatty, S. E., and Morgan, R. M. (2012). Customer engagement: exploring customer relationships beyond purchase. J. Mark. Theory Pract. 20, 122-146. doi: 10.2753/MTP1069-6679200 201

Weber, R., Tamborini, R., Westcott-Baker, A., and Kantor, B. (2009). Theorizing flow and media enjoyment as cognitive synchronization of attentional and reward networks. Commun. Theory 19, 397-422. doi: 10.1111/j.1468-2885. 2009.01352.x

Williams, L. J., Vandenberg, R. J., and Edwards, J. R. (2009). Structural equation modeling in management research: a guide for improved analysis. Acad. Manag. Ann. 3, 543-604. doi: 10.1080/194165209030 65683

Wu, J.-H., Wang, S.-C., and Tsai, H.-H. (2010). Falling in love with online games: the uses and gratifications perspective. Comput. Human Behav. 26, 1862-1871. doi: $10.1016 /$ j.chb.2010.07.033
Yang, H.-L., and Lin, C.-L. (2014). Why do people stick to Facebook web site? A value theory-based view. Inf. Technol. People 27, 21-37. doi: 10.1108/ITP-112012-0130

Zhao, L., Lu, Y., Wang, B., Chau, P. Y. K., and Zhang, L. (2012). Cultivating the sense of belonging and motivating user participation in virtual communities: a social capital perspective. Int. J. Inf. Manage. 32, 574-588. doi: 10.1016/j. ijinfomgt.2012.02.006

Zheng, X., Cheung, C. M. K., Lee, M. K. O., and Liang, L. (2015). Building brand loyalty through user engagement in online brand communities in social networking sites. Inf. Technol. People 28, 90-106. doi: 10.1108/ITP-08-20130144

Conflict of Interest: The authors declare that the research was conducted in the absence of any commercial or financial relationships that could be construed as a potential conflict of interest.

Copyright (C) 2020 Rodríguez-Ardura and Meseguer-Artola. This is an open-access article distributed under the terms of the Creative Commons Attribution License (CC BY). The use, distribution or reproduction in other forums is permitted, provided the original author(s) and the copyright owner(s) are credited and that the original publication in this journal is cited, in accordance with accepted academic practice. No use, distribution or reproduction is permitted which does not comply with these terms. 


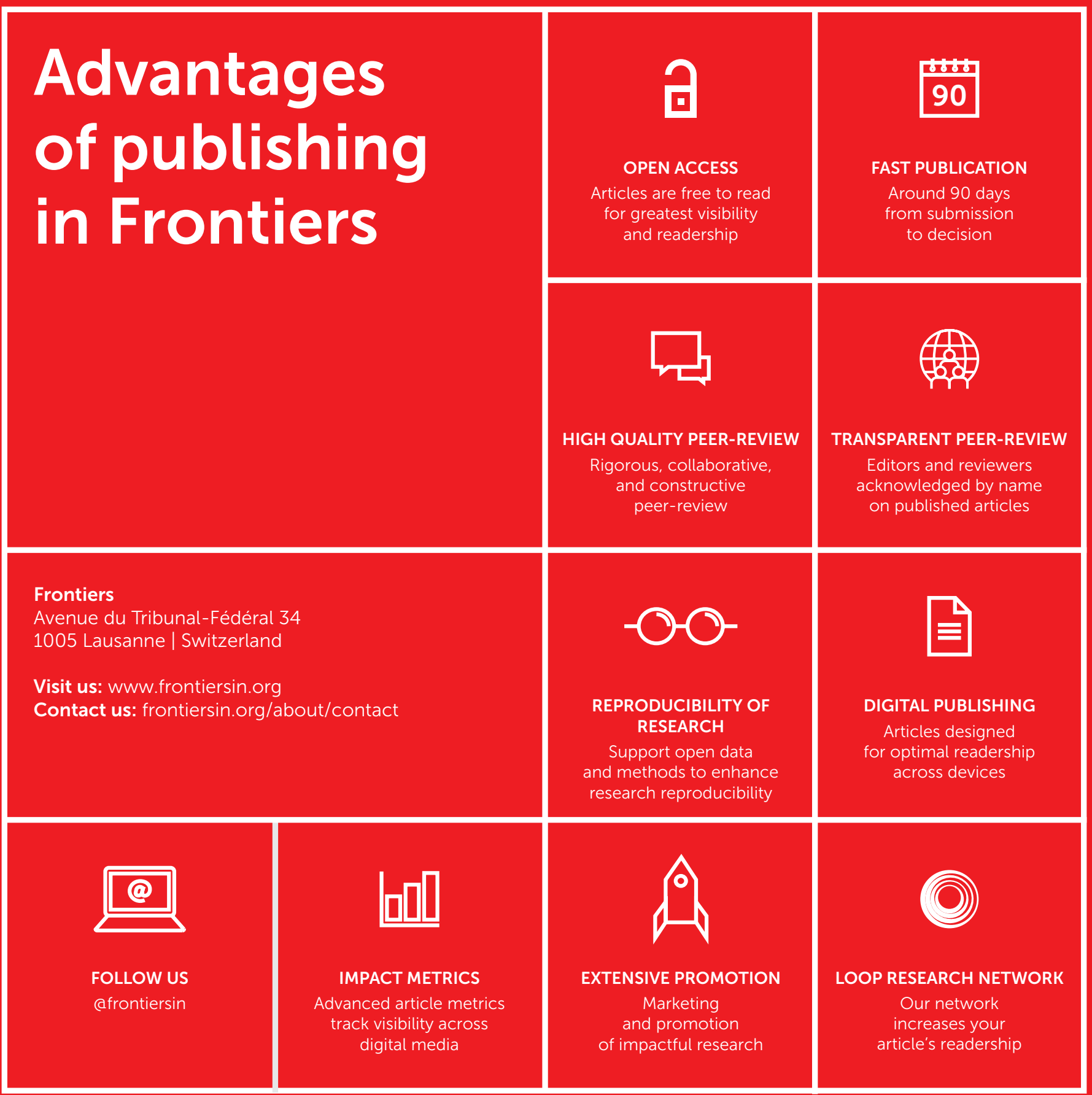

